\title{
A self-organization perspective on strategy formation
}

Citation for published version (APA):

Romme, A. (1992). A self-organization perspective on strategy formation. [Doctoral Thesis, Maastricht University]. Rijksuniversiteit Limburg. https://doi.org/10.26481/dis.19920522ar

Document status and date:

Published: 01/01/1992

DOI:

10.26481/dis.19920522ar

Document Version:

Publisher's PDF, also known as Version of record

\section{Please check the document version of this publication:}

- A submitted manuscript is the version of the article upon submission and before peer-review. There can be important differences between the submitted version and the official published version of record.

People interested in the research are advised to contact the author for the final version of the publication, or visit the DOI to the publisher's website.

- The final author version and the galley proof are versions of the publication after peer review.

- The final published version features the final layout of the paper including the volume, issue and page numbers.

Link to publication

\footnotetext{
General rights rights.

- You may freely distribute the URL identifying the publication in the public portal. please follow below link for the End User Agreement:

www.umlib.nl/taverne-license

Take down policy

If you believe that this document breaches copyright please contact us at:

repository@maastrichtuniversity.nl

providing details and we will investigate your claim.
}

Copyright and moral rights for the publications made accessible in the public portal are retained by the authors and/or other copyright owners and it is a condition of accessing publications that users recognise and abide by the legal requirements associated with these

- Users may download and print one copy of any publication from the public portal for the purpose of private study or research.

- You may not further distribute the material or use it for any profit-making activity or commercial gain

If the publication is distributed under the terms of Article $25 \mathrm{fa}$ of the Dutch Copyright Act, indicated by the "Taverne" license above, 


\title{
A Self-organization Perspective
}

\author{
on Strategy Formation
}

\section{PROEFSCHRIFT}

ter verkrijging van de graad van doctor aan de Rijksuniversiteit Limburg,

op gezag van de Rector Magnificus, Prof. mr. M.J. Cohen, volgens het besluit van het College van Dekanen, in het openbaar te verdedigen op vrijdag, 22 mei 1992 om 14.00 uur

door

Abel Georges Lodewijk Romme 
Promotor (supervisor):

Prof. dr. H. Schreuder

Beoordelingscommissie (dissertation committee):

Prof. dr. L.L.G. Soete (Rijksuniversiteit Limburg)

Prof. dr. H. Mintzberg (McGill University)

Prof. dr. J.M. Pennings (University of Pennsylvania)

CIP-GEGEVENS KONINKLIJKE BIBLIOTHEEK, DEN HAAG

Romme, Abel Georges Lodewijk
A self-organization perspective on strategy formation / Abel Georges Lodewijk Romme ; [ill, by the author].- [S.I. : s.n.] (Maastricht : Datawyse ; Meppel: Krips Repro). - IIl..
Proefschrift Maastricht. - Met lit. opg. - Met samenvatting in het Nederlands.
ISBN 90-9004827-8
NUGI 684
Trefw.: bedrijfsorganisatie

Copyright: 1992 A.G.L. Romme, Maastricht

Cover: A.G.L. Romme

Production: Datawyse Maastricht / Krips Repro Meppel 


\section{PREFACE}

This book, my doctoral thesis in business administration, has been written mainly for an audience of academics. Its primary target audience involves those interested in the strategic management of organizations. Most readers will probably find this a rather strange doctoral thesis. In contrast to conventional thesis work in the strategic management area, this study focuses on the development of a theoretical perspective. The current state of the field of strategy research is fragmentary, from a theoretical as well as methodological viewpoint. This study therefore aims at an integration of this fragmentary field.

I would like to thank those who have been most helpful while the book was being put together. Each thesis needs at least one sponsor. Hein Schreuder has been such a sponsor throughout all critical stages. He provided perceptive comments on a large number of draft chapters and other manuscripts related to this study, and opened doors which otherwise would have remained closed. Luc Soete, Hans Pennings and Henry Mintzberg evaluated the final version of the manuscript and provided useful comments. In addition, Hans Pennings worked through several draft chapters in earlier stages, always coming up with stimulating and constructive suggestions. I also want to express my gratitude to three special participants: Marlene Döderlein de Win, Aad Vijverberg and Thera Tolner. They spend a lot of their time and energy in coding cases for this study.

I am also indebted to several companies for the various kinds of contributions they made. The managers of 'Bellamy', who wish to remain anonymous, deserve a special tribute. A number of people commented on draft chapters or shared their thoughts on some of the topics in those chapters. I am indebted to Patrick van Cayseele, Alfred Chandler, Jan Cobbenhagen, Bas van Diepen, Henry Ergas, Margaret Grieco, John Hagedoorn, Roger Hall, David Hickson, Geert Hofstede, Sten Jönsson, Jorge Katz, Alfred Kieser, Hans Maks, Michael Masuch, Richard Nelson, Sjo Soeters, Arndt Sorge, Ad Teulings, Arjen van Witteloostuijn and R. Zuyderhoudt. The argument in this study has also profited considerably from the comments of anonymous reviewers on manuscripts submitted to several international journals.

Three persons did not contribute directly to this thesis, but provided some of its building blocks by teaching me the appreciation of academic research. Guido Geeraerts (IVA, University of Brabant) showed me the fun of doing organization research. From Jos de Beus (University of Amsterdam) I learned how to critically study and discuss literature. Joan Muysken (University of Limburg) taught me the pragmatics of setting up and implementing a research project. Joan can also be credited - or blamed, if you wish - for stimulating me to start an academic career. Finally, this work would not have been accomplished without Micheline Reulings. I dedicate this book to her. 



\section{CHAPTER 1 SCHOOLS OF THOUGHT}

1.1 Introduction 6

1.2 Schools of thought on strategy formation 6

1.3 The cultural school 7

1.4 The environmental school 9

1.5 The learning school 11

1.6 Toward a self-organization perspective 13

1.7 Concluding remarks 20

CHAPTER 2 ADDITIONAL CONCEPTS

2.1 Introduction 21

2.2 The dialectical paradigm 21

2.3 The concept of loose and tight coupling 23

2.4 The concept of dominant group 25

$\begin{array}{ll}2.5 & \text { Taking stock of the self-organization } \\ \text { perspective }\end{array}$

CHAPTER 3 TOWARD A SELF-ORGANIZATION MODEL

3.1. Introduction 29

3.2 Imaginizing how strategies form 29

3.3 Some forces in strategy formation 35

3.4 Conclusion 45

CHAPTER 4 VERTICAL INTEGRATION

4.1 Introduction 46

4.2 Forward integration by Hendrix' Fabrieken 47

4.3 Explanations of vertical integration 49

4.4 The state of the art of the vertical. integration literature $\quad 54$

4.5 Toward a model of vertical integration 55

4.6 Reconsidering the Hendrix' Fabrieken case $\quad 58$

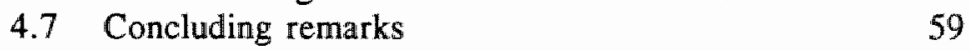




\section{CHAPTER 5 INNOVATION}

5.1 Introduction 62

5.2 Review of literature on innovation strategy 63

5.3 Innovation strategy at Bellamy 67

5.4 Toward a model of innovation by dominant groups 79

5.5 Conclusions $\quad 86$

Appendix A $\quad 87$

Appendix B $\quad 89$

Appendix C 92

Appendix D 94

CHAPTER 6 COMPARING CASES

6.1 Introduction 96

6.2 Comparing cases by means of Boolean analysis 97

6.3 Selection of cases 100

6.4 Categories and variables 103

6.5 Coding procedure 109

6.6 Boolean analysis 113

6.7 Discussion of the results 128

6.8 Evaluation of the comparative method 130 Appendix A 133

Appendix B 135

Appendix C 139

Appendix D 181

CHAPTER 7 SUMMARY AND CONCLUSION

7.1 Introduction $\quad 182$

$\begin{array}{lll}7.2 & \text { Summary } & 182\end{array}$

7.3 Methodological reflections 188

$\begin{array}{lll}7.4 & \text { Outlook } & 189\end{array}$

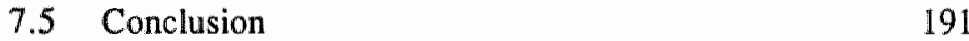

References 192

$\begin{array}{ll}\text { Glossary of terms } & 207\end{array}$

Summary in Dutch $\quad 211$

$\begin{array}{ll}\text { Curriculum vitae } & 215\end{array}$ 


\section{INTRODUCTION}

Every day the Naskapi Indians in Labrador (Canada) ask the question: Where should we hunt today?

The Naskapi use the following procedure to learn where they should hunt. They take the shoulder bone of a caribou, hold it over a fire until the bone begins to crack, and then they hunt wherever the cracks point. This procedure works. The Naskapi almost always find game, which is rare among hunting bands.

(Weick, 1987a: 231)

The following phenomena have been observed in the way top managers run their companies:

high involvement in and commitment to daily business operations tends to divert attention from threats and opportunities in the environment of the company;

restrictive, ingrained strategies impede the flexibility of top management;

focused, cohesive top management policies support efficient, wellorganized operations (e.g. Hampden-Turner, 1990; Starbuck, 1983; McLimore and Larwood, 1988).

These are typical observations made in the literature on 'strategy formation'. However, such observations have not produced a consensus on how strategies are actually made in organizations. Instead, a varied set of schools of thought on strategy formation has developed. This state of affairs may be understood by way of a famous old Hindu fable, which is well-known among strategy researchers. It is the fable of the blind men and the elephant. In this fable six blind men go 'to see' an elephant in order to get some understan* ding of what elephants are. They all touch different parts of the elephant, e.g. a knee, an ear or the trunk, and thus come to understand this animal from quite different images. The blind man touching a knee thinks elephants are much like trees. The one who feels the trunk suggests elephants highly resemble snakes. And so forth. Consequently, these blind men fall into a long dispute about what an elephant is like. Mintzberg (1990) suggests that we are the blind men and strategy formation is our elephant: "Since no-one has had the vision to see the entire beast, everyone has grabbed hold of some part or other and railed on in 'utter ignorance" about the rest" (Mintzberg, 1990: 107). This fable may help us understand why inductive research fails to produce 'universal' models of strategy formation. 


\section{Purpose of this study}

This study addresses the question: how do organizations form strategies and what kind of image(s) may lead us to understand strategy formation? A promising perspective appears to arise from self-organization thought. This study therefore sets out to provide a self-organization perspective for understanding strategy formation. More specificly, the purpose of this study is

(a) to provide a useful (set of) image(s) which helps us to understand strategy formation as a whole and not only parts of it;

(b) to elaborate this image in a systematic manner toward specific propositions;

(c) to evaluate the validity of these propositions.

Before giving a short outline of this perspective, we start with some remarks on strategy and strategy research.

\section{What is strategy?}

What is meant by strategy? A definition that is often referred to, is the one by Alfred Chandler: "The determination of the basic long-term goals and objectives of an enterprise, and the adoption of courses of action and the allocation of resources necessary for carrying out these goals" (Chandler, 1962: 13). This rather long definition can be summarized in Chandler's own statement that strategy is "concerned with the long-term health of the enterprise" (Chandler, 1962: 11).

A large number of very different definitions are presently available. For instance, Burgelman (1983a) defines strategy as a theory about the reasons for past and current success of the firm. Examples of other definitions can be found in, for instance, Chaffee (1985), Child (1972), Mintzberg (1978) and Miles and Snow (1978).

The majority of these definitions have two elements in common: strategy

- concerns survival, and

- deals with changing environments.

Thus, there is some consensus that strategy denotes the way organizations and their members try to cope with the world around them. Throughout this study the phrase 'strategy formation' rather than 'strategy making' or "strategic management" will be used. The emphasis is on describing and explaining how strategies are actually made instead of how they are supposed to be made. 


\section{Process and content of strategy}

The formation of strategy involves a variety of elements. Like the blind men in the Hindu fable, most strategy researchers have eagerly grabbed hold of some elements. One major demarcation line stands out: the demarcation between the process and content approaches in strategy research. The content approach especially attends to the actual actions taken by organizations. The majority of studies using the content approach focus on the positions organizations take in their environment, for instance, on financial and product markets. The process approach focuses on the cognitive and political processes by which actions come into being, for instance, in terms of incremental decision making. The content approach uses a highly deterministic framework (e.g. Lorange and Vancil, 1977; Porter, 1980), whereas the process approach starts from an evolutionary, stochastic worldview (e.g. Grinyer and Spender, 1979; Hickson et al., 1986).

Few studies have devoted attention to strategic change involving both content and process dimensions (Miles and Snow, 1978; Burgelman, 1983b). Even less attention has been given to the source of change and how it comes about. Thus, only disappointing degrees of progress in theory development have been made (Pennings, 1985).

\section{What is self-organization ?}

This study assumes the challenging task to frame major elements and findings from both the process and content approach in one kind of model. We will argue that major elements from the process and content approach can be combined in terms of self-organization thought.

Self-organization thought suggests human beings organize themselves relative to their environment. It emphasizes the reciprocity between environment and human organization. Moreover, self-organization takes place by both opening and closing toward the environment. What distinguishes human organizations from individual human beings is their collective sensemaking, for instance, by creating shared meanings. Especially those involved in strategy formation (e.g. top managers, staff specialists or major" shareholders) cannot simply step outside these collective sensemaking processes. As such, strategy arises by responding to environmental imperatives on the basis of established repertoires.

We all know examples of the self-organized nature of strategy formation. The Naskapi Indians go where the cracks in the bone point. These cracks get the Naskapi moving. Just like mission statements or strategic planning rituals (ought to) get managers moving. 


\section{Grounding and imaginizing}

This study emphasizes the generation rather than testing of theory. Our method of inquiry is essentially a cognitive process. In this cognitive process we move back and forth between conceptual en empirical domains to understand how strategies arise in organizations. The empirical domain involves so-called grounded theorizing (Glaser and Strauss, 1967). The conceptual domain involves what is known as imaginizing theory (Morgan, 1986).

The methodology of discovering grounded theory has been developed by Glaser and Strauss (1967). It involves generating theory from observation. However, generating theory is a two-sided process, involving grounding as well as imaginizing (Morgan, 1986). That is, conceptual categories arise from both observation and the way we see or think. The way we see or think can be usefully expressed in terms of a favored image or metaphor. Such images lead us to see and understand phenomena in distinctive yet partial ways.

As such, these images offer new information. That is, they have a certain redescriptive power arising from their cognitive content. In short, an image tells us something new about reality. For example, let our image be 'organizations as machines'. This image operates not on the basis of its current lexical meaning (found in a standard dictionary), but by virtue of the "system of associated commonplaces" (Ricoeur 1978: 87). To look at organizations as if they are machines evokes a number of common associations such as controllability, predictability and efficiency. That is, the machine image suppresses some characteristics and details of organizations and emphasizes others. The machine image (re)structures our view of the organizational world.

Generally speaking, both grounding and imaginizing are of central importance to theory development.

\section{Overview of chapters}

The first three chapters primarily deal with conceptual issues (imaginizing), although empirical insights will also be used. Chapter one considers the existing schools of thought on strategy formation. These are compared with an exposition of self-organization thought. Chapter two extends self-organization thought with dialectics, the concept of tight and loose coupling, and the concept of the dominant group. Chapter three specifies a preliminary self-organization model of strategy formation, also looking at some general observations made in the strategy literature.

The next three chapters especially deal with empirical issues (grounding), 
with a limited number of references to conceptual points. Chapter four and five focus on the vertical integration and innovation issue. Chapter six deals with a comparative test, based on Boolean logic, of most of the propositions generated in earlier chapters. Chapter seven summarizes the results of this study, reflects on some methodological issues and concludes with a short outlook on the future of self-organization models. 


\title{
CHAPTER 1
}

\section{SCHOOLS OF THOUGHT}

\author{
"The helmsman sets a new course \\ moving the wheel and rudder \\ yet the wind blowing and the current flowing \\ make the ship drift and respond differently, so \\ the helmsman sets a new course ..." \\ (Hampden-Turner, 1990: 15)
}

\subsection{Introduction}

This chapter describes the history of thought on strategy formation. It focuses on contrasting and comparing with self-organization thought.

This chapter is structured as follows. First, nine schools of thought on strategy formation are outlined. Subsequently, three schools receive closer attention: the cultural, environmental and learning school. Then, the emerging self-organization school of thought enters the stage. Finally, some concluding remarks are made.

Two remarks on terminology must be made. First, image or metaphor refers to a concept as a means of structuring scientific inquiry (Morgan, 1980). Metaphors favor certain kinds of insight for understanding and explaining social phenomena. Generally, a number of assumptions about the social world precede the use of metaphors (Morgan, 1980). To these constitutive, paradigmatic assumptions we will refer in terms of different schools of thought.

\subsection{Schools of thought on strategy formation}

According to Mintzberg (1990), the current literature on strategy formation can be divided into nine schools of thought. Three schools are prescriptive in nature and focus on the content of strategy, that is, certain actions (to be) taken. The design school (e.g. Andrews, 1971) characterizes strategy formation as an informal process of design, essentially one of conception. The planning school (e.g. Lorange and Vancil, 1976; Hax and Majluf, 1984) views strategy formation as a formal, systematic, step-by-step process revolving around a set of planning procedures. The most recent prescriptive approach can be labeled as the positioning school (e.g. Porter, 1980), focusing on the content of strategies rather than on the process by which they form, particularly on the selection of specific strategies in specific contexts. The prescriptive orientation of these schools implies that they are of no direct interest to this study. In so far as their prescriptions are followed in 
practice (which is certainly not always the case), the other schools should incorporate this.

The other six schools mentioned by Mintzberg (1990) focus on the process by which strategies actually seem to form. Thus, these schools are part of the so-called process approach (see Introduction). The entrepreneurial school (e.g. Kent, Sexton and Vesper, 1982) views strategy as a vision that is conceived in the creative mind of a forceful leader, often an independent entrepreneur. The cognitive school (e.g. Schwenk, 1984) seeks to get inside the brain of the strategist and thus focuses on concept attainment, mental blocks to strategic change and other cognitive forces at the individual level. The political school (e.g. MacMillan, 1978; Pfeffer, 1981) considers strategy formation as a process of exploitation and power, either within organizations or between organizations.

The cultural school considers the forces of collective values and cognition on the creation and especially the sustainment of strategy. According to the environmental school, strategy formation is open to environmental contingencies which drive organizations into particular niches. Finally, the learning school characterizes strategy as a piecemeal process, in which the organization or its leaders adapt(s) by taking small, incremental steps.

The entrepreneurial, cognitive and political school have not (yet) gained a wide audience. Their impact on strategy research appears to be rather low and, in addition, some of their major theoretical and empirical results have been incorporated in the other three schools. This chapter will therefore deal more extensively with the cultural, environmental and learning schools of thought. It will also describe the major elements of the emerging selforganization school (although the word 'school' may not yet apply to a relatively new way of thinking). As we will see, self-organization thought draws together major elements from the cultural, environmental and learning schools. That is, it explicitly allows for the influence of collective cognition and environmental contingencies, but does so within the context of a rather closed system of sensemaking (cf. learning).

\subsection{The cultural school}

Broadly speaking, the cultural school of thought considers the forces of ideology and cognition on the creation and especially the sustainment of strategy (Mintzberg, 1990). In doing so, the cultural school pays attention especially to collective cognition in describing and explaining strategy formation.

Collective cognition is said to arise in relation to conditions of uncertainty. That is, when uncertainty, according to existing cognitions, cannot be 
minimized by (organizational) action, strategists may alter their perceptions of the environment so that it appears more certain. Hence, strategy makers may suppress awareness of the uncertainty and act on a simplified model of reality which they construct on the basis of their past experiences (Michael, 1973; Grinyer and Spender, 1979).

An important contribution to the cultural school is made by Hedberg and Jönsson (1977), who attempt to explain how managers abandon prevailing strategies and embark on new ones. The model of Hedberg and Jönsson attempts to synthesize empirical findings in stagnating organizations and organizations in crisis. It suggests that organizations move from one strategy to another over time as a result of the interplay between (1) continuous processes that develop existing strategies and enrich and consolidate ruling 'myths', and (2) discontinuous processes that intermittently lead to new myths and reformulated strategies. Strategies are conceived as the more or less integrated sets of ideas and constructs through which problems are spotted and selected. These strategies are derived from myths, which are metasystems or 'theories of the world'. A myth cannot be tested directly, but only through acting in accordance with derived strategies. The main proposition Hedberg and Jönsson put forward is that organizations develop over time through wave patterns of myths (Hedberg and Jönsson, 1977). The myth metaphor has also served in reconstructing the role of planning, for instance by Broms and Gahmberg (1983) who point at the mythical or mantra-like character of strategic planning in many organizations.

A similar model is proposed by Grinyer and Spender (1979). Based on observations of the relative ease with which executives can move operations within an industry, but their greater difficulty in switching industries, they call the industry's pattern of managerial belief a 'recipe'. Thus, managers not only become socialized into a particular company's pattern of beliefs, but are also under the influence of a wider pattern of belief, some at the level of the industry and others cultural or societywide. The recipe concept broadens the Hedberg and Jönsson model, by distinguishing between collective cognition at the industry and the company lewel.

Starbuck $(1983 ; 1985)$ plays a leading role in the cultural school. According to Starbuck, most organizational actions originate in so-called action generators, or (automatic) behavior programs. People in organizations act consistently in that their actions resemble preceding and successive actions: most actions repeat familiar patterns, and most innovations are no more than small variations of familiar patterns. This consistency arises "because people unreflectively follow behavior programmes, because powerful people have vested interests, and because settings for action remain stable, rather than because people are striving consciously to conform to preformed strategies" (Starbuck, 1985: 339-340). One of the implications is that the replacement of top managers is an important prerequisite to bring about fundamental 
strategic change (Starbuck et al,, 1978). Research by Schreuder (1991) provides empirical support for this implication.

In sum, authors in the cultural school of thought suggest that the formation of collective cognitive frameworks and ideologies is essential in understanding strategy formation. These collective forces are especially conceived as impeding strategic change.

\subsection{The environmental school}

The environmental school attributes much of the content and process of strategy formation to the environment. It thus relies on an open system view of the organizational world.

The most pertinent research within the environmental school is driven by the so-called contingency metaphor. In a now classic article, Mintzberg (1973) outlines all basic elements of a contingency approach to strategy formation, by describing three modes of strategy formation: the entrepreneurial, adaptive and planning mode. In the entrepreneurial mode, strategy making is dominated by the active search for new opportunities; power is centralized in the hands of the chief executive or some other dominant leader in the organization; strategy making is characterized by dramatic leaps forward in the face of uncertainty; and growth is the dominant goal. In the adaptive mode clear goals do not exist; the strategy making process is characterized by the 'reactive' solution to existing problems rather than the 'proactive' search for new opportunities; decisions are made in incremental, serial steps; and decisions are generally disjointed, that is, not interrelated. The planning mode is characterized by: the analyst playing a major role in strategymaking; a focus on systematic analysis, particularly in the assessment of the costs and benefits of competing proposals; and above all, the integration or interrelatedness of decisions and strategies.

There are a number of conditions which, according to Mintzberg (1973), drive strategy makers to favor one mode of strategy formation over the others. The mode of strategy formation is thus contingent on a number of conditions such as characteristics of the organization and its management, and features of the environment. Organizations can mix the modes in various ways, depending on the set of conditions.

The entrepreneurial mode requires that strategic authority rests with one powerful individual. The environment must be open for risky, bold initiatives of the entrepreneur. The entrepreneurial mode may also be characteristic of the organization in crisis, which has little to lose by bold actions of its management (Mintzberg, 1973). Use of the adlaptive mode suggests that one faces a complex, rapidly changing environment and a divided coalition of 
influencing forces. Goals cannot be agreed upon unless they are in 'motherhood' form and non-operational (that is, they cannot be quantified). According to Mintzberg (1973), this is a clear description of large, established organizations with great sunk costs and many controlling groups holding each other in check. Finally, the planning mode is used in large organizations which can afford the costs of formal analysis. Moreover, they have goals that are operational and face an environment which is reasonably stable and predictable (Mintzberg, 1973).

An important empirical study using the contingency metaphor is known as the Bradford Studies (Hickson et all, 1986). The Bradford Studies involve a large-scale attempt to document a wide range of variables related to strategic decision making. Hickson et al. therefore focus on strategy as decisions and decision processes. The Bradford Studies are based on a 'dual rationality theory' (Hickson, 1987). This dual rationality is an attempt to draw together the ingredients that appear commonly in the strategy field, i.e. the assumption that strategic decision making is a process of handling both problems and politics. The implication is that "greater complexity of problems and greater politicality of interests ginger up activity and involvement; lesser complexity and lesser politicality allow a more quiescent process" (Hickson, 1987: 185).

The Bradford Studies identify three prevalent combinations of complexity and politicality from a multivariate analysis of 150 strategic decision processes. Most complex and political are the 'weighty and controversial' vortex matters. Less complex and least political are the 'unusual but non-controversial" tractable matters. Least complex, but rather more political than tractable matters, are the 'normal and recurrent' familiar matters. Each combination tends to generate a typical kind of movement toward a decision. A vortex matter is likely to generate a more 'sporadic' process, a tractable matter a more 'fluid' process, and a familiar matter a rather 'constricted' process.

Another major metaphor in the environmental school is strategic choice (Child, 1972; Thompson, 1967; Miles and Snow, 1978). On the surface, the strategic choice concept appears to be in disagreement with the contingency view that strategy is predetermined by conditions external to the strategy making system. Empirical studies based on the strategic choice concept extend the contingency metaphor by also allowing for environments as acts of managerial invention rather than mere discovery. For example, Miles and Snow (1978) describe the process by which prospectors, defenders, analyzers and reactors enact and respond to their environments. In essence, strategic choice constitutes a neocontingency metaphor (Miles and Snow, 1978) emphasizing the importance of decision makers who serve as the link between organizations and environments.

Recent work by Hambrick and Finkelstein reconciles the contingency and strategic choice concepts by means of the concept of managerial discretion. 
Managerial discretion refers to the latitude of action available to top executives. Where discretion is low, the role of top management is limited, and the contingency concepl has strong explanatory power. Where discretion is high, top managers can significantly shape the organization, which can be explained in terms of strategic choices (Hambrick and Finkelstein, 1987; Finkelstein and Hambrick, 1990).

The environmental school of thought has generated important theoretical contributions by bringing prior thinking together in terms of the conditions favoring specific kinds of strategy. The contingency metaphor, which is central to this school, emphasizes situational differences rather than similarities. The predominant focus is on actions, although the role of sensemaking is acknowledged by some authors (e.g. Miles and Snow, 1978). The organizational and managerial processes themselves are largely left to be inferred (e.g. Hickson et al., 1986; Miles and Snow, 1978): the environmental school does not really address the way strategies come into existence or how organizations move from one strategy to another.

\subsection{The learning school}

The learning school characterizes strategy formation as a process in which the organization adapts by means of small, incremental steps. The origins of the learning school can be traced to the early publications of Herbert Simon on the cognitive limits of rationality (Simon, 1955). Similar influence has been accorded to the work on public policy making by Lindblom (1980), who viewed organizational decision making as an incremental process of 'muddling through'. Important theoretical contributions within the domain of the learning school have been made by Weick (1979), Nelson and Winter (1982) and Aldrich (1979). These studies share a rather evolutionary view of organizations adapting to their environments. That is, a dynamic, stochastic, or fluctuating process of evolution is thought to be an essential aspect of the response of organizations to environmental forces. The remainder of this section focuses on the learning school's contribution to empirical research.

The first systematic empirical study of strategy formation within the learning school was conducted by Quinn (1980). Quinn conducted intensive interviews in a number of American and European companies, including General Motors, Chrysler, Volvo, General Mills, Pillsbury, Xerox, Texas Instruments, Exxon, Continental Group and Pilkington Brothers. These companies vary with respect to products, markets, time horizons, technological complexities, and national versus international dimensions. However, they all are very large, international, private sector organizations with a general record of success (at the time of Quinn's research).

Several findings emerge from Quinn's study. First, metaphors such as 
"planning" do not adequately characterize the way strategy processes operate. Second, strategies tend to emerge from a series of 'strategic subsystems', each of which attacks a specific class of strategic issues (e.g. acquisitions, major reorganizations) in a disciplined way, but which is blended incrementally and opportunistically into a cohesive pattern that becomes the company"s strategy (Quinn, 1978; 1980).

Third, because of cognitive and process limits, almost all of these subsystems - and the formal planning activity itself - are managed and linked together by an approach decribed as logical incrementalism. The cognitive limits parallel Simon's (1955) view on bounded rationality. Of equal importance are the 'process limits', that is, the imperatives which constrain the system, yet ultimately determine the decision itself. Examples are the timing and sequencing imperatives necessary to create awareness, build comfort levels, develop consensus, select and train people, etcetera (Quinn, 1978; 1980).

The rather successful executives in Quinn's sample of companies link together and bring order to a series of strategic processes and decisions spanning years. According to Quinn, strategy making involves forces of such great number, strength, and combinatory powers that one cannot predict events in a probabilistic sense. Hence logic dictates that one proceed flexibly and experimentally from broad concepts toward specific commitments, making the latter concrete as late as possible in order to narrow the range of uncertainty and to benefit from the best available information (Quinn, 1978).

A specific kind of incrementalism is described in the organized anarchy or 'garbage can' model (Cohen; March and Olsen, 1972). This model is especially suggested by studies of educational organizations. Such organizations have three characteristics.

1. Problematic preferences. That is, it is difficult to impute a set of preferences to the decision situation that satisfies consistency requirements. Thus, the organization must operate on the basis of a variety of inconsistent and ill-defined preferences. It can be described better as a loose collection of ideas than as a coherent structure, discovering preferences through action rather than acting on the basis of preferences.

2. Unclear, poorly understood technology. Although the organization manages to survive, its own processes are not understood by its members. It operates on the basis of simple trial-and-error procedures, learning from past experience and pragmatic inventions.

3. Fluid participation. Participants vary in the amount of time and effort they devote to different domains; involvement varies from one time to another. As a result, the boundaries of the organization are changing and uncertain. The audiences and decision makers for any particular kind of choice change capriciously. 
The organization as a garbage can is "a collection of choices looking for problems, issues and feelings looking for decision situations in which they might be aired, solutions looking for issues to which they might be the answer, and decision makers looking for work" (Cohen, March and Olsen, 1972: 2). That is, the garbage can involves rather independent streams of events. These streams of, for instance, solutions, problems and decision makers, are being stirred as if they were garbage. The pattern of strategy making therefore takes on a random quality.

Overall, the learning school of thought takes the outcome of strategy formation for granted and, consequently, tends to focus on sensemaking processes. For non-profit organizations this approach is often justified by referring to the fact that the content of decisions is often made and conveyed by a different organization, for example, the legislature, which mandates organizations to implement programs (Pennings, 1985). Moreover, Wilson (1982) shows that the degree of change in outcomes of strategy formation may vary independently of the incremental quality of the process leading up to the outcome. He therefore suggests a sharp distinction between processual incrementalism, arising from limited sensemaking abilities, and outcome incrementalism (Wilson, 1982).

To sum up, the learning school focuses on sensemaking processes in strategy formation. These processes are especially conceived as continuous, incremental streams. For a variety of empirical situations the learning school's metaphors (incrementalism and garbage can) appear to be very useful.

\subsection{Toward a self-organization perspective}

The limitations of current schools of thought have been recognized in some recent studies of strategy formation. These studies also integrate major elements from both the process and the content approach. They can be conceived as antecedents of self-organization models and therefore merit attention here.

Mintzberg and co-authors (e.g. Mintzberg and McHugh, 1985; Mintzberg and Waters, 1985) focus on the distinction and interplay between 'deliberate" and 'emergent' strategies. Deliberate strategies are, first of all, characterized by rather precise intentions which are also realized. In addition, there must be cohesion of these intentions across the most important actors. For a strategy to be emergent, there must be order - consistency in action over time - in the absence of intention about it. The fundamental difference between deliberate and emergent strategies is that the former focuses on stability, direction and control, whereas the latter opens up notions of instability and learning. By means of these conceptual categories Mintzberg and co-authors describe and interpret a number of cases in long-run strategy 
formation (e.g. Mintzberg and Waters, 1985; Mintzberg, Brunet and Waters, 1986). Learning is conceived as feed-back from realized emergent patterns to deliberate strategy (Mintzberg and Waters, 1985). A prewious study by this author and his colleagues (Romme et al., 1990) extends the deliberateemergent framework and describes learning in terms of 'deliberatization' of emergent strategies.

Burgelman (1983a; 1983b; 1985) has developed a model of strategy formation in large, complex firms which also allows for two fundamentally different dimensions. One dimension involves processes which are driven by top management, inducing strategic activities at the operational level. The other dimension is driven by autonomous strategic activities at the operational and middle levels of the organization. These processes fall outside the current concept of strategy and enact new environmental segments. Like Mintzberg, Burgelman recognizes the rather autonomous quality of a wide range of activities in large companies.

The concepts of induced and autonomous activity parallel the concepts of deliberateness and emergentness. Burgelman's level of analysis is the top management team which interacts with middle and operational managers. Mintzberg does not specify the level on which deliberate and emergent strategies operate. Nevertheless, the work of Burgelman and Mintzberg may be linked as follows. Deliberate strategies are carried out by inducing action, while emergent strategies arise from relatively autonomous action. In the latter case, deliberate strategy becomes a vehicle in identifying and recognizing (successful) emerging strategies.

These contributions to strategy formation research point at dualities of the autonomous versus induced kind. Such dualities are at the center of selforganization thought (cf. Burgelman, 1983c).

Self-organization thought originated from a diverse set of other disciplines, such as cybernetics, biology and physics (e.g. Sahal, 1979; Maturana and Varela, 1980; Prigogine, 1984). The idea of self-organization developed primarily in response to the prevailing open system view in these disciplines. It combines the closed and open system viewpoints. Recently, several authors have argued that the self-organization idea is also highly relevant for social systems, such as human organizations (e.g. Probst, 1987; Morgan, 1986; Beer, 1980; Kagono et al., 1985; Drazin and Sandelands, 1989).

The following assumptions may serve as an outline of the self-organization perspective to strategy formation (cf. Probst, 1987; Nonaka, 1988a; Luhmann, 1986 and 1990; Romme, 1990b).

1. Strategy formation takes place in a specific social system, the strategy system; 
2. the strategy system involves complex flows of forces;

3. the strategy system is self-referential;

4. the strategy system develops or maintains its autonomy;

5. the strategy system combines closure (in making sense) and openness (in actions) toward its environment.

Note that most of these assumptions are not new in the literature. However, together they provide a useful way of looking at strategy formation. We now turn to a more detailed discussion of the above assumptions and their implications.

Social systems involve 'natural' connections among individual human beings. These natural connections appear as non-artificial, self-evident relations. Note that even corporations, created as 'artificial' tools by their founders to accomplish the founders' goals, involve natural connections once they start working (Hill, 1990). A subset of the population of social systems more or less deliberately develops strategies in order to cope with their environment. "This kind of social system will be referred to as a 'strategy forming system' or in short strategy system. In principle, (holding) companies, business units, management teams and similar systems may all be conceived as strategy systems. Such systems incorporate both sensemaking and action. Strategy systems therefore have the capacity to generate or respond to change (by actions), but also to evaluate and question change (by sensemaking).

Strategy systems involve complex flows of forces. The behavior of a strategy system cannot be induced from its external imperatives or its internal conditions in isolation. Change in one element of the system is coupled with changes elsewhere, setting up continuous patterns of interaction. According to self-organization thought (Sahal, 1979), any strategy system is influenced by two kinds of forces. There are forces which drive the system (back) toward a steady, equilibrium state ('homeostasis'). But other forces pull the system toward substantially different states ('homeorhesis'). The steady state forces do provide some stability over time, but the continuous interplay with homeorhesis forces gives strategy systems a complex and unpredictable quality.

The interplay between these two kinds of forces can be understood from the point of view of chaos theory, which has made important contributions to self-organization thought (e.g. Prigogine, 1984). Following chaos theory, the complexity of strategy systems resembles the Butterfly Effect (Gleick, 1987), the notion that a butterfly stirring the air today in Sidney can transform storm systems next month in Paris. The Butterfly Effect follows from the socalled sensitive dependence on initial conditions. This sensitive dependence

1 This definition implies that strategy systems differ from other social systems (e.g. peer group, family) in the rather deliberate way in which they make strategies. 
implies that very small variations in, for example, its actions may trigger major changes of the system in later periods.

Strategy systems are self-referential. In making sense of the world (actors within) such systems refer to themselves. Self-reference constitutes the system's response to environmental imperatives. That is, strategy systems cannot step outside their own (socially constructed) sensemaking. For instance, management teams can be understood as being self-referential, driven by their view of the world around them and responding to environmental imperatives on the basis of established managerial recipes. Even 'information' is not something which the system takes in from the environment. "Pieces of information don't exist 'out there", waiting to be picked up by the system. As selections they are produced by the system itself in comparison with something else (e.g., in comparison with something which could have happened)" (Luhmann, 1986: 175).

Strategy systems develop or maintain their autonomy. Self-organization presupposes a self, a relatively autonomous system which tries to develop or maintain its own identity. Of course, there is always a question of degree of autonomy. However, some minimum degree of autonomy is essential to strategy and strategy systems. Autonomy may be defined as freedom from influence by external entities. Thus, firms (as strategy systems) can be rather autonomous and at the same time depend on external resources (e.g. human labor or technology) as long as they are not dominated by, for example, their holding company's headoffice. When such a dominance is not present, we may assume that the incumbent firms try to maintain or extend their autonomy.

The autonomy characteristic deserves some closer attention from a system theoretic viewpoint. Every strategy system is a subsystem embedded in larger (strategy or other) systems. For example, a division management team can be considered as a subsystem which is open to headoffice interventions or industrial influences. Actors on the system level of the holding, e.g. an executive committee, or industry, e.g. government agencies, may thus perceive division management as not working toward autonomy. However, that perception is an illusion, although it does have consequences for the strategies of management teams (Beer, 1979). For now they must respond to a special kind of constraint, i.e. treatment which attempts to deny their (striving for) autonomy.

The example of a multi-divisional company also provides another insight: an autonomous system (e.g. company) may include subsystems (e.g. profitcenters, new business ventures) which are rather autonomous themselves or strive for autonomy on their own accord. The autonomy of such subsystems will generally be somewhat lower than the autonomy of the whole system. If the autonomy of subsystems decreases to the level of mere dependency (e.g. 
departments under direct control of headquarters), they cannot be considered as fully self-organizing according to the assumptions we have listed thusfar.

The complexity, self-reference and autonomy of strategy systems combine in the following assumption: strategy systems are (relatively) closed and open at the same time. ${ }^{2}$ The self-organizing ability of any strategy system lies in "the continuous dissolution and creation of organizational order" (Nonaka, 1988a: 72), or the continuous change from unorganized to organized and vice versa (cf. Ashby, 1962). Strategy systems maintain their existence by opening up in particular ways to the 'outside world'. The way they open up, however, relies on their rather closed sensemaking. Thus, a strategy system opens up to environmental imperatives in ways that are preconditioned by meanings (re)produced in the system itself.

Recent developments in systems theory (Luhmann, 1990; Maturana and Varela, 1980; Sahal, 1979) suggest that closure and openness are reciprocal conditions. That is, closure is a condition for openness and vice versa. The openness of a strategy system's actions is based on self-referential closure. At the same time, sensemaking is based on actions which transcend the system's boundary, and, for instance, provide a perspective on the environment.

This reciprocity may be illustrated by an example of strategy formation given by Weick (1987a). The following incident happened during military maneuvers in Switzerland:

"The young lieutenant of a small Hungarian detachment in the Alps sent a reconnaissance unit into the icy wilderness. It began to snow immediately, snowed for two days, and the unit did not return. The lieutenant suffered, fearing that he had dispatched his own people to death. But the third day the unit came back. Where had they been? How had they made their way? Yes, they said, we considered ourselves lost and waited for the end. And then one of us found a map in his pocket. That calmed us down. We pitched camp, lasted out the snowstorm, and then with the map we discovered our bearings. And here we are. The lieutenant borrowed this remarkable map and had a good look at it. He discovered to his astonishment that it was not a map of the Alps, but a map of the Pyrenees" (Weick, 1987a: 222).

Apparently, collective sensemaking by the members of this military unit is self-referential (closed) in nature. Initially, waiting for the end appears to be the only legitimate 'solution' left. Self-referential closure thus conditions

2. Open systems interact with their environments, whereas closed systems have no interaction with their environments. In their pure form open or closed systems exist only as theoretical concepts. This author uses 'open' and 'closed' (or related terms) to refer to tendencies that are typical of either system in its pure form. 
action (if any). Later, finding a map takes on meaning as a means to get the military unit back. That is, the act of finding a map of 'the Alps' produces some sense of the environment and animates the members of the unit in trying to survive. The relative openness of action is a condition for sensemaking.

Self-organization, as outlined above, is a typical quality of social systems in general and strategy systems in particular. This may be illustrated with Boulding"s (1956) well-known hierarchy of system levels. This hierarchy arranges systems according to their degree of complexity. Boulding distinguishes between nine levels of complexity. At the seventh level is the human system, that is, the individual human being. In contrast to simpler systems (e.g. animals), a human being possesses self-consciousness. His or her image of the surrounding world has a self-reflexive quality: "he not only knows, but knows that he knows" (Boulding, 1956: 8). According to Boulding, it is the ability to produce, absorb, and interpret symbols (as opposed to mere signs like the warning cry of an animal) which most clearly distinguishes humans from less complex systems. In addition, humans are distinguished from animals by a more elaborate image of time and relationship (Boulding, 1956).

At the eighth system level we find the social system. What distinguishes the social system from systems at lower levels is collective sensemaking (e.g. the creation of shared meanings). Accordingly, social systems are not just groups of people but "sets of organizing rules" (Pondy and Mitroff, 1979: 29). Some authors (e.g. Ashby, 1962; Sahal, 1979) refer to self-organization as being characteristic to the fourth level of open systems (e.g. body cells). However, if we acknowledge that 'organization' in social and strategy systems especially pertains to collective sensemaking, 'self-organization' clearly goes beyond less complex systems and also pertains to social systems (cf. Probst, 1987; Nonaka, 1988a).

Thus, self-organization in social systems especially involves collective sensemaking. By consequence, there is no need for concepts such as 'goal' or 'choice'. Such concepts do not specify definite or observable processes, but only the outcomes of unspecified processes (Drazin and Sandelands, 1989). The self-organization perspective does not entirely discard these concepts. Merely, it does not a priori assume that goals or choices are part of strategy formation. Goals such as financial objectives or mission statements may be important especially as mental constructs. Thus, in certain cases the goal construct structures sensemaking (e.g. 'our mission is ...') and actions (e.g. by providing a direction). In other cases, however, goal constructs may be completely absent.

In sum, the self-organization school of thought recognizes both the openness and closedness of the way the incumbent system makes sense of its environ- 
ment.. As we have seen, the relatively closed nature of strategy formation is a central theme in the cultural school, emphasizing the forces arising from collective cognition. The self-organization school also links up with major elements in the environmental and learning schools of thought. A selforganizing strategy system allows for the influence of environmental imperatives but merely within the context of rather closed sensemaking. Moreover, these systems are conceived in terms of streams (cf. forces), as in the learning school of thought.

Figure 1.1 Four schools of thought in strategy formation research.

\begin{tabular}{|c|c|c|}
\hline Schools & $\begin{array}{l}\text { Major concepts and } \\
\text { metaphors }\end{array}$ & Major assumptions \\
\hline CULTURAL & $\begin{array}{l}\text { recipe, myth, behavior } \\
\text { program }\end{array}$ & $\begin{array}{l}\text { the formation of collec- } \\
\text { tive cognitions and } \\
\text { ideologies is essential } \\
\text { to the continuity of } \\
\text { strategy and tends to } \\
\text { impede change }\end{array}$ \\
\hline ENVIRONMENTAL & $\begin{array}{l}\text { contingency, strategic } \\
\text { choice, managerial } \\
\text { discretion }\end{array}$ & $\begin{array}{l}\text { strategy formation is an } \\
\text { open system of actions } \\
\text { and sensemaking, } \\
\text { which responds to } \\
\text { environmental } \\
\text { imperatives }\end{array}$ \\
\hline LEARNING & $\begin{array}{l}\text { incrementalism, } \\
\text { garbage can, learning }\end{array}$ & $\begin{array}{l}\text { human-beings are limi- } \\
\text { ted in their sensema- } \\
\text { king ability; strategy } \\
\text { formation is a continu- } \\
\text { ous, piecemeal process } \\
\text { of individual and } \\
\text { collective learning }\end{array}$ \\
\hline $\begin{array}{l}\text { SELF- } \\
\text { ORGANIZATION }\end{array}$ & $\begin{array}{l}\text { complexity, self- } \\
\text { reference, autonomy, } \\
\text { emergentness, flows of } \\
\text { forces, self-organization }\end{array}$ & $\begin{array}{l}\text { strategy formation is a } \\
\text { system of flows of } \\
\text { forces which is both } \\
\text { open (by means of } \\
\text { actions) and closed (in } \\
\text { sensemaking) }\end{array}$ \\
\hline
\end{tabular}




\subsection{Concluding remarks}

Early studies of social systems (e,g. Selznick, 1949: Crozier, 1964; Blau, 1955; Gouldner, 1954) observed the existence of impersonal, often implicit, rules which structure individual and collective action in organizations. Overall, these authors used a rather closed system view (cf. Scott, 1987). Apparently, the dominant transformation from closed to open system views (Scolt, 1987) is also reflected in studies of social systems in general, and strategy systems in particular. In this respect, the environmental school of thought dominates empirical research (e.g. Hambrick, 1983; Miller and Friesen, 1982; Harrison, Torres and Kukalis, 1988).

This chapter compared and contrasted the history of thought on strategy formation with self-organization thought. Three important schools of thought on strategy formation have been described more extensively: the cultural, environmental and learning school. These schools are part of the process approach to strategy formation research. In this respect, the content approach has not contributed much to our understanding of the complexity of strategy formation, due to its prescriptive orientation. In addition to the cultural, environmental and learning schools, we have also described the emerging self-organization perspective. Self-organization thought appears to bring together major ideas of the cultural, environmental and learning schools. Figure 1.1 provides an overview.

Self-organization thought emphasizes the reciprocity of openness and closure. Accordingly, strategy formation combines closure and openness: in its actions a strategy system may open up toward its environment, but it does so in the context of self-referential sensemaking. The self-organization perspective appears to offer a bridge between the divided worlds of the content and process approach. The next chapters set out to built this bridge. 


\section{CHAPTER 2}

\section{ADDITIONAL CONCEPTS}

"A universe comes into being when a space is severed into two."t

(Maturana and Varela, 1980: 73)

\subsection{Introduction}

An outline of the self-organization perspective on strategy formation was provided in the previous chapter. This chapter extends this perspective by describing a number of concepts which may be combined with this perspective. In particular, we will adopt several concepts from the dialectical paradigm, the concept of loose and tight coupling, and the dominant group concept.

\subsection{The dialectical paradigm}

This section puts forward the dialectical paradigm. Recall that one of the main tenets of self-organization in strategy systems is the simultaneous existence of closed and open system forces. The precise nature of the reciprocity between closure and openness remains undefined in systems theory. A solution to this problem may lie in the adoption of dialectics.

The closed and open system views in themselves constitute complete and consistent paradigms. ${ }^{1}$ The former assumes systems to be isolated from their environment, whereas the latter assumes they interact with their environment. How can these, in part contrasting, paradigms be reconciled? Dialectics provides a set of assumptions allowing for both open and closed system dynamics. The integrative nature of the dialectical paradigm has been recognized by some authors in the strategy field (Wilson, 1980; Starbuck, 1983; Bartunek, 1984).

The paradigm of dialectics, also known as dialectical opposition, is a universal one with firm roots in both oriental and western thinking. The social science literature usually restricts itself to Hegel's concept of dialectics and Marx's revision of the Hegelian concept (e.g. Giddens, 1971; Churchman, 1971; Mitroff and Mason, 1981; Sztompka, 1979; van den Berghe, 1963) although the idea has a longer history (e.g. Morgan, 1986).

1 Following Morgan (1980), a paradigm involves the rationale for a particular research strategy in terms of a set of constitutive assumptions. In this respect, metaphors attempt to concretize the constitutive assumptions available in paradigms. 
Interestingly, several authors have advocated a dialectical approach to strategic planning (Mason, 1969; Mitroff and Emshoff, 1979; Bresser and Bishop, 1983). These authors suggest that the process of systematically opposing plans by counterplans stimulates creativity and tends to expand the world view of managers. This application of dialectics involves a prescriptive kind of research. Moreover, the extensive debate on the relative advantages of the dialectical approach compared to other approaches to strategic planning is still unresolved (e.g. Cosier, 1981; Mitroff and Mason, 1981; Romme, 1989). The remainder of this section outlines the dialectical paradigm for the purpose of descriptive research.

Three assumptions represent the dialectical paradigm. The first assumption is that all opposites in the social world are complementary. Thus, all characteristics, tendencies, events, and relationships describing social worlds exist in fundamental opposites. This assumption can be summarized as the complementarity and antagonism of opposites (Morgan, 1986; Bresser and Bishop, 1983). This assumption accounts for processes of self-generated change whereby phenomena change themselves as a result of tension with their opposite. For example, an act whereby one person attempts to rule or control another tends to set up a process of resistance or countercontrol that undermines the initial attempt at control. The act of control itself sets up consequences that work against its effectiveness (Morgan, 1986). Another example is the dialectical opposition between human activity and the (unintended) consequences of that activity.

The second assumption is the so-called negation of the negation (Morgan, 1986; Bresser and Bishop, 1983). This law suggests that each negation rejects a previous form, yet also retains something from that form. Any completed change process inherits some oppositions from the past and also contains and develops new oppositions. Thus, an act of control may be negated by an act of countercontrol, which is in turn negated by a further act of control and so on (Morgan, 1986). Human activity may give rise to unintended outcomes, which may call for new activities, in turn generating other unintended outcomes.

The third assumption involves the so-called transformation of quantity into quality and vice versa (Morgan, 1986; Bresser and Bishop, 1983). Accumulated incremental changes in quantity eventually bring about a new quality, and gradual changes in quality ultimately lead to a new quantity. Thus, the accumulation of gradual changes in response to dialectical opposites will culminate in major quantitative or qualitative changes. For example, a process of control and counter control may continue until control is no longer possible, leading to a new phase of collaboration or destruction (Morgan, 1986). These three assumptions together constitute the paradigm of dialectics. 
In fact, the relation between closed and open systen dynamics has received extensive attention in Oriental thought on dialectics (e.g. Chan, 1963). In Oriental thought, opening and closure are forces characterizing each change process. Closure in its purest form appears as if the system is not embedded in a broader environment. The opening force pertains to the continuous interaction between environment and system, which provides a sense of direction for the system. Without the counterforce of closure, opening would result in the disintegration of the system (Chan, 1963).

Closure and openness are complementary but antagonistic opposites in any strategy system. For example, the day-to-day operational policy of a management team (as if the company were a closed system) is complementary to their task of scanning and responding to long-run threats and opportunities in the environment of the company (as an open system). However, extreme involvement of managers in operational activity tends to be detrimental to their responsiveness to major threats and opportunities. Thus, closure and openness are complementary and antagonistic opposites. Following the second assumption, closing of a strategy system tends to produce opening, and vice versa (negation of the negation). For example, extreme occupation of management with operational activity (closure) will ultimately produce severe problems (e.g. a dramatic decline in profitability) by which the strategy system is forced open (e.g. by shareholders' actions, take-over threat or similar forces).

The third assumption suggests that gradual changes in response to the dialectic between opening and closing will culminate in major qualitative and quantitative changes. For example, the contimuous quantitative growth of a firm at some point will necessitate qualitative changes, such as the introduction of new management systems or a new organizational structure.

In sum, dialectics appears to provide the missing paradigm under selforganization thought. The dialectical paradigm can be summarized in terms of three assumptions: complementarity and antagonism of opposites, negation of the negation, and transformation of quantity into quality and quality into quantity.

\subsection{The concept of loose and tight coupling}

This section outlines another useful concept for the study of strategy formation: tight and loose coupling. Closed systems generally give the impression of tight coupling, that is, an arrangement of elements of the system such that each is highly responsive to changes in the others (Scott, 1987). One of the main contributions of the open system view is the recognition that social systems contain elements that are only slightly related with other elements and that are capable of fairly autonomous behavior (Scott, 1987). This kind 
of connections among interacting elements we call loose coupling.

According to Weick (1976), loosely coupled elements are elements that are responsive but also preserve their own identity and some evidence of their physical or logical separateness. Loose coupling therefore connotes elements that "may be tied together either weakly or infrequently or slowly or with minimal interdependence" (Weick, 1976: 5). As such, it contributes to the viability of the system as a whole. That is, the system maintains persistent behavior in the face of variables that would normally disturb the behavior (Weick, 1979). Weick (1976) actually argues that there exists a broad class of organizations, including so-called educational organizations, which can be usefully regarded as loosely coupled systems. Here, we adopt the more general concepts of (tight or loose) coupling, which denotes the degree of responsiveness between seperate elements of a strategy system. Thus, strategy systems can be constituted by both loose and tight coupling among their elements.

This insight can be applied to many different dimensions of strategy formation. At this stage, it may be sufficient to mention one major example, i.e. the relation between intention and action. The tight or 'rational' coupling between intention and action can be summarized as follows.

"The specification of positions, role definitions, procedural rules and regulations, value and factual inputs that guide decision making - all function to canalize behavior in the service of predetermined goals. Individuals can behave rationally because their alternatives are limited and their choices circumscribed.

In a larger sense, however, rationality resides in the structure itself, not in the individual participants - in rules that assure participants will behave in ways calculated to achieve desired objectives, in control arrangements that evaluate performance and detect deviance, in reward systems that motivate participants to carry out prescribed tasks, and in the set of criteria by which participants are selected, replaced, and promoted" (Scott, 1987: 49).

Weick forcefully argues for the loose coupling between intentions and actions:

"There is a developing position in psychology which argues that intentions are a poor guide for action, intentions often follow rather than precede action, and that intentions and action are loosely coupled. Unfortunately, organizations continue to think that planning is a good thing, they spend much time on planning, and actions are assessed in terms of their fit with plans. Given a potential loose coupling between the intentions and actions of organizational members, it should come as no surprise that administrators are baffled and angered when things never happen the way they were supposed to" (Weick, 1976: 4). 
In fact, some empirical sfudies recognize the simultaneous existence of tight and loose coupling in strategy formation (e.g. Kanter, 1983; Peters and Waterman, 1982). For example, Peters and Waterman (1982) observed companies which pushed autonomy down to the shop floor or product development team (looseness) but are also fanatic centralists around a few core values (tightness).

Following Giddens (1971), the relationship between looseness and tightness is a dialectical one. This assumption allows for both tight and loose coupling in strategy formation. Tight coupling of some elements or relations occurs simultaneously with loose coupling somewhere else in the system, and vice versa.

\subsection{The concept of dominant group}

This section considers the 'dominant group' as the system under study. First, the concept of group is described. Subsequently, the more specific concept of dominant group is defined.

A group can be defined in numerous ways, but one widely adopted definition is in system terms: a group is a system "which behaves as an entity because of the interdependency of its members" (Fisher, 1974: 19). The concept of group is virtually never used in strategy formation research (e.g. Mintzberg and Waters, 1985; Miles and Snow, 1978; Quinn, 1980). One rare exception is the study by Janis and Mann (1977). This state of affairs is understandable given the fact that the large body of research on small group decision making is carried out primarily in the social psychology laboratory. Because the structure of strategy formation is determined by its very complexity, oversimplification in the laboratory removes the very element on which research should focus (Mintzberg et al., 1976).

The main motive for neglecting the group concept probably lies in the belief among strategy researchers that larger groups are less likely to support 'collective action'. The major source of this belief is Olson's book Logic of collective action (1965). Olson argues that individual participation in a group is decided consciously with attention to the opportunity to contribute to and extract from the group (i.e. the costs and benefits). His hypothesis is that large groups become instable, because rational individuals would never contribute towards collective action. The total costs of inducing and providing collective action exceed the small fraction of total benefit an individual in a large group would get.

Oliver and Marwell (1988), however, point out that Olson disregards the important case of jointness of supply. Actions with jointness of supply cost the same no matter how many people 'enjoy' it. Classic examples are the 
provision of bridges, defending national borders and national schooling systems; but also organizational strategy - enabling organizations as collections of individuals to survive - may be conceived as collective action with substantial jointness of supply. When an action has high jointness of supply, it may be provided by relatively few people. This is especially the case when the larger 'interest' group is heterogeneous. The problem of collective action then is

"not whether it is possible to mobilize every single person who would be benefited by a collective good. It is not whether it is possible to mobilize everyone who would be willing to be mobilized. It is not even whether all the members of some organization or social network can be mobilized. Rather, the issue is whether there is some social mechanism that connects enough people who have the appropriate interests and resources so that they can act. It is whether there is (...) a subset of individuals who are interested and resourceful enough to provide the good when they act in concert, and whether they have sufficient social organization among themselves to act together" (Oliver and Marwell, 1988: 6-7; emphasis added).

The last two conditions apparently exist in many - small and large - organizations. The group concept is therefore useful to the study of how strategies arise in organizations.

The preceding argument suggests that strategy formation research can be focused on a subset of the overall group. This subset parallels what is known as the dominant coalition or dominant group (Cyert and March, 1963; Penrose, 1959; Whitley, 1987). For each organization, a dominant group has to obtain some cohesion in order to impart a particular character and direction to organizational activity and develop particular ways of working together. Dominant groups give organizations their cohesive character and generate the, often tacit, distinctive repertoires to cope with strategic problems. Thus, one does not have to posit a survival need for the collectivity of all group members itself. It is sufficient to assume that some participants will have a vested interest in the survival of the organization (Scott, 1987). The dominant group concept parallels recent interpretations of "excellent" companies as social movements (Soeters, 1986). As in social movements, most of the action in high-performing companies originates from a relatively small number of extremely active participants.

It is useful to distinguish between the core and periphery of dominani groups. The core of a dominant group concerns those persons who can take care of their involvement in a typical strategy process by themselves, e.g. based on their authority or status (cf. Schreuder, 1981). The periphery includes those persons who contribute to a typical strategy process on the basis of their power to impose sanctions (e.g. withholding information, loans or support). Generally speaking, their power to sanction the strategy process does not imply that periphery members can participate on their own initiative 
(cf. Schreuder, 1981). However, if their sactions become very powerful, such as in the case of a shareholder revolt, the periphery may directly affect the way the group's core deals with strategy (e.g. by appointing new Board members).

The cohesiveness of a dominant group can be viewed in terms of loose/tight coupling of its members. Thus, dominant groups may range from extremely tight groups exhibiting 'group think' (Janis and Mann, 1977) to very loose coalitions of shifting interest groups (Pfeffer and Salancik, 1978; Cyert and March, 1963). Even in the latter case, group members share some interdependency, without which their interest or role in the formation of a certain strategy would not exist.

In sum, strategy formation can be conceived in terms of a group process. In particular, we will focus on the so-called dominant group.

\subsection{Taking stock of the self-organization perspective}

This section summarizes the major assumptions and concepts constituting the self-organization perspective to strategy formation. In doing so, we take stock of the first two chapters.

Self-organization is characteristic of strategy systems. Such systems are complex, self-referential and strive for autonomy. The complexity of strategy systems follows from the fact that interaction between elements of the system cannot be reduced to simple, unidirectional causalities. Its self-referential nature implies that the system refers to itself in making sense of itself and its environment. In addition, the strategy system tries to develop or maintain autonomy relative to its environment.

These assumptions combine in the simultaneous closure and openness of strategy systems. That is, strategy systems try to maintain their existence by opening up in particular ways to the outside world. The way they open up relies on self-referential sensemaking and is directed at the system's autonomy. Thus, the closed character of strategy systems refers to the way they come to understand themselves and their environments.

The simultaneity of closure and openness of strategy systems is explicitly acknowledged in the dialectical paradigm. The dialectical approach can be summarized in three assumptions. The first assumption is that opposites such as closing and opening are complementary. The second assumption is the socalled negation of the negation. It suggests that each negation rejects a previous form, yet also retains something from that form. Any completed change process inherits some oppositions from the past and also contains and develops new oppositions. Thus, closing of a strategy system tends to 
produce opening, and vice versa. The third assumption involves the so-called transformation of quantity into quality and vice versa. Accumulated incremental changes in quantity eventually bring about new quality, and gradual changes in quality ultimately lead to new quantities. Thus, the interaction between opening and closing of strategy systems will culminate in major qualitative and quantitative changes.

We also adopted the concept of tight and loose coupling, which denotes the degree of responsiveness within or between seperate elements of a strategy system. Strategy systems are constituted by simultaneous loose and tight coupling. Looseness and tightness relate to each other according to the three dialectical assumptions (see above).

Finally, the dominant group was adopted as the strategy system under study. The dominant group involves the central social mechanism in strategy formation. This social mechanism may or may not connect enough people with the appropriate interests and resources. 


\title{
CHAPTER 3
}

\section{TOWARD A SELF-ORGANIZATION MODEL'}

\author{
"Organizations are not just groups of people; \\ they are sets of organizing rules." \\ (Pondy and Mitroff, 1979: 29)
}

\subsection{Introduction}

This chapter aims at a preliminary self-organization model of strategy formation. First, a number of theoretical categories, pertaining to the phenomenon of strategy formation, will be presented. Subsequently, a wide range of observations by strategy researchers will serve to identify several forces in strategy formation.

\subsection{Imaginizing how strategies form}

This section deals with the development of a number of theoretical categories of strategy formation, using self-organization thought and the additional concepts outlined in chapters one and two.

Six categories will be defined:

1) difficulties of the dominant group

2) perception by and formation of the dominant group

3) repertoire of the dominant group

4) actions induced by the dominant group

5) actions autonomous to the dominant group

6) environment of the dominant group.

The remainder of this section describes these six categories more extensively, also referring to related categories in the strategy literature.

\section{Difficulties}

Dominant groups only act on the environment they perceive. In particular, dominant groups confront so-called difficulties. These difficulties may be perceived as given or externally determined. However, they are social constructs, which cannot be viewed separately from its creators, the members of the dominant group.

Major parts of this chapter have been published in a preliminary form in Romme 
The conventional conception of difficulties resides in any textbook on strategic management (e.g. Hax and Majluf, 1984; Hatten and Hatten, 1988). These textbooks use the terminology of 'opportunities' and 'threats' which are related to the strong and weak points of the organization. As such, any difficulty can be framed in terms of opportunities and/or threats.

A more unconventional approach is taken by Hampden-Turner (1990). Hampden-Turner conceives difficulties in terms of 'dilemmas'. Dilemmas concern the form in which potentially conflicting aims are expressed. A simple dilemma involves the extent to which departments having divided work and functions can also be effectively coordinated.

In sum, a difficulty is a problem which involves potentially conflicting interests and provides a fundamental challenge or threat to the dominant group.

\section{Perception and formation}

Perception by and formation of the dominant group are related categories. First, we will discuss dominant group perception and, subsequently we turn to group formation.

Two activities pertain to perception by the dominant group: sensory and cognitive activity (Romme, 1990a). Sensory activity involves exposure to difficulties as raw data, e.g. by search, exploration or informal contacts. It relies on the looseness of group perception as it especially involves the individual exposure to raw data. Cognitive activity pertains to interpretive schemes, enabling the interpretation and understanding of, for instance, difficulties. Although in many circumstances perception may be predominantly individual in kind, dominant groups continue to exist thanks to some sharedness of individual cognitive frameworks. Thus, perception is conditioned by some tightness of perception by individual group members. Every dominant group has to obtain some cohesion in individual perceptions in order to constitute some consensus in support of repertoires of action (Hedberg, Nystrom and Starbuck, 1976; Whitley, 1987).

Individual sensory activity must therefore be complemented with cognitive activity which encourages some level of shared problem understanding. The dialectical nature of perception can be summarized in terms of two graphs (Romme, 1990a). These graphs are reproduced in Figures 3.1 and 3.2. In both graphs the horizontal axis represents the cohesiveness of the dominant group and the vertical axis represents the perception of the group in terms of its effecliveness, or competence, to address difficulties. The graph in Figure 3.1 shows that both high and low cohesiveness are detrimental to effectiveness. This assumption is consistent with observations of strategy formation (e.g. Janis and Mann 1977; Mintzberg and Waters, 1985) as well as studies 
Figure 3.1 The relation between cohesiveness and perceptual competence of dominant groups.

Perceptual competence

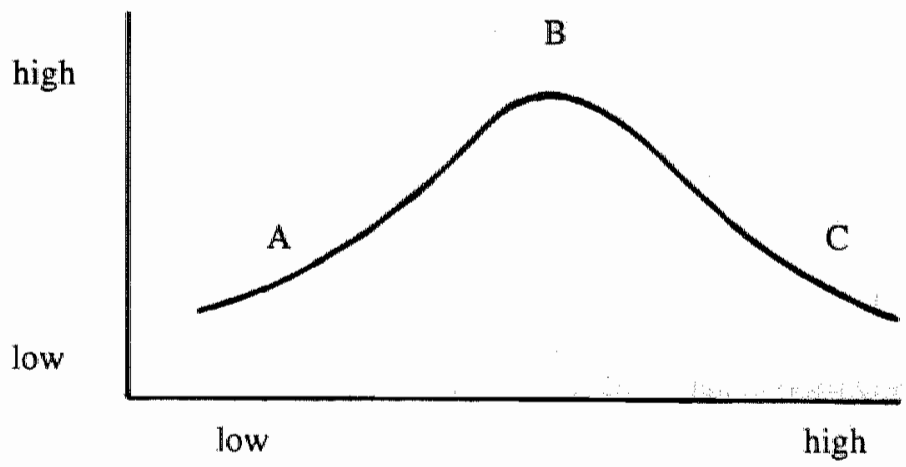

Cohesiveness

Figure 3.2 The relation between cohesiveness and sensory resp. cognitive competence of dominant groups.

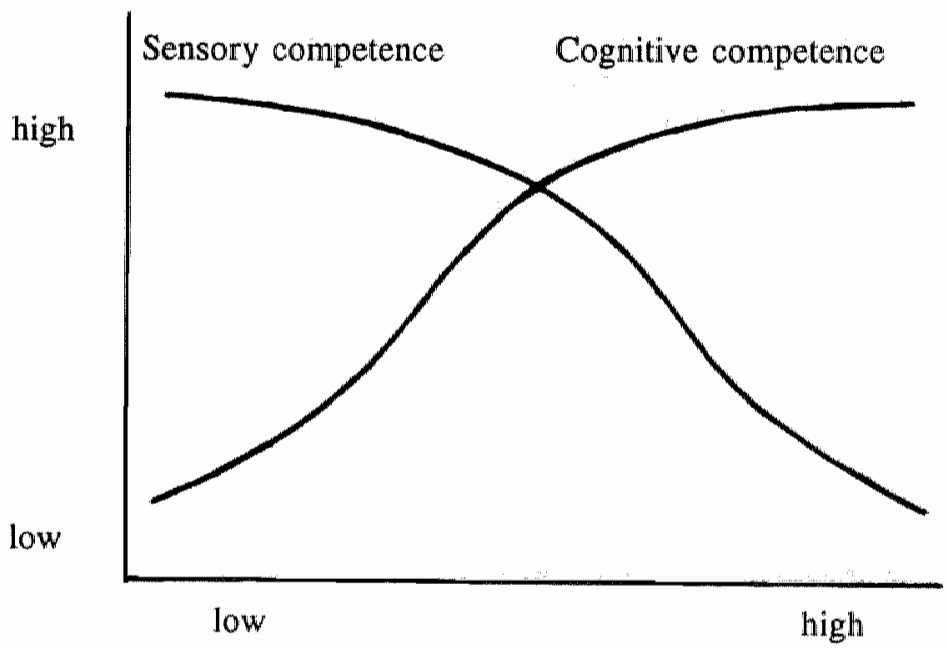

Cohesiveness 
of small group decision making (e.g. Fisher, 1974).

The overall effectiveness of perception can be broken down in its cognitive and sensory component, given in Figure 3.2. For the clarity of the argument, sensory and cognitive effectiveness have been given equal weight and add up to the overall effectiveness in Figure 3.1. A number of implications may be noted when viewing specific positions on these curves.

Position B represents a group of moderate cohesiveness that effectively combines rather high levels of sensory and cognitive effectiveness. Moving to the left, lower cohesiveness parallels a higher inclination to adapt and change (Simmel, 1955) but also more ambiguity and politicality by responding to seemingly random changes in the environment. Position $\mathrm{A}$ is typical of an open, fragmentized group acting in a hypervigilant way toward environmental difficulties and producing few, often inconsistent (shared) cognitions (Janis and Mann, 1977). In extreme cases (e.g. Mintzberg and Waters, 1985), this position consists of a number of loosely coupled individuals or enclaves.

Moving to the right reflects the dynamics of an increasingly cohesive group that closes itself by relying on its shared and accepted perceptions. Position $\mathrm{C}$ parallels the phenomenon of 'groupthink' as extremely closed group behavior based on collective defensive avoidance (Janis and Mann, 1977). A change in overall effectiveness (cf. learning effects) implies a vertical shift of the graph itself.

Note that perception and (trans)formation of the dominant group are related categories. Group formation connects a number of individuals and transforms their individuality into some collective identity. Group perception transforms individual cognitions into collective cognitions. Group perception and group formation can thus be viewed as two related categories, influenced by the same set of forces.

\section{Repertoire}

Whereas dominant group perception enables the conception and construction of (new) views of organizational reality, its repertoire converts these views into action. Of all six categories, the repertoire comes closest to what is commonly understood as 'strategy'. ${ }^{2}$ That is, the repertoire can be concei-

2 See the remarks on the strategy concept in the Introduction. The repertoire also resembles the concept of culture. In this respecit, culture (as collective mental programs) and strategy are partly overlapping concepts (Weick, 1985; Hofstede, 1991). We prefer the repertoire concept because it is firmly rooted in social theory (e.g. Giddens, 1979). Moreover, theoretical research by economists shows that the predictability of behavior arises from so-called behavioral repertoires (e.g. Heiner, 1983). 
ved as the stock of strategies that a dominant group is always ready to 'perform'. As such, the repertoire drives actions in the absence of more deliberate modes of addressing difficulties, such as planning procedures (Karpik, 1972; Miller and Friesen, 1980; Nelson and Winter, 1982). Dominant group members use it to limit what they perceive to that which they can subsequently act upon. As such, the dominant group repertoire is a kind of filter which is at once a help and a hindrance (Grinyer and Spender, 1979): it can be a source of judgement applied to help eliminate uncertainty, but it can also be a conceptual strait-jacket preventing group members to think innovatively. Repertoire is defined here as the collection of rules (directions) for action prevailing in a given dominant group at a certain moment in time.

The repertoire may comprise rules related to strategy content, e.g. with regard to actions in markets, technologies and industries. Grinyer and Spender (1979) suggest that such rules often arise from the collective experience of the industry (e.g. 'in our industry, cooperation between competitors is not done'). But also rules regarding the processes by which actions come into being (e.g. decision procedures) are part of the repertoire. Typically, the repertoire leaves room for a wide range of more specific intentions but provides enough structure to guide actions.

The repertoire does not necessarily involve clear-cut, explicit or conscious guidelines for organizational action. One may employ more tacit, global or unconscious rules. Also, repertoires do not necessarily involve consistency or coherence. They may contain a number of rival rules which are not (yet) integrated in terms of one dominant repertoire (cf. Greenwood and Hinings, 1988).

Basically, there are two modes of change related to group repertoires. The first mode involves change within the repertoire, by either de-activating active rules or re-activating dormant rules (Clark and Starkey, 1988). The other mode is change of the repertoire itself. In general, change within the repertoire is simpler than questioning and revising the repertoire itself (Nelson and Winter, 1982; Giddens, 1979; Unger, 1987).

\section{Induced and autonomous action}

We distinguish between actions which are induced by the dominant group and those which are relatively autonomous. A similar distinction is made by Burgelman (1983b). Although autonomous action may be purposeful to those engaging in it, its actual generation is decoupled from deliberate influence of the dominant group. In many respects, autonomous action is conceptually equivalent to entrepreneurial activity. Moreover, autonomous actions may be potentially dangerous to the dominant group, but also provide the means for innovation (Burgelman, 1983b; 1985). 
Induced and autonomous action can be taken by core members of the dominant group, for instance, the CEO, as well as peripheral members, for instance, marketing managers or consultants. Generafly speaking, actions by consultants are part of the environment, but on request of members of the core they enter the periphery as new (passing) members. Similarly, certain actions by competitors, for instance, making major business proposals to the dominant group, can be conceived as autonomous in kind. Recall that one becomes a member of the periphery on the basis of power to impose sanctions on the core of the dominant group, for instance, by withholding information or loans.

The distinction proposed by Burgelman is not exactly the same as the one adopted here. Burgelman (1983b; 1985) labels 'induced' versus 'autonomous' strategic behavior in view of the difference between strategic development versus strategic diversification. Strategic development concerns familiar environments and niches. Strategic diversification involves activities falling outside the organization's current conceptions of strategy. This distinction has been developed particularly for the large, multi-divisional company. The terminology adopted here should also apply to dominant groups in small organizations. Accordingly, the definitions of induced and autonomous actions have been adapted. The following definitions may capture the difference between induced and autonomous action.

Induced action includes action being deliberately initiated by the core of the dominant group. Autonomous action involves action by members of the core or periphery of the dominant group which appears as given to the core of the group, that is, without deliberate group influence.

\section{Environment}

The final category is the environment of the dominant group. The dominant group was defined in chapter two as a system which behaves as an entity because of the interdependence of its members. The environment of the dominant group includes all other entities in the world which influence or are influenced by the dominant group. It may include, for example, resources, actions, rumors, economic indicators, expected industrial developments, etcetera.

\section{Overview}

These six categories provide the building blocks for a preliminary model of strategy formation. They enable us to identify a variety of forces. Following chapter two, these forces are dialectical in nature and may involve either loose or tight coupling between categories. The next section takes a closer look at these forces in strategy formation. 


\subsection{Some forces in strategy formation}

A wide range of observations will now serwe to identify several forces in strategy formation. We aim at a broadly applicable self-organization model which is grounded in the strategy formation literature. The reader may anticipate the argument by looking at the resulting model in Figures 3.3 to 3.5 .

The self-organization model which is proposed here suggests that imperatives for change of the strategy system occur quite frequently and are integrated into the system by the relatively closed pattern of forces prevailing at the moment. In line with self-organization thought (see chapter one), we may distinguish between changes around a certain steady state (cf. Figure 3.3) and changes toward a substantially different state (cf. Figures 3.4 and 3.5). The latter changes occur in response to imperatives which arise in the course of action. These imperatives either involve the occurrence of unintended consequences of induced action (Figure 3.4) or autonomous action triggering major changes in the composition and perception of the dominant group (Figure 3.5).

Several individual forces will be described more extensively in the remainder of this section. We will do this by assuming all other things being equal. In fact, however, most of these forces tend to work simultaneously and, thus, they may reinforce or neutralize each other. For instance, unintended consequences of induced action tend to trigger change of the system but forces of the steady state may prevent this change.

Note that we will not deal extensively with forces related to the environment. As described in chapter one, self-organization thought suggests dominant groups open up toward their environments by way of action. The forces between action and environment may work in two directions. First, actions may create environments. This is what Weick (1979) refers to as the enactment process. Enacted environments may consist of talk, symbols, promises, lies, interest, attention, threats, agreements, expectations, memories, rumors, commitments, loyalties, economic indicators, etcetera (Weick, 1987b). In addition, the degrees of freedom in the creation of the environment may be limited. That is, environments may constrain or trigger actions. For example, economists have identified a variety of industrial-economic conditions which constrain or trigger certain actions (e.g. Porter, 1980).

\section{Difficulties and repertoire}

As we have seen, the repertoire may contain both active and non-active rules. Non-active, dormant rules can be activated and active rules can develop into dormant ones if no longer activated. Difficulties appear to be major stimuli which activitate certain rules in the repertoire. 
A clear example was observed by Clark and Starkey (1988) in the way the dormant repertoire of the management team in the sixties at Corah, a major garments supplier of Marks and Spencer (U.K.), was activated and brought into action. Fundamental shifts in consumer preferences led to the activation of a long dormant repertoire in designing garments.

Starbuck and Hedberg (1977) describe the case of Facit AB, a company primarily based in Sweden, that grew large while making and selling business machines and office furnishings. Although Facit made many products, the repertoire of Facit's top management steadily closed down around the rule that the key product line should be mechanical calculators. When the company ran into financial difficulties, this well-established repertoire, focusing on the production and marketing of mechanical calculators, was activated again and again. Facit's top management continued to respond to low financial performance by, for instance, laying off employees, major reorganizations, replacing individual managers and closing plants (Starbuck and Hedberg 1977). Other case-studies offer similar observations (e.g. Mintzberg, Brunet and Waters, 1986; Johnson, 1987; Grinyer and Spender, 1979).

With respect to a so-called decline situation, Czarniawska-Joerges (1989) and Miller and Friesen (1984) argue that the typical response is doing 'more of the same', for instance, tightening control. Studies by D'Aveni and MacMillan (1990) and Schreuder (1991) show that this kind of response to a demand-decline situation typically leads to less success or even complete failure. By contrast, paying more attention to the critical difficulties related to demand-decline is associated with survival and success (D'Aveni and MacMillan, 1990; Schreuder, 1991). In both the successful and less successful cases, management somehow reduces a broader set of perceived difficulties. The argument here is that especially the dominant group's repertoire limits what they perceive to that which can be acted upon.

Apparently, the forces between difficulties and repertoire are reciprocal in kind (see Figure 3.3): difficulties stimulate the use of certain rules, but at the same time, these rules eliminate, or filter, certain difficulties in favor of others.

We may summarize these forces in the following propositions.

Proposition 3.1a:

Difficulties activate the current repertoire.

Proposition 3.1b:

The current repertoire filters difficulties to those which can be acted upon. 
Figure 3.3 Forces in strategy formation when the repertoire of the dominant group remains largely unchanged.

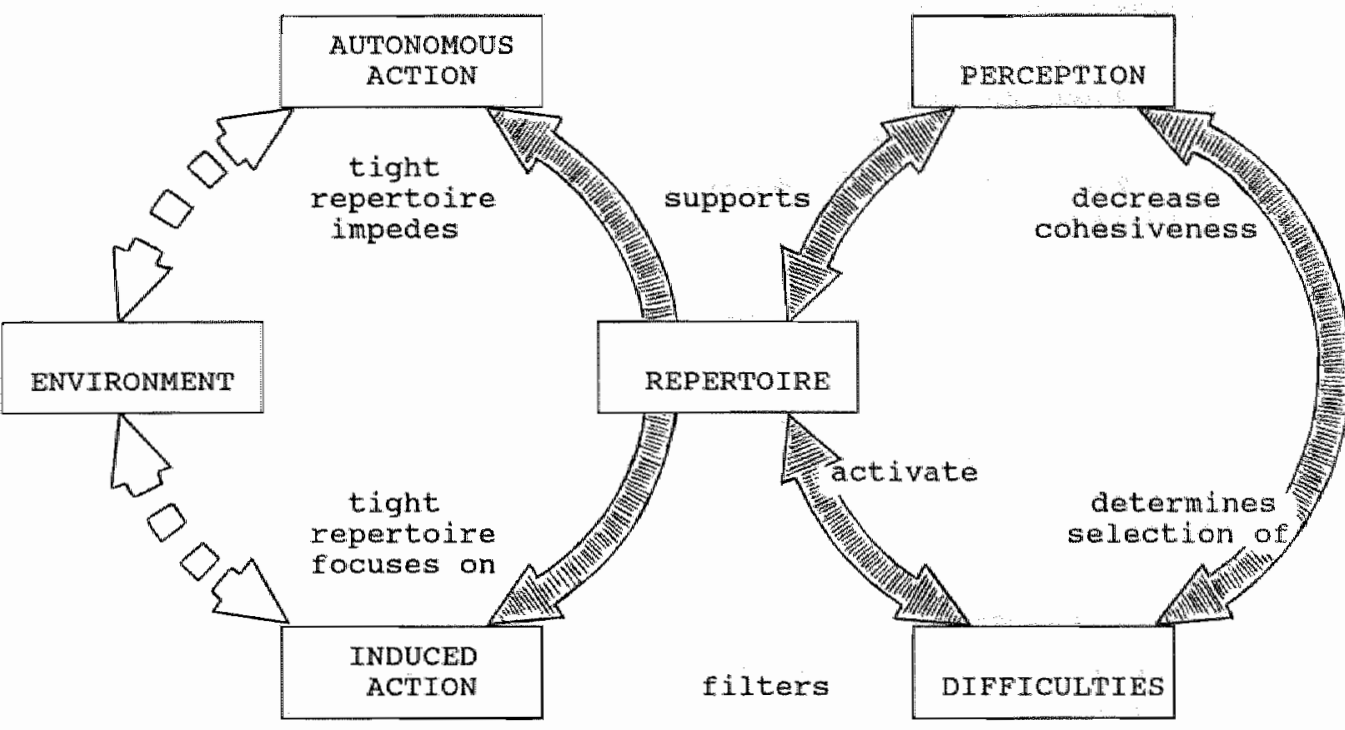

\section{Perception and repertoire}

The group acts on their repertoire constructed on the basis of past experiences accumulated in their collective cognitions (Grinyer and Spender, 1979; Hedberg and Jönsson, 1977). This process is referred to by Schwenk (1984) as cognitive simplification. Thus, the repertoire and a set of shared perceptions seem to complement each other.

Consider again the history of Corah (Clark and Starkey, 1988). A relatively new production unit within Corah was administered by a rather autonomous management team which did not include any long-serving manager with expertise in marketing. The repertoire of these managers did not include any rules providing guidance in responding to fundamental change of customer preferences. Hence, they did not succeed in their attempt to adapt to the new market conditions, in contrast to most of the other units in Corah. The lack of an appropriate repertoire and perceptual framework for coping with market change in the knitted goods industry is one major explanation (Clark and Starkey, 1988).

Janis and Mann (1977) observe that the level of group cohesiveness determines the extent to which groups develop tight, 'group think' repertoires. Other 
studies point at similar forces, although not in terms of the pure causality proposed by Janis and Mann. For instance, some studies suggest the disintegration of the top management repertoire parallels the breakdown of collective cognitions (e.g. Lewis, 1988; Pettigrew, 1985). The next proposition can therefore be advanced.

Proposition 3.2 :

The cohesiveness of perception supports the tightness of the repertoire (that is; higher cohesiveness will bring about a tighter repertoire), and vice versa.

\section{Difficulties and perception}

The third type of force works on the level of difficulties and group perception. A large number of studies (e.g. Starbuck, 1983; Kanter, 1983; Pettigrew, 1985; Bartunek, 1984; Czarniawska-Joerges, 1988; Manz, Bastien and Hostager, 1989) suggest that the perception of difficulties is initially individual in kind, countering group tendencies to produce a tight, shared understanding of the world outside. Dominant groups may thus profit from a variety of field, function, race, gender and culture represented. This means that a group whose composition is diverse and flexible is more likely to pick up external cues than one with a more homogeneous membership (Kanter, 1983). The relationship between cohesiveness and competence to 'sense' new difficulties can also be inferred from Figure 3.2.

Studies of shifts in top management positions provide observations of forces working in the other direction. Shifts in CEO and chair of the board positions in U.S. companies have been studied by Harrison, Torres and Kukalis (1988). They show that persistent difficulties (e.g. poor performance of the company) can reduce CEO and chair influence and lead to a (further) separation of the positions, including the appointment of a new CEO. Minor difficulties (e.g. strong performance) enhances CEO power, possibly leading to a consolidation of the two top positions under the current CEO. These findings suggest that major difficulties, such as a crisis of sufficient magnitude, can shift the locus of power temporarily to the board (Harrison, Torres and Kukalis, 1988). This suggests that major difficulties reduce the cohesiveness of the dominant group (which in most cases includes the CEO and board). To sum up, we present the following propositions.

Proposition 3.3a:

The level of cohesiveness of perception determines the selection of new difficulites.

Proposition 3.3b:

Major (new) difficulties tend to decrease group cohesiveness. 


\section{Repertoire and action}

A repertoire generates action by enabling the agents of action (Giddens, 1979). For instance, the repertoire gives rules for the allocation of resources (e.g. 'invest in our core-business') or delimits certain domains of managerial behavior (e.g. 'do not become involved with union representatives').

Consider again the case of Facit AB (Starbuck and Hedberg, 1977). The repertoire of Facit's top management centered around the rule that the key product line should be mechanical calculators. In line with this repertoire, actions focused on the production and sale of mechanical calculators by improving the quality and lowering the costs. For similar examples see Chandler (1977) and Czarniawska-Joerges (1989), Kanter (1983) and Meyer (1.982).

Repertoires are dual in nature. In addition to enabling action, they also constrain action (Giddens, 1979). Note that some of Peters and Waterman's (1982) 'excellent' companies have not been able to extend their excellence over longer periods of time (Soeters, 1986). Their well-defined, strong repertoires - so strong that one either buys into their norms or gets out apparently contribute to the risk of becoming myopic. For example, Levi Strauss held on too long to its repertoire of 'successful' jeans. It reacted too late when customer demand shifted away from jeans, resulting in a quick downfall of its financial results (Soeters, 1986). The strong, ingrained and often egocentric repertoires of the leadership of such organizations may severely constrain autonomous action and thus they truncate and distort their understanding of the wider context in which they operate (Morgan, 1986). Similarly, Janis and Mann (1977) observe that tight, narrow group repertoires may result in isolated and defensive (induced) group actions.

Organizations facing a crisis provide other examples (Nystrom, Hedberg and Starbuck et al., 1976; Starbuck, Greve and Hedberg, 1978; Starbuck and Hedberg, 1977; Bahlmann and Meesters, 1988; D'Aveni and MacMillan, 1990). They focus on the, especially induced, actions they believe important. Moreover, such repertoires tend to impede more autonomous actions by group members that often turn out to be more important (cf. Starbuck, 1983).

This phenomenon may be understood in terms of action moving away from the direct influence of the dominant group. Recall that autonomous action can be taken by any core member (e.g. CEO, board members) as well as periphery members (e.g. middle managers, consultants, major customers). The development of Facit $\mathrm{AB}$ presents dramatic examples (Starbuck and Hedberg, 1977). The highly focused repertoire of Facit's top management in other words, the core of its dominant group - prevented its members from undertaking any explorations with regard to the rise of the electronic calcula- 
tor. Action moved from lower-level managers and engineers, who signalled the electronic rewolution but did not succeed in bringing such awareness upward, to a loyal customer cancelling a large order and, finally, a larger firm taking over Facit. The advent of electronic calculators took Facit's top management and its "mechanical" repertoire by surprise (Starbuck and Hedberg, 1977).

The interaction between action and repertoire is a complex one. The repertoire both induces and constrains action. The following proposition summarizes these forces (see also Figure 3.3).

Proposition 3.4:

The repertoire induces group members to act, but also tends to constrain autonomous action. Tight repertoires tend to focus on inducing actions in line with the repertoire and impede autonomous actions by group members. Loose repertoires tend to tolerate more autonomy in action.

\section{Intermezzo: when the repertoire remains unaffected}

The pivotal role of the repertoire can be inferred from Figure 3.3. Thusfar we have implicitly assumed that the repertoire has already formed and basically remains the same. Under this assumption, some of the forces outlined above can be linked. Attention will be limited to the interactions between action, repertoire and difficulties. (The argument can be extended to the interactions between action, repertoire and perception).

The forces between action and difficulties are mediated by the repertoire. In some cases, this amounts to the repertoire diverting action from emerging difficulties. Note, for example, that many owner-controlled, entrepreneurial firms after having solved their start-up problems continue to focus (at least for some time) on these initial difficulties and ignore other difficulties which arise as a result of their continued growth (e.g. Mintzberg and Waters, 1982). The strength and durability of such forces can also be inferred from the history of Facit, whose management focused on the development, production and sales of mechanical calculators, although substitute products (electronic calculators) gained prominence (Starbuck and Hedberg, 1977). Other cases show examples of repertoires of 'excellence' which on the one hand continue to support existing action patterns, and on the other hand attend to past success and disregard problems related to future success (e.g. Peters and Waterman, 1982; Mintzberg et al., 1986; Pettigrew, 1985).

\section{How repertoires replace each other over time}

Thusfar we have assumed that the repertoire remains largely unchanged. The repertoire can be long-lived and much elaborated on for dominant groups 
relegating its electronic engineers to a small, jointly owned subsidiary. Top, middle, and lower managers agreed about how a mechanical-calculator factory should operate, what customers wanted, and so forth. No resources were wasted gathering 'irrelevant' information. The results were quite dramatic. Loyal customers cancelled large orders after Facit had failed repeatedly to produce machines of adequate quality. Also, overall demand for mechanical calculators dropped precipitously.

The literature provides a variety of other illustrations of unintended consequences of induced action (e.g. Taylor, 1986; Quinn, 1980; Johnson, 1987; Chandler, 1977). Obvious examples are revealed in studies of the U.S. government's escalation of military activity in Vietnam in the early sixties, involving dramatic consequences of 'over-realized' actions for the perceived difficulty set (Mintzberg, 1978; Mintzberg and Waters, 1985). HampdenTurner (1990) describes how the leadership in companies like Hanover Insurance and Apple confronted dilemma's arising from induced actions. For instance, Apple mounted an excess on its own previously 'successful' repertoire and actions (producing 'power tools for persons'). The Apple repertoire that had triumphed in the past subsequently threatened catastrophe through its unintended reliance on non-institutional customers when overcapacity and recession in the computer industry began to bite (HampdenTurner, 1990).

Once substantial unintended consequences of the current repertoire are included in the set of difficulties, other forces contribute to the repertoire's decline. The unintended consequences start to act as anomalies to the current repertoire. That is, the misfit between difficulties and repertoire triggers the actual breakdown of the repertoire. Moreover, the new difficulties start to undermine the shared cognitions of the group, which in turn affect the repertoire (see Figure 3.4). Some of these forces can be inferred from the battle of Walt Disney Production's (WDP) top management against the logic of financial markets (Taylor, 1986). WDP ran into an unintended situation in which their profitability declined and the book value of their real estate and other properties were understated (according to the general feeling at Wall Street). Thus, the threat of a rapid take-over attempt arose. WDP traditionally carried little debt and had never made an acquisition, but, in the face of this threat their repertoire broke down. Moreover, the composition of the dominant group changed dramatically, including a new CEO and Chairman of the board (Taylor, 1986).

The set of forces pertaining to the formation of a new repertoire are outlined in Figure 3.5. The initial impetus here comes from autonomous action carrying the elements for a new shared cognitive framework. In other words, new cognitions are brought into the group by autonomous actions. Remember that these actions are taken by either the existing membership or new members. Initially, a set of competing, incompatible cognitions may arise. 
This typically brings about a lot of conceptual confusion and emotional debate because a shared cognitive framework is still missing (Hedberg and Jönsson, 1977).

An example of how new repertoires form is provided by the history of Arcop (Mintzberg et al, 1986). In Arcop, a Canadian architecture copartnership, autonomous actions especially involved the diverse initiatives of individual partners and their attempts to carve out their own domains. Their repertoire basically focused on individual projects which are linked through collaborative efforts, invoked by architectural competitions. The history of Arcop also shows that the exit of partners and associates from the dominant group constitutes critical landmarks. Such major changes in size and composition of the dominant group may involve its complete disintegration, but also provide fresh opportunities to start anew. Other cases provide similar examples (Bartunek, 1984; Kanter, 1983; Mintzberg and McHugh, 1985; Hardy, 1990).

Recent studies of the role of executive leadership in strategy formation points at the potentially pervasive effect of (lack of) autonomous action on the cohesiveness of dominant groups (Manz, Bastien and Hostager, 1989). In

\section{Figure 3.5 Forces in strategy formation which lead to the formation of a} new repertoire.

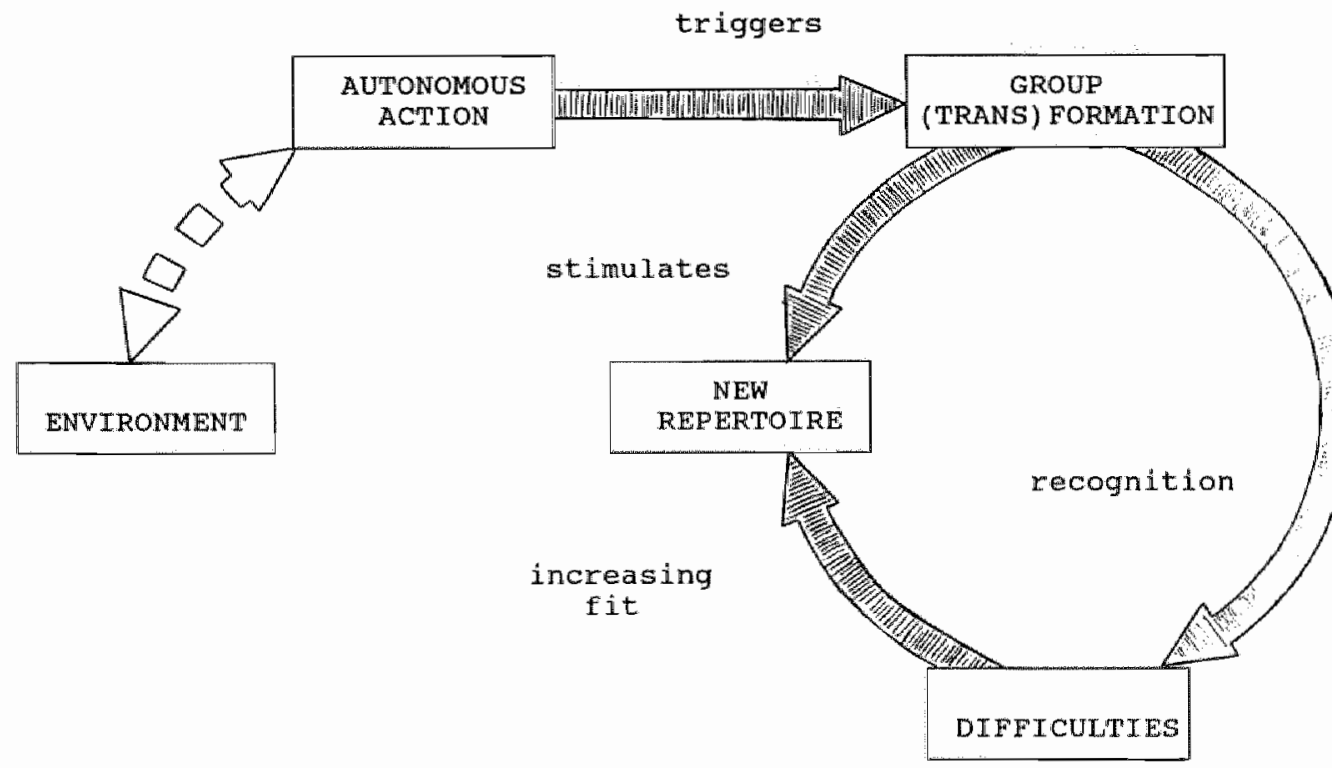


this respect, it appears that the replacement of top managers is essential in bringing organizations out of a crisis situation (Starbuck, Greve and Hedberg, 1978; Hedberg and Jönsson, 1977; Schreuder, 1991).

Following the impetus from autonomous action to group (trans)formation, the repertoire is actually constructed by way of some of the forces outlined in propositions 3.1 to 3.3 . The increasingly shared cognitions stimulate the social (re)construction of the new repertolre. Moreover, one now starts to recognize how the anomalies in the old repertoire fit into the new way of doings things. Figure 3.5 summarizes how a new repertoire forms.

When major elements of the new repertoire have formed and group members share some basic underlying cognitions, the repertoire further develops by way of the forces outlined in previous propositions. Note that breakdown of the old repertoire and formation of a new repertoire are largely simultaneous processes. In some cases the old repertoire gradually gives way to the new one (e.g. Lewis, 1988; Johnson, 1987). In other cases the new repertoire is imposed by external actors entering the dominant group and eliminating the old repertoire, for instance, by take-over (e.g. Starbuck and Hedberg, 1977) or governmental intervention (e.g. Mintzberg, Brunet and Waters, 1986).

Thus, repertoires replace each other by forces breaking down the old repertoire and forces forming a new one. The following propositions summarize these forces.

Proposition 3.5a:

Breakdown of the old repertoire is triggered by major unintended consequences of induced action. Once these unintended consequences are included in the difficulty set, they constitute misfits (anomalies) to the old repertoire. In addition, they tend to undermine group perception (i.c. decrease its cohesiveness) and, thus, support for the old repertotre decreases.

Proposition 3.5b:

Formation of a new repertoire is triggered by autonomous actions of (new) dominant group members. These actions introduce new perceptions into the group, and possibly also change its composition. In turn, new perceptions stimulate the emergence of a new repertoire and enable the recognition of previously neglected difficulties (e.g. unintended consequences). In addition, these difficulties increasingly fit the new repertoire. 


\subsection{Conclusion}

This chapter puts forward a preliminary model of strategy formation. Six theoretical categories, pertaining to strategy formation in dominant groups, have been presented: difficulties, perception, repertoire, induced action, autonomous action, and environment.

Subsequently, observations by strategy researchers served to identify a set of general forces at work in strategy formation. Several propositions have been advanced. 


\section{CHAPTER 4}

\section{VERTICAL INTEGRATION ${ }^{1}$}

"(H)e knew that Elephants, cannot be seen at all, These creatures live in human brains,

As myths which rise and fall.

Thought: Let these blokes watch Elephants,

Then I"ll give each a call!."

(Hedberg and Jönsson, 1977: 88)

\subsection{Introduction}

This chapter aims at a model of the formation of vertical integration strategy. It intends to elaborate the model put forward in chapter three, especially for the issue of vertical integration.

Vertical integration leads to the joint administration of two separable production stages. The vertical integration issue has been studied mainly by economists. Generally speaking, (industrial) economic theory only deals with the outcomes (or content) of strategy, either at the firm or industry level. This chapter aims at a model of both the process and content dimension in the formation of vertical integration strategy. ${ }^{2}$

The propositions put forward in the previous chapter will guide the empirical inquiry. This empirical inquiry involves the assessment of an extensive vertical integration case as well as the evaluation of existing explanations and observations in the vertical integration literature. The central question therefore is: does the selfworganization model lead us to understand vertical integration strategies?

The chapter is organized as follows. First, a detailed description of a typical vertical integration case, i.c. that of Hendrix" Fabrieken in The Netherlands, is given. Next, we provide a survey of existing explanations of vertical integration. Finally, a model of vertical integration strategy is formulated.

"Major parts of this chapter have been taken from Romme (1990a).

2 Generally, discussions of vertical integration strategy are restricted to private sector organizations. This chapter is written in line with this convention. 


\subsection{Forward integration by Hendrix" Fabrieken}

In the early seventies Hendrix' Fabrieken, a large cattle-fodder producer in the Netherlands, integrated forward into food-processing. This section describes how and why Hendrix' Fabrieken integrated forward into the processing industry. The case is not meant as an empirical validation of the model that follows, but as an illustration of real-life vertical integration. Numerous other cases (e.g. Chandler, 1962; 1977; Silver, 1984) could serve the same purpose. The description of the Hendrix' Fabrieken case is based on the detailed study by Bläsing (1986). ${ }^{3}$

Note that the animal food production chain comprises four technologically independent stages, i.c. input production (e.g. cattle fodder, chicken breeding), production of poultry and cattle, processing (slaughtering and working up into meat products) and distribution.

The history of Hendrix' Fabrieken goes back to the twenties. In those days the entrepreneur Wim Hendrix, a tradesman in agricultural products, started mixing fodder for chicken, pigs, cows, etc. Later, poultry breeding activities were added. In the early sixties strategies developed in Hendrix' Fabrieken within a nucleus of three persons: the founder Wim Hendrix and the two members of the Board of Directors, including the son of the founder. Wim Hendrix, who had led the company for forty years in a highly patriarchal style, still held the presidency of the supervisory board (president-commissaris). Although the Board had the overall responsibility for corporate strategy, Hendrix senior had a lot of influence especially in the early sixties when the relatively new Board members had to familiarize themselves with their roles.

After the death of Wim Hendrix in 1965, the administrative model that was set up and formally implemented by Hendrix was actually realized: it involved a Board of two members who were completely equal in authority and thus could only function on the basis of consensus. This top management structure was designed by Hendrix senior primarily in view of the very opposite characters and administrative styles of the two Board members: one is calm, thoughtful, introvert and inventive, while the other is dominant, active and frequently acts without careful consideration.

The agricultural sector experienced a tremendous growth in the sixties and seventies, which was favorable for the fodder industry. Total fodder produc-

3 On request, some additional information was provided by professor Bläsing, University of Brabant (The Netherlands). Also, certain critical interpretations in the second part of this chapter were checked with representatives from Hendrix" Fabrieken (now Hendrix Intermationall). In general, Bläsing"s (1986) study remains the basic source of all observations reported in this chapter. 
tion in the Netherlands expanded from 5.7 in $1964 / 65$ to 14.5 million tons in 1980. Hendrix' market share in total Dutch production was about 3 percent in 1964/65 and increased to 7 percent in 1980. As such, Hendrix became the largest private cattle-fodder producer in the Netherlands. The key to Hendrix ${ }^{3}$ success in the animal fodder and breeding industry was the development of specific competence in sales en aftersales, which was carried out by local representatives. Hendrix is now widely considered to be one of the most profitable fodder producers in Europe.

For Hendrix' policy in the post-war period a number of trends in the next production stage, the stock-raising by farmers, were pertinent. A basic trend was the increasing scale and concentration of farming activity. Especially the automation, rationalization and specialization of farming activities led to a decreasing number of farms with an increasing number of animalls. The growing need for capital, for instance to finance larger and modern stables, led farmers to call on the cattle-fodder producers, because Dutch banks were risk averse with regard to the financing of stock-raising facilities. As a result, foddler producers, including Hendrix, were confronted with large outstanding debts on their balance sheets.

The increasing involvement in the risks of animal production itself led the largest fodder producers to set up building departments for stable construction projects and staff departments for financing and credit control. At the same time, these companies moved into the use of pig-, calf- and chickenfattening contracts, in which the supplier of fodder guaranteed a certain selling price for the fattened animals. Bulk shipment stations (to load the lorries), fodder elevators at the farms and stable-construction kits were also introduced by the cattle-fodder companies.

With regard to fattening-contracts, bulk distribution, the financing of elevators and stable construction kits Hendrix was one of the most progressive firms in the industry. According to Hendrix" management, the long-run commitments to the farming stage gave Hendrix the advantage of a known and 'safe' fixed sale. On the other hand, they also perceived a greater involvement in the risks of the farming stage, reinforced by the development of over-capacities in the animal food industry.

In the fifties, the industrial slaughtering of fattened chicken was introduced in the Netherlands. A number of cattle-fodder producers followed, but Hendrix' Fabrieken stood aside for a long period. Hendrix senior, in particular, doubted the viability of stepping into food processing: did it relate to the competences of Hendrix? In the course of time, this appeared to be an unrealistic position. According to one member of the Board: "We are excellent cattle fodder producers, but if you want to survive you need the meat in your structure"; the other Board member stated that "fodder as an autonomous product is disappearing and will develop into an aid to produce 
for example meat" (Bläsing, 1986: 270).

In 1965, Hendrix therefore cooperated with eight small slaughter-houses. However, this soon appeared to be a problematic and inadequate solution. As most competitors already had been integrating into the food processing stage and Hendrix" managers observed important efficiency and product quality differences between slaughter-houses, they decided that Hendrix needed one large, integrated slaughter facility. The acquisition of a number of poultry processing facilities was thought to support fodder sales to farmers. More specifically: "you can sell fodder for fattening chicken to a farmer, as long as he can get rid of his fattened chickens" (Bläsing, 1986: 272). After these initial acquisitions in poultry processing Hendrix' Fabrieken extended the food products division at a quickened pace, by also entering cattle processing.

\subsection{Explanations of vertical integration}

The focus now switches to the following question: what explanations of vertical integration strategies, such as forward integration by Hendrix' Fabrieken, are available? We therefore turn to a survey of the literature on vertical integration.

Vertical integration can be defined as either a state or a process. In our attempt to understand vertical integration we assume that any state of vertical integration must be explainable in terms of the process that led to this state. Therefore, the following definition is adopted: vertical integration is the process leading to the joint administration of two or more, technologically separable, production stages (cf. Davies, 1987). This definition excludes vertical integration driven by technological imperatives which in most cases are built into the plant or firm from the outset. Examples of technological imperatives include the avoidance of cooling and reheating activity in an integrated steel-making plant, and the reduction of contamination risk and storage costs in an integrated slaughtering-processing plant in the food industry.

The element of joint administration is of major importance in the above definition. Joint administration occurs when the final authority is with one managerial hierarchy instead of multiple hierarchies (as in market transactions). Note that incomplete integration occurs when transactions are organized by establishing long-term, binding ties without actual administrative integration (see Figure 4.1). In the remainder of this chapter, complete integration refers to administrative integration, whereas incomplete integration refers to the whole set of intermediary longer-term ties without joint administration. In general, complete integration involves more tight coupling between production stages than incomplete integration. See Figure 4.1 for 
some examples. Four explanations of complete integration will now be considered: the entrepreneurial, market power, risk and transaction-cost arguments.

Figure 4.1 Strategies of organizing transactions (adapted from Child, 1987).

\begin{tabular}{|c|c|c|c|}
\hline STRATEGIES & $\begin{array}{l}\text { Market } \\
\text { transactions }\end{array}$ & $\begin{array}{l}\text { Incomplete } \\
\text { integration }\end{array}$ & $\begin{array}{l}\text { Complete } \\
\text { integration }\end{array}$ \\
\hline $\begin{array}{l}\text { CONTROL \& } \\
\text { COORDINATI- } \\
\text { ON }\end{array}$ & $\begin{array}{l}\text { terms of the } \\
\text { contract }\end{array}$ & $\begin{array}{l}\text { arms-length } \\
\text { control via } \\
\text { contractual } \\
\text { specification \& } \\
\text { deadlines; long- } \\
\text { standing trust } \\
\text { relations; formal } \\
\text { revenue } \\
\text { agreements; } \\
\text { monitoring of } \\
\text { service } \\
\text { standards } \\
\end{array}$ & $\begin{array}{l}\text { direct super- } \\
\text { vision; } \\
\text { direct or result } \\
\text { control; } \\
\text { periodic } \\
\text { review }\end{array}$ \\
\hline EXAMPLES & $\begin{array}{l}\text { auctions; } \\
\text { transactions } \\
\text { between } \\
\text { independent } \\
\text { traders }\end{array}$ & $\begin{array}{l}\text { joint ventures; } \\
\text { sub-contracting; } \\
\text { co-development } \\
\text { contracts; } \\
\text { licensing; fran- } \\
\text { chising; exclusi- } \\
\text { ve dealing } \\
\text { arrangements }\end{array}$ & $\begin{array}{l}\text { single } \\
\text { product firm; } \\
\text { multi- } \\
\text { divisional } \\
\text { company; } \\
\text { holding com- } \\
\text { pany }\end{array}$ \\
\hline
\end{tabular}

\section{The entrepreneurial argument}

Personal motives and visions of key decision makers are widely viewed to be of influence to vertical take-overs or mergers: strategic vision, the need for power, status and prestige are just a few lines in the financial news one frequently runs accross. These explanations are subsumed here under 'entrepreneurial' and all refer to some kind of human motive or vision. The precise role of human factors has not been established (cf. Lenel, 1968).

The most substantial claim appears to lie in 'entrepreneurial vision' trigge- 
ring vertical integration. Entrepreneurial vision has been observed in numerous case-studies (for an overview see Silver, 1984). For instance, Chandler argues that the first American integrators of mass production with mass distribution did so because they "were keenly aware of the national and international markets opened up by the new transportation and communication infrastructure" (Chandler, 1977: 287).

Apparently, the advantages of integration based on entrepreneurial vision may also accrue from incomplete integration. Moreover, entrepreneurial vision on future industrial developments seems to play a major role especially with respect to first-moving integration. For example, the U.S. pioneers of complete integration in the 1880 's, if successful, had their imitators in the $1890^{\prime} \mathrm{s}$ in a large number of industries, obviously experiencing significantly less uncertainty (Chandler, 1977). In other words, although entrepreneurial vision may be a relevant condition amongst others, it certainly is not a sufficient condition for complete integration.

\section{The market power argument}

A well-known economic explanation of vertical integration is in terms of market power. That is, when input materials or distribution outlets are scarce, integrated firms can refuse supply to new entrants or existing competitors. In more general terms, they can create barriers to entry, to mobility and to arbitrage in otherwise competitive markets (Crandall, 1968; Etgar, 1978).

One major explanation in the market power literature is the so-called foreclosure-theory. Foreclosure refers to the use of integration to remove existing competition, by taking away from competitors a part of their supply or demand (Comanor, 1967). Only in very specific conditions foreclosure seems to be justifiable. For instance, if significant efficiency and quality differences are perceived to exist between the suppliers or buyers of the firm, or if the price discipline between the firm and its competitors is strong out of fear for escalating price cuts (Lenel, 1968).

In a number of cases it is actually the fear of potential foreclosure by others that motivates firms to integrate (Bain, 1968). A good example is the U.S. cement industry taking over concrete producers. The resulting merger wave may have been based on the mistaken belief that vertical foreclosure was an effective way of protecting a vulnerable market share, but was also driven by the fear of being foreclosed (Allen, 1971). Obviously, the foreclosure literature refers to the creation of some kind of barriers but goes beyond it to acknowledge sensemaking factors, such as fear. 


\section{The risk argument}

A major explanation of vertical integration is based on the risk, or variability, of supply and demand. For instance, firms have an incentive to integrate backward in order to acquire information relevant to the market price of their inputs (Arrow, 1975). Such information allows the integrated firm to adjust on a timely basis the combination of inputs to variations in the outputs. Similarly, by forward integration suppliers may increase their knowledge of demand fluctuations (Bernhardt, 1977). Integration may also reduce actual supply variability itself for buyers: a buyer may integrate backward to save input costs for the high probability component of demand and only use suppliers for the low probability demand (Carlton, 1979).

In fact these risk incentives merely explain integration in a broad sense, that is, including incomplete integration (Figure 4.1). They still hold if the firm does not produce the inputs but simply increases its inventories of the input (Daems, 1982). Or, in case of downstream moves, incomplete integration may offer some of the same advantages (e.g. reducing variability) as complete integration.

MacMillan, Hambrick and Pennings (1986) argue that the risk argument should be complemented by taking potential retaliation into account. Particularly in oligopolistic or oligopsonistic situations, the decision to integrate is accompanied by a risk of supplier or buyer retaliation. For instance, a backward integrating firm may find that, unless it acquires enough capacity to satisfy its peak demand (in which case it has enormous overcapacity in normal times), its independent suppliers take punitive action when the firm turns to them for its remaining needs. Retaliation may range from refusal to do business at all to assigning lowest priority to the firm's requests or offerings.

Overall, the risk argument assumes that vertical integration is triggered by demand and supply variability. However, the risk of retaliation should also be considered.

\section{The transaction cost argument}

Transaction cost theory (Williamson, 1985) attributes vertical integration especially to the condition of transaction-specific investments. Transactionspecific investments are durable investments that need to be undertaken in support of particular transactions. Examples include investments in specific sites, physical assets or human assets. Transaction-specific investments render the incumbent firm vulnerable to opportunistic behavior of its suppliers or buyers. Complete integration solves this problem by safeguarding the specific investments. 
Silver (1984) suggests a motive for integration which stems from informational problems associated with innovations. For example, an innovating firm may perceive that a new product is potentially profitable, but it needs specialized or novel inputs or operations in which it has no expertise. In case these operations would be most efficiently undertaken by other suppliers, the firm is dependent on the willingness to commit the necessary resources. These suppliers may resist to make any definite commitments to the new product of the innovator. To break the resistance backward integration may be necessary (Silver, 1984). A similar argument can be developed for forward integration, for instance, if the need for changes in the way independent distributors handle the products gives rise to informational problems. The similarity of Silver's argument with transaction cost theory is obvious. In fact, he deals with the special case of the innovating firm which is dependent on transaction-specific investments by buyers or suppliers.

Transaction cost theory has not been without criticism. Klein, Crawford and Alchian (1978) argue that transaction parties may prevent opportunistic behavior not only by vertical integration, but also by entering into long-run implicit contracts, in which non-legal sanctions to opportunistic behavior are major elements (e.g. withholding transaction profits). In fact, these authors point to the fact that some managerial control can also be effected by means of incomplete integration modes (cf. Figure 4.1).

Another important comment on transaction cost theory is given by Perrow (1986). His critique centers around the advantages of "loosely linked components of a system where there are likely to be uncertainties or shocks from the environment or from within" (Perrow, 1986: 247). Perrow argues that disadvantages of a tightly coupled system are: less efficiency, loss of expertise in dealing with large suppliers or customers, and the loss of flexibility and adaptivity (Perrow, 1986). Transaction cost advantages of complete integration may therefore be offset by disadvantages of tight coupling. Generally speaking, incomplete integration involves less tight coupling than administrative integration (see Figure 4.1).

To sum up, the transaction cost argument attributes complete integration to transaction-specific investments. However, critics of transaction cost theory have pointed out that incomplete integration may also occur in these circumstances, especially when non-legal sanctions are useful means to protect transaction-specific investments, and when the advantages of complete integration are offset by disadvantages of tight coupling. 


\subsection{The state of the art of the vertical integration literature}

The desire to cope with certain difficulties obviously lies at the heart of vertical integration. Two types of difficulties can be distinguished: one related to systemic problems and the other related to behavioral problems.

Systemic difficulties arise from a lack of knowledge as to what the state of the world is going to be. Basically, they arise from uncertainty about the state of the market or industry, that is, from demand structure (e.g. size of market or market segments, desired product, appropriate customer approach), supply structure (e.g. best process or product technology) or externalities (e.g. social pressures and government intervention), as summarized by Wernerfelt and Karnani (1985). The entrepreneurial, risk, market power (e.g. entry barriers) and tight coupling arguments all refer to systemic issues.

Behavioral difficulties arise because of non-disclosure, disguise or distortion of information, or, in other words, opportunistic behavior (Williamson, 1985). The market power argument (i.c. foreclosure) focuses on opportunistic behavior of competitors, while the transaction cost and risk arguments involve opportunistic behavior of suppliers or buyers. Figure 4.2 provides an overview of difficulties related to integration strategy.

Figure 4.2 Overview of difficulties related to vertical integration.

\begin{tabular}{|c|c|}
\hline SYSTEMIC DIFFICULTY & BEHAVIORAL DIFFICULTY \\
\hline $\begin{array}{l}\text { evoking integration } \\
\text { e.g. supply/demand variability; } \\
\text { attractive returns in down- or } \\
\text { upstream industry; creation of } \\
\text { barriers to } \\
\text { entry, mobility or arbitrage }\end{array}$ & $\begin{array}{l}\text { evoking complete integration } \\
\text { vulnerability of own } \\
\text { transaction-specific } \\
\text { investments; resistance of supp- } \\
\text { liers or buyers to invest in transac- } \\
\text { tion-specific assets; foreclosure th- } \\
\text { reat by competitors }\end{array}$ \\
\hline $\begin{array}{l}\text { e.g. disadvantages of tight cou- } \\
\text { pling; specificity of local market } \\
\text { conditions }\end{array}$ & $\begin{array}{l}\text { impeding complete integration } \\
\text { retaliation threat by } \\
\text { suppliers or buyers; } \\
\text { possible use of non-legal sanctions } \\
\text { in transactions with suppliers or } \\
\text { buyers }\end{array}$ \\
\hline
\end{tabular}


The transaction cost and foreclosure arguments both point at necessary conditions evoking complete integration. Other arguments considered in the previous section do point at incentives for (dis)integration in general, but only transaction cost and foreclosure theory deal specifically with conditions for complete integration. Transaction-cost and foreclosure theory both attribute complete integration to some behavioral difficulty. Systemic difficulties, such as supply and demand variability, appear to contribute to integration in general, also allowing for incomplete integration modes.

Other difficulties, either systemic or behavioral, may drive strategy in the opposite direction, that is, toward the market transactions mode. Major examples have been provided in the previous section: retaliation threat by suppliers or buyers, or disadvantages of tight coupling between production stages. The survey focused on current explanations of complete integration and does not provide an adequate overview of conditions related to market transaction or incomplete integration strategies. ${ }^{4}$

However, the following argument appears to be plausible. If difficulties evoking market transactions co-exist together with difficulties evoking complete integration, incomplete integration will tend to arise. For instance, the specificity of local market situations requiring special, differentiated customer approaches is a condition typically requiring market transactions between producers and distributors (Porter, 1980). If this condition arises in combination with the need of transaction-specific investments (pointing toward complete integration), the franchising mode develops, as with dealerships in automobile distribution (Williamson, 1985).

Thus, transaction cost and foreclosure theory both contain necessary conditions evoking administrative integration. Moreover, these two arguments appear to have survived empirical scrutinity to some extent (e.g. Allen, 1971; MacMillan et al., 1986; Silver, 1984; Williamson, 1985; Walker and Weber, 1984), in any case, more than their systemic counterparts. The author is not aware of any empirical research providing substantial support for the systemic explanations of vertical integration.

\subsection{Toward a model of vertical integration}

Several of the explanations given in previous sections will now be combined. Basically, this section involves an application of the general model in chapter three to integration strategy.

First, we adopt the distinction made in the previous section between two

4 Several additional conditions are given by Porter (1980). 
types of difficulties relevant to vertical integration: systemic difficulties and behavioral difficulties. Some of these difficulties evoke and others impede complete integration.

We can now specify a set of hypotheses with regard to the forces leading to actual complete integration. Together they constitute the skeleton of a model of how vertical integration strategy arises. We assume that the initial repertoire of the dominant group excludes administrative integration.

The first proposition is based on several propositions in chapter three concerning the conditions under which the repertoire of the dominant group will change. Propositions $3.5 \mathrm{a}$ and $3.5 \mathrm{~b}$ suggest that behavioral difficulties may act initially as misfits and later as fits to the repertoire. In addition, propositions $3.2,3.3 \mathrm{a}, 3.3 \mathrm{~b}$ and $3.5 \mathrm{a}$ imply that a major impetus to repertoire change is constituted by a substantial decrease in the cohesiveness of perception. ${ }^{5}$ Thus, the following proposition can be formulated.

\section{Proposition 4.1:}

If the dominant group perceives one or more behavioral difficulties that evoke complete integration

and if the cohesiveness of dominant group perception decreases substantially,

then the repertoire will tend to include complete integration.

The second proposition follows from propositions 3.1 a and 3.4 in chapter three. It considers the forces leading to actual complete integration under the regime of the (new) repertoire including complete integration.

Proposition 4.2:

If the repertoire includes complete integration

and if behavioral difficulties evoking complete integration persist through time and relative to other difficulties (impeding complete integration),

then complete integration will be induced.

Two typical cases are the 'first moving' and the 'following' dominant group. The first mover has a looser, more pro-active repertoire supported by a relatively low cohesiveness of perception, as a result of dominant group formation in the past. Its repertoire will change toward first-moving integration (relative to competitors), in response to the early perception of (emer-

"Note that when the "new' repertoire becomes well-established, its tightness as well as the cohesiveness of perception may return to the same level as before the change. However, we suggest repertoire change can only be brought about by a (initial) decrease in the cohesiveness of perception. 
ging) difficulties evoking integration. ${ }^{6}$

The follower"s repertoire is more tight and re-active, supported by a higher cohesiveness of perception. It changes toward administrative integration only when cohesiveness of perception decreases substantially, in addition to the perception of severe behavioral difficulties. The latter may include, for instance, competitors having 'successfully' integrated along the industry chain and constituting severe threats to the availability of demand or supply sources.

The preceding propositions refer to change in the dominant group's cohesiveness as well as in the perception of difficulties. But how do these changes come about? Following propositions 3.5a and 3.5b (in chapter three), we suggest that:

Proposition 4.3a:

Behavioral difficulties (evoking complete integration) arise as unintended consequences of current modes of organizing transactions with suppliers/buyers.

Proposition 4.3b:

Change in cohesiveness of perception is triggered by autonomous actions of (new) dominant group members.

The issue of disintegration can be viewed from the same set of propositions. Assume that the initial repertoire contains complete integration and excludes incomplete integration or markets for organizing transactions. In that case, proposition 4.1 suggests that if the dominant group perceives major difficulties impeding complete integration and cohesiveness decreases substantially, the repertoire will change to include (also) incomplete integration or market transactions. The other propositions can be adapted in the same way for the case of disintegration strategy.

Figure 4.3 provides an overview of the propositions presented in this section. In addition, this figure shows how these propositions relate to the more general model in chapter three.

In sum, complete integration of two or more production stages appears to be triggered by, amongst other forces, the emergence of so-called behavioral difficulties. These behavioral difficulties involve threats arising from opportunistic behavior of competitors, suppliers or buyers. They typically arise as

6 Of course, the first moving dominant group may mistake certain phenomena as behavioral difficulties and thus enter into complete integration on false grounds. Howe ver, such a situation can only be established in retrospect. That is, only afterwards certain perceptions of dominant group members may be evaluated as 'false'. 
Figure 4.3 Overview of propositions on the formation of complete integration strategy.

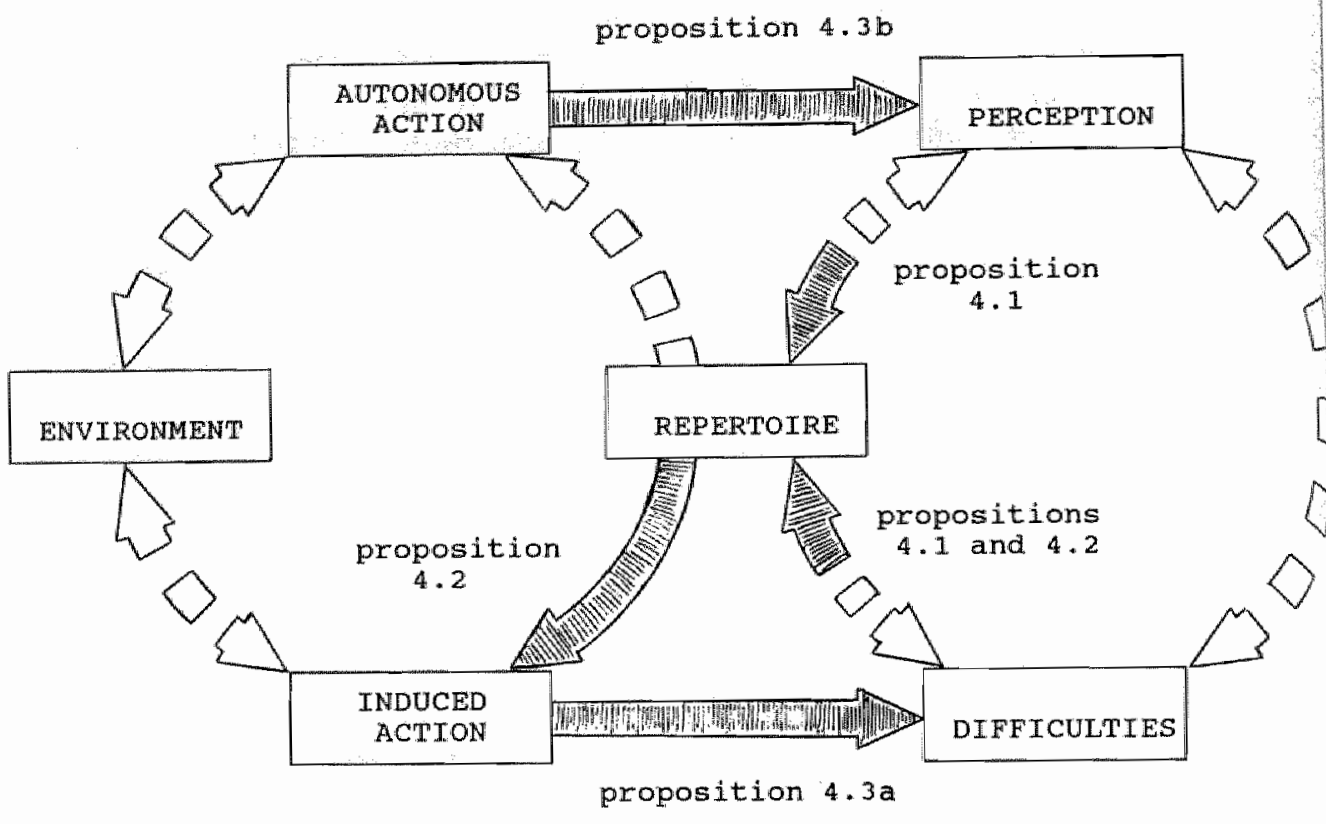

unintended consequences of the current mode of organizing transactions with suppliers or buyers.

\subsection{Reconsidering the Hendrix' Fabrieken case}

How to interpret the strategy of Hendrix' Fabrieken in terms of the model put forward (in the previous section and chapter three)? Figure 4.4 provides an interpretation of the Hendrix case in terms of the self-organization model. It involves a schematic presentation of two periods in the formation of Hendrix' integration strategy. This presentation was obtained by the author and a colleague who coded the case material according to a set of instructions which are described in detail in chapter six. Figure 4.4 also also illustrates some forces described in the general model in chapter three, in addition to the forces outlined in this chapter.

The first period illustrates how emerging difficulties are filtered by the repertoire. The dominant position of founder Wim Hendrix - which can be viewed as the result of dominant group formation in the past - firmly supports the existing repertoire. Toward the end of this period, Hendrix' managers are confronted with major unintended consequences of their 
commitment to the farming stage (see the fored betwer inducod aetow ans difficulties).

The lower half of Figure 4.4 shows how the repertoine changwa in respowsts to the foreclosure threat of competitors. This change is iriggered by the death of Wim Hendrix, conceived here as autonomous action anbstandly decreasing group cohesiveness. The Board of Directors becomes less cohesive and more sensitive to industrial trends and their consequences for the company. Thus, the repertoire changes to include such rules as 'defend against foreclosure' and 'develop our own production cycle'. When the foreclosure threat by competitors is perceived to persist, complete integration follows.

In sum, the well-established 'old' repertoire (excluding complete integration) dominates the scene in the first period, although the first signs of the repertoire's inadequacy are observed by Hendrix' managers. In the second period, the old repertoire actually breaks down and a 'new' (adapted) repertoire, which includes complete integration, forms. The formation of integration strategy in this case is typical of a follower who imitates more entrepreneurial first-movers.

Of course, this interpretation of the Hendrix' case is merely intended to illustrate the self-organization model. In this respect, some reservations need to be made. The self-organization model uncovers some forces, but probably leaves others unnoticed. Moreover, the observations of the case are to a large extent digested second-hand.

\subsection{Concluding remarks}

Does the self-organization model lead as to understand the formation of vertical integration strategy? In order to answer this question, a model of vertical integration strategy was formulated in this chapter.

In view of the Hendrix' case and the survey of the vertical integration literature four propositions have been put forward. According to these propositions, the forces specified in the general model are also at work in forming vertical integration strategies. In particular, we have emphasized the role of so-called behavioral difficulies, inwolwing threats arising from opportunistic behavior of competitors, suppliers or buyers. Such difficulties constitute severe threats to transactions with suppliers or buyers and are conceived as unintended consequences of induced action. 
Figure 4.4 The formation of forward integration strategy at Hendrix" Fabrieken.

0
0
on
in
in
in
-1

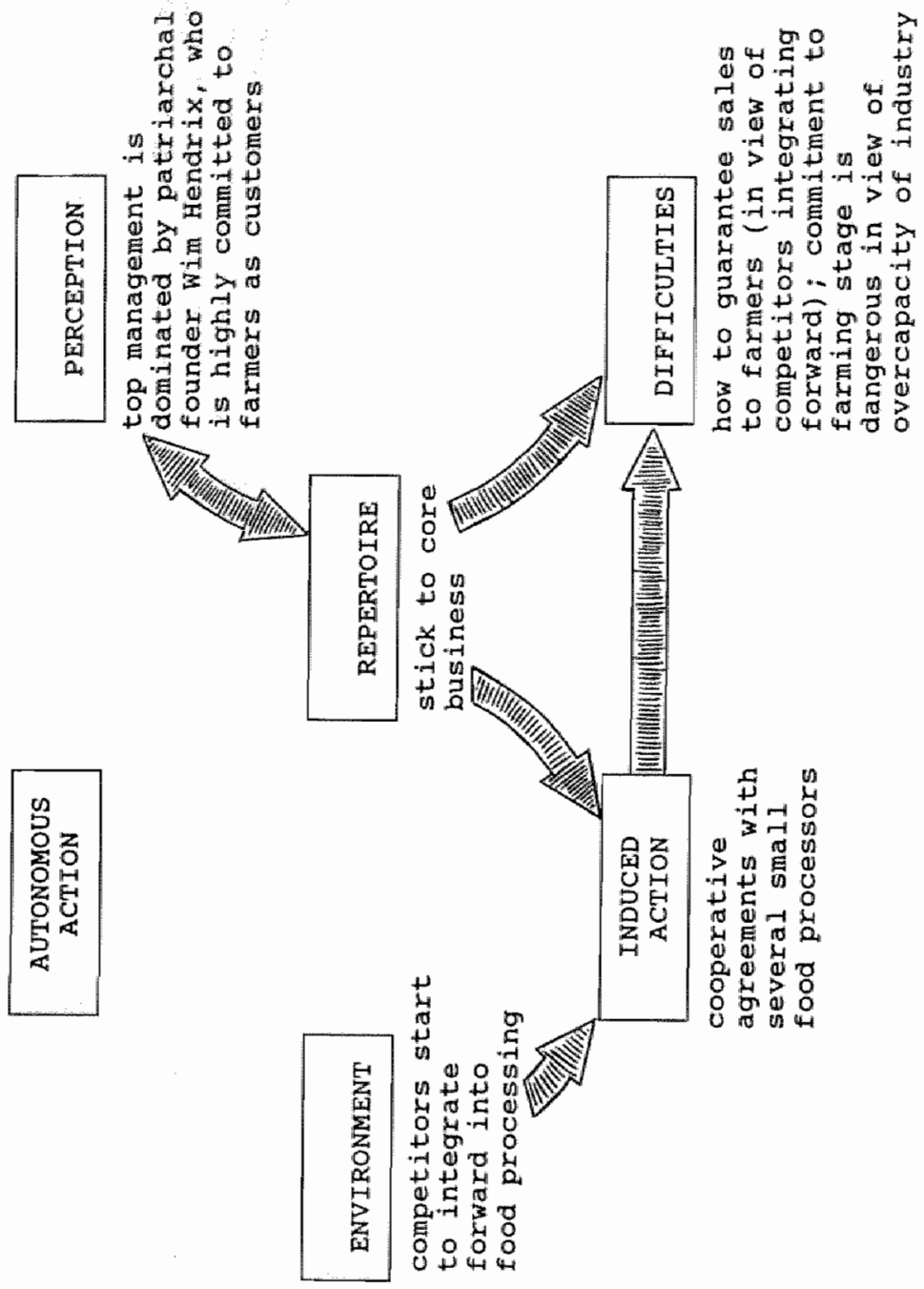




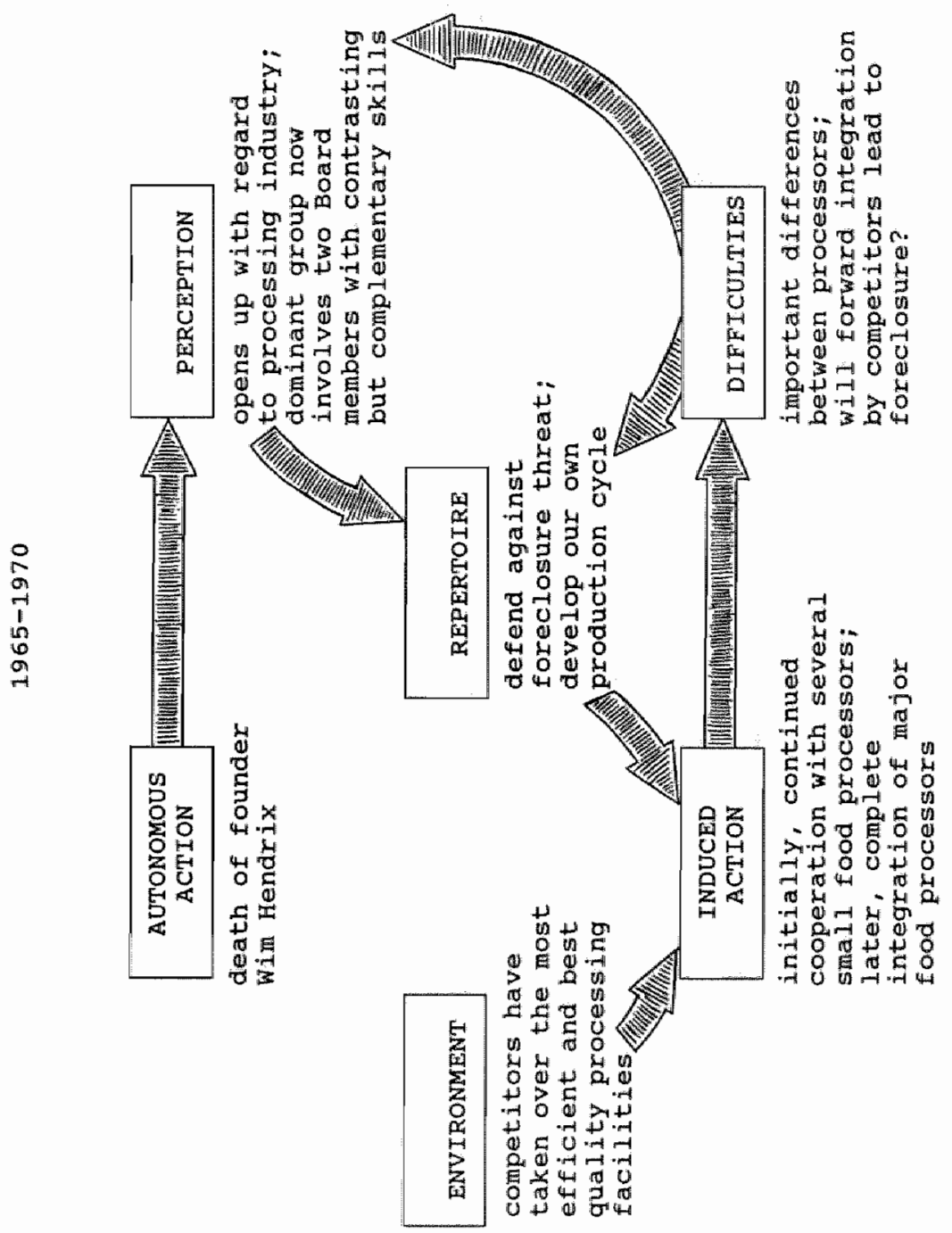




\section{CHAPTER 5}

\section{INNOVATION}

Laurel: "And then you said you felt as happy

as a lark, and thought you'd like to fly

around with the birds for a while."

Hardy: "Fly around with the birds?"

Laurel: "Sure. Then you opened the window and out you went. I can see you now - flapping your arms just like a cuckoo."

Hardy: "Well, why didn"t you stop me?"

Laurel: "I was celebrating too - and I thought

you could do it."

(Stan Laurel, Birds of a Feather, 1953)

\subsection{Introduction}

Innovation is one of the central themes in strategy research. This chapter elaborates the self-organization model with regard to innovation strategy. It involves an extensive case-study as well as an assessment of existing explanations and observations of innovation. As in the previous chapter the argument pertains to a specific application of the general model put forward in chapter three.

First, we will describe some observations by innovation strategy students. Subsequently, we will look at the results from an in-depth case-study. Finally, the results are interpreted in terms of the self-organization model.

Innovation involves renewal. Innovation research tends to focus on either organizational or technological renewal. Here, the innovation concept captures the broad range of both tangible innovation (e.g. use of new technology) and intangible innovation (e.g. new organizational forms and practices). The result of innovation is the adoption of ideas which are new to the dominant group.' Note that an idea is innovative in kind as long as it is new to the people involved, even though it may appear to others to be an imitation of something that exists elsewhere (Van de Ven and Angle, 1989). Accordingly, imovation strategy involves the way (cf. repertoire) the dominant group deals with new ideas.

1 The concept of idea basically conveys the same meaning as difficulty (which is given in chapter three) and is used as such in the context of imnovation. 


\subsection{Review of literature on innovation strategy}

This section describes some observations and concepts found in the literature on innovation strategy. The focus will be on innovation strategy rather than the innovation process itself (e.g. new product development)?

A large body of research shows that the support and orientation of 'those who have the final say' (e.g. top management) is central to understanding innovation strategy (e.g. Daft, 1978; Rothwell, 1977; Baldridge and Burnham, 1975; Dror Rafael and Rubenstein, 1984). Several other studies have documented the ways in which specific tasks and roles interact in the innovation process (Burgelman, 1983b; Maidique, 1980; Rothwell et al., 1974; Schön, 1963). Dean (1987) draws together the results of these and other studies in terms of justification, which conveys the idea that one set of people has made a decision and is now attempting to justify this decision to those who have the final say (Dean, 1987: 127). The process of justification is constructed by the proponents (or 'champions') of an innovative idea. Dean's own study of how five U.S. companies decided to step into advanced technologies confirms that the process which may lead to senior managers' approval is central to innovation.

Dean (1987) suggests that the process of justification is primarily a political process. However, it appears that especially in small, entrepreneurial organizations justification is primarily an individual cognitive process. In this respect, Maidique (1980) shows that small firms tend to be more tightly coupled, with individual entrepreneurs helping to define new activities while still maintaining control of the overall organization. Only in larger organizations, the entrepreneur is forced to give up most of his or her explicit involvement in generating new activities. In these organizations, sponsorship of projects that emerge from the technical community is passed on to others, especially middle managers (also Miller and Friesen, 1982; Burgelman, 1983b; Tushman, Newman and Romanelli, 1989; Kanter, 1983).

Nonaka (1988a) describes innovation processes in terms of "self-renewal". According to this author, the innovative ability of organizations lies in the creation rather than the processing of information. Observations of several innovation processes in Japanese firms suggest that innovation lies in the ability to manage the continuous dissolution and creation of organizational order. Organizations must consider "what kind of chaos to create, when and how to start a self-organizing movement, where to have the convergence, and when and where to recreate what kind of chaos. Key individuals within the organization and individuals belonging to a self-organizing team are

2 For useful overviews of the literature on innovation processes see Coombs at al. (1987), Nord and Tucker (1987) and Saren (1984). 
making these decisions or are serving as a "trigger" for this continuous process to take place. Information is created by these individuals, not just processed" (Nonaka, 1988a: 72).

Two cases of innovation strategy, Matsushita Electric and 3M, will now be described more extensively, based on the report by Kagono et al. (1985).

Matsushita did not have any long- or middle-range strategic plans in the 1960 's and early 1970's. Its strategy was comprised of visions expressed in very general terms. Distinctive values and beliefs (Matsushita's 'seven principles') were articulated and widely shared among its people. The company had been building upon its strengths by continually improving its production technologies and by creating exclusive domestic distribution channels. Continuous product development and modification was done by divisions, subsidiaries and affiliates, all of which were highly autonomous. The performance of each autonomous business unit was strictly evaluated and ranked in terms of sales" growth and return on sales, regardless of the maturity of product or market. Because all of Matsushita's businesses were closely related, very similar products were sometimes introduced by two or more divisions at the same time. In that case, there was no ex ante coordination but there was coordination to concentrate responsibility within one division, ex post, after observing the market reactions to both products. The confusion, redundancy and inefficiency that may arise from this product development process plays a vital role in Matsushita's overall strategy (Kagono et al., 1985).

Another typical example provided by Kagono et al. (1985) is $3 \mathrm{M}$. This company has about 50 thousand products and has been a leader in much new product development. It also has a distinctive corporate culture with certain values widely shared by its members. The company's more than 40 divisions are highly autonomous profit centers. Each $3 \mathrm{M}$ division has an R\&D department which is in charge of developing technology that is unrelated as well as related to the division's existing product lines. Division performance is evaluated in terms of return on sales, ROI, sales growth and its new product ratio. In order to achieve these targets, especially the last -25 percent of sales must be made with the products introduced in the last five years - each division must continuously develop new products. Two or more divisions sometimes compete with each other in the same or in closely related product markets, without much coordination by the headquarters. It is a source of internal chaos but also seems to be an unavoidable prerequisite for $3 \mathrm{M}$ 's ability to innovate. In order to organize this chaos, 3M's top management has a set of 'rules of the game'. These rules also organize 3M's corporate venturing. Any individual with a new product idea is permitted to apply for development funds to his own or other divisions, and also to other internal sources. The existence of multiple sources raises the probability of funding a new idea. When an idea is accepted and funded, an autonomous, 
'mini-company" team of major functional specialists is organized. If successful, it can become a department and, then, a division. The success of a project is determined through interactions with the market place. Top management accepts failures as part of the innovation process and has created various devices to increase the probability of new product ideas. These devices include so-called technological forums and a ' 15 percent policy'. The latter means that engineers can or should spend 15 percent of their working hours 'pursuing their own dream'. For a specific example of 3M's innovation strategy, see Ring and Rands' (1989) studly of the evolution of $3 \mathrm{M}$ 's microgravity research program.

Other descriptions of how innovation strategies arise include the development of the Honda City at Honda Motors (Nonaka, 1988b), the way Tom West and his people contributed to Data General's recovery (Kidder, 1981), and internal corporate venturing at one major U.S. company (Burgelman, 1983b). Similar observations have been labelled as 'skunkworks' (Quinn, 1985), in which small teams of engineers, technicians, designers and modelmakers are placed together with no intervening organizational or physical barriers in order to develop a new product from idea to commercial prototype stages. Somewhat broader is Wissema's (1989) 'unit management'. Unit management involves the deliberate use of entrepreneurial sub-units which are given substantial autonomy and report directly to topmanagement.

It thus appears that innovation in rather large companies relies on relatively autonomous groups with middle managers or other change agents taking care of the link between these groups and the corporate context. These organisations are structured so that at least some subunits have the autonomy to take substantial risks that do not jeopardize the existence of the whole organization.

Especially older and larger organizations often find that generating autonomous action is extremely difficult (Aldrich and Auster, 1986). This is frequently reported in studies of the older firms in established industries facing substantial technological threats. Such firms continue to make substantial commitments to old technologies, even when their sales have already begun to decline because of competitive pressures of new technologies (e.g. Cooper and Schendel, 1976; Miller and Friesen, 1982). In other words, they focus on inducing actions which continue their commitment to old technologies at the cost of entering new technologies. In this respect, some of the examples of large companies given earlier (e.g. 3M, Honda Motors) seem to illustrate exceptional rather than common practice. Burgelman (1983c) therefore notes that top management in large companies need not so much encourage autonomous action, but rather should take care not to supress it. A similar remark is made by Wissema (1989). He suggests that for top management the most important "do" with regard to autonomous subunits is: 'don't do too much'. 
Autonomous action in organizations does not imply the absence of control. Feldman (1989), in his study of innovation at "Smith Electronics", concludes that control and autonomy cannot exist without each other. Control informs autonomous action about the 'rules of the game' so that it produces results that are beneficial to the dominant group. When control and autonomy are not in balance, a vicious circle can develop that undermines commitment to the dominant group's repertoire. At Smith Electronics, the lack of control by top management allowed excessive autonomy on the middle-management level, and the lack of middle-management control allowed excessive autonomy on the technician level. The result was a change in motivation: there was more commitment to individual interests than to collective interests (Feldman, 1989). The dominant group repertoire here evidently excluded the exercise of managerial control or authority, which made it easy to permit autonomy but difficult to limit it (cf. Feldman, 1989). Thus, repertoires which do not maintain a balance between control and autonomy of action may lead to severe problems.

The most extensive research on innovation is conducted in the so-called Minnesota Innovation Research Program (MIRP). Schroeder et al. (1989) infer six general observations from seven extensive case-studies within the MIRP program. These observations are:

- Innovation is stimulated by shocks. That is, innovation is more prevalent when some major change occurs in the organization or its environment. Ideas are often generated but are not acted on in an organization until some form of shock occurs. Shocks may come in many different forms, including new leadership, product failure, a budget crisis, or an impending loss of market share.

An initial idea tends to proliferate into several ideas during the innovation process.

- In managing an innovation effort, unpredictable selbacks and surprises are inevitable; learning occurs whenever the innovation continues to develop.

As an innovation develops within an existing organization, the old and the new exist concurrently, and over time they are linked together. The new idea often represents a threat to the established order, and thus there is opportunity for establishing new organizations and linkages.

Restructuring of the organization often occurs during the innovation process; this restructuring can take many forms, including joint ventures, changes in organizational responsibilities, use of teams, and altered control systems.

Hands-on top managenent inwolvement occurs throughout the innovation period; several levels of management removed from the innovation itself are directly involved in all major decisions (Schroeder et all, 1989). 
The direct involvement of top management in innovation has also been observed in, for instance, some young Japanese companies, where top managers worked hand-in-hand on projects with young engineers (Quinn, 1985), and in the early stages of companies like Apple (Hampden-Turner, 1990).

In sum, the literature reviewed supports the following conclusions. First, core members of the dominant group, or 'those who have the final say', have a key role toward innovation. That is, their repertoire is of major importance to the (in)ability to innovate.

Second, the formation of innovation strategy can be understood in terms of justifying new ideas to the members of the dominant group. Justification of new ideas involves the creation rather than the processing of information. Adoption of new ideas by the dominant group appears to be stimulated by shocks.

Third, innovation strategy may involve generating autonomous action by taking care not to supress it. Dominant group repertoires which incorporate such rules are perhaps better fit to renew themselves. However, autonomous action cannot exist without some control, if autonomous action is to produce new ideas which are beneficial to the dominant group.

Fourth, other studies point at the importance of hands-on dominant group involvement in generating and adopting new ideas. Direct involvement of dominant group members is observed especially (although not exclusively) in smaller and younger organizations.

\subsection{Innovation strategy at Bellamy}

This section describes the formation of innovation strategy at 'Bellamy', a Dutch agribusiness firm.

In the summer of 1988 , the managenent team of Bellamy was requested to participate in a study focusing on:

a. how Bellamy's strategies (or repertoires) in general and innovation strategies in particular develop over time, and

b. how specific decision processes relate to these strategies. "

Subsequently, an in-depth study took place between September 1988 and March 1989. Strategy formation at Bellamy was studied by using interviews, questionnaires and documents. Seven informants were extensively interviewed. The documents included industry studies, minutes of Board meetings, long-term plans, brochures and articles in journals. In addition, interviews with two industry-experts, not related to Bellamy, took place. The methodology and instruments used in this case-study are described more extensive- 
Iy in appendix $A$.

The results of the case-study were described in a forty-page, confidential report. This section provides an overview of the original report. Some facts in the original report have been deleted for reasons of confidentiality. In addition, all names of persons, companies and products have been disguised. The most important product of Bellamy is referred to as $X$ seed and the broader industry as the seed industry.

The remainder of this section deals with the following issues. First, Bellamy and the seed industry are introduced. Subsequently, we turn to strategy formation at Bellamy over the past fifteen years. Next, decision making at Bellamy is described in more detail. In particular, we focus on two decisions on new technology.

\section{Bellamy and its environment}

The head office and main facilities of Bellamy are located in The Netherlands. Bellamy is currently part of the multinational CHEMIC but is to a large extent independent in formulating and implementing its strategies.

Bellamy now employs about 300 persons, including the employees of a number of small foreign subsidiaries. It's structure is of a functional, department-based kind, supported by permanent and ad-hoc project teams which formulate and evaluate policies with regard to product development and sales.

Bellamy produces $X$ seed, which includes many different varieties. There are two different markets for $X$ : the amateur market and the professional market. The professional market involves farmers and other large-scale growers and is most important for Bellamy. The leading companies serving the professional market are characterized by:

a. High levels of research expenditure in relation to sales.

b. In depth knowledge of developments affecting customers. Increasingly, central marketing boards and large supermarket chains are determining the quality and varietal specification of the seed they sell.

c. Marketing based on a strong service element.

d. Highly integrated operations in product development, processing and marketing; moreover, strict control of production.

e. The use of sophisticated international distribution channels through foreign subsidiaries and agreements with other companies.

f. Location of their major facilities where most buyers have their production fields. Location is thus closely tied to that of the down-stream, regionally specialized industry.

Companies like Bellamy are located in a small number of European coun- 
tries, the U.S.A. or Japan. In other countries, local seed companies exist but they rely to a large extent on agency agreements with, for instance, Dutch companies. These local companies specialize in distribution rather than product development.

The largest companies in the seed industry are located in Europe and the U.S.A., but are increasingly organized on a multinational basis. Product development lead times amount to about eight to ten years. Within a given product category typically only two to three product varieties dominate the market. These product varieties have relatively short product lives, about three years from launch to maximum market penetration, and five to six years in total. In order to maximize returns on research and development investments international sales are essential.

The technologies needed in producing $\mathrm{X}$ seed are threefold:

- classical seed development, involving traditional breeding technologies;

- advanced seed development, including the application of new genetic technology;

manipulation technology, involving the physical manipulation of the seed after it is produced, in order to increase its quality.

\section{More on the seed industry}

Until about 1930, the activity of the seed industry centered around the sale of the well-established, standard seed varieties. In the thirties, many companies began to develop intensive seed development programs, aiming largely at local markets. Thus, product development, production and sales were integrated in larger companies. In the postwar period, internal growth and acquisitions have resulted in a small number of leading companies worldwide. The large-scale, integrated type of firm now dominates the seed industry, although a lot of small, specialized firms still exist. Table 5.1 shows that Bellamy is a medium-sized firm in the Dutch seed industry. Note that the two leading companies are also prominent relative to their foreign competitors.

The most important causes and incentives contributing to the horizontal concentration of the seed industry are:

1. High investments in product development (10 to 15 percent of turnower) are necessary.

2. The decreasing economic life-span of most seed varieties (now about six years), which demands a high turnover to recuperate the investment costs within a reasonable pay-back period.

3. Broadening of the knowledge base for product development.

4. Internationalization of production and sales activity is easier in large companies (e.g. adaptation to local climates, benefiting from low wages). 
Table 5.1 Relative turnover of the five largest $X$ seed producers in the Netherlands.

consolidated turnover

relative to Bellamy

$\begin{array}{ll}\text { Competitor } 1 & 575 \\ \text { Competitor } 2 & 375 \\ \text { Bellamy } & 100 \\ \text { Competitor } 3 & 100 \\ \text { Competitor } 4 & 75\end{array}$

The professional customers of the seed industry can be divided in two groups: the processing segment (canners, freezers, pickle-packers and tomato-processors) and the fresh segment (farmers). The processing industry is mature and increasingly concentrated. The number of processors in Europe (now about two hundred compared to a few thousands in the fifties) is such that they can easily be served by a few specialists. Price is increasingly under pressure and only by means of specialty seeds (with high added value) acceptable margins can be made. The demand of pickle-packers is relatively stable but the other segments can be expected to decrease by about three percent per year. New trends, such as preference shifts toward 'readyto-eat' products, are beneficial to the fresh segment but will not compensate for the overall decrease of the processing segment.

Two recent developments in the seed industry are noteworthy. First, cooperative relationships with parent companies, competitors and universities increase in importance. The nature of these relationships influences the objectives with which the firm is managed and the resources available to it. In this respect, the seed industry is in a transition stage. Acquisitions by multinational companies have recently resulted in large seed-productiondivisions which include many units worldwide. A number of independent Dutch seed companies started a cooperative research firm (early 1989). ${ }^{3}$ Moreover, cooperative links to university research have been extended by most companies.

Second, the level of investment in research and development the company can bear is of increasing importance. In particular, comparatively high

3 In general, however, substantial cooperation belween independent companies in this kind of industry is still rare (Romme, Spangenberg and Swaen, 1987). 
turnover figures and profits are beneficial to the company's ability to finance r\&d.

\section{Strategy formation at Bellamy}

We now turn to the way strategies in Bellamy have evolved since the seventies. Figure 5.1 describes the major changes Bellamy underwent in terms of dominant group difficulties, perception/formation, repertoire and actions. The perception/formation category also documents the composition of the dominant group. ${ }^{4}$ In addition, the Figure divides the period from about 1970 to early 1989 in four episodes. These episodes have been inferred from observations in the case-study, and serve to reduce the complexity of strategy formation we have observed. All observations in this subsection are based on interviews and especially document study (see appendix A). Please also note that Figure 5.1 only summarizes the most important observations. Some additional remarks now follow.

Bellamy was founded in 1920 by Ben Meesters. With help of the technical consultant Schreurs, he acquired some land and started using it for the development of $\mathrm{X}$ seed. Bellamy gradually grew into a medium-sized company by developing the relatively simple product development technology of those days into applied research in which complex technologies are prominent.

Until the early 1980's Bellamy was owned by the Meesters' family. In the sixties, the early death of owner-director Meesters, grandchild of Ben Meesters, led to the appointment of Belkmans, formerly head of the administration department, as single director. Belkmans held his directorship until his retirement in 1983. Belkmans' leadership focused on the administration and exploitation of the Meesters' property. His management style was wellorganized and to a large extent inwardly oriented.

The competitive strategy of Belkmans centered around the quality of the product and manipulation technology, without much attention to product development efforts. All sales efforts were primarily directed at the domestic market.

During the seventies, the market and industry became more complex. In response to the higher demands on management, Belkmans formed a broader management team by appointing three managers to assist him in financial, technical and marketing affairs. Two of them were later appointed as directors by the stockholders: Eduard Longman and Bert Ooievaar.

* For definitions of the dominant group concept and related terms, see chapter three or the Glossary of terms. 
Figure 5.1. Strategy formation at Bellamy in terms of difficulties, perception/formation, repertoire and actions.

\section{DIFFICULTIES}

(No observations)

\section{PERCEPTION/FORMATION}

Belkmans, administrator par excellence, strongly supported by shareholding Meesters' family; very inward orientation and major insensitivity for industrial and technological developments.

\section{REPERTOIRE}

Give priority to development of administrative system and quality control.

\section{INDUCED ACTION}

Focus on exploitation and administration of company; hardly any learning from experience with previous or current strategues; Belkmans appoints three managers, incl. Longrian and Dolevaar, to assist him.

\section{AUTONOMOUS ACTION}

(No observations)

\section{DIFFICULTLES}

Low profitability; accelerating technological developments; internationalizing competitors.

\section{PERCEPTION/FORMATION}

Hardly any shared perception because of increasing antagonism between powerful Belkmans and Longman/Ooievaar: inward vs. outward, short-run vs. long-run, administer vs. invest, etc.

\section{REPERTOIRE}

Attend to both external and internal growth of company, and both product development and manipulation technology; substitute capital for labour as primary resource; administer a 'self-contained" company. Overall, a fragmentary, inward oriented repertoire.

\section{INDUCED ACTION}

Several acquisitions leading to foreign subsidiaries; rationalization and automation activities; decision making predominantly proceeds top-down.

\section{AUTONOMOUS ACTION}

The shareholding Meesters' family promotes Longman and Ooievaar to Board members next to Belkmans; later, unable to cope with continuing divergence in visions within management, stockholders sell all stock to Heed; Belkmans retires. 
(Fügure 5.1 continued)

1983

\section{DIFFICULTIES}

profitability low to moderate; need to expand to larger scale in order to catch up with major competitors; development of new technologies.

\section{PERCEPTION/FORMATION}

Longman and Ooievaar as top management; stockholder Heed is perceptive of technology and internationalization issues, and his experience contributes to skills of Longman and Ooievaar.

\section{REPERTOIRE}

More consistent repertoire, including: internationalize by way of acquisitions; invest in new technologies supporting classical techmiques; search for major opportunities; develop managerial resources and improve management of human resources. Also: make major decisions in an informal, collective way involving key persons from middle management level.

\section{INDUCED ACTION}

Searching and scanning for key information about potential acquisition candidates and technological options; several foreign acquisitions; inflow of 40 young graduates; investment in new labs; decision making basically top down, with limited participation of several department heads.

\section{AUTONOMOUS ACTION}

Development of investment need higher than expected by Heed, leading to multinational CHEMIC as single shareholder.

\section{DIFFICULTIES}

How to double turnover; shift of X production toward Southern Europe; scope of product line offered; how to organize subsidiaries. (...)

\section{PERCEPTION/FORMATION}

More cohesive dominant group with Longman and Ooievaar as Management Board, assisted by several expert department heads; loose coupling to CHEMTC. (...)

\section{REPERTOIRE}

Repertoire remains largely the same. (...)

\section{INDUCED ACTION}

New acquisitions; in decision making top management intends to build 'consensus"; the head of the product development department is promoted to assistantdirector. (...)

\section{AUTONOMOUS ACTION}

Outflow of major part of older generation of employees; on some topics there is unforeseen resistance within management team or within departments. (...) 
Within this team of three executives two contrasting strategic visions developed (see Figure 5.1). The overall repertoire was thus fragmentary and ambiguous. Unable to cope with these developments within the management team, in 1981 the Meesters' family was requested by some of the management team members to sell its stock to mr. Heed. In the eighties Heed, experienced in the internationalizing agribusiness industry, stimulated the internationalization process undertaken by Bellamy and provided capital for a number of foreign acquisitions in Italy, Spain, and other countries. These subsidiaries came to serve production, testing and marketing purposes. In this period, Bellamy also made major investments in new product development and manipulation technology.

When the investment need became higher than initially expected, Heed sold his stock to the multinational CHEMIC. This acquisition was part of CHEMIC's strategy to broaden its base in new technologies. Extended links with the technological and marketing expertise of firms like Bellamy were deemed necessary by CHEMIC to be able to commercialize investments in their own technologies. For Bellamy, the major advantage of CHEMIC's shareholding position was the strengthened financial base for new product development.

Currently, Bellamy's management perceives the need to expand to a larger scale as the most critical issue. They are especially anxious about getting 'stuck in the middle' between the largest competitors and smaller specialized companies, also in view of the aggressive leadership of its largest competitor. Bellamy's insufficient turnover growth and expanding product development costs (see Table 5.2) have led to a research/turnover ratio which is probably one the highest in the seed industry worldwide.

Table 5.2 The development of Bellamy's research budget in terms of a number of ratio's for the period $1984 / 85$ to $1987 / 88$.

$87 / 88 \quad 86 / 87 \quad 85 / 86 \quad 84 / 85$

research budget/

$\begin{array}{lllll}\text { turnover in of } & 16.8 & 12.6 & \mathbb{1} .8 & 11.4\end{array}$

research budget/

cash-flow in \%

251

347

247

163

research budget/ added-value in \%

26.2

20.4

17.1

17.7

research budget per

employee in $\%$

0.027

0.026

0.024

0.023 
The persistence of the repertoire of Bellamy's management is best illustrated by their reaction to the initiative of a number of Dutch competitors, early 1989 , to start the research alliance Nexus. From sources in the U.S.A. Bellamy"s management knew that "something was going on". However, what was going on, was not further researched. When the announcement of Nexus appeared in the press, several managers at Bellamy were amazed about the initiative of their competitors. Their overall opinion was summarized by one manager as: "Nexus is a still-born child".

\section{Decision making on innovations at Bellamy}

We now turn to the second question in this case-study: how do specific decision processes relate to the formation pattern outlined above? First, some general observations are made. Subsequently, the focus shifts to two new technology decisions.

Decision making on important, unstructured topics in Bellamy proceeds in a rather informal, collective sensemaking mode, especially since Belkmans' influence started to decline. Typically, participants include the two or (until 1983) three Board members and, depending on the topic, stockholders, department heads and staff members. In Bellamy there are no strict formal procedures for crafting strategic decisions, except for the final responsibility of the Board for formulating company strategy. Informally, one has agreed to report in writing all visits or (external) meetings that might be of any relevance. Also, documents and literature are read and reported to each other.

A typical decision process in Bellamy involves a chain of informal discussions and meetings. Discussion and consultation serve as the primary means to form a collective interpretation. Decision processes thus tend to cycle back and forth in Bellamy, with most topics returning a high number of times on the agenda. The amount of cycling for a number of (observed) topics ranges from 6 to 20 times.

Analytical activities supporting strategy making are conducted on a regular basis, with most attention given to the study of acquisitions and major investments. The Board frequently asks (internal or external) specialists to inform or assist them in decision making on major topics. In some instances, this has led to special studies performed by (expert) staff members.

Middle managers in Bellamy, i.c. the department heads, were all very perceptive of the critical issues the Board is facing. The two current Board members Ooievaar and Longman have quite different personalities, abilities and skills, which appear to complement each other. Ooievaar is more management and control oriented, setting clear lines and constraints; he prefers not to deviate from initial intentions and plans. Instead, Longman"s 
commercial background pertains more to the moulding and implementation of strategy by driving and motivating (new) activities.

In 1985 , a policy team was formed - including the Board and all department heads - for discussing and formulating overall strategies. This attempt more or less failed, the policy team was renamed 'management team' and now merely deals with coordination across departments and related issues.

The forces behind this failure to form a policy team can be understood by looking at a number of problematic decision processes. These decision processes are characterized by discontinuities, delays, irresolution, resistance and other impediments. They involved the following topics: "lack of aggressivity in sales department", "adjustment of the product development procedure $^{n}$, and several appointment and promotion decisions. The adjustment of the product development procedure deserves some closer attention.

In the early sixties, Bellamy's management developed the so-called $\mathrm{s}^{*} \mathrm{p}^{*} \mathrm{~d}$ meeting with the $s$ standing for sales, the $p$ for production and the $d$ for development. This meeting was meant to enhance the integration of product development into sales. The $\mathrm{s}^{*} \mathrm{p} * \mathrm{~d}$ meeting (one for every product line) developed into the central consultation process in which personnel from the product development department, the product development manager (department head), the sales manager and a Board member met. Important inputs for these meetings are: current market demand, projection for market potential in the next 10 to 15 years, expected results of product development, technical possibilities and potential of new technologies. The output is a report giving an evaluation of the technical and commercial potential of a given product line.

Recently, the $s^{*} p^{*} d$ meeting has grown into a unwieldy instrument. It is now merely the formal end-point of predominantly informal decision-making and tends to focus on the current situation instead of projections for the future. An improvement of the $s^{*} \mathrm{p}^{*} \mathrm{~d}$ procedure was proposed rather authoritatively by the Board. This proposal involved a simpler process in which one or two specialists evaluate the prospects of their product line as an input for an overall evaluation by the Board assisted by 1 or 2 department heads. Several proposals from top management to simplify the procedure along these lines met major resistance within the product development department. The product developers expected that the new procedure would reduce their influence on decision making. At the time of concluding the case-report, decision making with regard to the $\mathrm{s}^{*} \mathrm{p}^{*} \mathrm{~d}$ procedure was still in an impasse.

Overall, the sample of rather problematic decisions shared the following characteristics:

a. topmanagement does not have much knowledge or affinity with respect to the topic; 
b. moreover, they do not attempt to convince or get the commitment of key persons prior to the final decision, if any at all;

c. the cohesiveness of the participants is rather low, that is, the individual perceptions with respect to the topic differ to a great extent (especially among department heads).

\section{Two decisions on new technology}

To overcome some of the weaknesses of qualitative case research (cf. Yin, 1984), two decisions will now be assessed with some more accuracy. These decisions were selected in view of their importance and innovative content.

The assessment of the two decisions and their processing is based on the instrument provided by Hickson et al. (1986). The Hickson-instrument has been developed in a study of 150 decision processes in about 30 organizations and appears to be the most elaborate and best validated instrument currently available. In addition, this instrument can be easily linked to categories in the self-organization model.

The Hickson-instrument involves 25 items divided among three general categories (related self-organization categories are between brackets): ${ }^{1}$

a. the complexity of problems (cf. difficulties)

b. the politicality of process (cf. induced/autonomous action)

c. other process characteristics (cf. induced/autonomous action).

The assessment of the items are partly inferred directly from interviews and partly on evaluations by the author, based on documentary and interview material. All interpretations of these assessments will be made in the context of the results obtained by Hickson et al. (1986: 270).

The first new technology decision involves the investment in new product technology $Y$. First contact with this kind of technology was made by a representative of Bellamy at a technology symposium in 1976. It emerged as a decision topic in September 1982 when the Board recognized the potential relevance of technology $Y$ for Bellamy's production process. Also, stockholder Heed observed that competitor nr. 4 (see Table 5.1) was involved in some applications of technology $Y$.

Involved in the process were both Board members, single stockholder Heed and representatives from the product management and product development departments. Initiatives and guidance came predominantly from the Board. All parties, however, realized that they needed Heed's support for any final decision. Thus, at several stages in the decision process Heed's support was critical.

The perceptions of all participants in the process were clearly directed at scanning the environment and searching for information. Stockholder Heed 
particularly focused on technological issues. An important point that came up during the search for information was the fact that for one major product line no other suitable production method but technology $Y$ would be available in the near future. Information acquisition and scanning pertained to a diverse number of external sources, such as industry symposia, competitors, research organizations and university professors. All information was perceived as pointing in more or less the same direction. The only controversial 'hot issue" related to this decision topic evolved around the actual position the new production facility would get in the organization structure, i.c. under whose authority it would be placed. The final decision to invest in a production facility based on technology $Y$ was taken in March 1983.

In appendix $C$ the decision on technology $Y$ is characterized in terms of complexity, politicality and other process characteristics, using the Hicksoninstrument. ${ }^{2}$ Overall, the technology $\mathrm{Y}$ problem is of moderate complexity, that is, it is (relatively speaking) well-known with limited, non-precursive consequences, and does not set major parameters for subsequent decisions. The politicality of the process is low, following from an uneven influence pattern by internal interests only and a low contention. The process is also characterized by relatively few delays, impediments, and formal and informal interactions; a high number of information sources are readily available and less effort is made to actively acquire information; finally, the process is collective in character.

The second process studied pertains to the decision of how and when to enter new technology $Z$. The exact gestation point is hard to give, but can readily be assumed to be the summer of 1983. Around that time, the Board of Bellamy started to consider technology $Z$ as an investment opportunity. A few years earlier several large multinational companies were spotted in entering this new field.

The intention of all participants in this decision process again involved looking for innovation opportunities. During the decision process, the participants came to understand $\mathrm{Z}$ as a tool for product development cutting right through the traditional barriers between existing product lines, and also contributing to shorter product development lead times.

The key participants were the Board members, representatives of the product development department and product management department, and Heed. The Board set up two project teams. One project tean scanned the technical potential by means of studytrips to a number of (foreign) institutions and companies. Additional information was obtained from several. Dutch universities and research institutes. The other project team studied competitive and industrial developments with respect to technology $Z$. 
Initially, the participants of the product development department aimed at full-scale involvement of Bellamy in this kind of technology. Major result of the collective scanning and interpretation process was the view that technology type Z1 pertained to a major extension of Bellamy's technological expertise, while technology type $\mathrm{Z} 2$ involved completely new knowledge domains (adding new basic elements to $X$ seed). Also entering technology $\mathrm{Z} 2$ was perceived to imply exceedingly high investments, especially if the company had to move on its own. In this respect, the medium scale of Bellamy relative to its largest competitors was the critical bottle-neck to investments in $\mathbf{Z 2}$.

The final investment decision was to enter into a number of projects based on technology $\mathrm{Z} 1$. Technology Z2 was not entered as high-tech firms would be willing to do this kind of research on a sub-contractor basis and because Bellamy's financial resources were viewed as inadequate. After Bellamy had been acquired by CHEMIC, Bellamy stationed a polytechnician specialized in technology Z2 at CHEMIC's central laboratory.

In appendix $\mathrm{D}$ the decision process on technology $\mathrm{Z}$ is assessed in terms of its complexity, politicality and other process characteristics. Compared to the technology $\mathrm{Y}$ problem, the complexity is more serious, rare and precursive but about the same in diversity of involvements. The politicality is noncontentious and relatively evenly influenced by internal actors only. The process also has few delays and impediments and is typically collective in character; the number and disparity of information sources is higher, while also more effort is needed to acquire information; interaction is more intense, on an informal as well as formal level.

\subsection{Toward a model of innovation by dominant groups}

We now turn to a self-organization model of innovation strategy. This model recasts some observations of innovation strategy (section two) and the results of the Bellamy case-study (section three) into an overall model based on the propositions presented in chapter three.

Figure 5.2 summarizes some results of the Bellamy case-study in terms of the categories distinguished by Hickson et al. (1986) and the categories of our self-organization model. We now turn to several propositions on innovation by dominant groups, following the same format as propositions 3.1a to $3.5 b$ in chapter three. 
Figure 5.2 Some results of the Bellamy case-study. ${ }^{5}$

\begin{tabular}{|c|c|c|c|}
\hline Difficulty & TECHNOL. $Y$ & TECHNOL. Z & $\begin{array}{l}S * \mathrm{P} * \mathrm{D} \\
\text { PROCEDL }\end{array}$ \\
\hline Character & less complex & rather complex & \\
\hline $\begin{array}{l}\text { Fit between } \\
\text { difficuly } \\
\text { and repertoire }\end{array}$ & good & moderate & (bad) \\
\hline $\begin{array}{l}\text { Politicality } \\
\text { of process }\end{array}$ & moderate & low & (high) \\
\hline $\begin{array}{l}\text { Process } \\
\text { type }\end{array}$ & constricted & $\begin{array}{l}\text { fluid- } \\
\text { sporadic }\end{array}$ & (sporadic) \\
\hline
\end{tabular}

Proposition 3.1 suggested that the dominant group repertoire acts as a filter toward the set of difficulties the group confronts, and that difficulties appear to activate the repertoire. In the case of innovation, difficulties tend to arise in the form of new ideas, which constitute tension with the 'old' repertoire. The Bellamy case suggests that this tension between the old and the new is especially apparent in the complexity of the issue and the politicality of the process. If this tension is minimal or moderate, as in the technology $\mathrm{Y}$ and $\mathrm{Z}$ decisions, innovation occurs. But if this tension is large, which seems to be the case with the $s^{*} p^{*} d$ procedure, the repertoire will filter the idea away as a kind of 'misfit' and innovation is absent. This leads to the following propositions.

Proposition 5.1a:

New ideas (cf. difficulties) which to a large extent fit the current repertoire activate the repertoire.

5 The summary in Figure 5.2 for the technology $Y$ and $Z$ difficulties can be directly inferred from the observations in the previous section (see also appendix $C$ and D). The $s^{*} p^{*}$ d difficulty is taken as a major example from the set of 'problematic' issues observed in the Bellamy case. These difficulties and the processes they triggered have not been systematically measured. The assessment of this difficulty is therefore somewhat suggestive: 


\section{Proposition 5.1b:}

The current repertoire tends to filter away new ideas which to a large extent misfit the repertoire.

Proposition 3.2 in chapter three pointed at the association between the cohesiveness and repertoire of dominant groups. The Bellamy case suggests that the cohesiveness of group perception has major implications for the 'innovativeness' of its repertoire. Compare, for example, the high cohesiveness of Bellamy"s dominant group in the seventies with its rather low cohesiveness in the early eighties and its more moderate cohesiveness in more recent periods (see Figure 5.1). Also observe that innovativeness of the repertoire is highest in more recent episodes and rather low in the seventies and early eighties. It appears that too much cohesiveness is counterproductiwe to innovation, while too low cohesiveness leads to disruption of the repertoire. Also following the discussion by Angle (1989), we suggest the relationship between innovation and cohesiveness of perception is a curvilinear one:

\section{Proposition 5.2:}

The ability of the dominant group to transform its repertoire is positively associated with a moderate group cohesiveness. Too high cohesiveness as well as too low cohesiveness will be dysfunctional in this respect.

Following proposition 3.3a, the level of group cohesiveness determines the selection of new ideas. In the Bellamy case, this force can be inferred from the way group cohesiveness toward various difficulties develops. As we have seen, the cohesiveness of Bellamy's dominant group has decreased throughout the seventies until the early eighties (see Figure 5.1). Especially with the promotion of Ooievaar and Longman to Board members next to Belkmans, cohesiveness appears to reach its lowest level. Parallel to the group's decreasing cohesiveness, the set of perceived difficulties (cf. ideas) broadens. During the eighties, cohesiveness has increased again, which apparently shows up in a more focused set of difficulties. We therefore suggest the following proposition.

Proposition 5.3a:

The level of cohesiveness of perception determines the selection of new ideas. (Thus, higher cohesiveness tends to decrease the selection ratio for new ideas.)

If we translate proposition $3.3 \mathrm{~b}$ (chapter three) to the issue of innovation, this proposition suggests that the perception of major new ideas tends to decrease the cohesiveness of perception. This force can be inferred from the long-term development of Bellamy (see Figure 5.1). However, more reliable observations are obtained by considering the decision making processes we 
have studied in more detail.

The 'technology $\mathrm{Y}^{\prime}$, "technology $\mathrm{Z}$ ' and ' $\mathrm{s}$ " $\mathrm{p}$ "d procedure' issues all appear to constitute major new ideas to Bellamy's dominant group at that time (Ooievaar and Longman). However, confronted with these problems the cohesiveness of the dominant group appears to have remained largely unchanged. Instead, when confronted with the $s^{*} p^{*} d$ issue, the perceptions of members at the periphery of the group (i.c. middle management) increasingly diverged from those of the dominant group itself. Additional scrutiny of several other cases reveals that similar forces have been at work in, for instance, Newton Chambers (Grinyer and Spender, 1979) and Walt Disney Productions (Taylor, 1986). ${ }^{6}$

The Walt Disney case may illustrate this. In the face of a severe takeover threat - which constituted a completely new problem to Walt Disney's Executive Committee at that time - the cohesiveness of the Executive Committee did not appear to change significantly. However, major stockholders and several Board members increasingly perceived the takeover threat and its implications in other ways than the Executive Committee, which ultimately resulted in a major stockholder revolt.

The effect major new difficulties (ideas) have on cohesiveness appears to be more complex than was proposed in proposition 3.3b. Major new ideas may also decrease the cohesiveness between perceptions of the dominant group and major actors in the periphery of the group. The following proposition therefore extends proposition $3.3 \mathrm{~b}$, at least in the case of new ideas:

\section{Proposition 5.3b:}

Major new ideas tend to decrease the cohesiveness of perception of the dominant group, or, altematively, they tend to decrease the cohesiveness between perceptions of the dominant group and major actors in its periphery.

According to proposition 3.4 , the repertoire induces group members to act in line with this repertoire, but impedes autonomous action by group members. But what happens if new ideas arise? We again distinguish between two cases: new ideas which fit and those which misfit the repertoire. In the Bellamy case, ideas which fit the current repertoire involved the technology $\mathrm{Y}$ issue. The Technology $\mathrm{Z}$ issue falls outside the current repertoire, constiauting more of a misfit (see Figure 5.2). These two issues triggered decision processes which follow patterns similar to those observed by Hickson et al.

- The study of Newton Chambers also suggests that adoption of a so-called participative repertoire may compensate for the (negative) effects of this force. In our conceptual framework, participative repertoires - which are more loose in kind - tend to tolerate more autonomy in action (see proposition 3.4 in chapter three). 
(1986). The technology $\mathrm{Y}$ problem is of a rather normal and recurrent type. It triggers a so-called constricted process (Hickson et al., 1986). In constricted processes the dominant group responds by going through motions that have been gone through before, moving the decision along in a well defined way without too many interests beconing directly involved. Those concerned know the form and allow it to go ahead as usual. The departmental experts and staff members play their parts but there is no special research effort, and only the minimum committee work, for most can be settled informally between individuals. The decision stays within accustomed channels around the managing executives, there being little scope for negotiation over what it will be (Hickson et al., 1986).

The technology $Z$ difficulty is unusual in the sense that nothing quite like it has happened before. The technology $\mathrm{Z}$ difficulty triggers a fluid-sporadic process (cf. Hickson et al., 1986). Fluid processes involve more (diverse) interests but are non-contentious and are unlikely to be dominated by the influence of one or two powerful parties. The managerial and staff personnel involved are co-ordinated by bringing them together in project teams or similar small groups. The matter proceeds steadily in the normal manner without any notable delays to a decision (Hickson et al., 1986). Sporadic processes are likely to run into more disrupting delays, due to all kinds of impediments, from having to await a report to meeting resistance (Hickson et al., 1986).

We also observed a number of rather problematic decision processes in the Bellamy case. The topics of these processes did not necessarily involve innovation, although some of them did (e.g. the $s^{*} p^{*} d$ procedure). The characteristics of these problematic decisions (see section three) suggest they are very political in kind. Moreover, they involve new ideas which cannot be deall with by (or misfit) the current repertoire. According to the observations by Hickson et al. (1986), such ideas typically trigger sporadic processes. The processes triggered by the problematic decision types appear to be typical to the sporadic type (e.g. major resistance to change, delays, irresolution).

In general, new ideas which fit the repertoire appear to induce rather narrowly channeled actions, whereas ideas which misfit the repertoire will trigger unauthorized 'political' (autonomous) action. Note that terms like fit versus misfit and autonomous versus induced action refer to the ends of a continuum. In sum, we propose that: ${ }^{\text {? }}$

7 A similar proposition is suggested by Feldman's (1989) study of Smith Electronics: repertoires should maintain some balance between control and autonomy of action (see section two). 


\section{Proposition 5.4:}

When new ideas fit the current repertoire, the emphasis is on induced action. When new ideas largely misfit the current repertoire, the emphasis will increasingly be on autonomous action.

So far we discussed whether and how dominant groups adopt new ideas. We now turn to how these new ideas arise in the first place. Some studies reported in section two of this chapter conclude that hands-on top management involvement occurs throughout the innovation process. We observed such a direct involvement in both decision processes on new technologies in Bellamy. In both cases, the Board members recognized the potential relevance of the new technology for Bellamy and started to consider it as an investment opportunity. We have already seen that the adoption of these technologies largely fits the current repertoire of Bellamy's dominant group. Moreover, the repertoire remains largely unaffected by the (implications of) decisions on technology $Y$ and $Z$. As such, members of the dominant group may be heavily involved in the search for and evaluation of new ideas within the restrictions imposed by their repertoire. This repertoire allows them to focus on certain ideas but to neglect others. Thus, we propose:

Proposition 5.5a:

Induced action with high dominant group involvement may produce new ideas which, if adopted, do not require substantial change of the repertoire.

A number of other innovation studies (see section two of this chapter) suggest autonomous action may also generate new ideas. A well-known example is corporate venturing activity. In order to allow such autonomous actions to thrive, the dominant group should then take care not to supress them, although some control appears to be inevitable. At some point in time, autonomous action may produce new ideas which affect the perception of the dominant group. Think of, for instance, new ventures outside the traditional products and markets served. Once such ventures develop into potentially profitable units which require large amounts of capital, the dominant group is forced to either change its repertoire to a new product-market definition or sell the new venture.

The latter example shows that autonomous action may also be completely decoupled from the incumbent dominant group. Another example of decoupling is spin-off activity. Once this kind of autonomous action is completely decoupled, a new dominant group arises around a new, relatively autonomous company. In sum, we suggest that: ${ }^{8}$

8 The force from autonomous action to formation and perception of the dominant group has been discussed in chapter 3. Here, we have implicilly focused on a given dominant group whose composition remains largely unchanged. However, note that 
Proposition 5.5b:

Autonomous action with low dominant group involvement may also produce new ideas which tend to be - at least initially - loosely coupled to the current repertoire. If these ideas are adopred by the dominant group (which may involve substantial change of its repertoire), autonomous action changes into induced action. Altematively, autonomous action may also be completely decoupled from the dominant group.

Figure 5.3 provides an overview of the propositions presented in this section.

Figure 5.3 Some forces pertaining to innovation by the dominant group.
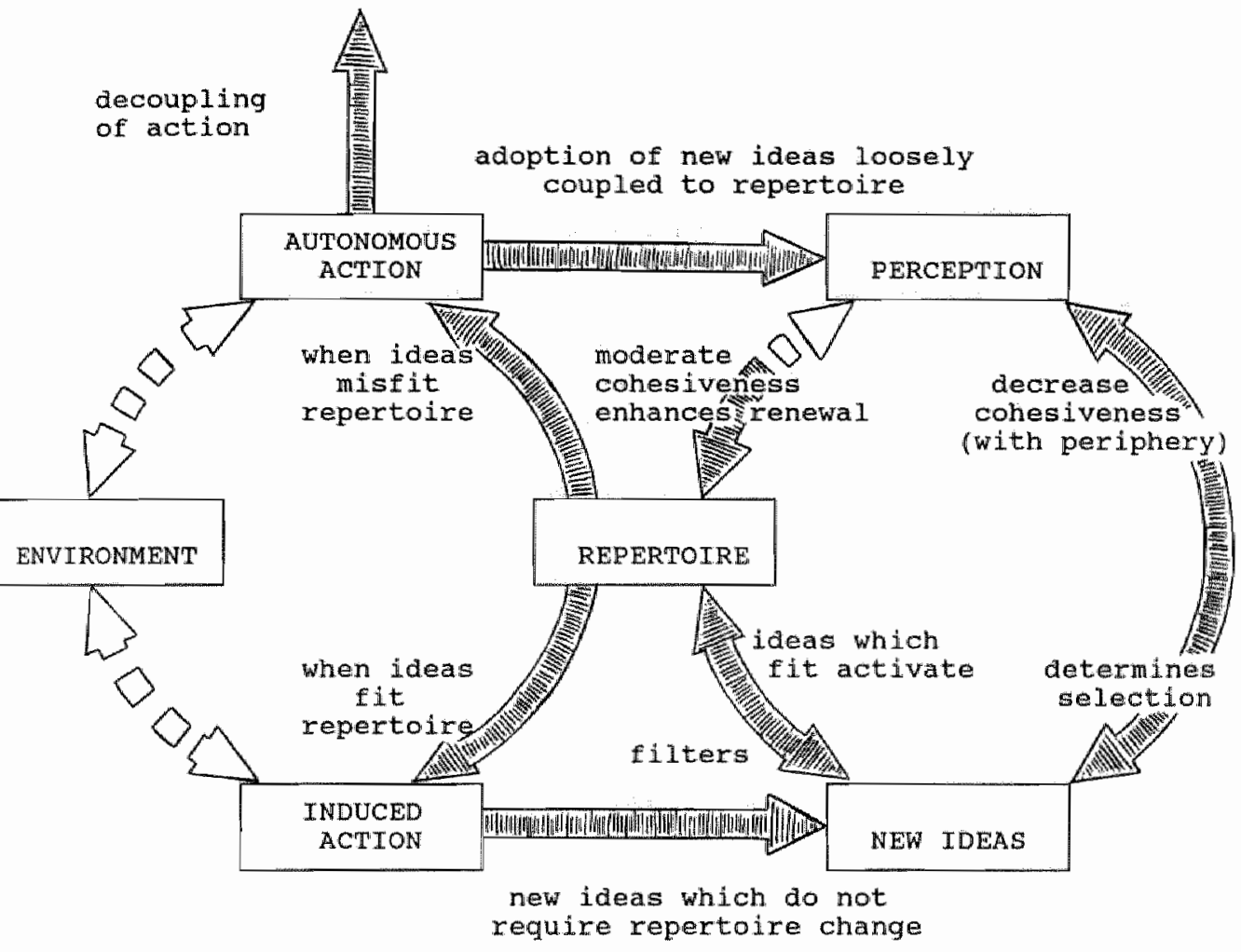

'timely management changes' (cf. Schreuder, 1991) may be a prerequisite to innovation, especially when group cohesiveness is dysfunctional. 


\subsection{Conclusions}

This chapter set out to elaborate the self-organization model with regard to innovation strategy. For dominant groups, innovation involves self-renewal by generating and adopting new ideas.

We first reviewed several studies of innovation strategy. This review suggests that dominant groups have key roles in inducing as well as impeding innovation. Their repertoire is of major importance to the ability to innovate. Moreover, the formation of innovation strategy can be understood in terms of justifying new ideas to the members of the dominant group.

We also inferred from the literature that in many cases innovation involves generating autonomous action by taking care not to supress it. Dominant groups which incorporate such rules in their repertoire may be better able to renew themselves. However, the dominant group should exert some control over autonomous action in order to increase the chance that its results are beneficial to the dominant group.

Some other studies point at the possibility of direct dominant group involvement in innovation. Direct involvement of dominant group members is observed especially in smaller and younger organizations.

Subsequently, we described the results of our case-study of Bellamy, a Dutch agribusiness firm. The evolution of the overall pattern of strategies was assessed over a period of almost twenty years. In addition, we scrutinized two recent new technology decision with some more accuracy.

Finally, we proposed a model of several forces affecting innovation by dominant groups (see Figure 5.3 for an overview). This model incorporates some of the conclusions of the literature review in addition to major results of the case-study. 


\section{Appendix A Case study method}

The case-study method employed basically uses two types of instruments: reactive and nonreactive. Interviews result in reactive observations, heavily relying on individual perceptions. The study of industry and company documents produces observations of a nonreactive kind.

In a first meeting with two representatives of Bellamy the goal and central questions of this case-study were explained. Also, some major strategic problems Bellamy was facing were listed and discussed. Several useful documents were provided to the author. In addition, six persons were selected and scheduled for an interview. The selection of these informants was based on their involvement in decision making on major strategic issues.

In the second stage of the case-study, a number of documents provided by Bellamy served in preparing interview questions. The documents several sales, production and finance records, internal reports, company publications and newspaper articles. On request some additional documents were provided, in particular the minutes of Executive Board (later Management Board) meetings from $1981 / 82$ to $1987 / 88$.

The third stage pertained to interviews with the six selected informants. Each initial interview took about two hours and some of them were followed by a second interview a few weeks later. During this interview stage, obserwations from the document study stage were used to check observations of informants (major events, names, dates, participants, competitors, etc.). Also, an additional (seventh) informant was requested to participate in thiss study.

The interviews were structured only to a modest degree. Some structure was provided by a list of open questions and a number of questionnaire items (see appendix B). Questions concerning items on which individual positions and perceptions might be expected to differ were asked in all or almost all interviews (e.g. contention of decision topic). Relatively clear-cut questions, for instance, about facts or visible practices, were used in a smaller number of interviews, although always larger than one (e.g. a department head and an executive).

The fourth stage involved a second analysis of some of the documents and, then, the drafting of a case-report. This case-report was discussed with some informants. The second draft of the case-report was presented at a meeting of the management team of Bellamy (including all informants), in which also some implications for Bellamy were discussed.

Finally, a preliminary version of the case-report was written. This draft circulated among the informants to assess its accuracy and completeness, and to provide them the opportunity to make suggestions for revisions. Moreover, a summary of the results was presented in a feedback session involving a broad group of representatives of the organization (including all informants). The final report was written in April 1989.

\section{List of informants}

The following persons participated as informants in the case-study (names have been disguised). 
Eduard Longman, Management Board member. Jan Moesters, manager research department. Bert Ooievaar, Management Board member. Hans Peeters, manager human resource department. Karel Ruskia, manager sales department.

Ralf Wolfs, manager product development department. 


\section{Appendix B Questionnaire items}

Several open questions and well-tested questionnaires have been used in the interviews. Part of the questionnaire developed in Romme et al. (1990) was used, but does not pertain to the argument of this chapter. The instrument developed by Hickson at al. (1986) serwed in assessing two decision processes on new technology. This instrument consists of 25 items divided among three general categories: the complexity of the problem, the politicality of the process, and other characteristics of the prooess.

The assessment of the items in this instrument are partly based on interviewees" answers to similar questions posed and partly on judgment by the author (relying on documentary and interview material). All interpretations of the results in this chapter have been made in wiew of the statistics obtained by Hickson et al. (1986: 270).

The items are reproduced below.

\section{COMPLEXITY OF PROBLEMS}

Rarity. The frequency with which similar matters recur, indicated by the number of times per year that topics of similar importance occur. As most occur less often than yearly, this gives megative scores (e.g. once every 5 years implies that rarity $=-5$ ).

Radicality of consequences. How far the decision changed things, indicated by a score on a five-point rating $(1=$ not at all; $2=$ a little; $3=$ quite a lot; $4=$ substantially; 5 $=$ radically).

Seriousness of consequences. How serious it would be for the organization if things went wrong, indicated by a score on a five-point rating $(1=$ not at all; $2=$ slightly; $3=$ quite; 4 = very; $5=$ extremely).

Diffusion of consequences. How widespread were the decision's effects, indicated by the number of categories of criteria used to judge its correctness from 11 categories (profit, quality, output, costs, sales, return on investment, service rendered, morale, personnel benefits, image, market share).

Endurance of consequences. How far ahead people looked when naking the decision, to the nearest tenth of a year.

Precursiveness. How far a decision was likely to set parameters for subsequent decisions (non-precursive $=$ the alternatives considered followed parameters within an overall strategy; precursive $=$ any or all of the altematives had no such parameters and therefore themselves set parameters for subsequent decisions).

Number of interests involved. The number of internal units/departments and extemal units/organizations named as having been involved.

Diversity of interests involved. The variety of interest, indicated by the number of categories of internal and external interests involved from a total of 14 categories. Internal interests = transformation, stability, conformity, adjudication, innovation, acquisition, domain, autonomy-devolution. External interests = inputs, outputs, employment, public standards, private standards, comparative performance. See for examples Hickson et al. (1986: 48). 
Openness to alternatives. How far there was a feeling that the decision had already been made $(4=$ no feeling of this kind; $3=$ partly; 2 = yes, clear to some interest groups; 1 $=$ yes, obvious to all interest groups).

\section{POLITICALITY OF THE PROCESS}

Pressure of influence. How great a weight of influence was exerted, indicated by the mean for all interest units of ratings by informants of the influence of each interest involved $(1=$ little; $2=$ some; $3=$ quite a lot; $4=$ a great deal; $5=$ a very great deal $)$.

Intervention. How far external influence was exerted, indicated by the percentage of the sum of influence ratings for all interest units that was due to external units.

Imballance. How far the total pressure was uneven across interest units, indicated by the range of the influence ratings between them (narrow range = balanced influence; wide range $=$ imbalance) .

Contention of objectives. How far the interest units that exerted influence did so in opposite directions, indicated by the range of scores on a five-point scale of opposition to, or support for, the eventual decision $(-2=$ strong opposition; $-1=$ qualified opposition; $0=$ neutral; $+1=$ qualified support; $+2=$ strong support).

\section{OTHER CHARACTERISTICS OF THE PROCESS}

Duration-process time. How long it took to arrive at the approved choice (or process outcome), indicated by the number of months from first deliberate consideration of a topic to an authorized decision.

Duration-gestation time. How long it took for a topic to emerge, indicated by the number of months from first recognition of a potential topic to the commencement of process time.

Disruption. How far the process was interrupted by delays, indicated by the highest score for the process on a four-point scale $(1=$ no delays; $2=$ intermittent; $3=$ continual; 4 $=$ prolonged).

Impedance. How far the process encountered impediments, indicated by the highest score for the process on a ten-point scale (see nine points listed by Hickson et al., 1986, page 109 , plus a zero score for no identifiable impediments).

Formal interaction. How many kinds of pre-arranged meeting were included in the process, indicated by the number of general committees/boards/councils, etc., specialized committees, e.g. finance or sales, and special purpose working parties/project teams.

Informal interaction. How much discussion, toing and froing, or arguments took place, indicated by the highest score for the process on a six-point scale $(1=$ none; $2=$ little; 3 $=$ some; $4=$ quite a lot; $5=$ a great deal; $6=$ a very great deal) .

Negotiation scope. How far there was room for negotiation and dissent, indicated by a score on a seven-point scale $(1=$ decision not open to negotiation; 2 = negotiation only 
in final stages; 3 = negotiation possible on choices but one man chooses the course of action (for example, the chief executive): $4=$ collective decision; $5=$ negotiation including dissenting parties; $6=$ negotiation resulting in limited consensus to the exclusion of dissenters; $7=$ decision reached with dissent remaining such as in voting).

Information sources - expertise. How many sources of data were drawn upon, indicated by the number of internal or external units providing information or views.

Information sources - externality. How far information from external sources contributed to the reduction of uncertainty, indicated by the percentage of the sum of confidenceratings for all sources that was due to external sources.

Information sources - confidence disparity. How much variation there was in the quality of information, indicated by the range of ratings of sources on a five-point scale of confidence in the information provided $(1=$ little; $2=$ some; $3=$ quite a lot; $4=\mathrm{a}$ great deal; $5=$ a very great deal).

Information sources - effort. How readily information was accessible, indicated by a score on a four-point scale $(1=$ info available from personal knowledge or opinions; $2=$ info obtained readily from records; 3 = info researched by scanning; $4=$ info synthesized by integrating disparate info from diverse sources, e.g. via a meeting to collate info or a report).

Authority - level in hierarchy. How high in the hierarchy did the process culminate, indicated by a score for the level at which implementation was authorized and could then commence $(1=$ below divisional levell or equivalent; 2 division level or equivalent; 3 $=$ chief executive; $4=$ chief executive and ratified by board; $5=$ board or equivalent top governing body; $6=$ board and ratified at higher external level; $7=$ outside and above the organization). 


\section{Appendix C Quantitative characterization of the decision process concerning technology $\mathrm{Y}$}

\section{COMPLEXITY}

Rarity

Radicality of consequences

Seriousness of consequences

Diffusion of consequences

Endurance of consequences

Precursiveness

Number of interests involved

Diversity of interests involved

Openness to alternatives

Overall assessment

\section{POLITICALITY}

Pressure of influence

Intervention

Imbalance

Contention

Overall assessment
1: once a year

3: quite a lot

3: quite serious

8: profit, quality, output, costs, sales, return on investment, image and market share.

5 years

Non-precursive: the altematives considered (going into technology $Y$ or not) followed parameters within the existing strategy, i.c. technology $Y$ was considered as a logical extension of existing production technologies.

4, that is, Management Board, Product dev, dept, stockholder Heed, Productmanagement

5 , that is, transformation, innovation, inputs (finance), outputs (product performance) and comparative performance (e.g. major competitors).

4: no feeling that the decision had already been taken. less" complex (compare: Hickson et al., 1986: 270271)

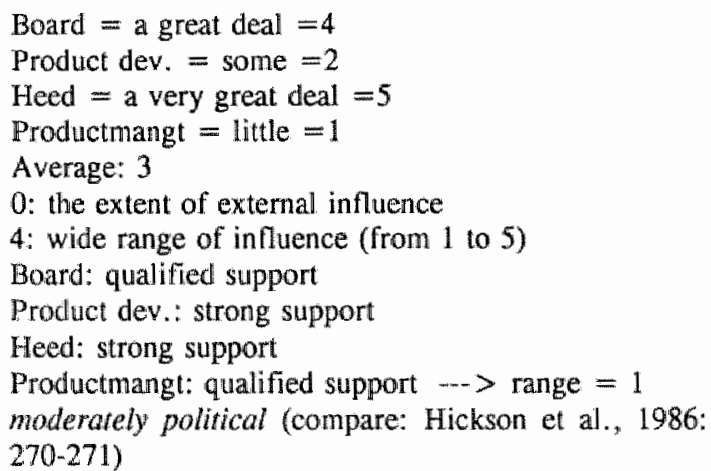

Product dev. $=$ some $=2$

Heed $=$ a very great deal $=5$

Productmangt $=$ little $=1$

Average: 3

4: wide range of influence (from 1 to 5 )

Board: qualified support

Product dev.: strong support

Heed: strong support

moderately political (compare: Hickson et al., 1986: 270-271) 


\section{OTHER PROCESS CHARACTERISTICS}

Duration-process time

Duration-gestation time

Disruption

Impedance

Formal interaction

Informal interaction

Negotiation scope

Information sources-expertise

Information sources-confidence disparity

Information sources-externality

Information sources-effort

Authority - level in hierarchy

Overall assessment
6 months

70 months

1: the process was hardly interrupted by delays

2: the issue of organization of new facility

1: Board, assisted and adwised by others

2: little discussion, toing and froing or arguments

Collective decision: 4

10: e.g. internal (prod, development department) and external (university professor)

range $=3$

the extent to which information from external sources contributed to reduction of uncertainty: $50 \%$

1: information available from personal knowledge or opinions

6: implementation was authorized at Board level and ratified by single stockholder

constricted" process (compare: Hickson et al., 1986: 117 and $270-271$ ) 


\section{Appendix D Quantitative characterization of the decision process concerning technology $Z$}

\section{COMPLEXITY}

Rarity

Radicality of consequences

Seriousness of consequences

Diffusion of consequences

Endurance of consequences

Precursiveness

Number of interests involved

Diversity of interests involved

Openness to alternatives

Overall assessment

\section{POLITICALITY}

Pressure of influence

Intervention

Imbalance

Contentiols

Overall assessment
-5: once every five years

4: substantially

4: very

8: profit, quality, output, costs, sales, retum on investment, image and market share.

10 years

Precursive: the alternatives considered (going into certain $Z$ technologies or not) involved parameters outside the existing strategy, i.c. the domain of $\mathbb{Z} 2$ technology.

4, that is, Board, Product dev. department, stockholder Heed, Productmanagement

6, that is, transformation, innovation, technology domain, inputs (finance), outputs (product performance) and comparative performance.

4: no feeling that the decision had already been taken. rather complex (compare: Hickson et al., 1986: 270271)

Board $=$ quite a lot $=4$

Product dev. = quite a lot $=3$

Heed $=$ quite a lot $=3$

Productmangt $=$ little $=1$

Average: 2.5

0 : the extent of external influence

2: moderate range of influence (from 1 to 3 )

Board: qualitied support

Product dev.; strong support

Heed: qualified support

Productmangt: qualified support $-\cdots>$ range $=\mathbb{1}$

less political (compare: Hickson et al., 1986: 270271)

\section{OTHER PROCESS CHARACTERISTICS}

Duration-process time

Duration-gestation time

Disruption

Impedance

Formal interaction

Informal interaction

Negotiation scope
12 months

20 months

2: the process was intermittently internupted by delays 3: the lack of financial resources was a major impediment until CHEMIC took shareholding position 3: Board, assisted and advised by project teams scanning the technical and industrial situation

5: a great deal of discussion

Collective decision: 4 
Information sources-expertise

Information sources-confidence disparity

Information sources-externality

Information sources-effort

Authority - level in hierarchy

Overall assessment
10: e.g. product dev. department and several external experts

range $=3$

the extent to which information from external sources contributed to reduction of uncertainty: $80 \%$

4: information synthesized by integrating diparate knowledge from diverse sources by study, scanning, meetings, etc.

6: implementation was authorized at Board level and ratified by stockholder

fluid-sporadic process (compare: Hickson et al., 1986: 117 and $270-271$ ) 


\section{CHAPTER 6}

\section{COMPARING CASES}

"(V)erifying as much as possible with as accurate evidence as possible is requisite while one discovers and generates his theory - but not to the point where verification becomes so paramount as to curb generation.

(...) This is especially true because evidence and testing never destroy a theory (of any generality), they only modify it. A theory's only replacement is a better theory."

(Glaser and Strauss, 1967: 28)

\subsection{Introduction}

This chapter aims at the comparative analysis of a number of cases in strategy formation. It reports on a study which uses Boolean logic to compare ten cases.

In previous chapters several propositions have been put forward. The arguments leading to these propositions pertained to theory generation, which relied predominantly on non-systematic observations of cases. Given the framework developed in previous chapters, the following question is now raised: can the propositions in earlier chapters be tested in a more rigorous study?

This requires both an in-depth scrutiny of specific cases and a systematic comparison across these cases. For this purpose, a comparative method using Boolean logic will be outlined in the next section, which also provides some brief comments on its potential contribution to strategy research. Subsequently, we turn to the selection of cases and a number of categories and variables which provide the coding system for the comparative analysis. Next, the coding procedure is described more extensively. The results of the coding procedure provide the data for the comparative analysis based on Boolean logic. Finally, the results of the analysis are discussed and the comparative method is evaluated.

1 The author wishes to acknowledge Marlène Döderlein de Win, Thera Tolner and Aad Vijverberg for their contribution as coders in the study reported in this chapter. The anthor is also grateful to Hein Schreuder who tested a draft of the coding instructions on several pilot-cases. 


\subsection{Comparing cases by means of Boolean analysis}

In the introduction to this study, the distinction between the process and content approach in strategy research was described. The content and process approaches differ to a large extent in their preferred methodology. The process tradition predominantly relies on fine-graimed, direct research methods (Mintzberg, 1979; Harrigan 1983), exemplified especially by casestudies of strategy formation over relatively long periods (e.g. Pettigrew, 1985; Mintzberg and Waters, 1985; Lewis, 1988; Hardy, 1990). Finegrained methods benefit from their attention to details in characterizing the complexities of strategy formation. However, the value of fine-grained studies tends to be limited due to problems in replicating and generalizing their results. In short, they tend to sacrifice rigor for relevance (cf. Schwenk, 1982).

The content tradition predominantly relies on coarse-grained, variableoriented methods (Harrigan, 1983), exemplified especially in rigorous crosssection studies of strategy formation (e.g. Miller and Friesen, 1982; Hambrick, 1983; Harrison et al., 1988). These studies tend to be rather deterministic in kind (Bourgeois, 1984). Here, strategy formation research is based on cross-sectional samples taken from large databases or populations, and great benefits are obtained from the use of multivariate techniques. Coarsegrained methods thus produce generalizable results. However, limited explanations of the way specific phenomena arise can be provided. Many interesting idiosyncracies are lost in the error terms of statistical analysis (Harrigan, 1983).

A few attempts have been made to combine fine-grained and coarse-grained methods in strategy formation research (e.g. Mintzberg et al., 1976; Harrigan, 1980; Kagono et al., 1985). However, these studies have not exploited the opportunity to impose greater rigor on their analysis. Overall, this is due to the predominantly exploratory nature of these studies. That is, testable hypotheses have not been incorporated in their initial designs. Moreover, they tend to rely on hybrid instead of synthetic methods, by artificially combining as many elements from the fine- and coarse-grained extremes as possible. In all likelihood, an effective synthesis selectively unites some elements of the two extremes.

Designing a rigorous synthetic study is not easy. The researcher desiging an ideal comparative study would probably turn to a combination of longitudinal analysis and comparison of a relatively high number of systems under study (i.c. dominant groups). Howewer, we lack the consistent long-period time series needed to develop the potential of this approach. Moreover, in a comparative study, an experimental or replication logic must be substituted for a sampling logic (Yin, 1981; 1984; Miles and Huberman, 1984; Eisenhardt, 1989). Thus, individual cases are considered as if they were single 
experiments, and the analysis follows cross-experiment rather than withinexperiment logic. Thus, one tries to reproduce findings in a new context or in another part of the data base (Miles and Huberman, 1984). An important prerequisite to this replication logic is the development of a rich, theoretical framework, stating the conditions under which a particular phenomenon is likely to be found or not.

Ragin (1987) presents a comparative, replication-like method, based on Boolean logic, which may bridge the gap between coarse- and fine-grained methods. This method accords high status to the qualitative analysis of a (small or large) number of cases. It especially pays attention to combinations of conditions and produces explanations that account for every different combination of conditions. That is, the results of comparative Boolean analysis are affected by each logically different observation, and not so much by the frequency of their occurrence. ${ }^{2}$

The comparative Boolean method can be used to address the complexity of strategy formation, especially apparent in patterns of so-called multiple, combinatorial causation (e.g. several forces working simultaneously). Given certain theoretical categories and propositions, this method has a strong inductive element because it proceeds from the bottom up, simplifying complexity in a systematic, stepwise manner. The steps taken in Boolean comparative analysis are as follows (cf. McDermott, 1985; Ragin, 1987; Roth, 1975).

(1) Select a number of propositions.

Select a set of propositions each involving a set of conditions for certain phenomena to occur.

(2) Construct a truth table using Boolean logic.

A truth table shows primitive expressions using Boolean logic (a short overview of Boolean logic is provided in Appendix A). There are two logical states of one single variable in Boolean logic: 1 (presence) and 0 (absence). We will follow the convention of using uppercase letters to denote the presence of a certain condition (e.g. 'A') and lowercase letters to denote its absence (e.g. 'a').

(3) Minimize the truth table.

Through so-called Boolean minimization of the truth table a Boolean expression is obtained which reflects a minimum set of existent combinations (or conjunctures) of conditions. Minimization is the most fundamental procedure in Boolean analysis. It is a simple and straightforward method for simplifying the complexity of truth tables. The basic rule in minimization is: if two Boolean expressions differ in only one condition yet produce the same

2 A short overwiew of Boolean logic is given in appendix A. 
outcome, then the condition that distinguishes the two expressions can be considered irrelevant and can be removed. We thus obtain the so-called prime implicants of the phenomenon under study, reflecting the key conditions for the phenomenon to arise.

(4) Select the essential prime implicants.

The essential prime implicants constitute the logically minimal conditions of a certain phenomenon. That is, they involve the sufficient and/or necessary conditions for certain phenomena to occur. This step is important when the reduced truth table expression (obtained in step three) includes so-called cyclic conjunctures, that is, a set of overlapping prime implicants which are not all needed to minimally cover the truth table.

(5) Evaluate the results.

Compare the results obtained in step four with the initial propositions in step one, or any other theoretical considerations. If necessary, adjust the initial propositions and start again with step one.

(6) Introduce simplifying assumptions.

One of the primary goals of qualitative comparison is to allow maximum causal complexity, that is, to avoid making simplifying assumptions at the outset (as is done in most conventional statistical analyses). After having conducted this kind of analysis, one can introduce simplifying assumptions. This procedure involves selecting conjunctures that are not included in the initial Boolean expression and adding these terms to the expression for the existing conjunctures. Simplifying assumptions are especially important in view of the problem of limited diversity. Limited diversity arises when the set of cases is taken from a larger universe of cases. This places constraints on possibilities for testing causal arguments. Thus, after having allowed for maximum causal complexity (in steps one to five), one may introduce simplifying assumptions in order to make inferences about the larger universe of real-world cases. Note that this approach is quite different from making general assumptions at the outset.

For an illustration of the use of simplifying assumptions consider truth Table 6.1. According to this table, the conditions $\mathrm{B}, \mathrm{C}$ and $\mathrm{D}$ are relevant as to whether A occurs. Simple inspection of Table 6.1 indicates that condition D is the dominant, if not the only, cause of A. However, in terms of Boolean logic three combinations of conditions exist:

$$
\mathrm{bcD}+\mathrm{bCD}+\mathrm{BcD}-\mathrm{A}
$$

This expression shows that three combinations of conditions each produce $A$ : for instance, the first combination implies that the absence of condition $B$ and $\mathrm{C}$ in combination with the presence of $\mathrm{D}$ will lead to the occurrence of A.

Computation of the minimized truth table expression (see step three) gives:

$\mathrm{bD}+\mathrm{cD} \ldots \mathrm{A}$ 
Table 6.1 Hypothetical truth table on conditions of A.

\begin{tabular}{llllll}
\hline \multicolumn{2}{c}{ Conditions: } & & & Number of & Existent \\
B & C & D & A & instances & Non-existent \\
& & & & & \\
0 & 0 & 0 & $?$ & 0 & $\mathrm{~N}$ \\
0 & 0 & 1 & 1 & 2 & $\mathrm{E}$ \\
0 & 1 & 0 & 0 & 1 & $\mathrm{E}$ \\
0 & 1 & 1 & 1 & 1 & $\mathrm{E}$ \\
1 & 0 & 0 & 0 & 2 & $\mathrm{E}$ \\
1 & 0 & 1 & 1 & 2 & $\mathrm{~N}$ \\
1 & 1 & 0 & $?$ & 0 & $\mathrm{~N}$ \\
1 & 1 & 1 & $?$ & 0 & \\
\hline
\end{tabular}

Thus, $\mathrm{bD}$ and $\mathrm{cD}$ are the prime implicants (that is, they "imply" the combinations $b c D, b C D$ and $B c D$ ). To produce the simple causal statement $\mathrm{D}->\mathrm{A}$, the following simplifying assumption is needed (see the last instance in Table 6.1):

$\mathrm{BCD} \ldots \mathrm{A}$

The Boolean comparative method allows the boundaries of comparison to be deliberately set by the investigator. In doing so, it appears to provide an attractive means for structuring the dialogue between propositions and observations. Note that this method does not intend to synthesize coarse- and fine-grained methods. Instead, it selectively unites certain features of the two (Ragin, 1987). In common with coarse-grained methods, the Boolean method allows assessment of a large number of observations. However, it does not incorporate the sophistication and intelligence of many coarse-grained (e.g. multivariate) techniques. In common with fine-grained methods, the Boolean method allows assessment of complex patterns of causation. It cannot, however, provide maximal attention to the wealth of historical details, as the fine-grained method typically does. The remainder of this chapter will address the design and results of our comparative study of cases in strategy formation.

\subsection{Selection of cases}

For the purpose of comparative analysis ten existing case-descriptions in strategy formation have been selected. The selection of cases was deliberately limited to organizations producing rather tangible goods or services, either as a state-owned or privately owned company. Studies such as those of the 
U.S. government dealing with the Cuban missile crisis (Allison, 1971) and Vietnam war (Mintzberg, 1978) and educational organizations (Hardy et al., 1984) were excluded. The "organized anarchy" nature of strategy formation in these cases introduces additional identification problems. For example, the low cohesiveness of (dominant) groups and fluid participation of a wide range of actors in organized anarchies complicates the identification of especially group perception and group repertoires. Although the group concept may still be adequate in explaining strategy formation in organized anarchies, this question deserves to be the subject of a separate study. Therefore, the database in this chapter is limited to privately or publicly owned companies. Given this constraint the selection of the cases was based on the following additional criteria.

Extensiveness and detailedness. The case-report should be based on multiple data sources, and at least incorporate both interview and documentary sources. Relying on the authors' intimate knowledge of the cases provides some assurance of the in-depth quality of the comparative analysis across these cases.

The variety in authors' viewpoints across all cases. The cases should be reported using a variety of images and explanatory frameworks. This criterion also limits the number of case-studies taken from one (team of) author(s).

Dominant group perspective. The authors' viewpoints should fit the dominant group perspective we have adopted. That is, the selected case-reports provide major observations of strategy formation in and around a given dominant group.

The replicability of the coding procedure. The selected cases are reported in widely accessible public sources (academic journals or books). Thus, the coding procedure can be checked and repeated by others.

Cases which do not meet (any of) these criteria include those by Hedberg (1974), Chandler (1962) and Pettigrew (1985). The case of Facit by Hedberg (1974) is based on a study of annual reports and newspaper articles and does therefore not meet the first criterion. Chandler's (1962) well-known study of five major American corporations also predominantly relies on documentary evidence. Pettigrew's study of strategic change at ICI is inappropriate for our purposes, because it takes the perspective of organization development professionals and thus actions and sense-making by ICI's top management cannot be clearly identified. Figure 6.1 provides an overview of some characteristics of the selected cases. 
Figure 6.1 Some characteristics of the selected cases.

\begin{tabular}{|c|c|c|c|c|c|}
\hline Organization & Mdustry & $\begin{array}{l}\text { Main } \\
\text { Location }\end{array}$ & Ownership & $\begin{array}{l}\text { Time } \\
\text { Span }\end{array}$ & Authors \\
\hline Air Canada & $\begin{array}{l}\text { air } \\
\text { transport }\end{array}$ & Canada & state & $1937-75$ & $\begin{array}{l}\text { Mintzberg, } \\
\text { Brunet \& } \\
\text { Waters } \\
1986\end{array}$ \\
\hline Arcop & $\begin{array}{l}\text { archi- } \\
\text { tecture }\end{array}$ & Canada & private & $1953-78$ & $\begin{array}{l}\text { Mintzberg } \\
\text { et al. } \\
1986\end{array}$ \\
\hline Berol Kemi & chemistry & Sweden & state & $1973-83$ & $\begin{array}{l}\text { Czami- } \\
\text { awska } \\
1988 ; \\
1989\end{array}$ \\
\hline $\begin{array}{l}\text { British Road } \\
\text { Services }\end{array}$ & $\begin{array}{l}\text { road } \\
\text { transport }\end{array}$ & U.K. & state & $1968-79$ & $\begin{array}{l}\text { Lewis } \\
1988\end{array}$ \\
\hline $\begin{array}{l}\text { Foster } \\
\text { Brothers }\end{array}$ & $\begin{array}{l}\text { menswear } \\
\text { retailing }\end{array}$ & U.K. & private & $1972-85$ & $\begin{array}{l}\text { Johnson } \\
1987\end{array}$ \\
\hline Honda Motors & $\begin{array}{l}\text { motor } \\
\text { vehicles }\end{array}$ & Japan & private & $1955-65$ & $\begin{array}{l}\text { Pascale } \\
1984 ; \\
\text { Pascale \& } \\
\text { Christian- } \\
\text { sen } 1983\end{array}$ \\
\hline $\begin{array}{l}\text { Pakhoed } \\
\text { Transport }\end{array}$ & $\begin{array}{l}\text { storage } \\
\text { and } \\
\text { transport }\end{array}$ & $\begin{array}{l}\text { Nether- } \\
\text { lands }\end{array}$ & private & $1975-86$ & $\begin{array}{l}\text { Bahimann } \\
\text { \& Mees- } \\
\text { ters } 1988\end{array}$ \\
\hline Steinberg & retailing & Canada & private & $1952-74$ & $\begin{array}{l}\text { Mintzberg } \\
\& \text { Waters } \\
1982\end{array}$ \\
\hline Toxicem & chemistry & U.K. & private & $1964-68$ & $\begin{array}{l}\text { Wilson } \\
1982 ; \\
1980\end{array}$ \\
\hline $\begin{array}{l}\text { Walt Disney } \\
\text { Productions }\end{array}$ & $\begin{array}{l}\text { enter- } \\
\text { tainment }\end{array}$ & U.S.A. & private & $1983-84$ & $\begin{array}{l}\text { Burns } \\
1986 ; \\
\text { Taylor } \\
1986\end{array}$ \\
\hline
\end{tabular}




\subsection{Categories and variables}

Previous chapters have explored the self-organization view on strategy formation. This section draws together some of the results of previous chapters by delineating a number of theoretical categories and variables. These categories and variables will provide the framework for comparing the cases we have selected. They constitute an outside conceptual framework (or coding system) which will be imposed on the cases selected in the previous section.

The categories are (cf. chapter two and three):
a. dominant group;
b. difficulty set;
c. perception/formation;
d. repertoire;
e. induced action;
f. autonomous action;
g. environment.

In addition, nine variables are defined. These variables involve change in one of these categories or in the relations (forces) between them. The variables are:

1. change of the difficulty set;

2. change in cohesiveness of perception;

3. change in composition of the dominant group;

4. change in tightness of the repertoire;

5 . change in content of the repertoire;

6. change of fit between the difficulty set and repertoire;

7. change in emphasis on induced versus autonomous action;

8. whether induced actions produce major unintended consequences;

9. whether autonomous actions have a substantial effect on perception and composition of the group.

The coding of the cases divides into two stages. In the first stage, each case is categorized in terms of the categories listed above. The first stage results in case-summaries in terms of the categories of our coding system. In the second stage, the nine variables are coded (on the basis of the results of the first stage). The results of the second stage tell us if change occurs in the categories and which direction this change takes. The coding procedure will be discussed in more detail in the next section. The remainder of this section discusses the categories and variables more extensively. In addition, we provide some examples of how these categories and variables have been applied to the cases. Most of these examples are taken from the British Road Services case reported by Lewis (1988). In order to make these examples more accessible, a short introduction to British Road Services appears to be 
in place (ef. Appendix C):

In 1948 British Road Services (BRS) was created by the U.K. government as a highly centralized organization with the objective of integrating and coordinating long-distance road transport. From its inception, BRS was primarily a long-distance road haulier involved in what is known as "general haulage".

The first twenty-five years of BRS' history were characterized by the countervailing influences of imposed government policy and the management philosophy and style of the acquired small hauliers from which BRS was forged. Government policy, driven by a desire to integrate the nation's road transport activities, imposed a highly centralized structure and bureaucratic style on the organization in its formative years. It soon became apparent that this approach was doomed, and the organization drifted toward the more entrepreneurial style of the small haulier.

Changes in government policy subsequently confirmed a more commercial orientation. Although the strategy of national integration was effectively abandoned, a large, professionally managed organization had been created. BRS came to operate a wide range of road transport activities within a framework of corporate plans and national product policies. During the subsequent decade (1968-1979) strategic changes were initiated by successive chief executives.

\section{Categories}

Dominant group. The dominant group includes those who impart a particular character and direction to the organization. We distinguish between the core and the periphery of dominant groups (see chapter three). The core concerns those persons who can take care of their involvement in a typical strategy process by themselves, e.g. based on their authority or status. In the periphery are those persons which can impose certain sanctions on the core of the group (e.g. withholding information, loans or support). In the remainder of this chapter 'dominant group' refers to its core, unless indicated otherwise. In the BRS case we assumed that the dominant group in 1968 includes the following members:

Top management of the British Road Services group, especially the managing director of the group and the managing directors of regional companies. At the periphery of the group are, amongst others, staff members at the group level (e.g. group controllers) and board members and managers at the regional company level.

Difficulty set. The difficulty set involves the major problems which confront 
the dominant group. Included are those problems which provide a fundantental challenge or threat to the dominant group. This is a rather vague guideline leaving much discretion to the coders. Therefore, we adopted the following additional instruction: a problem is part of the difficulty set if it is perceived as such by at least one member of the dominant group. In the BRS case we observed the following difficulties for the period 1968-1972:

Inherent conflict between BRS haulier culture and centralized coordination; the 1968 Act changes BRS' financial accountability from commercial accountability to balancing cash-flow (while profitability has become established way of judging managers' performances); devising the structure most appropriate to the many-sided activities of BRS; profitability crisis in general haulage; new uncertainty arising from the election of a conservative government.

Perception/formation. In chapter three we distinguished between two perceptual activities: cognitive and sensory activity. We argued that, although individual sensory activity is extremely important in strategy formation, dominant groups continue to exist due to some sharedness of individual cognitions. Thus, our interest here especially concerns the more or less shared cognitive frameworks of the membership of the dominant group. These cognitive frameworks may involve the interpretations of current difficulties or any other major understanding of the organization or industry the dominant group is embedded in. As pointed out in chapter three, significant changes in the composition of the dominant group should also be incorporated in this category, because new members tend to bring along new cognitions.

With Payne as the new (group) managing director, orientation is increasingly toward financial control, branch profitability and branch profit responsibility; questioning of $B R S^{\prime}$ role as a large general haulier and of natural systems and structures for the co-ordination of general haulage; general success of private hauliers is rather a myth from the perspective of BRS' management; continuation of emphasis on decentralization and profit as a measure of efficiency.

Repertoire. This category constitutes the core category of our coding system. ${ }^{3}$ The repertoire involves the set of behavioral rules prevailing in the dominant group at a certain moment in time. Essentially, a rule provides a sense of direction for action, by giving the dominant group and its periphery a shared mission or by pointing at accepted practice ("the way we do things

3 By way of a core category we try to account for most of the variation in a pattern of behavior, that is, its different kinds of appearances under different conditions. Most other categories and their properties are related to it (Strauss, 1989). In chapter three we described how the repertoire category may relate to other categories. 
around here'). Rules may leave room for a wide range of more specific intentions, but provide enough structure to guide actions. Note that rules can be expressed either verbally or in nonverbal symbols. Nonverbal symbols cannot be inferred in a reliable manner from verbal descriptions of cases. Nevertheless, we may assume that major rules will also somehow show up in verbal form. In the BRS case we found the following dominant group repertoire for the period 1968-1972.

Continuation of management philosophy focusing on commercial public company; give operating companies high degree of autonomy; withdraw from unprofitable general haulage activity: continuation of financial reporting as key to management control; overall, the repertoire loosens to include decentralization policy (with top management control diminishing) and also moves away from its focus on general haulage as core-business.

Induced action. Action of members of the core or periphery of the group being deliberately initiated by core members. Included in this category is any major action (including decisions) and its direct effects in a setting of major duration (e.g. months or years) with significant dominant group influence. In the BRS case we found the following induced actions in 1968-1972:

BRS joins the privately owned sector in the industry in the Road Haulage Association; the concept of branches as profit centres also leads to decentralization of control of operating assets (vehicles, trailers); policy of rationalization, that is, withdrawal from unprofitable activities; role of bureaucratic devices, such as the Management Manual, gradually diminishes; strategy of national co-ordination through a centralized operating structure and a bureaucratic control system is abandoned and local unit autonomy is re-established (with central performance control).

Autonomous action. Action of members of the core or periphery of the dominant group which appears as given to the core. Included in this category is any major action (including decisions) and its direct effects in a setting of major duration without deliberate influence of the dominant group. Note that certain actions by individual members of the group may be autonomous rather than induced, e.g. top managers leaving the group on their own rather than the group's initiative. Autonomous action in the periphery may involve action by consultants, middle management, shareholders, corporate raiders, etc. Also note that one enters the periphery by acquiring substantial power to impose sanctions on the core of the group (see definition given above). In the BRS case we coded the following action as autonomous: 
The Transport Holding Company is replaced by the National Freight Corporation (NFC) as central management entity of state-owned road transport interests.

Environment. This is the context of the dominant group, including all events, developments, actions, expectations, and so forth, which are outside the dominant group's direct influence sphere. Examples include (expected) world trade and industry developments, governmental intervention and monetary developments. For BRS in 1968-1972 the environment involved:

New government intervention (1968 Transport Act) by Labour politicians seeking legislative and regulatory co-ordination of the industry; following the election of a conservative government in 1970, industry is again faced with uncertainty, although, governmental change does not result in actual reorganization of transport industry.

\section{Variables}

The second stage of the coding work involves an application of the nine variables mentioned earlier to the observations for each category and period. A short description of the variables now follows.

Change in the difficulty set. This involves the difficulty set (not) broadening to include substantial new difficulties. In the example of the BRS case we gave earlier, the difficulty set includes substantial new difficulties relative to previous periods, such as the problem of balancing cash-flow.

Change in cohesiveness of perception. This variable refers to dominant group cognitions becoming more/less cohesive. A cohesive set of cognitions is apparent from the extent to which individual cognitions in the group differ or lack coherence. (Remember that we are referring to the core of the dominant group.) In the example of group perception in the BRS case we gave earlier, perception becomes less cohesive with the old cognitive structure breaking down and a new one emerging.

Change in composition of dominant group. This variable traces major changes in the composition of the dominant group, including its formation at the outset. In the BRS example the composition of the group changes with the arrival of Payne, the new managing director.

Change in tightness of the repertoire. This variable expresses whether the repertoire becomes more or less tight. A tight repertoire highly limits the behavior of members of the dominant group. The tightness of repertoires can be inferred from the degree of responsiveness between rules and actions. In the course of time, tight repertoires tend to develop into ingrained ones, which shows up in rules being taken for granted (cf. an automatic behavior 
program). A more ingrained repertoire is coded as if it is more tight. In the example taken from the BRS case, the tightness of group perception decreases, especially in view of the increasing decentralization and higher degrees of autonomy for the regional companies.

Change in content of the repertoire. This is change in the rules which constitute the repertoire. Change in content occurs when fundamental new rules enter the repertoire. We assume that this is also the case when a completely new repertoire forms. In the BRS group repertoire described earlier, the content of the repertoire changes. One major new rule is: 'withdraw from unprofitable general haulage'.

Change in fit between the difficulty set and repertoire. This variable indicates whether the existing difficulties can be more or less easily dealt with by the current repertoire. Several examples of increasing fit or misfit can be found in Appendix C.

Change in emphasis on induced versus autonomous action. This is the change in relative significance of induced and autonomous actions. For example, in the Pakhoed Transport case we observed that in 1975-1982 the emphasis shifts toward autonomous action because its units gain more independence in their actions.

Whether induced actions have major unintended consequences. This variable indicates whether induced actions produce major unintended consequences which are reflected in the difficulty set of the same period. An unintended consequence is a particular effect of induced action which is different from what was wanted at the moment of carrying out the act. This effect is present, for example, when reorganization attempts fail to bring about the desired results, when unexpected problems arise while entering new foreign markets, or when defensive measures against a takeover threat further depress stock values and thus increase the takeover threat.

Whether autonomous actions affect perception. This variable indicates whether autonomous actions include any action which substantially affects the perception - and possibly also the composition - of the dominant group. Examples of this effect are: a dominant group member finds important errors in accepted practices in the organization and questions their viability; major shareholders (in the periphery) enforce the appointment of a new chief executive; consultants (in the periphery) insist on certain measures which contrast the initial plan of the dominant group. 


\subsection{Coding procedure}

This section describes the coding procedure in more detail. The coding procedure involves so-called selective coding (Strauss, 1989), based on a coding system of categories and variables. The procedure divides into two stages. In the first stage, the observations in each case are periodized and categorized according to the categories defined in the previous section. This coding work was done by two or three coders per case (from a team of four). Subsequently, initial disagreements are resolved. Hence, disagreements in the second stage cannot arise from different results in the first stage. The second stage involves an assessment of the variables from period to period. In order to obtain maximum uniformity of the coding process in this stage, two fixed members (including the author) of the coding team did the coding work across all cases.

Both coding stages were structured by means of a five page instruction to the coders. A first draft of this instruction was revised on the basis of pilot-tests on several cases. In addition, the instruction also underwent a number of revisions in the course of the actual coding work. In particular, several definitions became more precise. Of course, the consistency of previously coded work with such revisions was checked and any inconsistencies were corrected. The final instruction text is reproduced in Appendix B.

The coding procedure in stage one includes the following steps. First, the two coders start by defining where the case is assumed to begin. Second, the members of the dominant group at the beginning of the case are specified. We are especially concerned here with the core of the dominant group (see previous section). The third step involves the division of the total period covered in the case into a number of key periods. In most cases we followed the key periods identified by the author(s) of the case. In the remaining cases we agreed on obvious turning points which serve in delimiting periods.

Subsequently, all major events and observations in the case are categorized according to the coding system of six categories (see previous section). These categories pertain to some perceptual or behavioral dimension of the dominant group. Some observations could be allocated to more than one category, for instance, their perceptual dimension as difficulty and their behavioral dimension as induced action. Finally, the results obtained are discussed with the other coder(s). Disagreements are resolved by requiring each coder to carefully justify his or her assessment. Any observations on which the coders continue to disagree are excluded from the results.

The coding procedure in stage two involves the assessment of the overall character of change in one of the categories or the forces between those categories (see the nine variables outlined in the previous section). In several 
Table 6.2 Results of the coding procedure (source: Appendix C).

\begin{tabular}{|c|c|c|c|c|c|c|c|c|c|c|}
\hline \multirow[t]{2}{*}{ ORGANIZATION } & \multirow[t]{2}{*}{ PERIOD } & \multicolumn{9}{|c|}{ VARIABLES } \\
\hline & & D & $\mathrm{C}$ & 0 & $\mathrm{~T}$ & $\mathrm{H}$ & $\mathrm{F}$ & A & $\mathrm{U}$ & B \\
\hline \multirow[t]{3}{*}{ Air Canada } & $1937-46$ & $\mathrm{i}$ & $?$ & $\mathrm{c}$ & $?$ & $\mathrm{c}$ & $?$ & $?$ & $\mathrm{n}$ & a \\
\hline & $1946-55$ & $\mathrm{i}$ & 1 & $\mathrm{c}$ & 1 & $\mathrm{n}$ & $?$ & $\mathrm{i}$ & $\mathrm{n}$ & a \\
\hline & $1955-75$ & $\mathrm{n}$ & 1 & $c$ & $\mathrm{~m}$ & $\mathbf{n}$ & $\mathrm{f}$ & i & $\mathrm{n}$ & a \\
\hline \multirow[t]{4}{*}{ Arcop } & $1953-58$ & $\mathrm{i}$ & $\mathrm{m}$ & $c$ & $\mathrm{~m}$ & $\mathrm{c}$ & $f$ & i & u & a \\
\hline & $1958-67$ & $\mathrm{i}$ & I & $c$ & 1 & $\mathrm{n}$ & $\mathrm{m}$ & $\mathbf{a}$ & u & a \\
\hline & $1967-70$ & $\mathrm{i}$ & 1 & $\mathrm{c}$ & 1 & $n$ & $\mathrm{~m}$ & $\mathrm{a}$ & $\mathrm{n}$ & a \\
\hline & $1970-78$ & $\mathrm{n}$ & $\mathrm{m}$ & $c$ & $\mathrm{~m}$ & $c$ & $\mathrm{f}$ & $\mathrm{i}$ & $\mathrm{n}$ & a \\
\hline \multirow[t]{3}{*}{ Berol Kemi } & $1973-74$ & $?$ & $?$ & $n$ & $?$ & $?$ & $?$ & $?$ & $?$ & $\mathrm{n}$ \\
\hline & $1975-78$ & $\mathrm{i}$ & 1 & $\mathbf{n}$ & $\mathrm{n}$ & $\mathrm{n}$ & $\mathrm{m}$ & n & n & $\mathrm{n}$ \\
\hline & $1978-83$ & $\mathrm{n}$ & $\mathrm{m}$ & $\mathrm{c}$ & $\mathrm{m}$ & $c$ & $f$ & $\mathrm{i}$ & $\mathrm{n}$ & a \\
\hline \multirow{3}{*}{$\begin{array}{l}\text { British Road } \\
\text { Services }\end{array}$} & $1968-72$ & $\mathrm{i}$ & 1 & $\mathrm{c}$ & 1 & $c$ & f & $?$ & $\mathrm{n}$ & $\mathrm{n}$ \\
\hline & $1972-76$ & $\mathrm{n}$ & $\mathrm{m}$ & $c$ & $\mathrm{~m}$ & $\mathrm{n}$ & $\mathrm{f}$ & $\mathrm{i}$ & $\mathrm{n}$ & a \\
\hline & $1976-79$ & $\mathrm{n}$ & 1 & $c$ & 1 & $\mathrm{n}$ & $?$ & $\mathrm{n}$ & $\mathrm{n}$ & a \\
\hline Foster & $1972-74$ & $?$ & 1 & $\mathbf{n}$ & $?$ & $?$ & $?$ & $?$ & n & $\mathrm{a}$ \\
\hline \multirow[t]{4}{*}{ Brothers } & $1975-77$ & i & 1 & $c$ & $\mathrm{n}$ & $\mathrm{n}$ & $\mathrm{n}$ & $\mathrm{n}$ & $\mathrm{n}$ & a \\
\hline & $1977-79$ & i & $\mathrm{m}$ & $c$ & $\mathbb{1}$ & $\mathbf{n}$ & $\mathrm{n}$ & $\mathrm{n}$ & u & $\mathrm{n}$ \\
\hline & $1980-83$ & i & 1 & $c$ & 1 & $\mathrm{n}$ & $\mathrm{m}$ & $\mathrm{n}$ & $\mathrm{u}$ & a \\
\hline & $1984-85$ & $\mathrm{i}$ & $\mathrm{n}$ & $c$ & $n$ & $\mathrm{c}$ & $\mathrm{m}$ & $a$ & $\mathrm{u}$ & a \\
\hline \multirow[t]{2}{*}{ Honda Motors } & $1954-59$ & $\mathrm{i}$ & n & $\pi$ & $n$ & $\mathrm{n}$ & $?$ & $?$ & $\mathbf{n}$ & $\mathrm{n}$ \\
\hline & $1959-65$ & i & $\mathrm{n}$ & $\mathrm{n}$ & $\mathrm{n}$ & $\mathrm{n}$ & $\mathrm{n}$ & $\mathrm{n}$ & u & $\mathrm{n}$ \\
\hline Pakhoed & $1975-82$ & $\mathrm{i}$ & 1 & $\mathrm{n}$ & $?$ & $\mathrm{c}$ & $\mathrm{m}$ & $\mathbf{a}$ & $\mathrm{u}$ & $n$ \\
\hline Transport & $1982-86$ & $\mathrm{i}$ & $\mathrm{m}$ & $c$ & $\mathrm{~m}$ & $c$ & $\mathrm{~m}$ & $\mathrm{i}$ & $\mathrm{n}$ & a \\
\hline \multirow[t]{3}{*}{ Steinberg } & $1952-53$ & i & $n$ & $\mathbf{n}$ & 1 & $\mathrm{n}$ & $\mathrm{f}$ & $\mathrm{i}$ & $\mathrm{n}$ & $\mathrm{n}$ \\
\hline & $1954-60$ & $\mathrm{n}$ & $\mathrm{n}$ & $\mathbf{n}$ & $\mathbf{n}$ & $\mathrm{n}$ & $?$ & $\mathrm{i}$ & $\mathrm{n}$ & $\mathrm{n}$ \\
\hline & $1960-74$ & $\mathrm{i}$ & 1 & $\mathrm{n}$ & $\mathrm{m}$ & $\mathrm{n}$ & $\mathrm{f}$ & $\mathrm{a}$ & $\mathrm{u}$ & a \\
\hline \multirow[t]{2}{*}{ Toxicem } & $1964-66$ & $\mathrm{i}$ & 1 & $\mathrm{n}$ & $\mathrm{n}$ & $\mathrm{n}$ & $\mathrm{m}$ & $\mathrm{a}$ & $\mathrm{n}$ & $\mathrm{a}$ \\
\hline & $1966-68$ & $\mathrm{n}$ & 1 & $\mathrm{n}$ & 1 & $\mathrm{c}$ & $f$ & $\mathrm{i}$ & $\mathrm{n}$ & $\mathrm{a}$ \\
\hline Walt Disney & 1983-84 & $\mathrm{i}$ & $\mathbf{m}$ & $c$ & $\mathrm{n}$ & $\mathrm{n}$ & $\mathrm{m}$ & $?$ & u & a \\
\hline Productions & $1984-84$ & i & 1 & $c$ & 1 & $\mathrm{n}$ & f & $\mathrm{a}$ & $u$ & a \\
\hline
\end{tabular}


The variables in this table are:

$\mathrm{D}=$ whether the difficulty set includes new difficulties

$\mathrm{C}=$ change in cohesiveness of perception

$\mathrm{O}=$ change in composition of group

$\mathrm{T}=$ change in tightness of repertoire

$\mathrm{H}=$ change in content of repertoire

$\mathrm{F}=$ change in fit between difficulty set and repertoire

$A=$ change in emphasis of actions

$\mathrm{U}=$ whether induced actions have unintended consequences

$\mathrm{B}=$ whether autonomous actions affect perception

Table 6.2 uses the following symbols to indicate the status of these variables. For all variables '?' implies that the status of the variable is not determined (missing value).

for $D: \quad \mathrm{i}=$ including new difficulties

$\mathrm{n}=$ not including new difficulties

for $C: \quad 1=$ less cohesive perception

$\mathrm{m}=$ more cohesive perception

$\mathrm{n}=$ no change

for $O: \quad \mathrm{c}=$ change in composition

$\mathrm{n}=$ no change

for $T: \quad 1=$ less tight repertoire

$\mathrm{m}=$ more tight repertoire

for $H: \quad \mathrm{c}=$ change in content

$\mathrm{n}=$ no change

for $F: \quad \mathrm{m}=$ increasing misfit

$\mathrm{f}=$ increasing fit

$\mathrm{n}=$ no change

for $A: \quad a=$ emphasis shifts to autonomous action

$\mathrm{i}=$ emphasis shifts to induced action

$\mathrm{n}=$ no change

for $U: \quad \mathrm{u}=$ induced actions have unintended consequences

$\mathrm{n}=$ induced actions have no unintended consequences

for $B: \quad a=$ autonomous actions affect perception

$\mathrm{n}=$ autonomous actions do not affect perception 
cases the environment category could not be adlequately documented in the first stage and is therefore not included in any variable. The coders are instructed to assign (independently from each other) one change code to each variable for each separate period. 'No change' (or a similar code) is to be used if no substantial change is observed, or if no clear overall tendency can be discerned. If insufficient observations are available, the coders are instructed to use a "?". If the direction of change in the variable can be determined by making a plausible assumption, one is allowed to do so. ${ }^{5}$

Subsequently, the results of this coding stage are discussed between the coders. They try to resolve any disagreements by carefully justifying their assessments. Disagreements which are not resolved are given the '?' code. The results of both stages in the coding procedure are reproduced in Appendix C.

Note that the coding work to a large extent relies on the perceptions of a small team of coders. Two measures have been taken to alleviate this problem. First, the process of interpreting the raw data is made as explicit and accessible as possible (in Appendices B and C). Second, all cases have been coded by two or three coders. The intercoder reliability of the results can thus be evaluated (Miles and Huberman, 1984). The intercoder reliability is calculated by taking the number of agreements as a percentage of the total number of agreements and disagreements. The reliabilities of the coding work in this study were quite acceptable: in the first stage intercoder reliability was on average 77 percent and in the second stage 92 percent (see Appendix $\mathrm{D}$ for more details).

Table 6.2 provides a summary of the results of the coding work. It includes 29 observations (or periods), each involving a specific combination of variables. In the next section these combinations of variables are used as separate instances to identify the key forces at work. All truth tables in the next section are directly derived from Table 6.2.

4 This is understandable in view of the fact that most of the case-studies used here do not include extensive descriptions of environmental developments (e.g. industry), because such descriptions do not fit the purpose of these case-studies.

${ }^{5}$ Such a plausible assumption may involve the content of the category in previous (not documented) periods. We made such an assumption for the repertoire category in the Honda Motors case (1954-1959). See Appendix C. 


\subsection{Boolean analysis}

In prewious chapters a number of propositions have been presented. These propositions suggest that there are certain forces at work in strategy formation. Ideally, one would like to conduct a separate analysis of each proposition. As in most real world systems, however, the forces we have outlined tend to work simultaneously. The comparative analysis in this section is therefore conducted by considering one of the variables as dependent and several others as independent variables. That is, we will successively analyze a number of dependent variables as the outcome of several conditions. This way, Boolean analysis may identify the existing combinations of conditions for each variable separately. The analysis will proceed as follows (cf. section 6.2).

Propositions. For a given dependent variable, the relevant propositions in previous chapters are translated into Boolean logic. This requires precise definitions of the 1 and 0 terms for the dependent and independent variables. Note that it is possible to distinguish between necessary and sufficient conditions in Boolean expressions. A condition is necessary if it must be present to produce a 1 term for the dependent variable. A condition is sufficient if by itself it can produce a 1 term for the dependent variable. Consider, for example:

A.$->$ C

In this example, $A$ is both necessary and sufficient. In, for example $\mathrm{A}+\mathrm{BD} \ldots \mathrm{C}$

variable $A$ is sufficient but not necessary, and $B$ and $D$ are not sufficient and not necessary.

In general, the propositions will be taken from chapters three and five. The propositions in chapter four (on vertical integration) are too specific to be tested here. To some extent the propositions in chapter four are specific versions of the more general propositions in chapter three.

Truth table. Subsequently, a truth table is constructed. This truth table is restricted to four or five independent variables. In addition to the two or three independent variables which follow from the propositions, we can thus include one or two independent variables which did not occur in any of these propositions. Truth tables with five or more independent variables generally gave similar results but require rather large numbers of simplifying assumptions to arrive at reduced expressions. All truth tables are derived from Table 6.2. Conjunctures which include missing values for one or more variables are not incorporated in the truth tables. Thus, the difference between the total number of instances in Table 6.2 and a given truth table is caused by the number of instances for which at least one of the variables in the truth table has a missing value. 
In the truth tables '-' for the dependent variable should be read as 'undecided', which means that this combination of independent variables arises in conjunction with both the 1 and 0 term for the dependent variable. A question mark '?' for the dependent variable means that this combination of conditions does not occur in our database.

Minimization of truth table. Minimized truth table expressions will be computed on the basis of those combinations of variables for which the dependent variable is 1 . We thus obtain a set of combinations of conditions (prime implicants) for the dependent variable to occur. If necessary, the essential combinations of conditions will be selected. ${ }^{6}$

Evaluation of minimized expression. Preliminary conclusions about the validity of a given proposition can now be drawn. That is, the minimized expression serves as a first attempt to test (or falsify) the given propositions. In other words, does this expression provide any evidence against the propositions at hand?

Simplifying assumptions: the undecided conjunctures. Simplifying assumptions involve selecting combinations that do not have a 1 term for the dependent variable and adding these to the expression for the combinations with a 1 term. First, any 'undecided' combinations, for which the dependent variable has both the 0 and 1 value, will be added to the minimized expression. ${ }^{7}$ This is a rather plausible step in view of the fact that these conjunctures of independent variables do occur in combination with the 1 term for the dependent variable (although not in all observed instances). At this stage of the analysis we may have two Boolean expressions. which serve as attempts to falsify the respective propositions. Actual falsification involves either the complete absence of the proposed independent variable(s) or a consistent 0 term for the variable across all conjunctures in the expressions. For example, assume the proposition is

$$
W+Y \rightarrow Z Z
$$

and the minimized truth table expression is:

$$
w+y v+w v-z
$$

Simplifying this expression by adding the undecided combinations of variables may give:

$$
W+w v-.>Z^{\prime}
$$

The expressions for $Z$ and $Z$ ' serve as attempts at falsification of the preceding proposition. Evidently, the proposed condition $W$ survives this test, because it has a 1 term in both expressions. By contrast, the proposed

- So-called cyclic expressions do not occur in the remainder of this chapter. Thus, the selection of essential prime implicants (cf. section 6.2) is of less relevance here.

7 For reasons which will be explained later, not all truth tables include undecided combinations of variables. 
condition $\mathrm{Y}$ does not survive this test, taking a 0 status in the expression for $\mathrm{Z}$ and not being included in the expression for $\mathrm{Z}$ '. The conjuncture ' $w v^{\prime}$ ' in the expression for $Z^{*}$ at this stage merely points at the need for further simplification.

Additional simplifying assumptions. The final step involves an attempt at further simplification of the expression obtained in the previous step (e.g. the expression for $Z^{\prime \prime}$ ). This simplification may or may not be accomplished by adding several 'plausible' non-existent combinations. Plausible combinations are those combinations whose existence is expected in view of the propositions or related considerations. In addition, plausible assumptions can not involve existent combinations which have a 0 term for the dependent variable. In the example given earlier, plausible assumptions include Wvy and wvY (if they do not have a 0 term for $Z$ ) but definitely not wvy or wVy.

This last step may be viewed as an attempt to identify expressions similar to the given proposition, given the restrictions imposed by the data. In other words, the question here is: can we derive the proposition by introducing additional simplifying assumptions? In the example given earlier further simplification might give:

$$
\mathrm{W}+\mathrm{Y}-->\mathrm{Z}^{\prime \prime}
$$

In this case the proposition is completely identified in the sense that it is possible to derive the same expression by introducing simplifying assumptions.

Alternatively, assume the following expression is obtained:

$$
W+V-->Z^{\prime \prime}
$$

Regarding condition $Y$, this expression confirms the outcome of the earlier (falsification) test, which leads us to conclude that condition $Y$ is irrelevant for $\mathrm{Z}$ to accur. In addition, the last expression points at variable $\mathrm{V}$ as a potential condition. Note, however, that this inference is purely based on simplification.

We now turn to the analysis of the conditions of five dependent (change) variables: change in the difficulty set, in cohesiveness of perception, in tightness of the repertoire, in the content of the repertoire, and, finally, in actions.

\section{Analysis of change in the difficulty set}

The following variables are defined for the analysis of conditions of change in the difficulty set (see Overview 1). 


\section{OVERVIEW 1}

Dependent variable:

$1=$ difficulty set includes new difficulties

$0=$ difficulty set does not include new difficulties

Independent variables:

C $1=$ perception becomes less cohesive

$0=$ no change or perception becomes more cohesive

T $\quad 1=$ repertioire becomes less tight

$0=$ no change or repertoire becomes more tight

U $\quad 1$ = induced actions have unintended consequences

$0=$ induced actions have no unintended consequences

I $\quad 1=$ emphasis shifts to induced action

$0=$ no change or emphasis shifts to autonomous action

Several propositions are relevant to the issue of change in the difficulty set. We can now formulate these propositions in terms of the above variables. Proposition 3.1b suggests that the repertoire filters difficulties to those which can be acted upon. In addition, proposition $5.1 \mathrm{~b}$ suggests the repertoire tends to filter out new ideas (cf. difficulties) which to a large extent misfit the repertoire. This implies that repertoires becoming tighter will tend to constrain the difficulty set by excluding (filtering) new difficulties:

$$
T-\ldots D
$$

Proposition 3.3a simply holds that the cohesiveness of perception determines the selection of new difficulties (see also proposition 5.3a):

$$
C-\cdots>D
$$

In addition, proposition $3.5 \mathrm{a}$ implies that new difficulties

arise in the form of major unintended consequences of action:

$$
U \ldots D
$$

Combining the three preceding propositions gives the central proposition:

$$
T+C+U \ldots D
$$

In addition to the independent variables included in this proposition, we will include an additional one in the truth table, i.c. the variable I (see list of variables).

Table 6.3 shows the truth table on conditions of change in the difficulty set. This truth table is the result of applying the five variables we have listed 
above to Table $6.2 .^{8}$ Minimization of the 1 terms in the truth table produces a minimized truth table expression. This expression tells us that four combinations of conditions lead to the inclusion of major new difficulties in $\mathrm{D}$ :

$$
\mathrm{cTuI}+\mathrm{Cti}+\mathrm{ctU}+\mathrm{Ui}-\mathrm{D}
$$

This expression does not falsify any of our propositions, as the T, C and $U$ variables are present in this expression.

It is possible to reduce this expression further through simplifying assumptions. Recall that this procedure involves selecting combinations from the set of combinations that do not have 1 terms and adding these to the expression for D. We first add the 'undecided' combinations ctul, CTui and CTuI. This gives the expression:

$$
\mathrm{ctI}+\mathrm{TuI}+\mathrm{Ci}+\mathrm{Ui}-\mathrm{D}^{\prime}
$$

Evidently, this expression does not falsify the preceding propositions either.

Table 6.3 Truth table on conditions of change in the difficulty set.

\begin{tabular}{lllllll}
\hline $\mathrm{C}$ & $\mathrm{T}$ & $\mathrm{U}$ & $\mathbb{I}$ & $\mathrm{D}$ & $\begin{array}{l}\text { Number of } \\
\text { instances }\end{array}$ & $\begin{array}{l}\text { Existent/ } \\
\text { Non-existent }\end{array}$ \\
0 & 0 & 0 & 0 & $?$ & 0 & $\mathrm{~N}$ \\
0 & 0 & 0 & 1 & - & 5 & $\mathrm{E}$ \\
0 & 0 & 1 & 0 & 1 & 2 & $\mathrm{E}$ \\
0 & 0 & 1 & 1 & 1 & 1 & $\mathrm{E}$ \\
0 & 1 & 0 & 0 & $?$ & 0 & $\mathrm{~N}$ \\
0 & 1 & 0 & 1 & 1 & 1 & $\mathrm{E}$ \\
0 & 1 & 1 & 0 & 1 & 1 & $\mathrm{E}$ \\
0 & 1 & 1 & 1 & $?$ & 0 & $\mathrm{~N}$ \\
1 & 0 & 0 & 0 & 1 & 3 & $\mathrm{E}$ \\
1 & 0 & 0 & 1 & 0 & 1 & $\mathrm{E}$ \\
1 & 0 & 1 & 0 & 1 & 1 & $\mathrm{~N}$ \\
1 & 0 & 1 & 1 & $?$ & 0 & $\mathrm{E}$ \\
1 & 1 & 0 & 0 & - & 2 & $\mathrm{E}$ \\
1 & 1 & 0 & 1 & - & 2 & $\mathrm{~N}$ \\
1 & 1 & 1 & 0 & 1 & 3 & \\
1 & 1 & 1 & 1 & $?$ & 0 & \\
& & & & & $==$ & \\
& & & & & 22 & \\
\hline
\end{tabular}

8 The difference between the total number of instances in Table 6.3 and Table 6.2 is caused by the number of instances for which at least one of the variables is not determined (see question marks in Table 6.2). 
The expression for $\mathrm{D}^{\prime}$ can be reduced further by assuming the existence of several plausible combinations of conditions which are non-existent in Table 6.3, including CTUI, CtUI, cTUI and cTui:

$$
\mathrm{T}+\mathrm{Ci}+\mathrm{CI}+\mathrm{U} \ldots \mathrm{D}^{\prime \prime}
$$

To a large extent this expression identifies the preceding propositions. Only condition $\mathrm{C}$ cannot be clearly identified as a sufficient condition. Also note that variable I occurs in all three expressions obtained.

\section{Analysis of change in cohesiveness of perception}

In order to analyze change in the cohesiveness of perception, a list of variables is given in Overview 2. Note that change in the dependent variable as well as in some independent variables ( $T$ and $A$ ) may work in two directions. Thus, $\mathbf{C}$ is 1 when cohesiveness either decreases or increases. For example, the independent variable $T$ (tightness of the repertoire) is 1 only if

\section{OVERVIEW 2}

If perception becomes less cohesive ('l' in Table 6.2):

Dependent variable $\mathrm{C}=1$

Independent variables:

D $\quad 1$ = difficulty set includes new difficulties

$0=$ difficulty set does not include new difficulties

T $1=$ repertoire becomes less tight

$0=$ no change or repertoire becomes more tight

A $1=$ emphasis shifts to autonomous action

$0=$ no change or emphasis shifts to induced action

B $1=$ autonomous actions affect perception

$0=$ autonomous actions do not affect perception

If perception becomes more cohesive (' $m$ ' in Table 6.2):

Dependent variable $\mathrm{C}=1$

Independent variables:

D $\quad 1=$ difficulty set does not include new difficulties

$0=$ difficulty set includes new difficulties

T 1 = repertoire becomes more tight

$0=$ no change or repertoire becomes less tight

A $\quad 1=$ emphasis shifts to induced action

$0=$ no change or emphasis shifts to autonomous action

B $\quad 1=$ autonomous actions affect perception

$0=$ autonomous actions do not affect perception 
tightness changes in the same direction as cohesiveness.

Because the direction of change is twofold, the instances where $C$ takes the unchanged status (" $n$ " in Table 6.2) are not incorporated. This is done because the case of $\mathrm{C}=0$ can not be consistently related to the independent variables. Moreover, the relevant propositions in previous chapters pertain to the presence and not so much to the absence of change.

The propositions dealing with $\mathrm{C}$ as the dependent variable are as follows. Proposition 3.2 implies that tightening (loosening) of the repertoire tends to bring about a more (less) cohesive perception:

$$
T-->C
$$

Proposition $3.3 \mathrm{~b}$ implies that major new difficulties tend to decrease the cohesiveness of perception:

$$
D-\rightarrow>C
$$

Proposition 5.3b also addresses the forces new difficulties may have on cohesiveness, but this proposition can not be adequately formulated in terms of the above variables.

In addition, proposition 3.5b suggests autonomous action may affect perception. In all likelihood, autonomous action therefore also affects the cohesiveness of perception:

$$
B->C
$$

Combining these three expressions gives the following central proposition:

$$
T+D+B \cdots C
$$

Table 6.4 shows the truth table for conditions of change in the cohesiveness of dominant group perception. In addition to the proposed conditions, the variable A (see list of variables) is included as a potential condition.

The minimized truth table expression for $\mathrm{C}$ is:

$$
\mathrm{TB}+\mathrm{DB}+\mathrm{ta}=(\mathrm{T}+\mathrm{D}) \mathrm{B}+\mathrm{ta}-->\mathrm{C}
$$

This expression does not falsify any of the preceding propositions. Because there are no undecided combinations, simplification of this expression can only be achieved by adding plausible non-existent combinations. Plausible combinations here inwolve all non-existent combinations in Table 6.4 except $\mathrm{dtAb}$. If we add these to the minimized expression for $\mathrm{C}$, we obtain the following expression:

$$
\mathrm{D}+\mathrm{T}+\mathrm{B}+\mathrm{a} \cdots \mathrm{C}^{\prime \prime}
$$

This expression completely identifies the central proposition for $\mathrm{C}$. The " $\mathrm{a}$ '

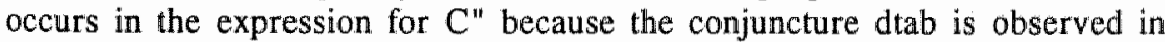
combination with a 1 term for $\mathrm{C}$ (see Table 6.4). The 1 term for the dtab conjuncture suggests there are other independent variables which have not been included here. 
Table 6.4 Truth table on conditions of change in cohesiveness of perception.

\begin{tabular}{lllllll}
\hline D & T & A & B & C & $\begin{array}{l}\text { Number of } \\
\text { instances }\end{array}$ & $\begin{array}{l}\text { Existent/ } \\
\text { Non-existent }\end{array}$ \\
0 & 0 & 0 & 0 & 1 & 1 & $\mathrm{E}$ \\
0 & 0 & 0 & 1 & 1 & 1 & $\mathrm{E}$ \\
0 & 0 & 1 & 0 & $?$ & 0 & $\mathrm{~N}$ \\
0 & 0 & 1 & 1 & $?$ & 0 & $\mathrm{~N}$ \\
0 & 1 & 0 & 0 & $?$ & 0 & $\mathrm{~N}$ \\
0 & 1 & 0 & 1 & 1 & 2 & $\mathrm{E}$ \\
0 & 1 & 1 & 0 & $?$ & 0 & $\mathrm{~N}$ \\
0 & 1 & 1 & 1 & 1 & 2 & $\mathrm{E}$ \\
1 & 0 & 0 & 0 & 1 & 1 & $\mathrm{E}$ \\
1 & 0 & 0 & 1 & 1 & 1 & $\mathrm{~N}$ \\
1 & 0 & 1 & 0 & $?$ & 0 & $\mathrm{E}$ \\
1 & 0 & 1 & 1 & 1 & 2 & $\mathrm{~N}$ \\
1 & 1 & 0 & 0 & $?$ & 0 & $\mathrm{~N}$ \\
1 & 1 & 0 & 1 & 1 & 2 & $\mathrm{E}$ \\
1 & 1 & 1 & 0 & $?$ & 0 & \\
1 & 1 & 1 & 1 & 1 & 6 & \\
& & & & & $===$ & \\
\hline
\end{tabular}

\section{Analysis of change in tightness of the repertoire}

We now turn to tightness of the repertoire as the dependent variable. The variables are defined in the list of variables (given in Overview 3). Note that change in several variables may involve two opposite directions. Thus, the instances in Table 6.2 for which tightness is unchanged $(T=n)$ are not included for reasons similar to those in the analysis of change in cohesiveness.

Several propositions in previous chapters pertain to the dependent variable $T$. First, proposition 3.1a refers to the general force of difficulties activating the repertoire. Validation of this proposition requires a more in-depth scrutiny of strategy formation cases and can not be dealt with in terms of the variables listed above. Instead, the more specific variable D (involving difficulties which are new to the dominant group) will be included in the analysis. Second, proposition 3.2 implies that the cohesiveness of perception positively 


\section{OVERVIEW 3}

If the repertoire becomes less tight (or more loose):

Dependent variable $\mathrm{T}=1$

Independent variables:

D $\quad 1=$ difficulty set includes new difficulties

$0=$ difficulty set does not include new difficulties

F $\quad 1$ = increasing misfit between difficulty set and repertoire

$0=$ no change or increasing fit between difficulty set and repertoire

C $\quad 1=$ perception becomes less cohesive

$0=$ no change or perception becomes more cohesive

A $1=$ emphasis shifts to autonomous action

$0=$ no change or emphasis shifts to induced action

If the repertoire becomes more tight:

Dependent variable $\mathrm{T}=1$

Independent variables:

D $\quad 1=$ difficulty set includes new difficulties

$0=$ difficulty set does not include new difficulties

F $\quad 1=$ increasing fit between difficulty set and repertoire

$0=$ no change or increasing misfit between difficulty set and repertoire

C 1 = perception becomes more cohesive

$0=$ no change or perception becomes more cohesive

A $1=$ emphasis shifts to induced action

$0=$ no change or emphasis shifts to induced action

affects repertoire tightness:

$C-->T$

Finally, proposition 3.5 a suggests that repertoire change is affected by, amongst other forces, difficulties which constitute misfits and bring about the loosening of the old (elements in the) repertoire. Similarly, proposition $3.5 \mathrm{~b}$ suggests difficulties which fit the new (elements in the) repertoire will lead to the tightening of this repertoire. The analytical distinction between the old and new repertoire was not incorporated in the coding system (described in section 6.4). Moreover, we may assume that old and new rules co-exist in any repertoire, with their relative significance changing over time. Together, propositions $3.5 \mathrm{a}$ and $3.5 \mathrm{~b}$ imply:

$F->>T$ 
The central proposition thus becomes:

$$
C+F \rightarrow T
$$

Table 6.5 provides the truth table for conditions of change in repertoire tightness. This truth table includes the variable $A$ (see list of variables) in addition to the three independent variables $D, C$ and $F$. Minimizing this truth table gives:

$$
\mathrm{fCa}+\mathrm{dFA}+\mathrm{Da}+\mathrm{DC} \ldots \mathrm{T}
$$

This result does not falsify the propositions on $C$ and $F$ as conditions for $T$. In addition, the independent variable $D$ occurs twice in this expression. Assuming the existence of the plausible combinations $\mathrm{dfCA}, \mathrm{dFca}, \mathrm{dFCa}$ and DFCA, we obtain the following expression:

$$
\mathrm{Da}+\mathrm{C}+\mathrm{F}-\mathrm{T}^{\prime \prime}
$$

This expression identifies the propositions on conditions $\mathrm{C}$ and $\mathrm{F}$. In addition, it confirms the importance of condition $D$ which was expected in view of proposition 3.1a. This suggests that major new difficulties tend to either loosen or tighten the repertoire.

Table 6.5 Truth table on conditions of change in tightness of the repertoire.

$\begin{array}{lllllll}\text { D } & \text { F } & \text { C } & \text { A } & \text { T } & \begin{array}{l}\text { Number of } \\ \text { instances }\end{array} & \begin{array}{l}\text { Existent/ } \\ \text { Non-existent }\end{array} \\ 0 & 0 & 0 & 0 & ? & 0 & \mathrm{~N} \\ 0 & 0 & 0 & 1 & ? & 0 & \mathrm{~N} \\ 0 & 0 & 1 & 0 & 1 & 1 & \mathrm{E} \\ 0 & 0 & 1 & 1 & ? & 0 & \mathrm{~N} \\ 0 & 1 & 0 & 0 & ? & 0 & \mathrm{~N} \\ 0 & 1 & 0 & 1 & 1 & 1 & \mathrm{E} \\ 0 & 1 & 1 & 0 & ? & 0 & \mathrm{~N} \\ 0 & 1 & 1 & 1 & 1 & 3 & \mathrm{E} \\ 1 & 0 & 0 & 0 & 1 & 2 & \mathrm{E} \\ 1 & 0 & 0 & 1 & ? & 0 & \mathrm{~N} \\ 1 & 0 & 1 & 0 & 1 & 1 & \mathrm{E} \\ 1 & 0 & 1 & 1 & 1 & 1 & \mathrm{E} \\ 1 & 1 & 0 & 0 & 1 & 1 & \mathrm{~N} \\ 1 & 1 & 0 & 1 & ? & 0 & \mathrm{E} \\ 1 & 1 & 1 & 0 & 1 & 1 & \\ 1 & 1 & 1 & 1 & 1 & 3 & \\ & & & & & == & \end{array}$




\section{Analysis of change in content of the repertoire}

The focus now shifts to the content of the repertoire as dependent variable. Analysis of the conditions of this variable starts with the set of variables listed in Overview 4.

\section{OVERVIEW 4}

Dependent variable:

$\mathrm{H} \quad 1=$ content of the repertoire changes

$0=$ no change in content of the repertoire

Independent variables:

D 1 = difficulty set includes new difficulties

$0=$ difficulty set does not include new difficulties

F $\quad 1=$ increasing fit between difficulty set and repertoire

$0=$ no change or decreasing misfit between difficulty set and repertoire

U $\quad 1=$ induced actions have unintended consequences

$0=$ induced actions have no unintended consequences

B $1=$ autonomous actions affect perception

$0=$ autonomous actions do not affect perception

o $\quad 1=$ composition of group changes

$0=$ composition of group does not change

Several propositions precede the analysis of repertoire change. First, proposition 3.5 a suggests that breakdown of the old repertoire is triggered by induced actions producing unintended consequences which are reflected as such in the difficulty set (see variable $U$ ). Note that $U$ is a compound variable which involves change in both induced actions and the difficulty set. This gives:

$$
U-->H
$$

Second, proposition $3.5 \mathrm{~b}$ holds that change toward a new repertoire is triggered by autonomous actions which affect perception (variable B) and possibly also group composition (variable $O$ ). This is expressed in:

$$
B+B O H
$$

In addition, propositions $3.5 \mathrm{a}$ and $3.5 \mathrm{~b}$ suggest repertoire change is accelerated by way of the increasing misfit between difficulties (e.g. which have arised as unintended consequences) and the old repertoire, and the increasing fit between difficulties and the new repertoire. In at least some cases, the old repertoire gradually gives way to a new one. As was pointed out earlier, the repertoire category incorporates elements of both the current (old) repertoire 
and emerging new repertoires. From propositions $3.5 \mathrm{a}$ and $3.5 \mathrm{~b}$ we therefore infer that change of repertoire content is especially stimulated by an increasing fit between difficulties and the (new) repertoire:

$$
F-\ldots \rightarrow
$$

Finally, proposition 5.2 suggests that dominant groups with moderate levels of cohesiveness of perception are most able to transform their repertoire (i.c. changing its content). This kind of proposition requires a more in-depth assessment of dominant group cohesiveness than we have been able to do in this study. Proposition 5.2 is therefore not considered in the analysis which follows. The preceding expressions can be summarized in the following central proposition:

$$
U+B+B O+F->H
$$

Table 6.6 provides the truth table for conditions of change in the content of the repertoire. In addition to the four independent variables in the central proposition (U, B, O and $F$ ) this table also includes $D$ as independent variable. Simple inspection indicates that for five combinations of conditions change in the content is undecided, five existent combinations have a 0 term and only two have a 1 term for the dependent variable. Minimization of the 1 terms in this table therefore gives the following expression:

$$
\mathrm{dFuBo}+\mathrm{DFubO}-.->\mathrm{H}
$$

Adding the five undecided combinations (see Table 6.6) gives:

$$
\text { DfUbo + DFubO + dFuB + DFBO + DUBO -.- }>\mathrm{H}^{\prime}
$$

The expression for $\mathrm{H}$ is based on a very small number of instances and can therefore not be considered as a serious test. The expression for $\mathrm{H}^{\prime \prime}$ is based on seven instances, but does mot falsify (any of the elements of) the proposition given earlier.

Adding all non-existent combinations except dfubo, dfubO and $\mathrm{DfubO}$, gives: $\mathrm{Ubo}+\mathrm{FuB}+\mathrm{fUB}+\mathrm{dF}+\mathrm{dU}+\mathrm{dB}+\mathrm{FO}+\mathrm{BO}-\mathrm{H}^{\prime \prime}$

This expression can be rewritten into:

$$
\mathrm{B}(\mathrm{Fu}+\mathrm{fU}+\mathrm{d})+\mathrm{U}(\mathrm{bo}+\mathrm{d})+\mathrm{F}(\mathrm{d}+\mathrm{O})+\mathrm{BO} \ldots \mathrm{H}^{\prime \prime}
$$

Independent variable BO is identified as a sufficient condition (as proposed). The expression for $\mathrm{H}^{\prime \prime}$ does however not identify $\mathrm{B}, \mathrm{U}$ and $\mathrm{F}$ as sufficient conditions for change in the content of the repertoire, although they appear to be of some relevance.

The relatively high number of undecided instances suggests change in the content of the repertoire is more complex than suggested in prewious chapters. This also follows from the fact that the conjuncture DFUBO is undecided. In all likelihood, there are other major conditions for $\mathrm{H}$ which have not been included in the analysis. 
Table 6.6 Truth table on conditions of change in content of the repertoire.

\begin{tabular}{|c|c|c|c|c|c|c|c|}
\hline D & $\mathbf{F}$ & $\mathrm{U}$ & B & 0 & $\mathbf{H}$ & $\begin{array}{l}\text { Number of } \\
\text { instances }\end{array}$ & $\begin{array}{l}\text { Existent/ } \\
\text { Non-existent }\end{array}$ \\
\hline 0 & 0 & 0 & 0 & 0 & $?$ & 0 & $N$ \\
\hline 0 & 0 & 0 & 1 & 0 & $?$ & 0 & $\mathbf{N}$ \\
\hline 0 & 0 & 1 & 0 & 0 & $?$ & 0 & $\mathbf{N}$ \\
\hline 0 & 0 & 1 & 1 & 0 & $?$ & 0 & $\mathbf{N}$ \\
\hline 0 & 1 & 0 & 0 & 0 & $?$ & 0 & $\mathbf{N}$ \\
\hline 0 & 1 & 0 & 1 & 0 & 1 & 1 & $\mathrm{E}$ \\
\hline 0 & 1 & 1 & 0 & 0 & $?$ & 0 & $\mathbf{N}$ \\
\hline 0 & 1 & 1 & 1 & 0 & $?$ & 0 & $\mathbf{N}$ \\
\hline 1 & 0 & 0 & 0 & 0 & 0 & 1 & $\mathrm{E}$ \\
\hline 1 & 0 & 0 & 1 & 0 & 0 & 1 & $\mathrm{E}$ \\
\hline 1 & 0 & 1 & 0 & 0 & - & 2 & $\mathrm{E}$ \\
\hline 1 & 0 & 1 & 1 & 0 & $?$ & 0 & $\mathrm{~N}$ \\
\hline 1 & 1 & 0 & 0 & 0 & 0 & 1 & $\mathrm{E}$ \\
\hline 1 & 1 & 0 & 1 & 0 & $?$ & 0 & $\mathbf{N}$ \\
\hline 1 & 1 & 1 & 0 & 0 & $?$ & 0 & $\mathbf{N}$ \\
\hline 1 & 1 & 1 & 1 & 0 & 0 & 1 & $\mathrm{E}$ \\
\hline 0 & 0 & 0 & 0 & 1 & $?$ & 0 & $\mathbf{N}$ \\
\hline 0 & 0 & 0 & 1 & 1 & $?$ & 0 & $\mathbf{N}$ \\
\hline 0 & 0 & 1 & 0 & 1 & $?$ & 0 & $\mathrm{~N}$ \\
\hline 0 & 0 & 1 & 1 & 1 & $?$ & 0 & $\mathbf{N}$ \\
\hline 0 & 1 & 0 & 0 & 1 & $?$ & 0 & $\mathbf{N}$ \\
\hline 0 & 1 & 0 & $\mathbb{1}$ & 1 & - & 3 & $\mathbf{E}$ \\
\hline 0 & 1 & 1 & 0 & 1 & $?$ & 0 & $\mathbf{N}$ \\
\hline 0 & 1 & 1 & 1 & 1 & $?$ & 0 & $\mathbf{N}$ \\
\hline 1 & 0 & 0 & 0 & 1 & $?$ & 0 & $\mathbf{N}$ \\
\hline 1 & 0 & 0 & 1 & 1 & - & 3 & $\mathbb{E}$ \\
\hline 1 & 0 & 1 & 0 & 1 & 0 & 1 & $\mathrm{E}$ \\
\hline 1 & 0 & 1 & 1 & 1 & - & 4 & $E$ \\
\hline 1 & 1 & 0 & 0 & 1 & 1 & 1 & $\mathrm{E}$ \\
\hline 1 & 1 & 0 & 1 & 1 & $?$ & 0 & $\mathrm{~N}$ \\
\hline 1 & 1 & 1 & 0 & 1 & $?$ & 0 & $\mathrm{~N}$ \\
\hline 1 & 1 & 1 & 1 & 1 & - & 2 & $\mathrm{E}$ \\
\hline & & & & & & $\frac{=}{21}==$ & \\
\hline
\end{tabular}




\section{Analysis of change of emphasis in actions}

Finally, we turn to action as the independent variable. The set of variables is listed in Overview 5. Note that the change direction of the dependent as well as several independent variables is again twofold.

\section{OVERVIEW 5}

If the emphasis shifts to autonomous action:

Dependent variable $\mathrm{A}=1$

Independent variables:

D $1=$ difficulty set includes new difficulties

$0=$ difficulty set does not include new difficulties

C $\quad 1$ = perception becomes less cohesive

$0=$ no change or perception becomes more cohesive

T $\quad 1=$ repertoire becomes less tight

$0=$ no change or repertoire becomes more tight

F $\quad 1=$ increasing misfit between difficulty set and repertoire

$0=$ no change or increasing fit between difficulty set and repertoire

If the emphasis shifts to induced action:

Dependent variable $\mathrm{A}=1$

Independent variables:

D $1=$ difficulty set includes new difficulties

$0=$ difficulty set does not include new difficulties

C $\quad 1$ = perception becomes more cohesive

$0=$ no change or perception becomes less cohesive

T $1=$ repertoire becomes more tight

$0=$ no change or repertoire becomes less tight

F $\quad 1=$ increasing fit between difficulty set and repertoire

$0=$ no change or increasing misfit between difficulty set and repertoire

The following propositions are relevant here. Proposition 3.4 suggests a tighter repertoire tends to focus on induced actions and tends to impede autonomous actions:

$T-\ldots>A$

Finally, proposition 5.4 suggests that an increasing fit between ideas and repertoire tends to trigger induced actions, whereas an increasing misfit tends 
Table 6.7 Truth table on conditions of change in action.

\begin{tabular}{lllllll}
\hline D & C & T & F & A & $\begin{array}{l}\text { Number of } \\
\text { instances }\end{array}$ & $\begin{array}{l}\text { Existent } \\
\text { Non-existent }\end{array}$ \\
0 & 0 & 0 & 0 & $?$ & 0 & $\mathrm{~N}$ \\
0 & 0 & 0 & 1 & 1 & 1 & $\mathrm{E}$ \\
0 & 0 & 1 & 0 & $?$ & 0 & $\mathrm{~N}$ \\
0 & 0 & 1 & 1 & 1 & 1 & $\mathrm{E}$ \\
0 & 1 & 0 & 0 & $?$ & 0 & $\mathrm{~N}$ \\
0 & 1 & 0 & 1 & $?$ & 0 & $\mathrm{~N}$ \\
0 & 1 & 1 & 0 & $?$ & 0 & $\mathrm{~N}$ \\
0 & 1 & 1 & 1 & 1 & 3 & $\mathrm{E}$ \\
1 & 0 & 0 & 0 & $?$ & 0 & $\mathrm{E}$ \\
1 & 0 & 0 & 1 & 1 & 2 & $\mathrm{~N}$ \\
1 & 0 & 1 & 0 & $?$ & 0 & $\mathrm{E}$ \\
1 & 0 & 1 & 1 & $?$ & 0 & $\mathrm{E}$ \\
1 & 1 & 0 & 0 & 1 & 1 & $\mathrm{E}$ \\
1 & 1 & 0 & 1 & 1 & 1 & \\
1 & 1 & 1 & 0 & 1 & 2 & \\
1 & 1 & 1 & 1 & 1 & 3 & \\
& & & & & $==$ & \\
\end{tabular}

to evoke autonomous actions. If we generalize these forces to the difficulty set category (by substituting 'difficulties' for 'ideas'), the following proposition results:

$$
F \rightarrow A
$$

The central proposition therefore is:

$$
T+F \cdots A
$$

In the truth table, we include the independent variables $C$ and $D$, which were implicitly assumed in previous chapters not to have a direct influence on actions, but do appear to matter in view of their relation with $\mathrm{T}$ and $\mathrm{F}$ respectively (see preceding analyses). Table 6.7 shows the truth table for conditions of change in action. The minimized truth table expression includes three conjunctures of conditions:

$$
\mathrm{ctF}+\mathrm{dTF}+\mathrm{CD}-->\mathrm{A}
$$

This expression includes 1 terms for the $T$ and $F$ conditions. As such, this result does not falsify any of the preceding propositions.

If we assume the plausible combinations dcTf, $\mathrm{dCtF}$, dCTf, DcTf and DcTF 
to exist, the expression for $\mathrm{A}$ is reduced to:

$$
\mathrm{CD}+\mathrm{T}+\mathrm{F} \ldots \mathrm{A}^{*}
$$

Thus, $\mathrm{T}$ and $\mathrm{F}$ are identified as sufficient conditions.

In addition, both expressions (for $A$ and $A^{\prime \prime}$ ) include the conjuncture $C D$. Within the conceptual framework of this study, the existence of the CD conjuncture may arise from the simultaneous nature of most forces in our model. The $C D$ conjuncture also calls for an exploration of the potential forces working between group cohesiveness and difficulties (C and D) and the nature of actions (A). Such an exploration, however, is outside the context of this chapter.

\subsection{Discussion of the results}

The comparative analysis in this chapter was conducted in order to test the propositions generated in previous chapters. In general, the results of this analysis give support for the propositions. Figure 6.2 provides an overview of the results of the analysis, arranged according to the propositions given in chapters three and five. For each proposition this figure summarizes the results (if any) in terms of

a. whether it stood the falsification tests based on the existing instances not producing a zero term for the dependent variable, and

b. whether the proposed condition(s) were identified as such.

Figure 6.2 includes sixteen different propositions, of which five have not been tested as such. Note that some propositions (e.g. propositions 3.2, 3.5a and 3.5b) implied more than one Boolean expression. In addition, several propositions imply identical expressions (e.g. propositions 3.1b and 5.1b). Also note that some of the propositions tested (e.g. proposition 5.4) have been operationalized imperfectly.

From a total of thirteen different Boolean expressions in Figure 6.2, none have been falsified. Ten expressions have been identified but three expressions have not been identified as proposed. The latter three expressions all pertain to propositions $3.5 \mathrm{a}$ and $3.5 \mathrm{~b}$, which intend to describe how repertoire change occurs. Although the forces described in chapters three and five do seem to matter, change in the content of repertoires appears to be far more complex.

Several propositions have not been incorporated in this test. Proposition 3.1a ('difficulties activate the repertoire') was not tested because its qualitative nature could not be captured in Boolean (binary) logic. Instead we included variable $D$ in the analyis of conditions of repertoire tightness $T$. The results of this analysis suggest new difficulties tend to either loosen or tighten the repertoire. Proposition 3.1a may therefore be extended by including this force. Other propositions (e.g. 5.2 and 5.3b) have not been tested because 
Figure 6.2 Overview of the results of the comparative analysis."

\begin{tabular}{|c|c|c|c|}
\hline $\begin{array}{l}\text { PROPOSITIONS IN } \\
\text { CHAPTER } 3\end{array}$ & RESULTS & $\begin{array}{l}\text { PROPOSITIONS IN } \\
\text { CHAPTER } 5\end{array}$ & RESULTS \\
\hline 3.1a: & not tested & 5.1a: & $\begin{array}{l}\text { not explicitly tested; } \\
\text { is related to } 3.5 \mathrm{~b}: \\
\mathrm{F} \rightarrow>\mathrm{T}\end{array}$ \\
\hline $\begin{array}{l}\text { 3. Ib: } \\
\mathrm{T} \rightarrow \mathrm{D}\end{array}$ & $\begin{array}{l}\text { not falsified; } T \\
\text { identified }\end{array}$ & $\begin{array}{l}5.1 \mathrm{~b}: \\
\mathrm{T} \rightarrow \mathrm{D}\end{array}$ & see $3.1 b$ \\
\hline $\begin{array}{l}3.2: \\
\mathrm{C} \ldots>\mathrm{T} \\
\mathrm{T} \ldots>\mathrm{C}\end{array}$ & $\begin{array}{l}\text { not falsified; suffi- } \\
\text { cient conditions } \\
\text { identified in both } \\
\text { directions. }\end{array}$ & $5.2:$ & not tested \\
\hline $\begin{array}{l}3.3 \mathrm{a}: \\
\mathrm{C}-\mathrm{-}>\mathrm{D}\end{array}$ & $\begin{array}{l}\text { not falsified; } \\
C \text { identified }\end{array}$ & $\begin{array}{l}\text { 5.3a: } \\
\text { C -..> D }\end{array}$ & $\operatorname{see} 3.3 \mathrm{a}$ \\
\hline $\begin{array}{l}3.3 \mathrm{~b}: \\
\mathrm{D}-->\mathrm{C}\end{array}$ & $\begin{array}{l}\text { not falsified; D } \\
\text { identified }\end{array}$ & $5.3 \mathrm{~b}:$ & not tested \\
\hline $\begin{array}{l}\text { 3.4: } \\
\mathrm{T} \rightarrow>\mathrm{A}\end{array}$ & $\begin{array}{l}\text { not falsified; } \\
\text { T identified }\end{array}$ & $\begin{array}{l}5.4: \\
\mathrm{F}-\mathrm{A}>\mathrm{A}\end{array}$ & $\begin{array}{l}\text { not falsified; } F \\
\text { identified }\end{array}$ \\
\hline $\begin{array}{l}3.5 a: \\
U \ldots>\mathrm{D} \\
\mathrm{F} \ldots>\mathrm{T} \\
\mathrm{U} \cdots>\mathrm{H} \\
\mathrm{F} \ldots>\mathrm{H}\end{array}$ & $\begin{array}{l}\text { mone of the expressi- } \\
\text { ons is falsified; } U \\
\text { identified (for } D \text { ); } F \\
\text { identified (for } T \text { ); } U \\
\text { and } F \text { are not identi- } \\
\text { fied (for } H \text { ) }\end{array}$ & 5.5a: & $\begin{array}{l}\text { not explicitly tested; } \\
\text { is related to } 3.5 \mathrm{a}\end{array}$ \\
\hline $\begin{array}{l}3.5 \mathrm{~b}: \\
\mathrm{B} \ldots \mathrm{C} \\
\mathrm{F} \ldots \mathrm{T} \\
(\text { see } 3.5 \mathrm{a}) \\
\mathrm{B}+\mathrm{BO} \ldots \mathrm{H} \\
\mathrm{F}-\ldots \mathrm{H} \\
(\text { see } 3.5 \mathrm{a})\end{array}$ & $\begin{array}{l}\text { none of the indepen- } \\
\text { dent variables is } \\
\text { falsified; B is identi- } \\
\text { fied (for C); } \mathrm{BO} \text { is } \\
\text { identified but } \mathrm{B} \text { is } \\
\text { not identified (for } \\
\mathrm{H} \text { ) }\end{array}$ & $5.5 \mathrm{~b}:$ & $\begin{array}{l}\text { not explicitly tested; } \\
\text { is related to } 3.5 \mathrm{~b}\end{array}$ \\
\hline
\end{tabular}

" Note that some variables are denoted with the same letter but are defined somewhat differently. See for precise definitions the lists of variables in section 6.6. 
this would have required work which is beyond the reach of the coding system and procedure adopted in this study.

Note that the propositions in previous chapters implicitly assumed all other things are equal. However, several Boolean expressions, especially those for repertoire change, point at some kind of confluence of forces. That is, forces may reinforce or neutralize each other (see chapter three). For instance, repertoire change may only occur when certain forces reinforce each other. This kind of interaction between forces can not be dealt with in terms of the analysis in this chapter.

To some extent, this problem follows from the nature of the strategy system itself. In chapter one, the complexity of strategy systems was characterized in terms of the so-called 'sensitive dependence on initial conditions'. The implication of this sensitive dependence is that the behavior of strategy systems may depend on very small variations in initial conditions. Incidental small variations in managerial repertoires, actions and so forth, may develop into large variations. Small variations tend to go unnoticed in any study of strategy formation. We may have captured some of the larger variations in this study, but at least some of the underlying conditions have gone unnoticed.

\subsection{Evaluation of the comparative method}

This section will provide some comments on the strengths and weaknesses of the comparative method adopted in this chapter.

In general, the comparative approach adopted here suffers from limitations in the coding system and coding procedure. One of these limitations may arise from substantial overlap between the categories in the coding system (e.g. perception and difficulty set). Other imperfections arise as the result of other steps in the coding procedure, for example, the selection of periods. If these periods are too large, Boolean analysis can not distinguish between closely associated but distinct forces, especially when these forces tend to coincide in time. Under such circumstances, one cannot clearly distinguish between closely associated forces, for instance between $\mathrm{X}>\mathrm{Y}, \mathrm{Y}-\mathrm{Z}$ and $\mathrm{X}-$ $>\mathrm{Z}$.

Another limitation of the coding procedure follows from the fact that all cases have been digested second-hand. Although we have used a double coding procedure (with two or three coders in all stages of the coding work), this second-hand use may have biased the coding results. To some extent this limitation is alleviated by gains such as the geographic diversity in the set of cases and efficiency in time and research effort. 
In addition, we may not have traced all actually existing instances (in terms of Boolean logic). Although this limitation constrains the conclusions derived from the analysis, it is less serious from the replication logic than from the conventional sample logic. Moreover, the use of simplifying assumptions may offer a bridge between our limited set of cases and the larger universe of real-world cases. Note that simplifying assumptions enter the analysis only after maximum causal complexity has been allowed for. Thus, conchusions about the validity of a given proposition can be based on the results before as well as after introducing simplifying assumptions.

The analysis in this chapter takes a certain set of concepts as given. Basically, these concepts together constitute the image of self-organizing dominant groups. Questions and observations falling outside this image tend to be neglected because this image suppresses some characteristics of strategy formation and emphasizes others. The image of the self-organizing dominant group, for example, tends to underestimate the importance of illegitimate actions (e.g. skunk-works) taking place in many organizations. We have only considered such forces if they are relevant from the perspective of the dominant group. The analysis therefore concerns the validity of the propositions given the conceptual framework developed in previous chapters.

The previous section pointed out that a serious limitation of Boolean analysis is its inability to deal in a systematic manner with confluence of forces. This is a limitation which the Boolean method shares with most coarse-grained methods (note that all data are binary). In this respect, the in-depth casestudy appears to be indispensable.

On a more general level, the study reported in this chapter shows that the Boolean comparative method unites certain elements of the fine-grained and coarse-grained traditions in strategy research. The case-study remains a useful, indispensable (fine-grained) method by itself. The added value of Boolean analysis is that it may compensate for some of the weaknesses of the case-study method (e.g. generalizability).

The coarse-grained, variable-oriented approach also offers important means to study the empirics of strategy formation. Its power especially lies in answering questions of general co-variations and trends in large populations of organizations, within a given, clearly defined conceptual framework. The usefulness of coarse-grained methods in understanding the complexity of strategy formation is thus, at least for the moment, limited. In this respect, the Boolean method enhances coarse-grained methods by providing a way to address large numbers of cases without forsaking complexity too much.

In sum, the Boolean method substantially enriches the toolbox for strategy research. It compensates for some of the weaknesses of the case-study and provides a way to systematically address large numbers of cases without 
forsaking complexity. However, the study in this chapter shows that the Boolean method cannot adequately deal with confluence of forces. In addition, the results of Boolean analysis may suffer from limitations in the data. 


\section{Appendix A Short overview of Boolean logic}

Several elements of Boolean logic are essential to its use in this chapter. The following presentation of these elements is based on Ragin (1987), Roth (1975) and McDermoti (1985).

Use of binary form. There are two conditions or states in Boolean logic: these are generally referred to as true (or present) and false (or absent). These two states are represented in terms of 1 and 0 respectively. We will also adiopt the convention of uppercase letters indicating the presence of a condition ( $A$ if $A=1$ ) and lowercase letters indicating its absence ( $\mathrm{a}$ if $\mathrm{A}=0$ ).

Use of truth tables to represent data. In order to use Boolean logic as a technique of comparison, it is necessary to reconstruct a raw data matrix as a truth table. The idea behind a truth table is straightforward. Once the data or observations have been recoded into binary form, one sorts these data into the different combinations of values on the variables. Each logical combination of values on the variables is represented as one row of the truth table. Thus, a number of historical combinations of conditions (as binary variables) are obtained. The number of instances of each combination of conditions does not enter into any of the following computations. In other words, frequency criteria are not explicitly incorporated in subsequent analytical exercises.

Boolean addition. Boolean addition (or logical $O R$ ) is based on the idea that if any of the additive terms is present, then the outcome is present. For instance: if $\mathrm{A}+\mathrm{B}=\mathrm{C}$ and $\mathrm{A}$ $=1$ and $\mathrm{B}=0$, then $\mathrm{C}=1$.

Boolean multiplication. A Boolean product (or logical AND) is a specific combination of conditions. For instance, Abc means that the present $A$ is combined with the absent $b$ and the absent $c$. Boolean multiplication, like Boolean addition, is not arithmetic. Boolean multiplication requires that all conditions are present. Boolean addition and multiplication can be conveniently summarized in the following tables:

Addition
\begin{tabular}{l|ll}
+ & 0 & 1 \\
\hline 0 & 0 & 1 \\
1 & 1 & 1
\end{tabular}

Multiplication

\begin{tabular}{c|cc}
$\mathrm{x}$ & 0 & 1 \\
\hline 0 & 0 & 0 \\
1 & 0 & 1
\end{tabular}

Combinatorial logic. Boolean logic gives the same status to the absence as the presence of a condition. Moreover, combinations of conditions are not viewed in isolation but always within the context of the presencelabsence of other causally relevant conditions. E.g. a truth table can be represented as

$\mathrm{Abc}+\mathrm{ABC}+\mathrm{aBC}$

indicating three combinations of conditions available in the data. Such a statement includes the total set of actual or existent combinations of conditions. In order to obtain an overview of the nonactual or nonexistent combinations, De Morgan's laws can be used.

Use of De Morgan's Laws. De Morgan's Laws involve a short-cut to determine the logical complement of a Bioolean expression. These laws (or theorems) are: 
complement $(X+Y)=x y$, and

complement $(X+1)=x+y$.

In fact, one recodes elements that are present as if they are absent (and vice versa), recodes logical AND to logical OR, and recodes logical OR to logical AND. We will use these laws primarily to compute the non-existing combinations of conditions. Suppose a minimized truth table is

$\mathrm{AB}+\mathrm{CD}$

According to De Morgan's laws, the logical complement which accounts for the combinations that do not exist in the truth table, is $b d+b e+a d+a c$.

Boollean minimization. There are simple and straightorward rules for simplifying the complexity of Boolean statements. The most fundamental of these rules is: if two Boolean expressions differ in only one condition yet produce the same outcome (i.c. are part of the same historical combination of conditions), then the condition that distinguishes the two expressions can be considered irrelevant and can be removed. In other words, minimization involves the repeated application of the theorem

$$
X Y+X Y=X
$$

Thus, the expression

$$
\mathrm{Abc}+\mathrm{ABC}+\mathrm{aBC}
$$

can be simplified into

$$
\mathrm{Abc}+\mathrm{BC} \text {. }
$$

For more complex expressions, a stepwise reduction is possible by repeatedly applying the above theorem. The combinations in the resulting expression are called prime implicants.

Implication and the use of 'prime implicants'. Another Boolean concept is that of implication. A Boolean expression is said to imply another if the membership of the second term is a subset of the membership of the first. For example, A implies $A b c$ because A embraces all the members of Abc. The goal of this second minimization rule is to 'cover' as many of the primitive expressions as possible with a logically minimal number of prime implicants. This step in Boolean minimization is used only when maximum logical parsimony is needed. Together, Boolean minimization and implication constitute the so-called Quine-McCluskey procedure.

Necessary and sufficient conditions. A condition is necessary if it must be present for a certain phenomenon to occur. A condition is sufficient if by itself it can produce a certain phenomenon.

Consider:
$\mathrm{AC}+\mathrm{BC}: \quad \mathrm{A}$ and $\mathrm{B}$ are not necessary and not sufficient, and
$C$ is necessary but not sufficient
A + Bc: $\quad$ A is sufficient but not necessary
B: $\quad B$ is both necessary and sufficient

Factoring Boolean expressions. Boolean factoring does not differ much from ordinary factoring. For example:

$$
A B+A C=A(B+C) \text {. }
$$

In addition to this 'distributive law', there is a second distributive law which is valid in Boolean logic only:

$$
(A+B)(A+C)=A+B C \text {. }
$$

Factoring is useful to show which conditions are necessary or sufficient, or causally equivalent ( $B$ and $C$ in the last example). 


\section{Appendix B Double-coding procedure}

The following double-coding procedure is adopted. The coding of each case falls into two distinct stages. After the frrst stage initial disagreements between the two coders are resolved and, if necessary, definitions are sharpened. This way, disagreements in the second stage cannot arise from different results in the first stage. The reliability of the results from both coding stages can be evaluated in terms of intercoder reliability.

A first draft of the following instructions underwent a number of revisions in the course of the coding work. In particular, several definitions became more precise. In case of major revisions the consistency of previously coded work with the new instructions was checked and any inconsistencies were corrected.

\section{Instructions for stage one}

1. The two coders start by defining where the case is assumed to begin.

2. Specify the members of the dominan group at the beginning of the case. The dominant group includes those who impart a particular character and direction to the organization, e.g. in terms of competitive strategy, organizational structure, shared values and reward systems. Distinguish between the core and the periphery of the dominant group. The core concerns those persons who can take care of their involvement in a typical strategy process by themselves, e.g. based on their authority or status. In the periphery are those persons which can impose certain sanctions on the core of the group (e.g. withholding information, loans or support). In most cases "the core of the dominant group can be specified in rather general terms, e.g. the 'Board of Directors', 'the management team and Board members $A$ and $B$ ' or 'single shareholder $X$ and Chief Executive $Y$ '. The periphery of the group tends to be more intractable and changeable than the core. In the remainder of these instructions, "dominant group" refers to its core, unless otherwise indicated.

3. Divide the total period covered in the case into a number of key periods. Follow the key periods identified by the author(s) of the case, unless there are obvious reasons to do otherwise. If the author(s) do not prowide any key periods, look for obvious turning points which may serve in delimiting periods.

4. Categorize all major events and observations in the case into one (or more) of the following categories. All these categories pertain to some perceptual or behavioral dimension of the dominant group. Note that it is possible to classify a single observation in more than one category, for instance, its perceptual dimension as a 'difficulty' and its behavioral dimension as an 'induced action".

\section{Difficulty sett}

The set of major problems which confront the dominant group. Include those problems which (are perceived to) provide a fundamental challenge or threat to the dominant group. In doing so, adopt the following guideline: a problem or issue is part of $\mathrm{D}$ if it is perceived, 'sensed' by at least one member of the dominant group.

\section{Perception/formation}

Perception refers to dominant group perception, that is, to the cognitive frame- 
works of its membership. These cognitive frameworks may involve the interpretatons of current difficulties or any other major understanding of the organization or industry the dominant group is embedded in. Significant changes in the composition of the dominant group (cf. group formation) should also be classified in this category.

\section{Repertoilre}

The set of rules prevailing in the dominant group at a certain moment in time (cf. "rule of thumb", 'managerial recipe"). Essentially, a rule provides a sense of direction for action, by giving the dominant group and its periphery a shared mission or by pointing at accepted practice (the way we do things around here"). Rules may leave room for a wide range of more specific intentions, but provide enough structure to guide actions. Note that the repertoire of rules can be expressed in either verbal form or in nonverbal symbols.

\section{Induced action}

Action of members of the core or periphery of the group being deliberately initiated by the core. Included in this category should be any major action (including decisions) and its direct effects in a setting of major duration (months, years) with significant and deliberate influence by the dominant group.

\section{Autonomous action}

Action of members of the core or periphery of the dominant group which appears as given to the core (as a whole). Include any major action (including decisions) and its direct effects in a setting of major duration without deliberate influence of the dominant group. Note that certain actions by individual members of the group may be autonomous rather than induced, e.g. top managers leaving the group on their own rather than the group's initiative. Autonomous action in the periphery may involve action by consultants, middle management, shareholders, corporate raiders, etc. Note that one enters the periphery by acquiring substantial power to impose sanctions on the core of the group (see step 2).

\section{Environment}

This is the context of the dominant group. That is, all events, developments, actions, expectations and so forth, which are outside the dominant group's direct influence sphere. Examples include (expected) world trade and industrial developments, customer action, governmental intervention, monetary development.

Before proceeding with the next step, discuss the results obtained thusfar with the other coder. Resolve the initial disagreements by requiring each coder to carefully justify his/her assessment. Leave out any events or observations on which the two coders continue to disagree. The result of stage one is a kind of case-summary in the six categories for each period in the case. In these summaries phrases like 'initially' or "later' refer to developments within the period (see appendix B).

\section{Instructions for stage two}

5. This step involves coding the overall character of change of one of the categories or the forces between those categories. The Environment category could in most cases not be adequately documented in stage one and is therefore not coded in the second stage. 
Assign one code to the categories for each period. Note that the assessment is relative to the (end of the) previous period, or, if it concerns the first period, to the beginning of the period.

Use 'no change' if no substantial change can be observed, or if no clear overall tendency can be discerned. If insufficient observations are available, indicate this with a "?". If change of the category can be determined by making a plausible assumption, do so. Specific guidelines for each variable are as follows.

change in Difficulty set

Change of $\mathrm{D}$ is coded in terms of the difficulty set (not) broadening to include substantial new difficulties (e.g. opportunities, threats). Thus, coce either new difficulities, no new difficulties, or

$?$.

change in Perception/formation

Change of $\mathbf{P}$ is coded in two dimensions. First, in terms of dominant group cognitions becoming more/less cohesive. Note that a cohesive set of cognitions is apparent from the extent to which individual cognitions in the group differ or lack coherence. (Remember that we are especially referring to the core of the group.) Thus, code either more cohesive, less cohesive, no change, or ?

Second, in terms of transformation of the group, that is, change in its composition (including group formation). Thus, code either

substantial change, no change, or ?.

change of Repertoire

Change of $\mathbf{R}$ is coded in two dimensions. First, in terms of the repertoire becoming more/less tight. A tight repertoire highly limits the behavior of members of the dominant group. The tightness of repertoires can be inferred from the degree of responsiveness between rules and (expected) actions. Tight repertoires tend to develop into ingrained ones (especially when time passes), which shows up in rules being taken for granted (cf. an automatic behavior program). A more ingrained repertoire can be coded as if it is more tight. Thus, code either

more tight,

less tight,

no change, or

?.

Second, in terms of change in the content of $R$, that is, the rules. Change in content occurs when fundamental new rules enter the repertoire. (Note that this is also the case when a whole new repertoire forms). Code either

substantial change,

no change, or

?. 
change of fit $D / R$

Also code the change in fit between $D$ and $R$. In other words, determine whether the difficulties can be more/less easily dealt with by the current repertoire. Code either increasing fit, increasing misfit, no change, or

$?$.

change of emphasis $I / A$

Code the change in emphasis on induced or autonomous actions (that is, their relative significance). Code whether the emphasis

shifts toward I, shifts toward $A$, does not change, or

?.

change of $I / D$ (in terms of unintended consequences)

Code whether I produces major unintended consequences which are reflected in the difficulty set of the same period. An unintended consequence is a particular effect of induced action which is different from what was wanted at the moment of carrying out the act. Code either unintended consequences, no unintended consequences, or ?.

\section{change of $A / P$ (does $A$ affect $P$ ?)}

Code whether $\mathrm{A}$ includes actions by members of the dominant group core which affect the perception or composition of the dominant group core. Thus, code either affects perception or composition of dominant group, does not affect perception or composition, or ?.

Discuss the results obtained with the other coder, and discuss and resolve any disagreements by requiring each coder to carefully justify his/her assessment. Code disagreements which cannot be resolved this way with a question mark. 


\section{Appendix C Summaries of the cases}

The following summaries are the result of the double-coding procedure described in Appendix B. Text in standard letter type is the outcome of stage one and text in tialic refers to stage two in the coding work.

\section{Air Canada}

Source: Mintzberg, Brunet and Waters (1986).

\section{Introduction}

Since its inception in 1937 Air Canada (AC) has been a state-owned 'crown corporation" in Canada. The case traces AC's strategies from its founding in 1937 until 1976.

In 1937 the Canadian government founds $\mathrm{AC}$ as a mail carrier. A few years later wonld war II efforts of the Canadian government require major contributions by $\mathrm{AC}$. In the early 1950s domestic demand for passenger services develop. In the late 1950s and the 1960 s the major industry trends also affect $\mathrm{AC}$. These trends include the increasing dominance of large, world-class, capital intensive airlines and their diversification into tourist services.

\section{Periods}

In coding this case we closely followed the periods identified by Mintzberg, Brunet and Waters (1986).

\section{Dominant group (in 1937)}

Senior management of Air Canada (AC) and the federal government minister responsible for AC. Key persons are the Chief Executive Officer, minister Howe, and several senior managers. Howe later gradually moves from the core of the dominant group to its periphery. The periphery includes unit managers, staff associates, McKinsey consultants, and others.

\section{7 (foundation year) - 1946}

\section{DIFFICULTY SET}

How to learn about aircraft maintenance, new ports of call, etc.; how to deal with Canada"s weather and geography; how to develop good governement relations and how to be responsive to governmental and other forces. Inchudes a whole set of new difficulies as the result of $A C$ 's foundation.

\section{PERCEPTION/FORMATION}

A truncated management team within $\mathrm{AC}$ arises, lacking a full-fledged management structure and a full-time chief executive; increasingly, $A C$ is externally controlled and dominated by minister Howe in the federal cabinet; perception of $A C$ 's business as passenger aircraft develops. Change of perception: ? Composition changes (i.c. formation of a new dominant group).

\section{REPERTOIRE}

Initially, try to get on our feet through the addition of new destinations/routes within Canada; provide these services on a reliable and efficient basis; reactive focus on Howe's consent ("what Howe said, went") as the driving force behind $\mathrm{AC}$; overall, a rather loose, disjointed repertoire with a reactive stance toward a dominant leader. Tighmess: ? 
Comtent (of repentoire) is formed.

\section{INDUCED ACTION}

Flying small aircrafts within Canada; initially carrying especially mail, later also more passengers; war diverts attention from civil transport to war service; mail revenues gradually give way to passenger revenues; maintenance and overhaul work for the Royal Canadian Air Force; AC volunteers to run the Canadian Air Service during the war in the hope of developing overseas expertise.

\section{AUTONOMOUS ACTION}

The Canadian government founds air mail carrier $\mathrm{AC}$; the government requires major contributions of $\mathrm{AC}$ to world war $\mathrm{II}$; the government purchases a number of $\mathrm{DC}-4$ aircraft, modifying them to 'Northstars', and has 23 of them delivered to $\mathrm{AC}$, which has only ordered 12 (thus increasing its seating capacity by $61 \%$ in two years).

D/R: ?

HA: ?

I/D: no unintended consequences.

A/P: A affects $P$ (formation of Air Canada by Canadian government).

$1946-1955$

DIFFICULTY SET

Taking hold of our company; commercialization of passenger aircraft; shaping organizational structures accordingly; how to grow autonomy from government. Includes substantial new difficulties (e.g. autonomy from government).

\section{PERCEPTION/FORMATION}

McGregor becomes first full-time chief executive of AC; the attainment of some autonomy from the government is accelerated by taking over own corporate functions (previously performed at governmental level). Perception becomes less cohesive Ress imposition of cognitive framework by governmental leadership). Composition changes (arrival of McGregor).

\section{REPERTOIRE}

Our dominant trsk is the comprehensive provision of regular passenger services to Canadians. Tightness: less. Content: no change.

\section{INDUCED ACTION}

Emphasis definitely shifts toward regular passenger transport, in response to developing domestic demand; second surge of expansion in Canadian destinations; moving into the US and later also Europe and the Carribean (the latter in order to make use of the unexpected Northstars); available seats increase dramatically (because of arrival of early 'workhorse' planes), as does total route miles; establishment of operational planning systems, and later, the elaboration and formalization of these systems; steady gain of autonomy from government.

\section{AUTONOMOUS ACTION}

Howe becomes less a controller, more a protector ("keep your hands out of the taxpayer's 
pocket, and I'll keep the politicians off your back").

$D / R:$ ?

I/A: emphasis shifts toward I.

I/D: no unintended consequences.

A/P: A affects $P$ (Howe moves to periphery of group and thus his perceptions become less dominant).

$1955-1975$

\section{DIFFICULTY SET}

How to sustain our operations as airline, facing strong demand for passenger services and limited competition from other Canadian carriers; how to gain further autonomy from government. Does not include new difficulties.

\section{PERCEPTION/FORMATION}

Conflicts arise within the relationship with government, causing temporary setbacks to the increased autonomy of $\mathrm{AC}$; cargo, charter, tourist services receive scant attention; an outsider, Pratte, arrives as CEO against the wishes of some senior managers; Pratte conceives of a diversification strategy for $\mathrm{AC}$; much time and attention is given to operational issues. Perception becomes less cohesive. Composition changes (arrival of Pratte).

\section{REPERTOIRE}

Similar repertoire as in previous decade, but with increased focus on programming of operations, by responding and following industry trends. Tightness: more fwith increased planning focus). Content: no change.

\section{INDUCED ACTION}

No new Canadian destinations are added; rounding out service to existing destinations; new destinations outside Canada increase in cyclical fashion; new (types of) airplanes are acquired in a carefully sequenced mode; larger airplanes cause AC to deliver better service, attract more passengers, etc.; operational planning systems are further developed; also, a more analytical mode of operating at the executive levels; diversification attempts initiated by Pratte decline significantly after one of his associates leaves AC; reorganization attempts by Pratte, and supported by McKinsey consultants; these reorganizations shake up the management structure but does not lead to major change in strategy; in general, actions involve creation of new ways to serve existing markets.

\section{AUTONOMOUS ACTION}

Howe appoints Pratte as new CEO.

D/R: increasing fit.

I/A. emphasis shifts toward $I$.

IID: no unintended consequences.

A/P: A affects $P$ (appointment of Pratte by Howe affects dominant group perception). 


\section{Arcop}

Source: Mintzberg et al. (1986).

\section{Introduction}

Arcop ("Architects in Co-partnership") evolved from a working relationship of three architects in a basement in Montreal, and became a renowned designer of major builidings in Canada.

\section{Dominant group}

Four partners who start architectural co-partnership in 1953, gradually joined by other partners and associates. At the periphery are a variety of other actors. (Number of Arcop's employees alternates between 5 at the start and 140 after a decade.)

\section{Periods}

We closely follow the presentation by Mintzberg et al. (1986) into four periods.

\section{3 - 1958 'Getting started'}

\section{DIFIFICULTY SET}

Challenge of competing and providing excellent designs; later, also how to manage all stages of a certain project (procurement of sites, design, construction, etc.); clients prefer dealing with a single primary contact amongst all partners working on a project. These are all new difficulties.

\section{PERCEPTION/FORMATION}

Small group of architects who initially merely poole their resources, come to make sense of collaborative efforts. Perception becomes nore cohesive. Composition changes (group formation).

\section{REPERTOIRE}

Be innovative and excellent in architecture; the initial emphasis on independency develops into a co-partnership emphasizing equality and collaboration; let each job be taken charge of by one partner. Tightness: more (with increasingly collaborative efforts). Content: changes (formation of a new set of rules).

\section{INDUCED ACTION}

Initially, each architect obtains and conducts own work; later they begin to enter major collaborative projects, encouraged and accelerated by successful participation in architectural competition; formal charge of each project is taken by one partner (which one is worked out informally).

\section{AUTONOMOUS ACTION}

Four young architects start architectural partnership in 1953; major U.S. company, I.M. Pei and Associates, approaches Arcop with affiliation proposal; Pei hires Arcop to manage a major project.

\section{ENVIRONMENT}

Arcop's joint entry in a competition is awarded first prize.

D/R: increasing fit. 
I/A: emphasis shifts toward I.

TD: unintended consequences (collective projects need to be "managed").

A/P: A does not affect $P$.

1958 - 1967 'Growth and coping with growth'

\section{DIFFICULTY SET}

How to sustain the initial success of Arcop (in competitions and soliciting new business) in the context of rapid growth and increased workloads; how to manage especially large projects; work volume continues to grow and becomes more diverse; profitability of most jobs is too low; how to select partner-in-charge on desirable projects. Includes substaniial new difficulties (e.g. low profitability and selection of parner-in-charge).

\section{PERCEPTION/FORMATION}

Initially, intense collaboration among partners; a number of young architects and two associates enter the periphery of the dominant group; fundamental differences among partners develop with regard to issue of formal organization and structure (loose structure versus clearer and tighter structure); one of the partners leaves partnership (see autonomous action); cohesiveness further decreases as rest of the staff also polarizes with the increased antagonism between partners; finally, there is the feeling of a "lost touch". Perception becomes less cohesive. Composition: no change.

\section{REPERTOIRE}

Be innovative and excellent in architecture; initially, equality and collaboration remain major rule; later, collaboration rule breaks down by increasingly working on own jobs. Tightness. less (with collaboration rule breaking down). Content: no change.

\section{INDUCED ACTION}

Arcop enters seven competitions (winning five of them); overall staff grows from 15 to 43 , including a number of 'bright young architects' which are given major responsibilities on various jobs; most collaboration among partners occurs in early stages of conceptual design work; with the increased workload, tensions arise around the participation of one of the partners; learning to manage bigger jobs results in project teams; selection of partner-in-charge on desirable projects becomes source of tension; management consultants are hired; some of their suggestions are implemented (e.g. matrix management, expertise building in several disciplines, and appointment of project and product managers); staff grows to 146 in 1966; number of associates grows to 6; lobby by interior design department for more independent work is rejected by partners; management committee is formed, which makes effort at formalization and control; partners work increasingly on their own jobs again, while lobbying for prestigious partner-in-charge positions; breakdown in communication between partners; actual disintegration of partnership.

\section{AUTONOMOUS ACTION}

One of the partners leaves the partnership because of tensions around bis participation; management consultants advise to seek balance between design quality and profitability, and urge to reach consensus on a desired size, services and work type of Arcop; they also suggest to increase emphasis on business affairs, scheduling and planning; interior design department begins to lobby for a more independent practice; later, another consultant recommends more standardized accounting and performance control; some partners resist efforts at formalization and control 
D/R: increasing misfit.

1/A: emphasis shifts toward A.

I/D: unintended consequences (e.g. working in project teams generates the problem of how to select partners-in-charge).

A/P: A affects $P$.

$1967-1970$ 'Disruption and decline'

\section{DIFFICULTY SET}

Focus is especially on: what is 'soul" of Arcop (in contrast to its 'business'); other issues involve scaling down the firm in response to declining work volume, and the lack of a base in small, private (commercial, industrial or residential) work. Includes substantial new difficulties (e.g. soul-searching and the need to down-scale).

\section{PERCEPTION/FORMATION}

Partnership shrinks to 3 active partners (two leaving); 6 out of 8 associates also leave, for many reasons (including the reluctance of partners to involve them in management of the firm, general decline work volume and the slim prospects of becoming full partners); partners exclude each other in all stages of their work; fundamental differences arise in perceptions of Arcop's (ideal) size and style/type of work; finally, deep conflict over important project (La Cité) leads to complete disintegration of dominant group. Perception becomes less cohesive. Composition changes (e.g. two partners leaving).

\section{REPERTOIRE}

Don't try to coordinate the uncoordinatable; extreme individualistic thrust (not even to be abandoned in the prospect of competitions); that is, focus on own jobs; make no collective efforts but preserve spirit of excellence and innovation (e.g. take no cut fee jobs). Tightness: less (with more individualistic thrust). Content: no change.

\section{INDUCED ACTION}

Study and planning jobs become significant complement to design/construction jobs; several areas/functions other than design and drafting are scaled down or eliminated, implying in fact the dismantling of existing organization structure; entrance in two competitions not successful; overt disagreement about one of the study/planning jobs provides final blow to original partnership; decision to terminate partnership agreement.

\section{AUTONOMOUS ACTION}

Major part of partners and associates leave the firm, taking several jobs and staff members with them. Major (potential) clients of Arcop withdraw jobs, offering them to competitors.

\section{ENVIRONMENT}

Declining architecture inclustry.

D/R: increasing misfit.

1/A: emphasis shifts toward $A$.

I/D: no unintended consequences. 
A/P: A affects $P$.

\section{0 - 1978 'Starting again'}

\section{DIFFICULTY SET}

Opportunity of continuing the Arcop practice; business-searching again instead of 'soulsearching" because public projects begin to dry up and in view of an increasingly competitive industry; continuing decline in work in parallel with decline in industry as a whole. Does not include new difficulties.

\section{PERCEPTION/FORMATION}

The partnership is continued by two partners; as successors to the Arcop practice; two associates become partners; fewer tensions in partnership than in previous period; a decline in the ideology of equality, that is, a hierarchy develops in partnership (two senior partners and two junior partners); much of attention is directed inward; differences in perception among partners develop (with respect to design, style, etc.); finally, a strong rivalry between several partners develops, ending up in sharp conflicts and competition in the office. Perception becomes more cohesive (relative to previous period). Composition changes.

\section{REPERTOIRE}

Change from management to task orientation; 'go where the action is', that is, focus on tasks closer to architectural work instead of administration; move away from departmentalization of staff; definite decline of equality and collaboration rules; stay clear of organizational issues which created conflict in earlier years. Tightness: more (with increasingly shared "working" rules). Content: changes (e.g. 'stay clear ...').

\section{INDUCED ACTION}

Study/planning work shifts from single sites to urban development; departmentalization of staff is abandoned; few remaining management positions are eliminated; no other formal management positions other than connected to particular jobs; affiliate operations are established elsewhere; shift to private projects and working with private developers; staff grows to 68 people and associates to 11; agressive search for work by partners (even in overseas locations); staff declines to 19 people and 7 associates; entrance into federally sponsored competitions.

\section{AUTONOMOUS ACTION}

Two partners take initiative to continue partnership; some major jobs are offered on the basis of Arcop's reputation and experience; conflict between senior partners results in one of them mowing to the affiliate office located elsewhere.

\section{ENVIRONMENT}

Initially, continued decline of architectural industry; later, renewed industrial growth.

D/R: increasing fit.

\section{I/A: emphasis shifts toward I.}

I/D: no unintended consequences. 


\section{Berol Kemi}

Source: Czarniawska-Joerges (1988; 1989).

\section{Introduction}

Berol Kemi $A B$ is a Swedish chemical company with headquarters located in Stenungsund, a small town on the west coast of Sweden. Berol Kemi is part of a state-owned holding company.

\section{Dominant group}

The Execulive Management Body of Berol Kemi (composed of the president, financial wice president and three representatives of unions) and the Board of Directors (chaired by the vice president of the holding company). The periphery of the dominant group is primarily constituted by the Operations Committee and the Corporate Development Committee, whose recommendations meet in the Executive Management Body. The periphery also includes - althougli their role appears to be less substantial compared to the two committees - a number of managers of divisions/regions and foreign subsidiaries, which relate to the Executive Management as profit centers. A member of the Executive Management Body sits on every profit center"s own Board.

\section{Periods}

The case is assumed to begin in 1973 when Statsforetag, a holding company owned by the Swedish state, became full owner of MoDoKemi $\mathrm{AB}$ (which later changed its name to Berol Kemi $A B$ ). We distinguish three periods, which are separated by the following events. In 1975 the oil crisis drives up prices of raw materials and Berol management takes notice of this crisis (start of the second period in 1975). With the appointment of a new president on 1 February 1978 the third period begins.

\section{$1973-1974$}

\section{DIFFICULTY SET}

Expansion and self-sufficiency in supplies. Change: ?

\section{PERCEPTION/FORMATION}

President of Berol is primarily interested in expansion and backward integration; holding company focuses on complementary interests (profitability, creation of employment). Change of perception: ? Composition: no change.

\section{REPERTOIRE}

Expand; invest heavily; focus on production and new technologies; headquarters should not interfere with details of managerial work; similarly, the owner's philosophy holds that their subsidiaries must be autonomous; state ownership is 'guarantee of security". Tighness: ? Conten:?

\section{INDUCED ACTION}

Several exparision projects, including the ambitious OXO-project (which consumes most of the new capital invested); company changes its name to Berol Kemi (October 1974); with increased product prices financial results improve "fantastically"; thus ${ }_{\text {" }}$ heavy investment continues; in face of first symptoms of oil crisis, Executive Management tries to maintain good relations with owner. 


\section{AUTONOMOUS ACTION}

Most units within Berol act like self-governed islands.

\section{ENVIRONMENT}

Swedish state is interested in investing in profitable activities as well as creating additional employment in nothern part of Sweden; first symptoms of crisis on oil market.

$D / R^{*}$ ?

IIA: ?

I/D: ?

A/P: A does not affect $P$.

\section{5 - Februari 1978}

\section{DIFFICULTY SET}

How to cope with the oil crisis, affecting raw material prices and thus producing losses for Berol. Includes substantial new difficulty.

\section{PERCEPTION/FORMATION}

Crisis is fully perceived by all members of dominant group; the owner becomes increasingly unhappy about OXO project; later, the owner starts to consider the closing/selling of certain plants; finally, the owner's support for Executive Management policy ceases. Perception becomes less cohesive (with the owner's support decreasing). Composition: no change.

\section{REPERTOIRE}

No fundamental changes (see previous period). Tightness: no change. Content: no change.

\section{INDUCED ACTION}

In the face of losses in 1976, OXO-advocates continue to present calculations proving the soundness of the project; a loan by holding company helps to cover the losses; later, calculations of OXO-project are clearly established as in error, but fear of 'political consequences' contribute to decision to continue; attempts by headquarter to cut personnel are not successful.

\section{AUTONOMOUS ACTION}

Foreign subsidiaries (sales companies) act in complete isolation without headquarter's interest or support, and decide to 'succeed in spite of our parent company'.

\section{ENVIRONMENT}

Prices of raw materials follow increased product prices (1975).

D/R: increasing misfit.

I/A: no change.

I/D: no unintended consequences. 
A/P: A does not affect $P$.

\section{Tebruari 1978-1983}

\section{DIFFICULTYY SET}

Some divisions start to show diminished losses; the remaining debts are positively affected by the devaluation of the krona; further increase in profits. Does not include new difficulities.

\section{PERCEPTION/FORMATION}

A new president enters the core of the group (see autonomous action); the new president"s initial focus is on control of operations and turnaround; mutual understanding develops that state-ownership is no guarantee for survival of Berol; later, profitability is emphasized as the main element in both headquarters" control over its divisions and regions and the holding company"s control over Berol. Perception becomes more cohesive. Composirion changes (entrance of new president).

\section{REPERTOIRE}

Overall mission becomes: be the world champions at what we are doing, and to be one of Sweden's most attractive companies; focus on output control and innovation; guidelines and goals are set by headquarters, or 'strategy to the top, operations to the bottom"; tangible, quantitative indicators serve as symbols of goals. Tightness: more. Content. changes (e.g. control rule).

\section{INDUCED ACTION}

The new president (see autonomous action) holds a meeting with all executives; consultants are called in; most of the management is replaced by younger people; the Beroxo unit, working on $\mathrm{OXO}$, is separated from Berol, taking their project along with it; another division is liquiditated; managers are replaced, weakening possible resistance from old cadre; a sales company is formed in the USA, thus entering a new market; business ideas for each division are established; involvement and commitment to headquarters' policy is strengthened; Development Committee, as a device to pool creativity, focuses on future strategies and development projects, leaving operations to line managers; planning procedures become relatively formalized; restructurings are achieved without major conflicts with union representatives.

\section{AUTONOMOUS ACTION}

A new President is appointed by the holding company on 1 February 1978; a new catalyst is invented by Berol researchers.

\section{ENVIRONMENT}

"The Social Democratic Party comes back to power in Sweden, devalluing the Swedish krona.

D/R: increasing fit.

I/A.: emphasis shifts toward 1 .

I/D: no uniniended consequences.

A/P: A affects $P$. 
British Road Services

Source: Lewis (1988).

\section{Introduction}

In 1948 British Road Services (BRS) was created by the U.K. government as a highly centralized organization with the objective of integrating and coordinating long-distance road transport. From its inception, BRS was primarily a long-distance road haulier involved in what is known as "general haulage".

The first twenty-five years of BRS" history were characterized by the countervailing influences of imposed government policy and the management philosoplyy and style of the acquired small hauliers from which BRS was forged. Government policy, driven by a desire to integrate the nation's road transport activities, imposed a highly centralized structure and bureaucratic style on the organization in its formative years. It soon became apparent that this approach was doomed, and the organization drifted toward the more entrepreneurial style of the small haulier.

Changes in government policy subsequently confirmed a more commercial orientation. Although the strategy of national integration was effectively abandoned, a large, professionally managed organization had been created. BRS came to operate a wide range of road transport activities within a framework of corporate plans and national product policies. During the subsequent decade (1968-1979) strategic changes were initiated by successive chief executives. "These changes will be outlined in more detail.

\section{Periods}

The division into three periods closely follows the presentation given by Lewis (1988).

\section{Dominant group (in 1968)}

Top management of the British Road Services group, especially the group managing director and the managing directors of regional companies. (In 1976 a new position, the supervising chief executive, is created in the core of the group.) At the periphery of the group are, amongst others, staff nembers at the group level (e.g-group controllers) and board members and managers at the regional company level.

\section{$1968-1972$}

\section{DIFFICULTY SET}

Inherent conflict between BRS haulier culture and centralized co-ordination; the 1968 Act changes BRS' financial accountability from commercial accountability to balancing cashflow (while profitability has become established way of judging managers. performances); devising the structure most appropriate to the many-sided activities of BRS; profitability crisis in general haulage; new uncertainty arising from the election of a conservative government. Includes substantial new difficulies (e.g. cash-flow balance).

\section{PERCEPTION/FORMATION}

With Payne as (group) managing director, orientation is increasingly toward financial control, branch profitability and branch profit responsibility; questioning of BRS' role as a large general haulier and of natural systems and structures for the co-ordination of general haulage; general success of private hauliers is rather a myth from the perspective of BRS' management; continuation of emphasis on decentralization and profit as a measure of efficiency. Perception becomes less cohesive (with old cognitive structure 
breaking down and new one emerging). Composition changes (arrival of Payne).

\section{REPERTOIRE}

Continuation of management philosophy focusing on commercial public company; give operating companies high degree of autonomy; withdraw from unprofitable general hatlage activity; continuation of financial reporting as key to management control; overall, the repertoire loosens to include decentralization policy (with top management control diminishing) and also moves away from its focus on general haulage as corebusiness. Tightness: less (with increasing decentralization). Conient: changes (e.g. 'withdraw from unprofitable general haulage' is a major new rule).

\section{INDUCED ACTION}

BRS joins the privately owned sector in the industry in the Road Haulage Association; the concept of branches as profit centres also leads to decentralization of control of operating assets (vehicles, trailers); policy of rationalization, that is, withdrawal from unprofitable activities; role of bureaucratic devices, such as the Management Manual, gradually diminishes; strategy of national co-ordination through a centralized operating structure and a bureaucratic control system is abandoned and local unit autonomy is re-established (with central performance control).

\section{AUTONOMOUS ACTION}

The Transport Holding Company is replaced by the National Freight Corporation (NFC) as central management entity of state-owned road transport interests.

\section{ENVIRONMENT}

New government intervention (1968 Transport Act) by Labour politicians seeking legislative and regulatory co-ordination of the industry; following the election of a conservative government in 1970, industry is again faced with uncertainty, although, governmental change does not result in actual reorganization of transport industry.

$D / R$ : increasing fit.

I/A: ?

I/D: no unintended consequences.

A/P: A does not affect $P$.

$1972-1976$

\section{DIFFICULTY SET}

Continuing problems of general haulage profitability; BRS suffers inherent disadvantages in general haulage in relation to smaller hauliers (which have lower overheads and greater labor flexibility). Does not include new difficulties.

\section{PERCEPTION/FORMATION}

A new group co-ordinator of BRS, Thompson, reporting to the chairman of NFC; definite recognition of discontinuation of national general haulier role; within this recognition, major incongruities remain in perception of general haulage; new cognitive structure centers around rapid diversification into other transport activities; Thompson's style is perceived by company directors as autocratic and dominant although decision making at 
the Group Policy Committee (GPC) is based on equal votes. Perception becomes mort cohesive (with a more dominant leadership). Compasition changes (with Thompson).

\section{REPERTOIRE}

BRS should be a "total transport service" operator; the in previous period emerging new repertoire (decentralization, diversification into other activities and financial performance control) now becomes firmly entrenched. Tightness: more (with more entrenched repertoire). Content: no change.

\section{INDUCED ACTION}

BRS is restructured into eight legally separate, regional companies operating autonomously within agreed financial constraints; Group Policy Committee (GPC) is created as key co-ordination and policy mechanism; slimming down of headquarters management; corporate planining becomes basically bottom-up in kind; product-market strategy fundamentally changes by diversifying away from traditional general haulage as fast as the growth of other activities allow; overall, strategy and structure are aligned, with company and branch managers no longer being subject to conflicting expectations of maximizing branch profits while optimizing traffic movements between branches.

\section{AUTONOMOUS ACTION}

A new coordinator (Thompson), who previously held management positions in several major British (transport) corporations, is appointed by NFC, no other autonomous actions of evident significance.

\section{ENWIRONMENT}

\section{No observations}

$D / R$ : increasing fit (as the repertoire tightens).

\section{I/A: emphasis shifts toward $I$.}

I/D: no unintended consequences.

A/P: A affects $P$.

$1976-1979$

\section{DIFFICULTY SET}

Rapidly declining general haulage fleet still unprofitable; can growth rate of new activities compensate for decline in general haulage?; cash constraints within NFC result in additional pressure on profit as well as capital requirements; these issues combine in the socalled 'general haulage dilemma', involving the incompatibility between the decentralized decision and power structure and general haulage. Does not include new difficulties.

\section{PERCEPTION/FORMATION}

In 1976 White succeeds Thompson, who is promoted to chief executive, a new level in the hierarchy with a direct influence on BRS (White has previously been maraging director of one of the regional companies); White perceives strong group product management as key success factor for diversification strategy; managing directors resent group centralization and guard right to run own companies; rate of general haulage decline becomes fundamental disagreement between chief executive Thompson and BRS management (Thompson believing that the activity should be pared down and BRS management 
believing that contraction would jeopardize BRS" key strength, a national network of marketing and operating locations); also within BRS headquarters views start diverging on this dilemma. Perception becomes less cohesive (with old cognitive framework breaking down). Composition changes (with White succeeding Thompson).

\section{REPERTOIRE}

Repertoire of previous period (decentralization, performance controll and diversification) loosens in the face of the general haulage dilemma. Tightmess: less. Content: no change.

\section{INDUCED ACTION}

The influence of managing directors decreases, especially as a result of a newly appointed managing director replacing a strong, experienced director who firmly opposed group policy toward general haulage; the decentralized structure, which has been eagerly embraced by company directors, combined with their central role in policy-making process, gives them the power to resist change; a compromise between BRS and NFC regarding cash flow requirement is worked out; White uses his formal authority and various political tactics (e.g. alternatives are not seriously examined, working parties are introduced) to change the decision-making structure; general haulage dilemma serves as catalyst for the search for a new strategy, which would improve profitability of general haulage while maintaining the decentralized management structure; a new strategy based on the use of information technologies is conceived by White and (tacitly) approved by Thompson and the GPC.

\section{AUTONOMOUS ACTION}

Thompson is promoted to a new position, chief executive at the NFC level, supervising the BRS group (and thus confirming NFC"s support for Thompson"s policies); as a result of NFC's cash crisis, NFC imposes more cash constraints on the activities by its subsidiaries; Bates, an experienced opponent of White in the GPC, retires.

\section{ENVIRONMENT}

No observations.

$D / R:$ ?

I/A: no change.

IID: no unintended consequences.

A/P: A affects $P$. 
Foster Brothers

Source: Johnson (1987).

\section{Introduction}

Foster Brothers is a major menswear retail chain in the United Kingdom. William Foster, the founder of the company, opened his first shop in 1876. He sold cheap, ready-made clothing for men and boys. Joined by John Shannon, a clothes manufacturer, Fosters grew to a chain of more than 80 shops. Until 1966 , the company remains a family-based business. During the $1960 \mathrm{~s}$, Fosters begins to alter its product range and image, moving toward a greater emphasis on jackets and trousers in particular. These mowes are especially guided by the Merchandise Director, Tom Jacks. With Tom Jacks the company moves to centralized control and purchase of stock. Together with the increasing proportion of merchandise bought abroad (e.g. Hong Kong, South Korea), this led to a rise in the status and influence of the merchandising department and its director Jacks. Despite the fact that the company had its own factories, these produced only 13 percent of tumover, so a great deal of buying from outside the company had always taken place. In 1968 the company moved to a new Head Office and a large warehouse, which enabled the central distribution of merchandise. Throughout the 1960 s and into the $1970 \mathrm{~s}$ growth occurred through the acquisition of new shops and companies. These acquisitions included Dormie Menswear, Jessops (1967) and Bradleys (1970), a Chester-based menswear outfitter with 160 shops.

In 1971 , Foster Brothers is a so-called outfitter with minimal commitment to manufacturing. The company has built up a property portfolio of some 450 shops which are, in the main, small outlets staffed by two or three persons, often in smaller towns than those in which the larger tailors (e.g. Burtons) were sited. Traditionally it is the shop older men go to for clothes they wear to work, or to which mothers take their children in order to buy school clothes.

The menswear retailing industry in 1971 comprises three main sectors. There were the multiple tailors who concentrate on the sale of suits and other outerwear (e.g jackets, overcoats), which are made to the individual measurement of the customer. This is the business Hepworths and Burtons and other (smaller) companies are in. This sector is dominated by the large, vertically integrated multiples such as Burtons, for which manufacturing is the central focus of the business.

The second sector comprises the outfitters. These are companies such as Foster Brothers, Harry Fenton and Ray Alan, smaller than the largest multiple tailors. They sell shirts, ties, knitwear as well as jackets and trousers, usually ready to wear. Some of these companies have their own manufacturing capacity but to a much more limited extent tham the tailors. In this sector resides the great majority of 14000 independent retailers in the U.K.. Many of these retailers are to make the most rapid adjustments throughout the 1970s. Foster Brothers was the first of the large menswear companies to import in quantity so they got the benefit of bulk buying, together with the ability to price below competition whillst achieving margins greater than competition.

The third sector comprises companies who were not menswear specialists at all, e.g. departmental stores and wariety chains which sell menswear products as part of their overall range. The focus for these companies is mainly the sort of products sold by the outfitters and, in particular, they hawe a high proportion of sales of underwear, ties and socks. This sector, and Marks and Spencers in particular, is to become a major force in 
the retailing of menswear.

In the period 1972-1985 the structure of the retail market for men"s clothes changes fundamentally. Foster begins the $1970 \mathrm{~s}$ as the dominant chain of outfitters. However, the fashion changes of the 1970s, the demise of the tailors, the successful re-positioning of companies such as Burtons and the growing power of Marks and Spencers, throw this market into turmoil.

\section{Periods}

Johnson's (1987) study of Foster Brothers especially depicts strategy formation from 1972 to July 1985 when Foster Brothers is taken over by Sears. The following presentation closily follows the periods identified by Johnson (1987).

\section{Dominant group}

The (Group) Main Board, especially the Chairman and the Joint Managing Directors of the Group. In 1972 Geoffrey High is Chairman and Joint Managing Director with John Foster, the last member of the Foster family in the company, as the other Joint Managing Director. Other Main Board members include the Group Accountant, the Merchandise Director (Tom Jacks), the Company Secretary (Barry Dawison), and others.

\section{$1972-1974$}

\section{DIFFICULTY SET}

Growth of the Mothercare chain is an indicator (to Davison, company secretary) of an opportunity for a similar Foster Group venture; how to administer the considerable growth of properties and branches; can womenswear market be developed by applying the existing operating systems of Foster Brothers; 1974 is a difficult year (profits down) with rising inflation, a reduced working week (early 1974) and the imposition of price controls (late 1974); should we move up market to higher-income groups; are the large supermarkets and wear departments a major threat to Foster Brothers (with their low-overhead structure enabling them to devastate our price structure); should we therefore differentiate from supermarkets? Change: ?

\section{PERCEPTION/FORMATION}

Widely shared understanding of excellence of current merchandising practice; merchandising policy is dominated by Tom Jacks, supported by High. In 1973, Barry Davison (who was company secretary), an accountant by education, is appointed Joint Managing Director (with John Foster); High remains Chairman. Major differences in perception develop between Jacks (supported by High), John Foster and Barry Davison. Perception becomes less cohesive. Composition does not change substantially (Davison being promoted to Jain Managing Director).

\section{REPERTOIRE}

Focus on workwear (utility clothing) for men and low pricing; concentrate on the 35-50 age group; 'buy big and sell it big'; emphasize branch development; decentralize responsibility to each retail activity within the Group; our buying arrangements with the Far East can be imposed with success on business other than menswear; tighten controls in times of hardship to minimize the effects on profitability and cash flow; emphasize loyalty and caring for the well-being of staff (loyalty especially personalized around Chairman High). Tighness: ? Contert:? 


\section{INDUCED ACTION}

Acquisition of sites in areas of the country in which the company is poorly represented (from 385 Foster Menswear branches to 448 by 1974); first move into areas other than menswear with the purchase of $\mathbb{D} . P$. Adams, a small retailer of children's wear; within twelve months, the new subsidiary Adams Childrenswear is expanded from the initial five to thirty shops; decision to restructure the Group into a holding company so that each retail activity within the organization has clearly defined responsibilities which are reported upon to the Main Board; sales virtually doubled (since 1969/70) and profit and return on capital are far in excess of any of the major companies in the industry; decision to use the available cash to diversify further; Stone-Dri, a chaim of 118 shops selling cheaper women's and men's clothing, is acquired in 1973; Fosters puts their own managers into Stone-Dri; Stone-Dri proves to be an unprofitable venture; and branches are closed or converted to selling men"s or children's clothes; in response to decline in profitability, short-term borrowings; overdrafts and stock levells are reduced; Barry Davison is appointed Joint Managing Director with High remaining as Chairman.

\section{AUTONOMOUS ACTION}

John Foster argues that reliance on cheap importing is unwise and advocates a nove further up the market to higher-income groups; Davison argues that the emergence of the large supermarkets and wear departments could be a major threat to Foster Brothers; lobbying and infiltration of small amount of more fashionable merchandise, available to Area Sales managers (since the late 1960 s).

\section{D/R: ?}

I/A:?

I/D: no unintended consequences.

A/P: A affects $P$.

\section{5 - Summer 1977}

\section{DIFFICULTY SET}

How to deal with dangers in changing from a proven approach to buying; how to cope with doubts and resistance to change within the company. Includes substantial new difficulties (e.g. resistance to change).

\section{PERCEPTION/FORMATION}

Perceptions of Foster, Davison and Jack/High increasingly diverge; Davison and Foster view each other as rivals for political status as joint Managing Directors; older directors are wedded to the outfitting tradition of the company; following the retirement of Foster (1975), Davison assumes the role of sole Managing Director, now prevailing to some extent over Jacks; later, Jacks retires. Perception becomes less cohesive. Composition changes. Composition changes (with the departure of Jacks).

\section{REPERTOIRE}

Beginnings of a shift away from the traditional market segment (workwear for men iri 3550 age range), especially toward womenswear and wear for the younger factory worker; move slowly, in order to overcome resistance and to make relatively low levels of buying commitment; take little risk; growing commitment to overseas buying; always promote personnel from within the company; emphasize loyalty (especially to Davison) and caring 
for the well-being of staff. Tighness: no change. Content: no change.

\section{INDUCED ACTION}

Policy adjustment by attempting to reduce the cost of operation, without getting substantial senior management support; initially, experiments with more fiashionable merchandise are of limited success; later, experiments with three-piece suits do have some success (1975): Jacks becomes ill and Davison seizes the opportunity to have an influence on merchandise policy, in 1975, a number of shops are converted to womenswear (called "Crowds"); a year later, a more radical reorganization programme involves the conversion of about 30 shops; in 1976, the merchandise range is further widened in 20 experimental shops; branches are selected on basis of proven suitability to range extension and ranges are introduced so as not to offend existing customers; sourcing to the merchandise remains mainly overseas; also, there is little branded merchandise bought; gradually branches receive greatter proportions of fashion merchandise and more conventional merchandise is phased out; in 1976 two factories producing own clothing are closed down; throughout this period there is a progressive conversion to and opening of larger retail outlets, search for sites where the company is unrepesented, and the closure of some of the smaller; less profitable shops; number of shops rises to about 500 .

\section{AUTONOMOUS ACTION}

Lobbying and infiltration of small amount of more fashionable merchandise, available to Area Sales managers; managers at lower levels in the company (in both retail and buying) become aware that sales are being lost in the shops because the company does not provide the more fashionable clothes their traditional customers are now looking for; some of these managers experiment with buying their own merchandise and promote gradual change by trying to influence decisions upwards, however, with little success; in 1975 John Foster decides to take early retirement; Dawison begins to actively promote the idea of buying more fashionable merchandise; Jacks decides to retire.

D/R* no change.

I/A.: no change.

I/D: no unintended consequences.

A/P" A affects $P$.

\section{Autumn $1977-1979$}

\section{DIFFICULTY SET}

What to do with the severely escalating costs in virtually every direction; how to realize the desirability of entering the womenswear market, which is fiercely competitive and sophisticated; with cash to spend, is the growth of cut-price drug and cosmetic stores in the USA and the beginnings of a similar operation in the UK ("Superdrug") an opportunity for Fosters; later (after having acquired 'Discount'), how to cope with the depressed turnover in the drugs business; opportunity of retailing jeans and denim goods to people in their teens and early twenties; what can we do with the residual shops from the StoneDri operation; do we have the necessary experience in a specialist business like jeans (casual wear). Includes substantial new difficulties re.g. escalating costs, opportunity of retailing jeans).

\section{PERCEPTION/FORMATION}

Davison assumes an increasingly central position, by chairing the boards of the subsidia- 
ries, but also in considering and deciding on diversifications; at lesst one senior board member, Mike Adams, is entirely against moving into the jeans business; overall, commutment among senior managers to diversification outside menswear retailing increases during this period; after the retirement of High (1979), Dawison takes over the position of Chairman and he and Adams become joint Managing Directors; particularly the views of Davison exert a direct and powerful influence on the subsidiaries. Penception becomes more cohesive (with an increasingly dominant position of Davison): Composition changes (with the departure of High).

\section{REPERTOIRE}

Seek ventures outside menswear retailing; apply the successful management and control procedures in operation at Fosters Menswear to improwe the operations at other subsidiaries, promote personnel within the company; toward the end of this period, the 'paternalistic' rules of loyalty and caring for the well-being of staff start breaking down; growing concern about the jeans venture. Tightness: less (with some rules breaking down). Content: no change.

\section{INDUCED ACTION}

Decision to pull out of the Crowds venture (womenswear shops); the menswear activity improves its results; in August 1977, acquisition of 'Discount for Beauty", a cut-piece retailer of toiletries and cosmetics with 18 shops; within 12 months, the number of shops of Discount for Beauty rises to 35; in 1978, acquisition of 'Staff Facilities Limited', a retailer in cosmetics, toiletries and perfumery (selling at discount prices through representatives directly to people in the factory of office); initially, this venture appears successful and is expanded; later, in 1979, it becomes clear that neither Discount nor Staff Facilities are making losses; acquisition of Millets of Bristol Limited, a chain of 50 shops specializing in camping equipment, casual wearm leisurewear and menswear (1978); decision to expand the Adams Childrenswear business further (1978) and a new head office and warehouse complex is built to house the Adams operation (1979); plans are developed for the operation of a mail-order service in the children's field (followed by market research and the development of a new design concept by a design consultant; for each of these diversified business operations, Davison assumes a position on their board, usually as Chairman, and appoints Foster Menswear managers to senior positions; extension of the retailing of fashion goods by opening a limited number of shops retailing jeans and denim goods (1979), which does not result in any profits, partly because of the rise of specialist jeans shops; some of the residual shops from Stone-Dri are used to experiment with specialist jeans shops (1979); decision to step into jeans business is primarily driven by Davison, who overruled recommendations of a committee; finally, the jeans venture definitely fails, although the company"s overall results remained positive; in July 1979 Chairman High retires and is replaced by Dawison; Davison and Mike Adams become joint Managing Directors; Brian Wood, the Foster Menswear Sales Director is appointed Assistant Managing Director of the Menswear company (1979); Richard Haynes, head of the company's advertising agency, is recruited (by Davison) as Marketing Director with Group-wide responsibilities (end of 1979).

\section{AUTONOMOUS ACTION}

A small retail committee (of the chief executives of six of the smaller subsidiaries) recommends that the shops and locations available are not appropriate; also, semior (main) board member Adams, opposes the jeans venture.

D/R: no change.

1/A: no change. 
I/D: unintended consequences (e.g. failure of jeans venture).

A/P: A does not affect P.

$1980-1983$

\section{DIFFICULTY SET}

Does the position and management style of Davison still fit the company; opportunity of widening our market position from the older factory worker to the younger factory worker; what is precisely our market position and how should it develop; how to meet the needs of our traditional customers who are becoming more educated and sophisticated and are demanding more quality; results decline because of economic influences (recession) and because competitor Burtons has decisively moved into the market that Fosters regards as theirs, and performs exceptionally well; the financial press carries articles applauding the Burtons recovery and highlights the role of its chief executive and drawing unfavorable comparisons with the Burtons performance; after several cost control programs and divestments, the performance of Foster Menswear continues to be too low; what should Foster Brothers do and where should it go; (at Stratford meeting) should we radically reposition Foster Brothers; with the new image of the company (developed by Saunders), the current merchandise is unsuitable; how to change the buyers and their practice, which has been so successful in the past; U.S. subsidiary performs counter to expectations (following the decline in the U.S. economy in 1982/83); are the conversions to the "new image" too expensive; how to decentralize strategic responsibilities in the company. Includes substantial new difficulties (e.g. position of Davison, entrance of Burtons in our market

\section{PERCEPTION/FORMATION}

In January 1980 'outsider' Richard Haynes joins the board of Foster Menswear as marketing director; Haynes feels deliberately excluded as a newcomer; Adams and Haynes" views are not in line with the mainstream approach; overall agreement develops regarding the group's course, although the Chairman remains largely committed to the traditional down-market posture, reconciling itself to marginal changes; Davison realizes his company is a relative failure (compared to Burtons) and becomes sensitive both personally and in terms of confidence in the City; Main Board members feell that company floats "around like a ship without a rudder", no one knowing what to do or where to go; the arrival of a new Group Financial Director, John Fallon, acts as a catalyst toward a new cognitive framework; the Stratford meeting provides a new direction for the company; especially the partnership between Haynes and Saunders becomes a central force for changing the prevailing cognitive framework in Fosters" management; the old cognitive framework (e.g., focus on the transfer of people and systerns from Foster Menswear to acquisitions) breaks down; Norman Phillips is increasingly antagonistic to Saunders and Haynes and he becomes politically isolated politically; in May 1983, Phillips resignes; from 1982 onwards, there is an influx of new managers at senior and middle management levels; moreover, by 1983 Davison's leadership style contributes to more decentralized decision-making, letting middle management take decisions. Perception becomes less cohesive (with the old cognitive framework breaking down and new cognitions emerging). Composition changes (e.g. arrival of Follon and departure of Phillips).

\section{REPERTOIRE}

Never widen the market focus outside 'our' factory workers; pursue the image of the younger factory worker, yet retain the older factory worker; do this by gradual evolution of the merchandise mix; sell merchandise bought specially for Fosters at the higher 
margins achieved from importing (rather than branded goods); tighten controls in times of hardship; by 1983 the practice of internal promotion and transfer of Foster management to new subsidiaries starts to break down; also, the "automatic "transfer of central control of merchandise selection and distribution to acquisitions is increasingly regarded as inappropriate (especially when there are small numbers of shops); focus on planning and strategic control; try to achieve a greater decentralization of strategic responsibility. Tightmess: less (with some rules breaking down). Content: no change.

\section{INDUCED ACTION}

Haynes commissions market research, which shows that the view customers have of Fosters is very different from what managers believe they have (1980): the company is viewed as rather cheap, nasty and old-fashioned, highly focused on the older male, while merchandise is seen as out-dated and of rather poor quality; initially, Foster Menswear managers, faced with the report, can not accept its wider implications; the first response is to address some of the more admissable findings (move to a younger market, window design, merchandise layout, and so forth); throughout 1980, the company"s results (especially profits) decline; almost all activities contribute to this decline, except Dormie; initially, the response to the decline is the traditional tightening of (cost) controls (stock controls, sales incentive programs, aggressive pricing policies); also, attempts to cut wages; when Metra Proudfoot consultants enter the stage (see Aut. Action), the board seizes the opportunity to overcome the problems of retail (managers) resistance; a team of retail managers is formed to work alongside the consultants; the recommended changes in staff levels and the introduction of a system of shop-based control results in major cost savings; however, the trading decline continues, mitigated through low borrowings, cost reduction and strict cash management; John Fallon, a financial manager from Burtons, is recruited as Financial Director on the Main Board (1981); the subsidiaries Discount for Beauty and Staff Facilities, which continue to make losses, are disposed of; decision to convene a management meeting in June 1981, the so-called Stratford meeting; there, decision to "establish leading value lines at new lower prices" (instead of discounts) in each department and 'market this concept'; also, decision to set up a Strategic Planning Committee; this committee, set up by Davison and chaired by Haynes, consists of mostly middlle managers and two junior directors (Wood and Phillips are deliberately ommitted in view of their over-commitment to past practice); the committee start to work on a highly operational instead of strategic level of discussions (e.g. window dressing, pricing, opening hours, etc); moreover, merchandise practice is not critically evaluated and time horizons of discussions are short and geared to immediate action; following recommendations by the committee (and especially Haynes), the board decides to brief new design consultants; the brief requires to concentrate on corporate image, shop appearance, window displays, interior design, and so forth; out of four presenters, David Saunders is selected as the new design consultant; Saunders tests his proposed shop design in a new shop, which is an immediate success (early 1982); thus, Saunders is retained to extend the 'new image' shops; by mid-1983 a refitting plan include 300 shops for redesigri over a three-year-period, with the likelihood that the other 200 shops will be sold, converted or relocated; target sales for 1983 are met and profitability rises; until mid-1982 the focus of management is on the retail side, but subsequently switches to the buyers and their merchandise, which (according to Saunders) is unsuitable; Saunders is given authority to go out and order the kind of merchandise he thinks Fosters ought to have; the objections of Norman Phillips are overruled by Davison; the resistance of the Merchandise Department decreases in view of the successes of the new image shops; after appointing Norman Phillips to the Main Board (1983), Davison sets about trying to find a new Merchandise Director for Foster Menswear, despite the unwillingness of Phillips to cooperate; in May 1983, Norman Phillips resignes (which was seen by many managers as inevitable); acquisition of 75 per cent interest in Anglo American Retail Inc., a U. S. company with a 
coast-to-coast coverage of 280 shops (1982); by the end of 1982 this acquisition was experiencing a downtum in expected salles; late 1983, Saunders is asked to redesign 60 of the U.S. shops; in 1983 a Management Board is set up, consisting of the managing: director of each subsidiary together with certain senior managers representing central functions such as personnel and finance (this implies a decentralization of responsibilities from the Main Board to the subsidiaries); the decentralization to subsidiaries goes hand in hand with attempts to introduce a more participative style of management within the subsidiaries.

\section{AUTONOMOUS ACTION}

Brian Wood takes a radical position by adwocating the need to widen the range and attack a wider range of people; Area Sales Managers resist attempts to cut wages; Metra Proudfoot, consultants specializing in productivity programs, approaches Foster Brothers; John Fallon acts as a catalyst to divestment decisions (e.g. Discount for Beauty); at the Stratford meeting, Haynes suggests to radically reposition Foster Brothers; Haynes uses the Strategic Planning Committee as a political vehicle (forum) for advancing and legitimizing his ideas; David Saunders, the new design consultant, advocates the need to attract the missing 'under age 25 ' group, counter to the guidelines in the design brief; the Merchandise Department and the buyers resist the changes proposed by Saunders; Phillips also objects to the demands of Saunders and Haynes.

D/R: increasing misfit (cf. position Dovison and declining results).

I/A." no change (in fact a slight shift back toward A).

I/D: unintended consequences (several tumaround measures do not produce the desired results).

$A / P: A$ affects $P$.

\section{4 - July 1985}

\section{DIFFICULTY SET}

By June 1984 the company reports a substantial rise in profits (as a result of upturn in demand and the performance of the new image shops of which there were 120 by early 1984); the rise in performance also extends to the smaller subsidiaries and the U.S. subsidiary; in the beginning of 1985 the company is in serious financial difficulties, due to the decline of the U.S. venture (resulting in a major cash drain on the U.K. parent); the decline of the $U_{n} S$. venture pertains to the new merchandise team buying merchandise not suitable to the sort of stores the company has, and a major control and distribution problem following the introduction of computer control systems; how to control Davison in his commitment to expansion in the U.S.; is there insufficient release of executive autonomy and discretion from the centre?; problems with the U.S. venture come at the same time as the growing of capital costs of the shop refitting program throughout the Foster Menswear chain (with the returns on the refits not being at the levels of 1983); the acquisition of Richards does nothing to help a worsening situation (not generating profits but absorbing investments); the combined effect of these problems, together with rapidly increasing bank borrowings place Foster Brothers in the position of a prime takeover target; with the U.S. situation not known outside the company, the takeover threat by" Ward White and Sears is the more difficult to defend. Inchudes substantial new difficulties (e.g. takeover theat). 


\section{PERCEPTION/FORMATION}

The principal personalities in the dominant group remain the same and make sure they protect themselves with people who are loyal to them; thus, a clear and significant gap between different management levels continues to exist (and substantial decentralization is not achieved); problems are attributed to the policy of the new Merchandise Director; some senior executives come to feel that their own role is problematic (see difficulty set); after the company is taken over by Sears, Davison leaves the company and is replaced by Adams, and three Sears executives enter the board. of Foster Brothers. Perception: no substantial change in cohesiveness (until the takeover by Sears). Composition changes (with the takeover).

\section{REPERTOIRE}

Little change in the way the company is run (see repertoire in previous period) until the takeover by Sears. Tighmess: no change (until takeover). Content: changes (assuming that the new owner imposes a largely new repertoire on Foster Brothers).

\section{INDUCED ACTION}

Acquisition of Peter Richards, a womenswear chain of 29 shops (July 1984); by May 1984 the early trials of Saunders" new image for the U.S. subsidiary show encouraging sign of turnover growth; when the Saunders redesign is extended to other branches, more capital is required, but the sales in the Autumn period and during the Christmas period of 1984 are disastrous; the new Merchandise Director introduces a more fashionable range across all the Foster Menswear shops; these actions, together with rapidly increasing bank borrowings (see also previous period), produce takeover threat.

After the takeover by Sears, Barry Davison is replaced by Mike Adams and a number of Sears executives enter the (now divisional) board of Foster Brothers.

\section{AUTONOMOUS ACTION}

In February 1985, before the U.S. problems have become known outside the company, the retail conglomerate Ward White declares an interest in Foster Brothers; prompted by the Ward White offer, Sears too declares an interest in March 1985; in July 1985 Foster Brothers is taken over by Sears and becomes a division of Sears.

$D / R$ : increasing misfit (until takeover).

I/A: emphasis shifts toward A (especially with the takeover by Sears).

I/D: unintended consequences (e.g. takeover threat)

A/P: A affects $P$ (several changes in top management positions by new owmer Sears). 


\section{Honda Motors}

Source: Pascale (1984) and Pascale and Christiansen (1983)

\section{[ntroduction}

In 1947 Honda Motors (HM), a Japanese firm, introduced its first motor engine, not leading to significant commercial success. HM's need for additional finance was severe in the early fifties. This problem remained until entrepreneur Honda, pressed by his business partner Fujisawa, developed a breakthrough design (the so-called 4 stroke engine) which also made HM one of the leaders in the Japanese motorcycle industry in 1954. By this time, FM had begun to reduce dependency on suppliers and distributors by becoming a full-scale motorcycle manufacturer, also seeking more flexible distribution channels. A sewing machine plant was bought (1952) and converted to a motorcycle factory. In 1959 HM enters the U.S. market.

The reports by Pascale (1984) and Pascale and Christiansen (1983) focus on the way Honda enters the US market by a rather autonomous start-up team. Studies by Nonaka (1988b) show that the pattern of entrusting start-up groups with relatively high degrees of responsibility and autonomy is also typical to HM in the sixties and seventies.

\section{Dominant group (in 1954)}

The final say clearly is with Fujisawa and Honda, who deliberately allow for major clecision making authorities (e.g. of U.S. start-up team) in their periphery. Thus, the core of the group involves Hondla and his partner Fujisawa. Sochiro Honda is a self-confident, creative and controversial person. Takeo Fujisawa provides especially financial and marketing expertise. The periphery of the group includes other senior executives, such as Kawashima, the leadler of the U.S. start-up team.

\section{Periods}

In the Honda Motors case there appears to be no clearly distinctive turning point. Sensemaking and actions by Honda's dominant group evolve in a rather evolutionary way. Nevertheless, we took the actual entrance of Honda into the U.S. market to separate the periods 1954-1959 and 1959-1965.

\section{$1954-1959$}

\section{DIFFICULTY SET}

How to foctis the attention of $\mathrm{mr}$. Honda on the requirements of running an enterprise; can we use what we have learned from racing to come up with an inexpensive, safelooking motorcycle that is attractive to the Japanese wife, who resists conventional motorcycles; how to cope with distributors in Japan (their loyalties laying with older manufacturers and selling on a consignment basis); which foreign markets should we enter; opportunity of potential market for inexpensive, safe-looking motorcycle which can be driven by one hand; opportunity of entering South-east Asian market which, as it turns out later (in this period), brings no success; opportunity of American market as a vast, untapped and affluent market (compared to unattractive European market, which is dominated by own brand names and the popular mopeds). Includes substantial new difficulties (can we come up with an imexpensive, unconventional motorycle; entrance into foreign markets.

\section{PERCEPTION/FORMATION}

Complementary perceptual abilities of founder Honda and his business partner Fujisawa: 
Sochiro Honda is an "inventive genius" with a llarge ego and a mercurius temperament, whereas Takeo Fujisawa is especially perceptive of the practical requirements of running a company (finance, marketing).

Fujisawa continuously tries to turn Honda's attention to the runining of HM. Neither of them has managerial or manufacturing experience. Perception." no substantial change in cohesiveness. Composition: no change.

\section{REPERTOIRE}

Express inventive ability through the company, especially by building and racing highperformance, special purpose motorcycles. Adjust/innovate toward market realities; seek new challenges ("success against all odds") by also entrusting staff teams (e.g. the U.S. start-up team) with high degrees of responsibility and autonomy; become a full-scale motorcycle manufacturer; seek flexibility in distribution channels. Tightness: mo change (assuming that this repertoire prewailed in a similar way in the preceding period). Content: no change (idem).

\section{INDUCED ACTION}

Work is done as long as necessary each day to keep up with orders; as a result of racing success in Japan, Honda raises its sights to the international arena; most of the company's resources are invested in racing effort; innovations gained from motorcycle racing begin to pay off in more efficient engines; Fujisawa challenges Honda to come up with an inexpensive, safe-looking motorcycle (1956); in 1958 the $50 \mathrm{cc}$ Supercub is introduced; total salles of HM become dominated by Supercubs and by the end of 1959 HM is the largest Japanese motorcycle manufacturer; as a relatively late entrant into the motorcycle industry, Fujisawa arranges for several distributors to carry Honda as a secondary line; weak product positioning is compensated by going directly to the consumer with advertising; experiments with South-east Asian markets (1957/58) bring Jittle success; decision to focus on US as primary foreign market; late 1958, two executives explore the US to see "if we could sell something in the US"; based on their impressions decision to authorize a relatively autonomous start-up team to enter the US market with predominantly heavy type motorcycles (1959); restructuring of distribution channels in Japan by selling directly to retailers (primarily small bicycle shops) with a cash-on-delivery system.

\section{AUTONOMOUS ACTION}

Success for HM's motorcycles in Japanese racing. Traditional distribution channels in Japan agree with image of Supercub as "something much more like a bicycle than a motorcycle' and thus refuse to distribute Supercub.

\section{ENVIRONMENT}

Competitors in the Japanese motorcycle industry arrange for distribution channels to carry their products as primary lines.

Japanese market responds overwhelmingly to $50 \mathrm{cc}$ Supercub.

\section{$D / R:$ ?}

I/A: ?

ID: no unintended consequences.

A/P: A does not affect $P$.

1959 - 1965 (starting with HM's entrance into U.S. market) 


\section{DIFFICULTY SET}

Opportunity of U.S. market as a vast, affluent and untapped market; first attempts to conquer U.S. market are discouraging; that is, HM motorcycles are reported to leak oil and encounter clutch failure, as it turned out because of the fact that motorcycles in the U.S. are driven much farther and much faster than in Japan; thus, HM's fragile reputation is threatened.

Supercubs seem wholly unsuitable for U.S. market so focus is on larger motorcycles; later, the smaller supercub provides an unexpected opportunity to target at a large, untapped market segment. Includes substantial new difficulties fe.g. technical problems with motorcycles sold in the U.S.; threat to FIM's reputation).

\section{PERCEPTION/FORMATION}

See observations of cohesiveness in previous period. Fujisawa and Honda focus attention on the U.S. market by means of a start-up team lead by Kawashima (periphery of dominant group). The perception of HM's position on the U.S. market (especially by the start-up team members) changes during this period. Perception: no substantial change in cohesiveness. Composition: no substantial change.

\section{REPERTORE}

Adjust/innovate toward market realities; seek new challenges ("success against al] odds") by also entrusting staff teams with high degrees of responsibility and autonomy; become a full-scale motorcycle manufacturer (that is, produce all components of motorcycle); seek flexibility in distribution channels. Tightness: no change. Content: no change.

\section{INDUCED ACTION}

Engulfed by demand for the Supercub, a new plant is opened in 1960; in international motorcycle racing, HM leapfrogges past European and American competitors (19591961).

Learning in U.S. start-up team occurs: machine problems are solved and by trial-anderror a distribution and marketing strategy develops which targets at a large, untapped market segment (including advertising campaign and cash-on-delivery distribution); HM's U.S. sales grow from 1315 in 1960 to 227000 in 1965 (about half of total motorcycle sales in the U.S.).

\section{AUTONOMOUS ACTION}

Japanese government imposes severe restrictions on the start-up team's inventory and cash reserves; sporting good stores (instead of motorcycle dealers) offer to sell the Supercubs; Grey Advertising offers the 'You meet the nicest people on a Honda" campaign for sale to HM.

\section{ENVIRONMENT}

Initially, the U.S. market does not respond positively (minor sales, complaints about machine failures affecting Honda's fragile reputation); moreover, motorcycle business season does not coincide with HM entering the U.S. market; later, demand in the U.S. develops, especially because the Supercub creates excitement among U.S. customers; banks and other consumer credit companies begin to finance motorcycles, causing a shift away from dealer credit, the traditional purchasing mechanism.

An undergraduate advertising major (at UCLA) submits an advertising campaign titled "You meet the nicest people on a Honda"; this idea is sold to Grey Advertising. 
I/A: no change.

IID: unintended consequence (problems which arise when entering the U.S. market). A/P: A does not affect $P$. 


\section{Pakhoed Transport}

Source: Bahlmann and Meesters (1988).

\section{Introduction}

Pakhoed is a large Dutch holding company located in Rotterdam. In 1975, the company has three major divisions:

- Paktank International: actiwe in the storage of oil, oil products and chemicals, and related activities;

- Pakhoed Corporation: active in storage of dry products and environmental technology (in U.S.);

- Pakhoed Transport" container terminals, multi-purpose stuwadoors, cargadoors, containerdepots, specialized road transport and distribution, air freight and air flight handling.

The Pakhoed Company is managed in an extremely decentralized way. The divisions do their own finance, pricing, personnel policy, and so forth. Therefore, the case describes strategy formation at the Pakhoed Transport division, which underwent a major crisis in the early eighties. The Pakhoed Transport diwision includes about twenty units which are run by four sector directors. These sector directors have major financial as well as commercial and operational responsibilities for a number of the units.

\section{Periods}

The total period covered is 1975 - 1986. Following Bahlmann and Meesters (1988), we distinguish two periods. The 'crisis' provides the demarcation point between period 1975 - November 1982 and period December 1982 - 1986.

\section{Dominant group}

The core of the dominant group includes the division director, head of the holding company"s Personnel department and several sector directors (responsible for sectors within the division). The periphery includes, amongst others, executives at the company's head office and external consultants.

\section{5 - November 1982}

\section{DIFFICULTY SET}

Lack of coherence between the units in the division (in terms of markets, capital intensity, competition, etc.). 'Specialized transport' is typically a business of many (small) suppliers in a competitive market. Also capital intensity is low. By contrast, 'Container terminals and related activities' are extremely capital intensive and the market is tather monopolistic. The market situation of the 'Storage and Expedition' units (SE-units) is rather unstructured: there are a number of large, integrated companies which operate worldwide, and many small firms which operate locally or in a few market segments. The SE-units are all confronted with a buyers market in which prices are continuously under pressure. To a large extent, the SE-units lack a common denominator. In the second half of this period, the Dutch SE-units run into serious trouble (i.c. severe unprofitability). This is accorded to high costs (of storage facilities, personnel, etc) and low profit margins (because of market conditions). Some countermeasures (cost reduction) are without the desired effect. Also, in foreign units some mino: problems arise (Switzerland, Belgium). Inchudes substantial new difficulites (e.g. unprofitability of Storage and Expedition units). 


\section{PERCEPTION/FORMATION}

The cohesiveness of division management decreases. The division actually consists of a number of profit centres which act autonomously. The managers of these profit centres are "entrepreneurs' focusing on their own units. The "crisis' (see difficulty set) and its solutions are viewed in terms of external factors and/or costs. Initially, the division also established non-financial goals (e.g. social responsibility). Near the end of this period, however, financial goals such as EBIT (Equity before tax and interests) are increasingly emphasized. Perception becomes less cohesive. Composition: no change.

\section{REPERTOIRE}

Until 1978 the repertoire is largelly centered around structure, based on the assumption that the decentralized structure of the organization is of major importance to its success. Increasing decentralization of division inanagement: the sector directors have major responsibilities for the units they supervise. The division does not contribute substantially to the management of sectors and units. The division (as well as the holding) acts fron an "asset' philosophy, the supply of capital. Focus on growth in financial terms. After 1978, the human factor grows in importance ('human resource thinking'). Tighmess: ? Content: changes.

\section{INDUCED ACTION}

In january 1976 Pakhoed Transport starts Multi-Terminals Rotterdam, a $50 / 50$ joint venture (with SHV) involved in stuwadooring. First reorganizations at the SE-units are announced in 1978. Some of these reorganizations are actually implemented starting in 1981 (especially aimed at cost cutting); these reorganizations are unstructured and locally (to prevent disruptions of other units). Generally, the reorganizations in 1981 and 1982 are rather unsuccessful. Some attempts to improve the cooperation between units (by way of sector-directorships). Investments in real estate, resulting in assets which prove to be too expensive.

\section{AUTONOMOUS ACTION}

Within the decentralization policy of Pakhoed Transport (see repertoire) the units all act rather independently, determining their own investments, prices, etcetera. This independence grows stronger in the course of the period.

\section{ENVIRONMENT}

The stagnating Swiss export (as a result of developments on the currency market) negatively affects the results of the unit in Basel. Other units suffer from negative influence of declining trade with Iran (1979).

\section{D/R: increasing misfit (cf. unprofitability).}

I/A: emphasis shifts toward A (with growing independence of units within Pakhoed Transpont).

I/D: unintended consequences (e.g. reorganization attempts are not successful).

\section{A/P: A does not affect $P$.}

\section{December 1982 - 1986}

\section{DIFFICULTY SET}

Units in cold-storage and freezing facillities are unprofitable. Development of rather large units harms management of a lot of smaller (unprofitable) units. Investments in alir freight 
also unprofitable (from 1983 to 1987 losses in each year); aur freight appears not to be a viable activity unless it merges with another (large) air freight company. The acquisition of Multi-Terminals provides the opportunity to divest a number of activities (especially in view of economies of scale). Task definition between holding and units within division (e.g. units are responsible for personnel policy while the holding has a personnel departrient delineating personnel policy). Increasingly, one recognizes that problems of profitability are not necessarily caused by external factors, but are also related to incompetence of management. Inchudes substantial new difficulties (e.g. incompetence of management).

\section{PERCEPTION/FORMATION}

Initially, all unit managers continue to stand for their own unit: "this is my toko". Managers and staff on the division (as well as holding) level take a financial point of view. Performance is evaluated in terms of overall growth/expansion.

New division director (1983) immediately focuses on: "what are we doing?". He triggers a reorganization process toward concentration on the core-business of Pakhoed Transport. The reorganization is imposed by division management; that is, lower management has to swallow the solutions designed by the top. Perception becomes more cohesive (with increasing focus on core-business). Composinion changes (arrival of new division director).

\section{REPERTOIRE}

Work with larger units, divest units which are too small and (tend to be) unprofitable. Compensation of directors is not related to their performance. Avoid too many management layers, report directly to division management. Division staff should be small and should not be involved in information acquisition (which is a task for unit management). Let units be managed by 'entrepreneurs' (without much diplomacy but skilled in 'direct communication').

Assess performance by means of quantitative criteria; decisions are taken on basis of quantitative criteria and have quantitative content (usually reduction of costs). Exclude human considerations in administering Pakhoed Transport; lay-offs are to be realized by following state regulations.

Until 1985 the overall goal is: service. After 1985 the scope of Pakhoed Transport broadens to include the supply/production of information.

Tightness: more (with more direct control of quantitative results at unit level). Content: changes (e.g. supply/production of information).

\section{INDUCED ACTION}

With regard to colld-storage and freezing units, the work council is consulted and external consultants are hired; they recommend intensified acquisition, reallocation of tasks and improvement of productivity. The $50 \%$ share of SHV in Multi-Terminals is acquired (1983). Thus, Pakhoed is now full owner of Multi-terminals. During weekly meetings of division director, director SE-Netherlands, manager of Personnel policy department (holding) and a few others, (new) strategies are formulated. This team especially focuses on restructuring the SE-units by concentrating on their core-business. A number of units are sold or closed (including Rutges Terminal Alphen). The freezing facilities are taken over by Christian Salvesen (august 1984). The restructuring plans are partly realized (a smaller number of units are divested). In 1984 a report titled 'Paktrans Quo Vadis' is made, after two conferences in which unit managers discussed the strategy of the division as a whole.

Acquisition of air freight firm (1983). In 1984 air freight becomes separate division (Pandair) because its scale becomes too large and holding directors want direct supervision. In 1986 the restructuring of the SE-units comes to an end. All remaining SE-units are 
profitable again from 1986 onwards. Air freight (until then an activity within Pakhoed Transport) becomes large enough to warrant an independent position in Pakhoed. Thus the Pandair division is created.

Analysis of alternatives is done extensively (world economy, the Rotterdam harbour, etc). Frequently, external consultants are hired to support decision making.

\section{AUTONOMOUS ACTION}

A new division director is appointed by the holding. Employees of Rutges Terminal Alphen take initiatiwe to acquire this unit; with Pakhoed"s support this is scrmmlished.

\section{ENVIRONMENT}

Intense competition from other (larger) air freight companies, which renders Pakhoed's investments in air freight unprofitable. Competitors spread rumor that Pakhoed does not 'belief' in tramsport anylonger (in regard of the closure of a number of units).

D.R: increasing misfit.

I/A: emphasis shifts toward I.

WD: no unintended consequences.

A/P: A affects $P$. 


\section{Steinberg}

Source: Mintzberg and Waters (1982).

\section{Introduction}

The overall character of this case is entrepreneurial, centering on the vision of one man, who opportunistically and flexibly adapts to problems, threats and opportunities. This forced Mintzberg and Waters (1982) to rely to a large extent on a few informants" memories, especially in the early development of Steinberg. For the analysis in this study difficulties, repertoires and perception can therefore not be adequately separated and appear to merge into one category. Thus, the case inadequately (for our purposes) reports the details of the first forty years of Steinberg's development (1917-1952). A short description of this period now follows.

In 1917 mrs. Ida Steinberg opened a tiny fruit and vegetable shop in Montreal, operated by members of the family (mother and children). Food is merchandized 'over the counter" with intimate knowledge of customers, selling to them on credit and often delivering goods to them. Sam, the second eldest son joins the store on a full-time base at the age of 13. First innovation in service is developed (exposure of goods), the first store expands and new stores are opened. Subsequently, Steinberg mowes into bulkpurchasing and warehousing.

The business expands to 'take care' of members of the family and to pursue old customers to new areas of Montreal. The business is increasingly run by Sam Steinberg (SS), making "all the decisions at all times". New stores are frequently opened with success being attributed to the single minded dedication of the Steinbergs to the business and their reputation for the quality of the products/services delivered. The depression in the thirties leads to decline of overall retailing industry but does not affect Steinberg's performance. The forties brought a prolonged interruption of growth, the second World War. Materials became scarce, labor was in short supply, prices were under government control, etc. In this period new retailing concepts were perfected, a policy of land banking was pursued, future stores were designed, institutional advertising was started, etc. In the period 19481952, expansion was resumed and Steinberg returned to their central focus of attention: the expansion of the number of retail outlets.

\section{Dominant group}

Sam Steinberg, whose mother opened up a fruit and vegetable shop in Montreal in 1917, later supported by other executives.

\section{Periods}

In coding the case we closely followed the presentation by Mintzberg and Waters (1982) in the following periods: 1952-1953,1954-1960 and 1960-1974.

$1952-1953$

\section{DIFFICULTY SET}

How to solidify the changes which have been made, especially by bringing up the logistical support; what new forms of merchandising fit the expanding retail business?; can we exploit the trend toward shopping centers with our expertise in banking choice land sites?; should we go to public markets for capital? Includes substantial new difficulties (e.g. external financing). 


\section{PERCEPTION/FORMATION}

Sam Steinberg's vision continues to constitute 'dominant group" perception. Perception: no change in cohesiveness. Composition: no change.

\section{REPERTOIRE}

Service to the customer by offering good quality merchandise; dedication to retail business (continuation of old repertoire); expand number of retail outlets by 'test-thewater-then-plunge'; exploit trend towards shopping center, based on our land banking activity; conventional forms of (internal) financing are no longer sufficient. Tightness: less (with the 'internal finance' rule breaking down). Content: no change.

\section{INDUCED ACTION}

Important wave of expanision of the company in response to the retail industry's growth rates; decision to go to public markets for capital; financer is found who is willing to support debt issue, allowing SS to retain 100 percent control; planning mode of behavior develops in accordance with external requirements imposed by financial market.

\section{AUTONOMOUS ACTION}

Potential financers require "plans' of SS.

\section{ENVIRONMENT}

Retail industry is perched for a dramatic expansion (postwar baby boom and population shift to suburbs).

D/R: increasing fit (e.g. with regard to external financing).

I/A: emphasis shifts toward I.

I/D: no unintended consequences.

A/P: A does not affect $P$.

$1954-1960$

\section{DIFFICULTY SET}

Further expansion (finding new places to put stores); 'make it or break it". Does not include new difficulties.

\section{PERCEPTION/FORMATION}

See previous period. Perception: no change in cohesiveness. Composition: no change.

\section{REPERTOIRE}

The repertoire is largely the same as in previous period. "Test-the-water-then-plunge' rule is de-activated, that is, becomes dormant. Tightness: no change. Content: no change.

\section{INDUCED ACTION}

Entering the development of shopping centers (as a means to sell food); rapid expansion is resumed (esp. in shopping centers, also outside Montreal area); policies of public financing, private labeling and bakery manufacturing are vigorously pursued; entrance into the Ontario market by purchasing 39 stores of another chain (for the first time a plunge without a testing of the water), with Ontario competitors responding by price wars. 


\section{AUTONOMOUS ACTION}

None:

\section{ENVIRONMENT}

Initially, benevolent environment (expanding retail industry); later, expansion rates diminish and price wars and other competitive pressures develop.

\section{$D / R^{*}$ ?}

\section{I/A: emphiasis shifts toward I.}

I/D: no uninended consequences.

A/P: A does not affect $P$.

$1960-1974$

\section{DIFFICULTY SET}

Increasingly, how to outsmart competitors (esp. in Ontario) and more effectively serve the customers (that is, shift in empliasis from expansion to consolidation, from opening new stores to making the new ones more efficient and attractive); how to turnaround the Ontario operation (with a lack of land banking expertise/position contributing to its fallure); overall, shift from expansion to consolidation. Includes substantial new difficulties (e.g. turnaround of the Ontario verture).

\section{PERCEPTION/FORMATION}

Attention in larger group (still dominated by SS) is drawn to wider range of spheres. Perception becomes less cohesive. Composition does not change substantially fwith SS as the only core member of the dominant group).

\section{REPERTOIRE}

Return to basic no-nonsense retailing (consolidate activities, improve existing facilities and integrate the new Ontario operation into the company); test-the-water-then-plunge. Tightness: more (with re-activation of test-the-water-then-plunge rule). Content: no change.

\section{INDUCED ACTION}

Faced with competitive pressures, most of the Ontario stores are closed down; existing stores are modernized; significant, permanent, across-the-board price reductions coupled with a shift in merchandising philosophy ("Miracle Pricing'); attempts at centralization and formalization by one senior executive are stopped by SS; company is drawn into backward integration, which later also gives rise to diversification (discount stores, fast food restaurants, etc.) and divisionalization of structure; results of diversification attempts are mixed; overall, supermarket business continues to dominate; sales in early seventies fluctuate strongly" turnaround of the Ontario operations by Miracle Pricing (see above).

\section{AUTONOMOUS ACTION}

Head of Quebec Food Division acts as major proponent for the supermarket business in the company; surge of centralization and formalization by a new executive vice-president.

\section{ENVIRONMENT}

Supermarket business shows tendencies toward saturation, reflected in heavier competition (use of stamps, games, contests, heavy advertising pressures); social changes in form of 
strikes, consumer protests and boycotts, and government investigations; retail chains cannot longer maintain personal touch with customer; overall, enwironment becomes economically hostile and socially militant.

$D / R$ : increasing fit.

IA: emphasis shifts toward A.

ID: unintended consequences (e.g. failure of the Ontario venture).

A/P: $A$ affects $P$. 


\section{Toxicem}

Source: Wilson (1982; 1980).

\section{Introduction}

"Toxicem' is the disguised name of a large chemical company, located in the United Kingdom. The following summary is based on Wilson's description of two key periods in the formation of Toxicem's strategy to enter private electricity generation (PEG).

\section{Dominant group}

Board of Directors (headed by a non-executive Managing Director ??) and three senior managers, i.c. the Production, Development and Purchasing Directors. Actors at the periphery include other senior managers (e.g. electrical engineers, chemists, chief accountant).

\section{Periods}

Following Wilson (1982), the turning point between the first and the second period is in October 1966, when the Managing Director announces his impending retirement (see autonomous action in second period).

\section{4 - September 1966}

\section{DIFFICULTY SET}

Should a chemical company like Toxicem enter private electricity generation, while available funds are limited. This is a substantial new difficulty.

\section{PERCEPTION/FORMATION}

Managing Director is neutral with regard to electricity issue;

increasingly, Purchasing and Development Directors as well as Capital Control Committee (CCC) members perceive electricity generation to be outside Toxicem's proper business. Perception becomes less cohesive. Composition: no change.

\section{REPERTOIRE}

Quick action on highly quantifiable, accurate information; emphasis on standard, formal procedures; let the Board act in a rubber stamping capacity; overall, the repertoire pemains rather unchanged relative to previous periods. Tightness: no change. Content: no change.

\section{INDUCED ACTION}

Detailed search for information and solutions for PEG issue (see difficulty set); the Board asks for information about Toxicem's requirements for steam and related issues (late 1964); the need of a second boiler arises and is solved by a higher pressure boiler using cheap fuel, on recommendation of the Purchasing Director (with full support from the Production Director and his engineers); Managing Director proposes to let the debate on PEG take place in the CCC (early 1966); CCC meets a number of times, but makes no progress; Chairman of $\mathrm{CCC}$ (?) and the Managing Director ask for clarification of positions of opponents and proponents; thus, both parties go out to seek information to substantiate their cases; because of high standby charges by public producers, decision is taken not to enter PEG. 


\section{AUTONOMOUS ACTION}

Spare pressure capacity of new boiter (built in 1962) stimulates engineers to develop the idea that this spare capacity could be used in a productive way, especially PEO (1964); chemists and engineers, encouraged by Production Director, advocate the feasibility of PEG and argue that it should be given top prionity; proponents of PEG find support with National Industrial Fuel Efficiency Service (1964); the Purchasing Director also gathers information about the specification of new boilers, concluding that PEG is 'ludicrous', the higher pressure boiler with its large spare capacity lends one additional argument for the proponents (Production Director and others); after the deadlock reached in the CCC (see induced action), both parties in the debate approach the Accountancy Dept, to confirm their calculations (July 1966); Accountancy is non-commital to both parties; opponents (Purchasing and Development Directors) find support with public electricity users (August 1966), which are hostile to the idea of PEG; public electricity producers respond very hostile to PEG plans of Toxicem and, being urged by Toxicem's representatives; suggest an extremely high charge for standby electricity supplies.

D/R. increasing misfit (regarding private electricity generation).

I/A: emphaxis shifts toward $A$.

I/D: no unintended consequences.

A/P: A affects $P$.

October $1966-1968$

\section{DIFFICULTY SET}

Should we enter private electricity generation (see previous period); the debate centers on the "real' cost of electricity generation;, later, the issue of resolving the debate by political means arises. Does not include new difficulties.

\section{PERCEPTION/FORMATION}

After the Managing Director has announced his impending retirement, the Purchasing and Production Directors are viewed as prime candidates for the vacated directorship; in addition, all members of the group perceive that success is linked to debate about electricity; this sharp personal competition increasingly divides the group. Perception becomes less cohesive (with the comperition between Purchasing and Production Directors dividing the group). Composition: no change.

\section{REPERTOIRE}

Let track record of candidates in the debate about electricity determine success in gaining the Managing Directorship; let the Board act in a rubber stamping capacity. Tighwess: less (with decreasing emphasis on accurate information and procedures). Content: changes (with competition between candidates for the Directorship determining the electricity issue).

\section{INDUCED ACTION}

The only firm figure which is obtained is the cost of standby charges from the Electricity Board; the standby charge is found to be illegitimate (October 1966) (see also autonomous action); feuding between proponents and opponents becomes bitter (November 1966 . October 1967); negotiations with Electricity Board result in agreement on standby charges (in January 1968); proponents and opponents of issue try to strengthen their position by 
scrutinizing old and new information (see under autonomous action); Managing Director puts forward a political solution to the unresolved controversy through a vote among all servior managers (August 1968); proponents win thils vote and the case is presented from the CCC to the Board (September 1968); Board decides to enter electricity generation by giving the go ahead to the purchase of a turbine.

\section{AUTONOMOUS ACTION}

Managing Director announces his impending retirement (October 1966); Production Director scrutinizes all data and finds an important error in figures on standby charges, obtained from electricity suppliers (October 1966); he informs the CCC, with the effect of reopening the debate (see under induced action); Purchasing and Development Directors circulate a memo to CCC (January 1968) which states all their objections to PEG, introducing a new argument concerning the practice of at least six well-known British chemical companies (having tried and rejected PEG); the Production Director counters all objections in a detailed memo to the CCC (January 1968), his main argument being that PEG is an economic proposition and that Toxicem stood to make a substantial profit in PEG; the debate sharpens with derogatory and personal arguments directed at the other party.

D/R: increasing fit between the electricity difficulty and the political solution which is adopied).

I/A: emphasis shifs back in the direction of 1 .

IND: no unintended consequences.

A/P: A affects $P$. 


\section{Walt Disney Productions}

Source: Bums (1986) and Taylor (1986).

\section{Introduction}

Walt Disney Productions (WDP) was established early this century as a family enterprise, based on the partnership of the brothers Walt and Roy Disney. Disney"s original mission was to 'provide the finest in family entertainment'. Since its foundation it has focused on media innowation, trying to 'get on with bigger and better things'. The wish to control the product from the design stage to the ultimate user also led to innovation in marketing and distribution. Thus, forward integration in all company units was seeked. Moreover, each of the product lines serves to promote the other areas of the company (e.g. films support theme parks). Eamings are systematically invested to reduce debt and finance new undertakings. In 1966 Walt Disney dies, and in 1971 his brother and business partner Roy dies.

In the sixties and seventies, Walt Disney World (Florida) was constructed, a cable channel venture (Disney Channel) is launched with major start-up losses and a new amusement park (EPCOT) is opened. Some other investments are not well-received (write-downs to nearly 50 million). While stashing cash for one of the major investments, WDP bylaws are amended to provide protection against unfriendly take-overs by requiring approval of 80 percent of stockholders.

Historically, WDP has not produced hard objectives, or engaged in an annual planning. proces. Walt Disney did not like formalized planning, although many of WDP's actions had their own plans. Walt Disney felt that the major objective was to be the "finest: provider of family entertainment", and that the revenues would follow if that objective was met.

\section{Dominant group (November 1983)}

The four-man Executive Committee (Miller, Watson, Walker and Tatum) and Board of Directors of WDP. Key persons are Watson and Miller. Watson is Chairman of the Board since May 1983, previously Board member for more than ten years; has strong planning and management abilities and a background in architecture and community development; views his role as adviser to Miller. Miller is President and $\mathrm{CEO}$; also son-in-law of Walt Disney, founder of WDP; experienced in film production activities.

In the periphery of the group are about nine Executive Vice-Presidents, WDP's investment banker Morgan Stanley, WDP's attorney Filom, representatives from Bank of America, and major WDP stockholders, especially Roy Disney jr. (son of Roy Disney).

Note that Roy Disney jr. has two roles. As a board member, Roy Disney jr. is a member of the core of the dominant group. When he resignes from the board, Roy Disney is still at the periphery as a major stockholder who represents the Disney family interests.

\section{Periods}

The following analysis especially relies on Taylor's (1986) report, with additional observations taken from Burns (1986). Taylor (1986) describes the period from November 1983 to September 1984. In March 1984 WDP more than triples its line of credit with Bank of America and Roy Disney jr., representing the Disney family interests in WDP, resignes from the Board. We have therefore distinguished two periodis, which are separated by the events in March 1984. 


\section{November 1983 - March 1984}

\section{DIFFICULTY SET}

Florida properties offer attractive ground for new investments; Disney Channel is current commitment with excellent (expected) returns, but racks up expenses of $\$ 60$ million (in 1984); prior efforts (in mid-1960s and the 1970s) to enter the winter recreation industry (e.g. ski resorts) have falled because of barriers and requirements at the level of state and government, but winter recreation is still perceived as a major opportunity.

Attendance at theme parks decreases; profitability declines for the third consecutive year; institutions, which thold an estimated two-thirds of the outstanding shares, bail out of the former 'glamour' stock, general feeling at Wall Street that the book value of WDP's real estate and film library is grossly understated leads to rumors of takeover efforts; thus, threat of a rapid takeover attempt in which buyers could recoup a substantial portion of the purchase price simply by raiding the cash and marketable securities. Includes substantial new difficulites (especially the takeover threat).

\section{PERCEPTION/FORMATION}

Watson, chaiman of the Board since May 1 , 1983 , feels that WDP should start to plan for specific returns, profits, margins, and so forth. Roy Disney jr., one of WDP's largest stockholders, resignes from the Board in March 1984 with rumors that he is unable to exercise any influence at the company and will try to take it ower from the outside. Perception becomes more cohesive (because the resignation of Roy Disney appears to have increased the coherence of the individual perceptions of core members of the dominant group). Composition changes (resignation of Disney).

\section{REPERTOIRE}

Provide the finest in family entertainment; carry little debt and finance from current revenues; maintain independency; 'get on with bigger and better things" in media, distribution and marketing innovations; try to enter the winter recreation field. Tightness: no change. Content: no change.

\section{INDUCED ACTTION}

Ron Miller checks out rumors that Coca-Cola is planning a move on WDP; senior WDP executives consult their advisers at Morgan Stanley; the latter suggest to extend line of credit; WDP thus triples credits with Bank of America; other defensive measures include amending corporate bylaws.

\section{AUTONOMOUS ACTION}

Roy Disney jr. resignes from the Board in March 1984; raider Steinberg starts buying WDP stock.

D/R: increasing misfit (especially regarding the takeover threat).

H/A: ?

I/D: unintended consequences (e.g. undervalued WDP stock).

A.P: A affects: $P$.

\section{April 1984 - September 1984}

\section{DIFFICULTY SET}

Threat of takeover increases; should WDP revise its mission to consider possible 
acquisitions outside its core-business?; defensive measures have no major effects on the threat of a takeower, but further depress the value of WDP stock; the threat of being sued draws public attention to WDP's leadership crisis.

All other difficulties (see previous period) are now - at least for the time being - minor issues relative to the take-over threat. Includes substantial new difficulties racquisitions outside our core-business; defensive measures do not reduce takeover threat).

\section{PERCEPTION/FORMATION}

Distraught about take-over threat grows; the Executive Committee announces that acquisitions are not matters for shareholders to consider, but are management decisions to be approved/rejected by the Board; one Board member (successor of Miller) opposes the Arvida acquisition; four new members, including Roy Disney jr, are (re-)elected to the Board; all four oppose the Gibson acquisition; in the periphery of the dominant group, major stockholders (including raiders) oppose any acquisition at all; in the end, Miller is forced to resign ( 7 September) and Watson steps down as Chairman a few weeks later. Perception becomes less cohesive. Composition changes (with several changes in Board' and Executive membershipl.

\section{REPERTOIRE}

Part of the repertoire in the previous period breaks down: especially the financial rule (carry little debt) is discarded in order to 'maintain independency'. Tighmess: less. Content: no change.

\section{INDUCED ACTION}

A public relations-firm, experienced in take-over threats, is hired; launch of "Project Fantasy": Morgan Stanlley (investment bank) investigates potential acquisition candidates in broadcasting, real estate and consumer products; Miller and other executives are handed 'golden parachutes" prowiding a way out if asked to leave the company; Arvida Corp., a Florida land developer is purchased for 200 million in stock (in May 1984); another attractive acquisition candidate appears in Gibson Greetings, a producer of greeting cards; the Gibson acquisition is worked out in detail; in June WDP announces that it is going to buy Gibson for 300 million; in response to the increased takeover threat, a large greenmaill exercise is initiated (WDP buying back stock from Steinberg and others); the Board decides to cancel the Gibson deal; Miller is forced by the Board to resign on September 7 th; Watson steps down as Chairman a few weeks later (remaining a board member).

\section{AUTONOMOUS ACTION}

Steinberg continues to turn up the heat by buying WDP stock; Roy Disney jr., as protector of Disney family interests, expresses his opposition against any possible acquisition (as it would dilute the holdings of all established stockholders); Ray Chambers (from Wesray, a private investment firm) suggests Gibson Greetings as an ideal acquisition candidate, by calling an acquaintance at Morgan Stanly); also other companies are suggested to Morgan Stanley as potential take-over candidates; Steinberg announces a proxy fight (by seeking consents of other stockholders) to unseat the WDP Board and sues WDP in order to block the acquisition of Arvida; politicians, shareholders and editorial writers publicly protest against WDP's greenmail exercise; the announced Gibson deal infuriates a variety of other raiders, who subsequently besiege WDP to prevent the transaction; raider Jacobs, supported by a substantial part of stockholders, sues WDP and forces its Board to cancel the Gibson acquisition. 
IA. emphasis shifts toward A.

W/D: unintended consegiuences (e.g. defensive measures do nor reduce takeover threat but further depress stock value).

A/P: A affects $P$. 


\section{Appendix D Intercoder reliability}

\begin{tabular}{|l|l|l|}
\hline \hline Organization & Srage one & Stage two \\
\hline Air Canada & $73 \%$ & $82 \%$ \\
\hline Arcop & $73 \%$ & $94 \%$ \\
\hline Berol Kemi & $64 \%$ & $100 \%$ \\
\hline British Road Services & $79 \%$ & $85 \%$ \\
\hline Foster Brothers & $68 \%$ & $84 \%$ \\
\hline Honda Motors & $82 \%$ & $94 \%$ \\
\hline Pakhoed Transport & $89 \%$ & $89 \%$ \\
\hline Steinberg & $75 \%$ & $93 \%$ \\
\hline Toxicem & $74 \%$ & $94 \%$ \\
\hline Walt Disney Productions & $88 \%$ & $100 \%$ \\
\hline Average & $77 \%$ & $92 \%$ \\
\hline
\end{tabular}

1. Intercoder reliability is defined as follows: the number of agreements as a percentage of the totall number of agreements and disagreements (Miles and Huberman, 1984). 


\section{CHAPTER 7}

\section{SUMMARY AND CONCLUSION}

"(P)eople who write about methodology often forget that it is a matter of strategy, not of morals. There are neither good nor bad methods but only methods that are more or less effective under particular circumstances in reaching objectives on the way to a distant goal" (Homans, 1949: 330)

\subsection{Introduction}

This chapter concludes our exploration of strategy formation in terms of selforganization. The next section summarizes the findings of previous chapters. Subsequently, we will reflect on some methodological issues. Finally, some remarks on the potential of self-organization models are made and some general conclusions regarding this study are drawn.

\subsection{Summary}

There is some consensus that 'strategy' concerns survival and deals with changing environments, or in other words, the way we try to cope with the world around us. Organizational strategy therefore involves the way organizations and their members cope with their environments.

This study addresses the question: how do organizations form strategies and what kind of image(s) may lead us to understand strategy formation? This study set out to provide a self-organization perspective for understanding strategy formation. More specificly, the purpose of this study is

(a) to provide a useful (set of) image(s) which helps us to understand strategy formation as a whole and not only parts of it;

(b) to elaborate this image in a systematic manner toward specific propositions;

(c) to evaluate the validity of these propositions.

The methodology of this study involves imaginizing and grounding theory. The emphasis thus lies on generating rather than testing theory. Chapters one to five pertain to theory generation, whereas chapter six especially deals with a test of the propositions put forward in earlier chapters.

Chapter one considers the existing schools of thought in strategy formation research. These are compared with an exposition of self-organization thought. This chapter distinguishes between nine schools of thought in strategy formation research, but focuses on three schools of thought: the 
cultural, environmental and learning school. The cultural school emphasizes the forces of collective ideologies and cognitions on the creation of strategy: These forces tend to sustain current strategies and impede strategic change. The environmental school attributes strategy formation to the environment, especially relying on contingency thought. Certain kinds of situational conditions favor specific kinds of strategy: The learning school characterizes strategy formation as a process of adaptation by means of small, incremental steps. The focus here is on sensemaking processes conceived as continuous, incremental streams.

Subsequently, this chapter provides an exposition of self-organization thought. The following assumptions serve as an outline of the selforganization perspective to strategy formation:

1. Strategy formation takes place in a specific social system, the strategy system;

2. the strategy system involves complex flows of forces;

3. the strategy system is self-referential;

4. the strategy system develops or maintains its autonomy;

5. the strategy system combines closure (in making sense) and openness (in actions) toward its environment.

Self-organization thought emphasizes the reciprocity of openness and closure. Accordingly, strategy formation combines closure and openness: in its actions a strategy system may open up toward environmental influences, but it does so in the context of rather closed sensemaking. In this respect, selforganization thought may bring together major ideas of the cultural, environmental and learning schools. In addition, the self-organization perspective appears to offer a bridge between the so-called content and process approach.

Chapter two extends self-organization thought with dialectics, the concept of tight/loose coupling, and the concept of the dominant group. The precise nature of the reciprocity between closure and openness remains undefined in systems theory. A solution to this problem may lie in the adoption of dialectics. Dialectics provides a set of assumptions allowing for both open and closed system dynamics. The concept of tight and loose coupling denotes the degree of responsiveness within or between separate elements of a strategy system. Strategy systems are constituted by simultaneous loose and tight coupling. Looseness and tightness can be assumed to relate to each other as dialectical opposites. Finally, the dominant group is adopted as the strategy system under study. The dominant group involves the central social mechanism in strategy formation. This social mechanism may or may not connect enough people with the appropriate interests and resources. 
Chapter three specifies a preliminary self-organization model of strategy formation. First, six theoretical categories, pertaining to the phenomenon of strategy formation, are presented. Basically, these categories arise by imaginizing how strategies form. These categories are:

1) difficulties of the dominant group

2) formation of and perception by the dominant group

3) repertoire of the dominant group

4) actions induced by the dominant group

5) actions autonomous to the dominant group

6) environment of the dominant group.

Generally speaking, the forces between these categories are dialectical in nature and may be either loose or tight.

In the second half of chapter three, observations by strategy researchers serve to identify several forces in strategy formation. We distinguish between changes around a certain steady state and changes toward substantially different states. In the steady state part of the model, the repertoire of the dominant group remains unchanged. This part of the model can be summarized in the following propositions.

\section{Proposition 3.1a:}

Difficulties activate the current repertoire.

\section{Proposition 3.1b:}

The current repertoire filters difficulties to those which can be acted upon.

\section{Proposition 3.2:}

The cohesiveness of perception supports the tightness of the repertoire (that is, higher cohesiveness will bring about a tighter repertoire), and vice versa.

\section{Proposition 3.3a:}

The llevel of cohesiveness of perception determines the selection of new difficulties.

Proposition 3.3b:

Major (new) difficulties tend to decrease group cohesiveness.

\section{Proposition 3.4:}

The repertoire induces group members to act, but also tends to constrain autonomous action. Tight repertoires tend to focus on inducing actions in line with the repertoire and impede autonomous actions by group members. Loose repertoires tend to tolerate more autonomy in action.

The other part of the model deals with changes toward a new repertoire of the dominant group. These changes can be described in terms of forces breaking down the old repertoire and forces forming a new repertoire. The 
following propositions summarize these processes.

\section{Proposition 3.5a:}

Breakdown of the old repertoire is triggered by major unintended consequences of induced action. Once these unintended consequences are included in the difficulty set, they constitute misfits (anomalies) to the old repertoire. In addition, they tend to undermine group perception (i.c. decrease its cohesiveness), and, thus, support for the old repertoire decreases.

\section{Proposition 3.5b:}

Formation of a new repertoire is triggered by autonomous actions of (new) dominant group members. These actions introduce new perceptions into the group, and possibly also change its composition. In turn, new perceptions stimulate the emergence of a new repertoire and enable the recognition of previously neglected difficulties (e.g. unintended consequences). In addition, these difficulties increasingly fit the new repertoire.

Chapter four aims at a model of the formation of vertical integration strategy. As such, this chapter elaborates the model in the previous chapter, especially regarding vertical integration. Vertical integration leads to the joint administration of two separable production stages. Does the selforganization model lead us to understand the formation of vertical integration strategy? In order to answer this question, chapter four formulates a model of vertical integration strategy. The propositions put forward in the previous chapter guide the assessment of a vertical integration case as well as the evaluation of existing explanations and observations in the vertical integration literature.

According to the propositions developed in chapter four, the forces specified in the general model are also at work in vertical (dis)integration strategy. In particular, we emphasize the role of so-called behavioral difficulties, which involve threats arising from opportunistic behavior of competitors, suppliers or buyers. Such difficulties constitute severe threats to transactions with suppliers or buyers and are conceived as unintended consequences of induced action. The following three propositions are depicted.

\section{Proposition 4.1:}

If the dominant group perceives one or more behavioral difficulties that evoke complete integration

and if the cohesiveness of dominant group perception decreases substantially, then the repertoire will tend to include complete integration. 


\section{Propasition 4.2:}

If the repertoire includes complete integration

and if behavioral difficulties evoking complete integration persist through time and relative to other difficulties (impeding complete integration), then complete integration will be induced.

\section{Proposition 4.3a:}

Behavioral difficulties (evoking complete integration) arise as unintended consequences of current modes of organizing transactions with suppliers/buyers.

\section{Proposition 4.3b:}

Change in cohesiveness of perception is triggered by autonomous actions of (new) dominant group members.

Chapter five sets out to elaborate the self-organization model with regard to innovation strategy. For dominant groups, innovation involves self-renewal by generating and adopting new ideas. As in the previous chapter the argument pertains to a specific application of the general model put forward in chapter three. A review of some previous studies in innovation strategy suggests that dominant groups have key roles in inducing as well as impeding innovation. Their repertoire is of major importance to the ability to innovate. Moreover, the formation of innovation strategy can be understood in terms of justifying new ideas to the members of the dominant group.

The literature on innovation strategy also suggests that in many cases innovation involves generating autonomous action by taking care not to supress it. Dominant groups which incorporate such rules in their repertoire may be better able to renew themselves. However, the dominant group should exert some control over autonomous action in order to increase the chance that its results are beneficial to the dominant group. Some other studies point at the possibility of direct dominant group involvement in innovation. Direct involvement of dominant group members is observed especially in smaller and younger organizations.

Subsequently, this chapter reports the results of an extensive case-study of a Dutch agribusiness firm. Finally, a self-organization model of how innovation strategies form is formulated. This model incorporates conclusions from the literature review as well as some of the results of the case-study.

\section{Proposition 5.1a:}

New ideas (cf. difficulties) which to a large extent fit the current repertoire activate the repertoire. 
Proposition 5.1b:

The current repertoire tends to filter away new ideas which to a large extent misfit the repertoire.

\section{Proposition 5.2:}

The ability of the dominant group to transform its repertoire is positively associated with a moderate group cohesiveness. Too high cohesiveness as well as too low cohesiveness will be dysfunctional in this respect.

\section{Proposition 5.3a:}

The level of cohesiveness of perception determines the selection of new ideas. (Thus, higher cohesiveness tends to decrease the selection ratio for new ideas.)

\section{Proposition 5.3b:}

Major new ideas tend to decrease the cohesiveness of perception of the dominant group, or, alternatively, they tend to decrease the cohesiveness between perceptions of the dominant group and major actors in its periphery.

\section{Proposition 5.4:}

When new ideas fit the current repertoire, the emphasis is on induced action. When new ideas largely misfit the current repertoire, the emphasis will increasingly be on autonomous action.

\section{Proposition 5.5a:}

Induced action with high dominant group involvement may produce new ideas which, if adopted, do not require substantial change of the repertoire.

\section{Proposition 5.5b:}

Autonomous action with low dominant group involvement may also produce new ideas which tend to be - at least initially - loosely coupled to the current repertoire. If these ideas are adopted by the dominant group (which may involve substantial change of its repertoire), autonomous action changes into induced action. Alternatively, autonomous action may also be completely decoupled from the dominant group.

Finally, the argument turns to testing theory. Chapter six deals with a test, based on Boolean logic, of some of the propositions presented in previous chapters. Such a test requires both an in-depth scrutiny of cases and a systematic comparison between those cases. For this purpose, a comparative method using Boolean logic is outlined. Some brief comments on the potential contribution of this method to strategy research are also provided. Subsequently, we turn to the selection of ten cases and a number of categories and variables which provide the coding system which is applied to these cases. Next, the coding procedure is described more extensively. The results of the coding procedure provide the data for the subsequent 
comparative analysis.

In general, the results of this analysis give support for the propositions generated in chapters three and five (the propositions presented in chapter four are not included in this test). The analysis involves, first, an attempt at falsification, and second, an attempt at identification of the propositions. None of the propositions tested is falsified. Most propositions are identified but three propositions could not be identified. These three pertain to (elements of) propositions $3.5 \mathrm{a}$ and $3.5 \mathrm{~b}$, which describe how repertoire change occurs. Although the forces described in chapters three and five do seem to matter, change in the content of repertoires appears to be far more complex.

In addition, the analysis suggests that proposition $3.1 \mathrm{a}$ ('difficulties activate the repertoire') can be extended by the following statement: new difficulties tend to either loosen or tighten the repertoire.

The results of the analysis also point at some kind of confluence of forces. That is, forces may reinforce each other. For instance, repertoire change may only occur when such a confluence of several forces takes place. This phenomenon can not be dealt with by the analysis in this chapter. To some extent, reinforcement between forces follows from the complex nature of the strategy system itself.

Finally, the Boolean comparative method is evaluated. This method appears to enrich the toolbox for strategy research. It compensates for some of the weaknesses of the case-study and provides a way to systematically address large numbers of cases without forsaking complexity. However, the study in this chapter shows that the Boolean method cannot adequately deal with confluence of forces. In addition, the results of Boolean analysis may suffer from limitations in the coding system and coding procedure.

\subsection{Methodological reflections}

The aim of this study was to generate relatively new theory on strategy formation. Conventional methodology and its philosophical underpinnings (e.g. Popper, 1972) is concerned with the critical testing of existing theory and not with how this theory is generated. Thus, conventional methodology texts have nothing to offer to rebut the rather unconventional methodological position taken by, for instance, Feyerabend (1978). According to the latter, 'anything goes' when we try to generate new knowledge.

The position taken here is that the generation of new theory might benefit from the same systematic and cumulative ambition that guides the testing of theory. That is, researchers should make their point of departure as clear as 
possible, especially in terms of the assumptions and images underlying their initial views. This is the imaginizing or deductive part of theory generation. In addition, one should use empirical procedures which link observations to theory in a simple, straightforward manner. This is the grounding or inductive part of theory generation.

The result of imaginizing and grounding new theory is some kind of modell. Models are simplifications of the real world, or in other words, less complex systems than the reall world systems they intend to describe. To a large extent such models are driven by certain favored images which lead us to see and understand phenomena in distinctive yet partial ways. At this point the fundamental question arises whether we can step outside these images, for instance, in order to 'test' their usefulness? Generally speaking, this author is tempted to answer: no! This position also follows from the assumption of self-reference adopted in this study. It would be naive to recognize the selfreferential character of many organizational processes, and yet to continue to think of our own research activity as if it were not self-referential.

Some qualification of this position is necessary. First, the propositions generated with help of a given image should be tested. Researchers should go to great lengths to increase and test their understanding of real-world systems. In principle, conventional validity and reliability criteria can guide these attempts. However, such criteria are applicable merely to rich, welldeveloped theories. Most validity and reliability criteria are insufficient in exploring new ways of looking at reality, especially when the latter can only be assessed in qualitative terms. Explorative research is a craft activity which involves not just the application of a formal set of techniques and rules, but also the application of skills, knowledge and the personality of the researcher in varying settings (Pettigrew, 1989). As craftsmen we deal with a continuous dialogue between images, assumptions, propositions and observations. In this respect, scientific research has its subjective and artistic aspects in addition to its intersubjective and formal sides.

\subsection{Outlook}

Self-organization thought carries the potential for major breakthroughs in the study of strategy formation and the study of organizations in general.

As was pointed out in the introduction to this study, the state of the art of strategy research falls into two distinct approaches. The so-called content approach especially attends to the actions and positions taken on, for instance, product markets. It views the organization as made of tangible parts, such as structure, people, (e.g. administrative) systems, tasks and resources. Implicit in most content studies is the perspective of the rational manager who adapts to environmental conditions by (re)designing structures 
and systems, formulating tasks and employing resources in the pursuit of simple goals, such as profit maximization. As such, the content approach is rather deterministic in kind and tends to value prescriptive inferences more than the descriptive validity of their models. That is, the primary interest is in questions such as "how should managers formulate strategies", and not so much in the actual conditions and complexities of strategy formation.

The so-called process approach attends to the cognitive and political processes by which actions come into being. Organizations are considered here as made up of especially less tangible, symbolic processes (e.g. decision making, politics, values, cognitive frameworks). The process approach starts from evolutionary, stochastic assumptions which acknowledge the unpredictable, complex nature of strategy formation. In contrast to the content approach, recent studies in the process approach tend to value the correspondence of their models to reality more than their prescriptive usefulness.

Self-organization models may be able to transcend the traditional demarcation between these two approaches. They incorporate both the tangible and symbolic dimension of strategy systems. In addition, although the intention of the self-organization model in this study is primarily descriptive in kind, the step to prescriptive inferences may be fairly easy. In all likelihood, the prescriptive value of self-organization models is advanced by taking the perspective of the actors themselves, for instance, dominant group members.

However, if we are to accomplish this ambitious task, several fundamental questions will have to be answered. These questions constitute a research agenda:

- This study assumed that strategy systems are closed and open at the same time. This is a fundamental assumption underlying self-organization models. However, an important question remains to be answered: is it possible to develop a consistent paradigm based on open and closed system dialectics?

- Management research has offered us quite a lot of insight into what managers actually do (e.g. they emphasize informal, personal contacts instead of formal, desk work). But how do managers actually cope with the multiple and changing forces they face? Which management skills, if any, determine success and failure in this respect?

- The terminology of 'self-reference', 'flows of forces', 'repertoire', etcetera, is not used by most mainstream strategy researchers (in the content as well as process approach). The central assumptions, concepts and propositions of self-organization models therefore need to be linked to the predominant terminology in mainstream strategy research. How to do this? Perhaps we also need additional concepts? 
- What kind of research methods, in addition to those employed in this study (in-depth case study and comparative analysis), contribute to the further development of self-organization models? What is the potential contribution of, for example, simulation techniques?

\subsection{Conclusion}

Having come at the end of this study, I hope to have accomplished the

(a) provision of a useful image which may help to advance our understanding of strategy formation;

(b) elaboration of this image in a systematic manner toward more specific models and propositions, which in turn may trigger more extensive research;

(c) (preliminary) demonstration of the validity of most of these propositions.

I am aware of certain general shortcomings of this study. A major shortcoming follows from the fact that the paradigmatic underpinnings of self-organization thought are still somewhat ambiguous. In addition, the propositions have been tested in an imperfect and preliminary way. Finally, prescriptive inferences have not been obtained. (Note that the intention of this study is descriptive in nature.) On balance, self-organization thought poses intriguing questions and deserves further exploration. This kind of research may constitute a challenging avenue for students of strategy formation. 


\section{REFERENCES}

Adrich, Howard E.

1979 Organizations and environments. Englewood Cliffs: Prentice-Hall.

Aldrich, Howard E. and Ellen R. Auster

1986 "Even dwarfs started small: liabilities of age and size and their strategic implications." Research in Organizational Behawior, 8: 165-198.

Allen, Bruce $\mathrm{T}$.

1971 "Vertical integration and market foreclosure: the case of cement and concrete." Journal of Law and Economics, 14: 251-274.

Allison, Graham $\mathrm{T}$.

1971 Essence of decision: explaining the Cuban missile crisis. Boston: Little, Brown and Company.

Andrews, Kenneth $\mathbb{R}$.

1971 The concept of corporate strategy. Homewood: Irwin.

Angle, Harold L.

1989 "Psychology and organizational innovation." In Andrew H. Van de Ven, Harold L. Angle and Marshall S. Poole (eds.), Research on the management of innovation: 135-170. New York: Harper \& Row.

Arrow, Kenneth J.

1975 "Vertical integration and communication. "Bell Journal of Economics, 6: 173-183.

Ashby, W. Ross

1962 "Principles of the self-organizing system." In Heinz von Foerster and George W. Kopf (eds.), Principles of self-organization: 255-278. New York: Pergamon.

Baert, Patrick

1991 "Unintended consequences: a typology and examples." International Sociology, 6: 201-210.

Bahlmann, J.P. and B.A.C. Meesters

1988 Denken en doen. Delft: Eburon.

Baiin, J.S.

1968 Industrial organization (second edition). New York: Wiley.

Baldridge, J. Victor and Robert A. Burnham

1975 "Organizational innovation: individual, organizational, and environmental impacts." Administrative Science Quarterly, 20: 165-176.

Bartunek, Jean M.

1984 "Changing interpretive schemes and organizational restructuring: the example of a religious order." Administrative Science Quarterly, 29: 355-372.

Beer, Stafford

1979 The heart of enterprise. Chicester: Wiley. 
Beer, Stafford

1980 foreword to H. Maturana and F. Varela, Autopoiesis and cognition: the realization of the living. London: Reidl.

Berghe, Pierre L. van den

1963 "Dialectic and functionalism: toward a theoretical synthesis." American Sociological Review, 28: 695-705.

Bernhardt, I.

1977 "Vertical integration and demand variability." Journal of Industrial Economics, 25: 213-229.

Bläsing, J.F.E.

1986 Op het spoor van de Körver. Leiden: Martinus Nijhoff.

Blau, Peter M.

1955 The dynamics of bureaucracy. Chicago: University of Chicago.

Boulding, Kenneth $\mathrm{E}$.

1956 "General systems theory - the skeleton of science." Management Science, $2: 197$ 208.

Bresser, Rudi K. and Ronald C. Bishop

1983 "Dysfunctional effects of formal planning: two theoretical explanations." Academy of Management Review, 8: 588-599.

Broms, Henri and Henrik Gahmberg

1983 "Communication to self in organizations and cultures." Administrative Science Quarterly, 28: 482-495.

Burgelman, Robert A.

1983a "A model of the interaction of strategic behavior, corporate context and the concept of strategy." Academy of Management Review, 8: 61-70.

Burgelman, Robert A.

1983b "A process model of internal corporate venturing in the diversified major firm." Administrative Science Quarterly, 28: 223-244.

Burgelman, Robert A.

1983c "Corporate entrepreneurship and strategic management: insights from a process study." Management Science, 29: 1349-1364.

Burgelman, Robert $\mathrm{A}$.

1985 "Applying the methodology of grounded theorizing in strategic management: a summary of recent findings and their implications." Advances in Strategic Management, 3: 83-99.

Burns, Bill

1986 "Walt Disney Productions, November 1983," In James M. Higgins and Julian W. Vincze, Strategic management and organizational policy (third edition): 556.592. Chicago: Dryden. 
Carlon, Demis $W$.

1979 "Vertical integration in competitue markets under uncertainty." Journal of Industral Economics, 27: 189-209.

Chaffece, Ellen Earle

1985 "Three models of strategy." Academy of Management Review, 10; 89-98.

Chan, Wing-Tsit

1963 A source book in Chinese philosophy. Princeton: Princeton University.

Chandler, Alfred D.

1962 Strategy and structure. Chapters in the history of the industrial enterprise. Cambridge (Mass.) and London: M.I.T.

Chandler, Alfred D.

1977 The visible hand: the managerial revolution in American business. Cambridge, Mass.: Harvard.

Child, John

1972 "Organizational structure, environment, and performance: the role of strategic choice." Sociology, 6: 1-22.

Child, John

1987 "Information technology, organization, and the response to strategic challenges." California Management Review, 1987 (Fall): 33-50.

Churchman, C. West

1971 The design of inquiring systems: basic concepts of systems and organization. New York: Basic Books.

Clark, Peter and Ken Starkey

1988 Organization transitions and innovation-design. London: Pinter.

Cohen, Michael D., James G. March and Johan P. Olsen

1972 "A garbage can model of organizational choice." Administrative Science Quarter$1 y, 17: 1-25$.

Comanor, W.S.

1967 "Vertical mergers, market powker and the antitrust laws." American Econonic Review, Papers and Proceedings, 57: 254-265.

Coombs, Rod, Paolo Saviotti and Vivien Walsh

1987 Economics and technological charge. Bastingstoke: MacMillan.

Cooper, Arnold $\mathrm{C}_{*}$ and Dan Schendel.

1976 "Strategic responses to technological threats." Business Horizons, 19 (February): $61-69$.

Cosier, Richard A.

1981 "Dialectical inquiry in strategic planning: a case of premature acceptance?" Academy of Management Review , 6: 643-648. 
Crandall, Robert

1968 "Vertical integration and the market for repair parts in the United States automobile industry." Journal of Industrial Economics, 16: 212-234.

Crozier, Michel

1964 The bureaucratic phenomenon. Chicago: University of Chicago.

Cyert, R.M. and J.G. March

1963 A behavioral theory of the firm. Englewoods Cliffs:. Prentice-Hall.

Czamiawska-Joerges, Barbara

1988 "Dynamics of organizational control: the case of Berol Kemi AB." Accounting, Organizations and Society, 13: 415-430.

Czarniawska-Joerges, Barbara

1989 Economic decline and organizational control. New York: Praeger.

Daems, Herman

1982 "Inter-industry differences in forward vertical integration by ownership." Working paper, Department of Applied Economics, University of Leuven, Paper No. 82-1.

Daft, Richard L.

1978 "A dual-core model of organizational innovation." Academy of Management Journal, $21: 193-210$.

D'Aveni, Richard A. and Ian MacMillan

1990 "Crisis and the content of managerial communications: a study of the focus of attention of top managers in surviving and failing firms." Administrative Science Quarterly, 35: 634-657.

Davies, Steve

1987 "Vertical integration." In Roger Clarke and Tony McGuinness (eds.), The economics of the firm: 83-106. Oxford: Basil Blackwell.

Dean $_{\text {, James W. }}$.

1987 Deciding to innovate. Cambridge, Mass.: Ballinger.

Drass, Kriss

1988 QCA: a microcomputer package for qualitative comparative analysis of social data (version 2.02). Center for Urban Affairs and Policy Research, Northwestern University.

Drazin, Robert and Lloyd Sandelands

1989 "Autogenesis and the process of organizing." Unpublished manuscript, Emory University/Columbia University.

Dror Rafael, Israel and Albert H. Rubenstein

1984 "Top management roles in R\&D projects." R\&D Management, 14: 37-46.

Eisenhardt, Kathleen M.

1989 "Building theories from case study research." Academy of Management Review, 14: $532-550$. 
Etgar, Michael

1978 "The effects of forward vertical integration on service performance of a distributiwe industry." Journal of Industrial Economics, 26:249-255.

Feldman, Steven P.

1989 "The broken wheel: the inseparability of autonomy and control in innovation within organizations." Journal of Management Studies, 26: 83-102.

Feyerabend, Paul

1978 Against method: outhine of an anarchistic method of knowledge. London: Verso.

Finkelstein, Sidney, and Donald C. Hambrick

1990 "Top-management-team tenure and organizational outcomes: the moderating role of managerial discretion." Administrative Science Quarterly, 35: 484-503.

Fisher, B.A.

1974 Small group decision making: communication and the group process. New York: McGraw-Hill.

Giddens; Anthony

1971 Capitalism and modern social theory. Cambridge: Cambridge University.

Giddens, Anthony

1979 Central problems in social theory. London: MacMillan.

Glaser, Barney G. and Anselm L. Strauss

1967 The discovery of grounded theory. Chicago: Aldine.

Gleick, James

1987 Chaos: making a new science. London: Cardinal.

Gouldner, Alwin W.

1954 Patterns of industrial bureaucracy. Glencoe, Ill.: Free Press.

Greenwood, Royston and C.R. Hinings

1988 "Organizational design types, tracks and the dynamics of strategic change." Organilzation Studies, 9: 293-316.

Grinyer, Peter H. and J-C. Spender

1979 "Recipes, crises, and adaptation in mature businesses." International Studies of Management and Organization, 9: 113-133.

Hambrick, Donald C.

1983 "High profit strategies in mature capital goods industries: a contingency approach." Academy of Management Joumal, 26: 687-707.

Hambrick, Donald C., and Sydney Finkelstein

1987 "Managerial discretion: A bridge between polar views on organizations. "In L. L. Cummings and Barry M. Staw (eds.), Research in Organizational Behavior, 9: 369-406. Greenwich, CT: JAI Press.

Hampden-Turner, Charles

1990 Charting the corporate mind. Oxford: Basil Blackwell. 
Hardy, Cyrthia

1990 Strategies for retrenchment and turnaround: the politics of survival. Berlin: De Gruyter.

Hardy, Cynthia, Ann Langley, Henry Mintaberg and Janet Rose

1984 "Strategy formation in the university setting." In James L. Bess (ed.), College and uniwersity organization: insights from the behavioral sciences: 169-210. New York: New York University.

Harrigan, Kathryn R.

1980 Strategies for declining businesses. Lexington, Mass.: Heath.

Harrigan, Kathryn R.

1983 "Research methodologies for contingency approaches to business strategy." Academy of Management Review, 8: 398-405.

Harrison, J. Richard, David L. Torres and Sal Kukalis

1988 "The changing of the guard: turnover and structural change in the top-management positions." Administrative Science Quarterly, 33: 211-232.

Hatten, Kenneth J. and Mary Louise Hatten

1988 Effective strategic management: analysis and action. Englewood Cliffs: PrenticeHall.

Hax, Arnoldo $C_{\text {. }}$ and Nicolas S. Majluf

1984 Strategic management: an integrative perspective. Englewood Cliffs: Prentice-Hall.

Hedberg, Bo

1974 "Reframing as a way to cope with organizational stagnation. A case study," Working paper, International Institute of Management, Berlin, Paper No. I/74-51.

Hedberg, Bo L. T., Paul C. Nystrom and William H. Starbuck

1976 "Camping on seesaws: prescriptions for a self-designing organization." Administrative Science Quarterly, 21: 41-65.

Hedberg, Bo L.T. and S.A. Jönsson

1977 "Strategy formulation as a discontinuous process." International studies of Management and Organization, 7: 89-109.

Heiner, Ronald A.

1983 "The origin of predictable behavior." American Economic Review, 73: 560-595.

Hickson, David J., Richard J. Butler, David Gray, Geoffrey R. Mallory and David C. Wilson

1986 Top decisions: strategic decision-making in organizations. Oxford: Basil Blackwell.

Hickson, David J.

1987 "Decision-making at the top of organizations." Annual Review of Sociology, 13: 165-192.

Hill, Winston $W$.

1990 "Chaos theory: can this new paradigm help explain organizations?" In Hans-J. 
Daumer, Winston W. Hill, Claudia Rawlins, Gordon Hughes and Thomas Mccready, A symposium to consider the applicability of chaos theory to management and organization theory: a proposal: 1-7. Academy of Management Meeting. Organization and Management Theory Division.

Hoistede, Geert

1991 Cultures and organizations. London: McGraw-Hill.

Homans, George C.

1949 "The strategy of industrial sociology." American Journal of Sociology, 54: 330339.

Janis, I.L. and L. Mann

1977 Decision making. New York: Free Press.

Johnson, Gerry

1987 Strategic change and the management process. Oxford: Basil Blackwell.

Kagono, Tadao, Ikujiro Nonaka, Kiyonori Sakakibara and Akihiro Okumura

1985 Strategic vs. evolutionary management: a U.S.-Japan comparison of strategy and organization. Amsterdam: North-Holland.

Kanter, Rosabeth Moss

1983 The change masters. New York: Simon \& Schuster.

Karpik, Lucien

1972 "Les politiques et les logiques d'action de la grande entreprise industrielle." Sociologie du Travail, 14: 82-105.

Kent, Calvin A., Donald $\mathbb{L}$. Sexton and Karl H. Vesper (eds.)

1982 Encyclopedia of entrepreneurship. Englewood Cliffs: Prentice-Hail.

Kidder, Tracy

1981 The soul of a new machine. Boston/Toronto: Little, Brown and Company.

Klein, Berjamin, Robert G. Crawford and Armen A. Alchian

1978 "Vertical integration, appropriable rents, and the competitive contracting process." Journal of Law and Economics, $21: 297-320$.

Lenel, Hans Otto

1968 Ursachen der konzentration (second edition). Tübingen: Mohr.

[-wis, Geoffrey

1988 Corporate strategy in action. London: Routledge.

Lindolom, Charles E.

1980 The policy making process (second edition). Englewood Cliffs: Prentice-Hall.

Lorange, Peter and Richard F. Vancil

1976 "How to design a strategic planning system. " Harvard Business Review 54 (5): 7581. 
Lorange, Peter and Richard F. Vancil

1977 Strategic planning systems. Englewood Cliffs: Prentice-Hall.

\section{Luhmann, Niklas}

1986 "The autopoiesis of social systems." In Felix Geyer and Johannes van der Zouwen (eds.), Sociocybernetic paradoxes: 172-192. Beverly Hills: Sage.

\section{Luhmann, Niklas}

1990 Essays on self-reference. New York: Columbia University.

MacMillan, Ian C.

1978 Strategy formulation: political concepts. St. Paul: West.

MacMillan, Ian C., Donald C. Hambrick and Johannes M. Pennings

1986 "Uncertainty reduction and the threat of supplier retaliation: two views of the backward integration decision." Organization Studies, 7: 263-278.

Maidique, M.A.

1980 "Entrepreneurs, champions, and technological innovation:" Sloan Management Review, 21 , no. 2: 59-76.

Manz, Charles C., David T. Bastien and Todd J. Hostager

1989 "Executive leadership under conditions of organizational change." Discussion paper, Strategic Management Research Center, University of Minnesota, Paper No. 110 .

Mason, Richard O.

1969 "A dialectical approach to strategic planning." Management Science, 15: B403B414.

Maturana, H. and F. Varela

1980 Autopoiesis and cognition: the realization of the living. London: Reidl.

McDermott, Robert $\mathbf{M}$.

1985 Computer-aided logic design. Indianapolis: Sams.

McLimore, In Fred and Laurie Larwood

1988 Strategies - successes - senior executives speak out. New York: Harper \& Row.

Meyer, Alan D.

1982 "How ideologies supplant formal structures and shape responses to environments." Journal of Management Studies 29: 45-61.

Michael, D.

1973 On learning to plan and planning to learn. San Francisco: Jossey-Bass.

Miles, Matthew B. and A. Michael Huberman

1984 Qualitative data analysis: a sourcebook of new methods. Beverly Hills: Sage.

Milles, Raymond E. and Charles C. Snow

1978 Organizational strategy, structure, and process. New York: McGraw-Hill. 
Miller, Danny and Peter H. Friesen

1980 "Momentum and revolution in organizationall adaptation." Academy of Management Joumal, $23: 591-614$.

Miller, Danny and Peter H. Friesen

1982 "Innovation in conserwative and entrepreneurial firms" two models of strategic momentum:" Strategic Management Joumal, 3: 1-25.

Miller, Danny and Peter Friesen

1984 Organizations: a quantum view. Englewood Cliffs: Prentice Hall.

Mintzberg, Henry

1973 "Strategy making in three modes." Callifomia Management Review, 16 (2): 44-53.

Mintzberg, Henry

1978 "Patterns in strategy formation." Management Science, 24: 934-948.

Mintzberg, Henry

1979 "An emerging strategy of "direct' research." Administrative Science Quarterly, 24: $582-589$.

Mintzberg, Henry

1990 "Strategy formation: schools of thought." In J.W. Frederickson (ed.), Perspectives on strategic management" 105-235. New York: Harper \& Row.

Mintzberg, Henry, J. Pierre Brunet and James A. Waters

1986 "Does planning impede strategic thinking? Tracking the strategies of Air Canada from 1937 to 1976." Advances in Strategic Management, 4: 3-41.

Mintzberg, Henry and Alexandra McHugh

1985 "Strategy formation in an adhocracy." Administrative Science Quarterly, 30: 1601.97.

Mintzberg, Henry, Duru Raisinghani and Andrê Théorêt

1976 "The structure of unstructured decision processes." Administrative Science Quarterly, 21: 246-275.

Minkzberg, Henry and James A. Waters

1982 "Tracking strategy in an entrepreneurial firm." Academy of Management Journal, 25: 465-499.

Mintzberg, Henry and James A. Waters

1985 "Of strategies, deliberate and emergent." Strategic Management Journal, 6: $257-$ 272.

Mintzberg, Henry, Suzanne Ottis, Jamal Shamsie and James A. Waters

1986 "Strategy of design: a study of "architects in co-partnership." "In John Grant (ed.), Strategic management frontiers. Greenwich: JAI.

Mitroff, Ian I. and J.R. Emshoff

1979 "On strategic assumption-making: a dialectical approach to policy and pllanning." Academy of Management Review, 4: 1-12. 
Mitroff, Ian 1. and Richard O. Mason

1981 Creating a dialectical social science. Dordrectht: Reidel.

Morgan, Gareth

1980 "Paradigms, metaphors, and puzzle solving in organization theory." Administrative Science Quarterly, 25: 605-622.

Morgan, Gareth

1986 Images of organization. Beverly Hills: Sage.

Nelson, Richard $\mathbb{R}_{\text {, and Sidney G. Winter }}$

1982 An evolutionary theory of economic change. Cambridge, Mass.: Harvard University.

Nonaka, Ikujiro

1988a "Creating organizational order out of chaos. self-renewal in Japanese firms." California Management Review, 30 (Spring 1988): 57-73.

Nonaka, Ikujiro

1988b "Toward middle-up-down management: accelerating information creation." Sloan Management Review, 29 (Spring 1988): 1-18.

Nord, Walter R. and Sharon Tucker

1987 Implementing routine and radical innovations. Lexington, Mass: Lexington Books.

Nystrom, Paul C., Bo L. Hedberg and William H. Starbuck

1976 "Interacting processes as organization designs." In Ralph Kilmann, Louis R. Pondy and Dennis P. Slevin (eds.), The management of organization design, vol. I: 209-230. New York: Elsevier North-Holland.

Oliver, Pamela E. and Gerald Marwell

1988 "The paradox of group size in collective action: a theory of the critical mass. II." American Sociological Review, 53: 1-8.

Olson, Mancur

1965 The logic of collective action. Cambridge, Mass.: Harvard University.

Pascale, Richard T.

1984 "Perspectives on strategy: the real story behind Honda's success." Calliforniat Management Review, 26: 47-72.

Pascale, Richard T. and E. Tatum Christiansen

1983 "Honda (B)." Case nr. 9-384-050, Harvard Business School. Boston: Harvard Business School.

Pennings, Johannes $\mathrm{M}$.

1985 "Introduction: on the nature and theory of strategic decisions." In Johannes $M$. Pennings (ed.), Organizational change and strategy: 1-34. San Francisco: JosseyBass.

Penrose, E.

1959 The theory of the growth of the firm. Oxford: Basil Blackwell. 


\section{Perrow, Charles}

1986 Complex Organizations (third edition). New York: Random House.

Peters, Thomas J. and Robert H. Waterman, Jr.

1982 In search of excellence. New York: Harper \& Row.

Pettigrew, Andrew $M$.

1985 The awakening glant. Continuity and change in Imperial Chemical Industries. Oxford: Basil Blackwell.

Pettigrew, Andrew $\mathrm{M}$.

1989 Longitudinal freld research on change: theory and practice. Working paper, Centre for Corporate Strategy and Change, University of Warwick.

Pfeffer, Jeffrey

1981 Power in organizations. London: Pitman.

Pfeffer, Jeffrey and Gerald R. Salancik

1978 The external control of organizations. New York: Harper \& Row.

Pondy, Louis R. and Ian I. Mitroff

1979 "Beyond open system models of organization." Research in Organizational Behavior, $1: 3-39$.

Popper, Karl $\mathbf{R}$.

1972 The logic of scientific discovery. London: Hutchinson.

Porter, Michael $\mathbb{E}$.

1980 Competitive strategy. New York: Free Press.

Prigogine, $\mathrm{I}_{\text {. }}$

1984 Order out of chaos. New York: Random House.

Probst, Gilbert J.B.

1987 Selbst-organisation. Berlin/Hamburg: Paul Parey.

Quinn, James Brian

1978 "Strategic change: "logical incrementalism"." Sloan Management Review, 20 (Fall): 7-21.

Quinn, James Brian

1980 Strategies for change: logical incrementalism. Homewood: Irwin.

Quinn, James Brian

1985 "Managing innovation: controlled chaos." Harvard Business Review, 63, MayJune: 73-84.

Ragin, Charles $\mathrm{C}$.

1987 The comparative method. Berkeley: University of California.

Ricoeur, Paul

1978 The nule of metaphor. London: Routledge \& Kegan Paul. 
Ring, Peter Smith and Gordon P. Rands

1989 "Sensemaking, understanding, and committing: emergent interpersonal transaction processses in the evelution of $3 \mathrm{~N}$ 's micrograwity research program." In Andrew H. Van de Ven, Harold L. Angle and Marshall S. Poole (eds.), Research on the management of innovation: 337-366. New York: Harper \& Row.

Romme, A. Georges L.

1989 "Methoden voor het strategisch besluitvormingsproces." Maandblad voor Accountancy en Bedrijfseconomie, 63: 423-432.

Romme, A. Georges L.

1990a "Vertical integration as organizational strategy formation." Organization Studies, 11: 239-260.

Romme, Georges

$1990 \mathrm{~b}$ "The formation of firm strategy as self-organization." In C. Freeman and $\mathbb{L}$. Soete (eds.), New explorations in the economics of technical change: 38-54. London: Pinter.

Romme, Georges, Paul Kunst, Hein Schreuder and John Spangenberg

1990 "Assessing the process and content of strategy in different organizations." Scandinawian Joumal of Management, 6: 45-61.

Romme, Georges, John Spangenberg and Maurice Swaen

1987 "Biatechnologisch onderzoek door ondernemingen, instituten en universiteiten in Nederland." Working paper, Faculty of Economics, University of Limburg, Paper No. 87-5.

Roth, Charles $\mathbf{H}$.

1975 Fundamentals of logic design. St. Paul: West.

Rothwell, Roy

1977 "The characteristics of successful innovators and technically progressive firms (with some comments on innovation research)." R\&D Management, 7: 191-206.

Rothwell, R., C. Freeman, A. Horsley, V.T.P. Jervis, A.B. Robertson and J. Townsend 1974 "SAPPHO updated-project SAPPHO phase II." Research Policy, 3: 258-91.

Sahal, D.

1979 "A unified theory of self-organization." Journal of Cybernetics, 9: 127-142.

Saren, M.A.

1984 "A classification and review of models of the intra-firm innovation process." R\&D Management, 14: 11-24.

Schön, Donald A.

1963 "Champions for radicall new inventions." Harvard Business Review, 41, no. 2: 77 86.

Schreuder, Hein

1981 Maatschappelijke verantwoordelijkheid en maatschappelijke berichtgeving wan ondernemingen. Leiden: Stenfert Kroese. 
Schreuder, Hein

1991 "Timely management changes as an element of organizational strategy." Working paper, European Institute for Advanced Studies in Management, Paper No. $91-5$.

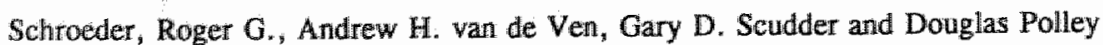
1989 "The development of innowation ideas." In Andrew H. Van de Ven, Harold $L$. Angle and Marshall S. Poole (eds.), Research on the management of innowation: 107-134. New York: Harper \& Row.

Schwerik, Charles $\mathrm{R}$.

1982 "Why sacrifice rigour for relevance? A proposal for combining laboratory and field research in strategic management." Strategic Management Journal, 3: 213225.

Schwenk, Charles $\mathrm{R}$.

$\$ 984$ "Cognitive simplification processes in strategic decision-making." Strategic Management Journal, 5: $111-128$.

Scott, W. Richard

1987 Organizations: rational ${ }_{*}$ natural and open systems (second edition). Englewood Cliffs: Prentice-Hall.

Selznick, Philip

1949 TVA and the grass roots. Berkeley: University of California.

Silver, Morris

1984 Enterprise and the scope of the firm. Oxford: Martin Robertson.

Simmel, Georg

1955 Conflict and The webb of group-affiliations. New York: Free Press.

Simon, Herbert A.

1955 "A behavioral model of rational choice." Quarterly Journal of Economics, 69: 99118.

Soeters, Joseph L.

1986 "Excellent companies as social movements." Journal of Management Studies, 23: 299-312.

Starbuck, William H.

1983 "Organizations as action generators." American Sociological Review, 48: 91-102.

Starbuck, William H.

1985 "Acting first and thinking later: theory versus reality in strategic change." In Johannes M. Pennings (ed.), Organizational change and strategy: 336-372. San Francisco: Jossey-Bass.

Starbuck, William H. and Bo L.T. Hedberg

1977 "Saving an organization from a stagnating environment." In Hans. B. Thorelli (ad.), Strategy + structure $=$ performance: 249-258. Bloomington: Indiana University. 
Starbuck, William H., Arent Greve and Bo L.T. Hedberg

1978 "Responding to crises:" Journal of Business Admimistration, 9: 111-137.

Strauss, A.

1989 Qualitative analysis for social scientists. Cambridge: Cambridge University.

Sztompka, Piour

1979 Sociological dilemmas: toward a dialectic paradigm. New York: Academic Press.

Taylor, John

1986 "Project Fantasy, a behind-the-scenes account of Disney's desperate battle against the raiders." In James M. Higgins and Julian W. Vincze, Strategic management and organizational policy (third edition): 593-609. Chicago: Dryden.

Thompson, James D.

1967 Organizations in action. New York: McGraw-Hill.

Tushman, Michael, William Newman and Elaine Romanelli

1989 "Convergence and Upheaval: managing the unsteady pace of organization evoluti: on." In Michael L. Tushman, Charles O'Reilly, and David A. Nadler (eds.), The management of organizations: 477-489. New York: Harper \& Row.

Unger, Roberto Mangabeira

1987 False Necessity. Cambridge: Cambridge University.

Van de Ven, Andrew H., and Harold L. Angle

1989 "Suggestions for managing the innovation joumey." In Andrew H. Van de Ven, Harold L. Angle and Marshall S. Poole (eds.), Research on the management of innovation: 663-697. New York: Harper \& Row.

Walker, Gordon and David Weber

1984 "A transaction cost approach to make-or-buy decisions." Administrative Science Quarterlly, 29: 373-391.

Weick, Karl E.

1976 "Educational organizations as loosely coupled systems." Administrative Science Quarterly, 21: 1-19.

Weick, Karl E.

1979 The social psychology of organizing (second ed.). Reading: Addison-Wesley.

Weick, Karl E.

1985 "The significance of corporate culture." In P.J. Frost et al. (eds.), Organizational culture: $381-389$. Bewerly Hills, CA: Sage.

Weick, Karl E.

1987 a "Substitutes for strategy." In David J. Teece (ed.), The competitive challenge: 221-233. Cambridge, Mass.: Ballinger.

Weick, Karl E.

$1987 \mathrm{~b}$ "Perspectives on action in organizations." In J.W. Lorsch (ed.), Handbook of organizational behavior: 10-28. Englewood Cliffs: Prentice-Hall. 
Wernerfelt, Bind A. Karnani

1985 "Competitive strategy under uncertainty." Academy of Management. Proceedings, 1985: $42-46$.

Whitley, Richard

1987 "Taking firms seriously as economic actors: towards a sociology of firm behaviour." Organization Studies, 8: 125-147.

Williamson, Oliwer E.

1985 The economic institutions of capitalism. New York: Free Press.

Wilson, David $\mathrm{C}$.

1980 Organizational strategy. Ph.D. thesis. Uniwersity of Bradford.

Wilson, David $\mathrm{C}$.

1982 "Electricity and resistance: a case study of innovation and politics." Organization Studies, 3: 119-140.

Wissema, J.G.

1989 Unit management. Assen/Maastricht: Van Gorcum.

Yin, Robert K.

1981 "The case study crisis: some answers." Administrative Science Quarterly, 26: 5865 .

Yin, Robert $\mathbb{K}$.

1984 Case study research: design and methods. Beverly Hills: Sage. 


\section{GLOSSARY OF TERMS}

\section{Aclion}

Something that somebody does knowingly and intentionally (cf behawior).

\section{Autonomous action}

Action by members of the core or periphery of the dominant group which appears as given to the group as a whole, that is, without deliberate group influence.

\section{Autonomy}

Freedom from (envirommentall) influence.

\section{Behavior}

Something that somebody or something does (cf, action).

\section{Category}

Conceptual class in which elements of systems can be classified.

\section{Closed system}

A system which has no interaction with its environment. In their "pure" form such systems exist only as theoretical concepts. There appear to be, however, relativelly closed real systems, in which significant interaction with the environment is very low.

\section{Closure}

Characteristic of a closed system.

\section{Cognitive activity}

Act of interpreting (or understanding) the raw data in the surrounding world.

\section{Content of strategy}

the actions taken by organizations and their members. Involves especially positioning relative to the environment.

\section{Core of the dominant group}

Persons who "have the final say". Includes those persons who can take care of their involvement in strategy formation by themselves (not depending on others).

\section{Dialectics}

Paradigm constituted by three assumptions: complementarity and antagonism of opposites, negation of the negation, and transformation of quality into quantity (and vice versal).

\section{Difficulty}

Major problem (e.g. opportunity, threat) perceived by the dominant group.

\section{Dominant group}

A subset (cf. system) of individuals, such as a management team, who are interested and resourceful enough to provide the basis for collective action of a broader group, such as the membership of the company, stockholders, etc. In general, the use of 'dominant group' is restricted to its core, unless indicated otherwise.

\section{Environment}

The set of elements that affect the system or are affected by the system. Although clearly relevant to the system, they are regarded as falling outside the system. 


\section{Grounding}

Generating theoretical models through existing data or own field studies.

\section{Idea}

Difficulty which arises in the context of innovation (self-renewal) by the dominant group. An idea may be adopted by the dominant group or not.

\section{Image}

see metaphor.

\section{Imaginixing}

Generating theoretical models by way of images.

\section{Induced action}

Action by members of the core or periphery of the dominant group, deliberately initiated by the group as a whole, that is, with significant group influence.

\section{Loose (coupling)}

Arrangement of two or more elements of a system such that each is only slightly related with the other(s).

\section{Periphery of the dominant group}

Persons who contribute to strategy formation on the basis of their power to impose sanctions (e.g. by withholding information, loans or other resources).

\section{Metaphor}

Image (or concept) which provides a means of structuring scientific inquiry. A metaphor favors certain kinds of insight for understanding and explaining social phenomena.

\section{Model}

A description of a (real or hypothetical) system which is used to understand (and possibly explain or predict) its behavior. In general, the model involves a less complex system than the system it intends to describe.

\section{Open system}

A system which interacts with its environment.

\section{Openness}

Characteristic of an open system.

\section{Paradigm}

A set of assumptions about the social world which precede the use of certain images.

\section{Perception}

Act of making sense. Involves sensory as well as cognitive activity.

\section{Process of strategy}

The way the content of strategy comes into being. Inwolves especially cognitive and political factors.

\section{Repertoire}

The collection of rules (or directions) for action prevailing in the dominant group. Acts as a kind of filter which induces as well as constrains action. 


\section{Schooll of thought}

A set of assumptions about the social world which precede the use of metaphors (cf. paradigm), and which are shared by a substantial number of socilal scientists.

\section{Self-organization}

The comprehensive idea that systems organize themselves relative to their environments. Self-organization in social systems (e.g. dominant groups in organizations) particularly involves the creation of shared repertoires. Implies self-reference, complexity and the attempt to develop autonomy.

\section{Sensory activity}

Act of being exposed to raw data in the surrounding world.

\section{Self-reference}

Sense-making by referring to self. Implies that one cannot step outside own (individual or socially constructed) meanings created in the past.

\section{Social system}

A system which consists of natural connections (interdependencies) among individual human beings.

\section{Strategy}

The way organizations and their members try to cope with the world around them. Strategy concerns survival and deals with changing environments.

\section{Strategy (forming) system}

A social system which - rather deliberately - tries to develop strategies in order to cope with its environment.

\section{System}

An entity, or whole, which consists of interdependent elements. This entity is identified by someone who is interested in it ( $\mathrm{e} . \mathrm{g}$. the researcher, manager or consultant).

\section{Tight (coupling)}

Arrangement of two or more elements of a system such that each is highly responsive to changes in the ather(s).

\section{Unintended consequence}

particular effect of action which is different from what was wanted at the moment of carrying out the action. 


\section{EEN ZELF-ORGANISATIE PERSPECTIEF OP STRATEGIEVORMING}

Het begrip 'strategie" heeft betrekking op overleving in een veranderende omgeving. De strategie van organisaties betreft de wijze waarop organisaties en hun leden met ontwikkelingen in de omgeving omgaan. Deze studie behandelt de tweeledige vraag: hoe vormt men in organisaties strategieên en op welke manier kunnen we hier het beste naar kijken? In het antwoord op deze vraag staat het zelf-organisatie perspectief centraal. Dit perspectief leidt middels 'imaginizing" (conceptuele verbeelding) en 'grounding' (empirische onderbouwing) tot inzicht in strategievorming in organisaties. Het accent ligt in dit proefschrift derhalve op het genereren van nieuwe theorie en slechts in beperkte mate op het empirisch testen van deze theorie. Kort samengevat, is het doel van dit proefschrift

(a) het ontwikkelen van een perspectief op strategievorming dat niet alleen inzicht verschaft in de componenten maar ook in het geheel;

(b) het op een systematische wijze uitwerken van dit perspectief in termen van concrete proposities;

(c) het toetsen van de validiteit van deze proposities.

Hoofdstuk 1 tot en met 5 zijn gericht op het genereren van theorie en hoofdstuk 6 bespreekt een empirische test van de meeste proposities die in voorgaande hoofdstukken zijn gepresenteerd. Hoofdstuk 7 bevat een samenvatting en afsluiting van dit proefschrift.

Hoofdstuk 1 bespreekt de bestaande 'denkscholen' in het onderzoek naar strategievorming en vergelijkt deze met een eerste aanzet vanuit het zelforganisatiedenken. Nadat een onderscheid is gemaakt naar een negental denkscholen, besteden we aan drie scholen uitgebreid aandacht: de culturele, omgevings- en leerbenadering.

De culturele benadering benadrukt collectieve ideologie en cognitie als ontstaansbodem van strategie. Dergelijke krachten ondersteunen vooral de bestaande strategie en remmen strategische veranderingen over het algemeen af. De omgevingsbenadering wijst op de omgeving als ontstaansbodem voor strategie. Verschillende omgevingscondities en andere situationele factoren (bijvoorbeeld de grootte van de organisatie) leiden tot verschillen in strategie en strategievorming. De leerbenadering beschrijft strategievorming in termen van een aanpassingsproces dat bestaat uit kleine, incrementele stappen. Deze school benadrukt met name de rol van veranderingen in betekenisgeving door actoren in organisaties (ofwel hun leergedrag).

Vervolgens bespreken we in een korte uiteenzetting van het zelf-organisatie gedachtengoed de volgende veronderstellingen:

strategievorming vindt plaats in een bepaald type sociaal systeem, namelijk het strategie(vorming)systeem;

dit strategiesysteem is complex en zelf-referentieel, en tracht relatief 
auronoom te worden of blijven;

het strategiesysteem is zowel gesloten (wat betreft betekenisgeving) als open (wat betreft handelingen) ten opzichte van zijn omgeving; dit correspondeert met de 'steady state' krachten die het systeem trachten te stabiliseren (ofwel homeostasis) resp. de krachten die het systeem naar een geheel andere toestand drijven (ofwel homeorhesis).

Het zelf-organisatiedenken benadrukt de wederkerigheid van omgeving en strategiesysteem, en daarmee ook de wederkerigheid van openheid en geslotenheid van het systeem. Op deze wijze kan het zelf-organisatiedenken elementen van de culturele, omgevings- en leerbenadering bijeenbrengen.

Hoofdstuk 2 behandelt een aantal conceptuele kaders die een aanvulling vormen op het zelf-organisatiedenken. Deze kaders zijn gebaseerd op achtereenvolgens dialectiek, strakke en losse koppeling, en dominante groep. Het ontstaan en de ontwikkeling van een dominante groep kan beschouwd worden als het centrale sociale mechanisme in strategievorming. In het overige deel van deze studie nemen we derhalve de dominante groep als strategiesysteem onder de loupe.

In hoofdstuk 3 beschrijven we de ontwikkeling van een algemeen model van strategievorming in en door dominante groepen. Eerst worden een aantal theoretische categorieen beschreven:

- $\quad$ problemen van de dominante groep;

- formatie van en perceptie door de dominante groep;

- repertoire van de dominante groep;

- acties die door de dominante groep tot stand worden gebracht (geïnduceerd);

- acties die autonoom zijn ten opzichte van de dominante groep;

- de omgeving van de dominante groep.

Vervolgens worden deze categorieën gebruikt in de ontwikkeling van een voorlopig model, gebaseerd op verschillende empirische bevindingen uit de strategieliteratuur. Het model zelf valt uiteen in twee delen. Het eerste deel bestaat uit een aantal krachten rond de "steady state' van het strategiesysteem, waarbij het repertoire van de dominante groep niet of nauwelijks verandert. Het tweede deel van het model beschrijft de krachten die het systeem naar een geheel andere toestand drijven, door enerzijds het afbrokkelen van het bestaande repertoire en anderzijds de vorming van een nieuw repertoire. Een en ander leidt tot een aantal proposities waarin de verschillende krachten zijn weergegeven.

Hoofdstuk 4 ontwikkelt een model van de vorming van verticale integratiestrategie. Dit model bouwt voort op het meer algemene model in het vorige hoofdstuk. De ontwikkeling van het model vindt plaats middels de beschrijving van een casus (Hendrix' Fabrieken) en de verschillende verklaringen van verticale integratie die in de literatuur te vinden zijn. Dit resulteert in 
een drietal proposities.

In hoofdstuk 5 gaan we nader in op het vraagstuk van innovatie door dominante groepen. $\mathrm{Na}$ een bespreking van de literaturur over innovatie, volgt een beschrijving van een uitgebreide case-studie van een Nederlandse 'agribusiness' onderneming. De resultaten van literatuur- en case-studie worden vervolgens samengevat in een model van innovatiestrategie, dat voortbouwt op het model uit hoofdstuk 3. Ook dit model wordt beschreven in een aantal proposities.

De proposities uit de voorgaande hoofdstukken worden in hoofdstuk 6 getoetst in een vergelijkende analyse van tien cases. Deze analyse maakt gebruikt van Boole'se logica. De meeste proposities uit hoofdstuk 3 en 5 worden door de resultaten van deze analyse ondersteund. (De proposities uit hoofdstuk 4 kunnen niet via deze analyse worden getoetst.) De resultaten wijzen echter ook op tekortkomingen in het model dat in hoofdstuk 3 is beschreven, met name wat betreft de wijze waarop veranderingen in het repertoire van de dominante groep plaatsvinden. Bovendien blijkt dat de (versterkende of neutraliserende) interactie tussen de afzonderlijke krachten niet adequaat door het model wordt beschreven.

Hoofdstuk 7 bevat een samenvatting van hoofdstuk 1 tot en met 6 , enkele methodologische overwegingen en een vooruitblik. Tot slot spreekt de auteur de hoop uit dat deze studie

(a) een aanzet geeft tot een zelf-organisatie perspectief op strategievorming dat niet alleen inzicht verschaft in de componenten maar ook in het geheel;

(b) dit perspectief op een systematische wijze uitwerkt naar concrete proposities;

(c) de validiteit van de meeste proposities in voldoende mate aantoont. 


\section{CURRICULUM VITAE}

The author of this dissertation was born on 29 th February 1960 in Nijmegen (The Netherlands). From 1978 to 1.984 he studied economics at the University of Brabant and the University of Amsterdam. After accomplishing his Masters degree at the Faculty of Economics of the University of Brabant (cum laude), he worked as a research assistant in the department of Macroeconomics of the University of Limburg (September 1984 - March 1986). In this period, the focus was on labor market research. From April 1986 onwards, the author is a member of the department of Business Administration and the research institute MERIT of the University of Limburg. His research now focuses on strategic management.

De auteur van dit proefschrift is geboren op 29 februari 1960 te Nijmegen. In 1978 werd het Gymnasium B met goed gevolg afgesloten aan het SintJanslyceum te 's-Hertogenbosch. Van 1978 tot 1984 studeerde hij Economie aan de Katholieke Hogeschool Tilburg (nu Katholieke Universiteit Brabant) en Universiteit van Amsterdam. Tijdens zijn studie was de auteur werkzaam als student-assistent bij de Wetenschapswinkel (KHT) en het sociaal-wetenschappelijk onderzoeksinstituut IVA in Tilburg. Na het behalen van het doctoraaldiploma in de Economische Wetenschappen aan de KHT (cum laude) was hij vanaf september 1984 werkzaam bij de vakgroep Algemene Economie, FdEW, Rijksuniversiteit Limburg. In deze periode deed hij met name onderzoek op het terrein van de arbeidsmarkt. Vanaf april 1986 was hij wetenschappelijk assistent bij de vakgroep Bedrijfseconomie, FdEW, Rijksuniversiteit Limburg, en verrichte hij vooral onderzoek naar het ontstaan en de ontwikkeling van ondernemingsstrategieën. Tevens was hij in deze periode aan het onderzoeksinstituut MERIT verbonden. Sinds september 1989 is de auteur dezes verbonden als universitair docent 'Strategisch Management' aan de vakgroep Bedrijfseconomie. 